UNIVERSIDAD NACIONAL DE LA PLATA

FACULTAD DE CIENCIAS NATURALES Y MUSEO

ICTIOPLANCTON DEL ESTUARIO DE LAGOA DOS PATOS, BRASIL

TESIS

GRAC LLLA WLLSS

1981 
DIRECTOR DE TESIS

Prof. Dr. FERNANDO CESAR RAMIREZ

El presente trabajo de Tesis es para optar al grado de Doctor en Ciencias Naturales (Orientación Zoología). Fue realizado en la "Base Oceanográfica Atlântica" perteneciente a la "Fundação Universidade de Rio Grande" det estato de Rio Gronn de do Sul, Brasil. 
$I-$ RESUIEN $\ldots \ldots \ldots \ldots \ldots \ldots \ldots \ldots \ldots \ldots \ldots \ldots \ldots \ldots \ldots \ldots \ldots$

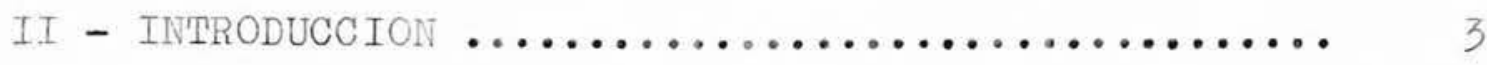

A - Importancia de los biotopos estuarinos ...... 3

B - Generalidades de Iagoa dos Patos............ 4

C - Objetivos .........................

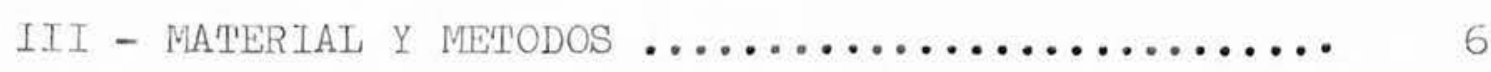

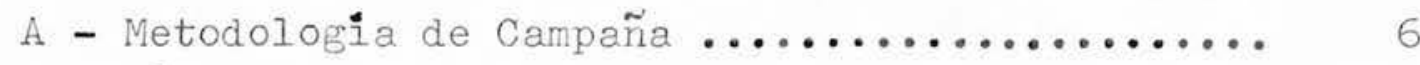

B - I'écnicas de estudio .................. ?

IV - RESULTADOS Y DISCUSION ..................... 13

PARTE A: DESCRIPCIUN DE LAS ESPECIES

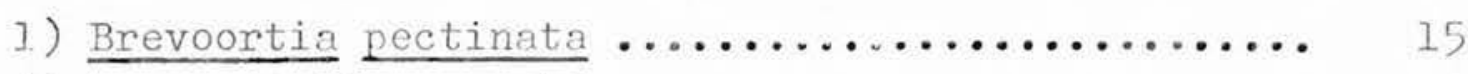

2) Iycengraulis grossidens $\ldots \ldots \ldots \ldots \ldots \ldots \ldots \ldots \ldots \ldots \ldots$

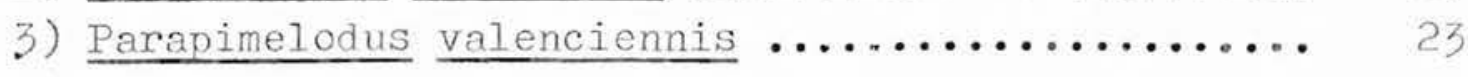

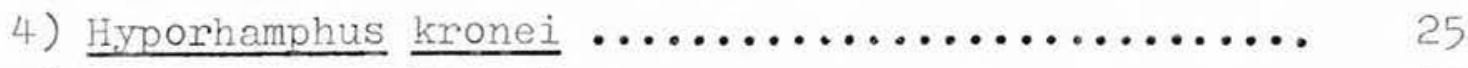

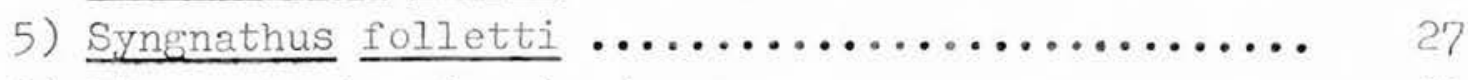

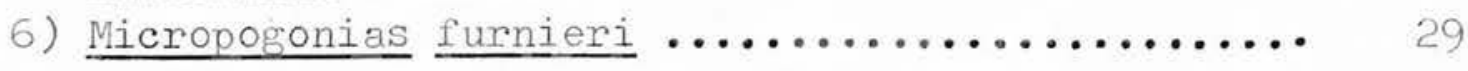

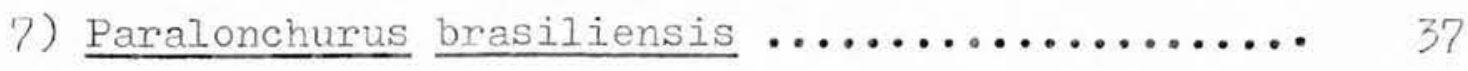

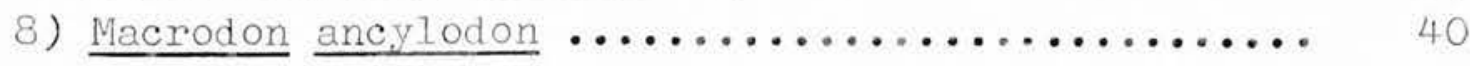

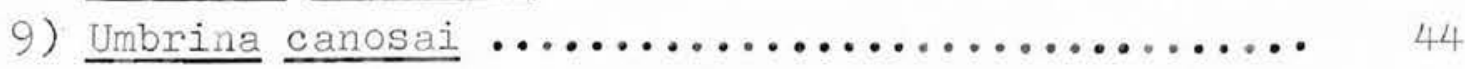

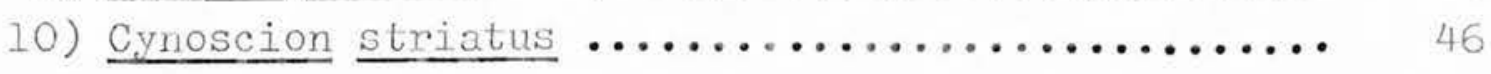

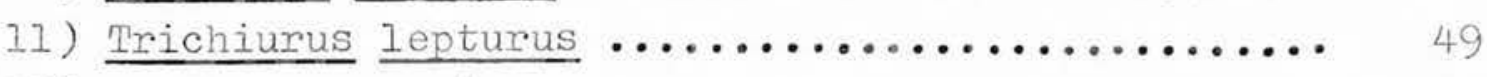

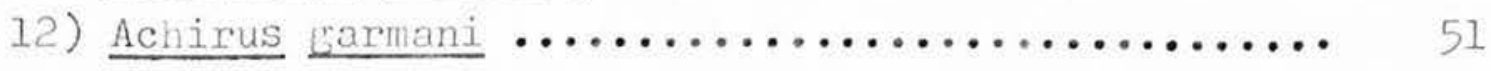

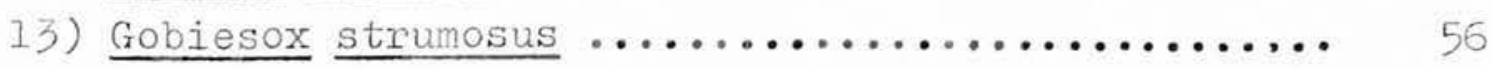

PARTE B: DISTRIBUCION HORIZONTAL DEL ICTIOPLANCTON

1) Fluctuaciones cuantitativas en relación con los factores ambientales ................... 59

2) Composición numérica de los hucvos y larvas .... 62

3) Variación cuantitativa estacional de las especies 64

4) Análisis individunl de 1 a distribución temporal en relación con la salinidad y temperatura ..... 71

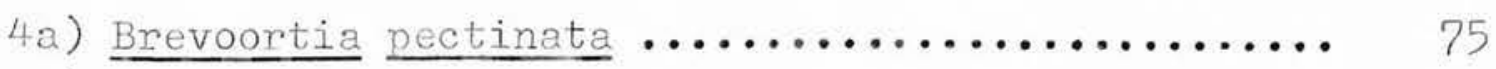

4b) Iycengraulis grossidens $\ldots \ldots \ldots \ldots \ldots \ldots \ldots \ldots$. 80

4c) Paranimelodus valenciennis $\ldots \ldots \ldots \ldots \ldots \ldots \ldots$

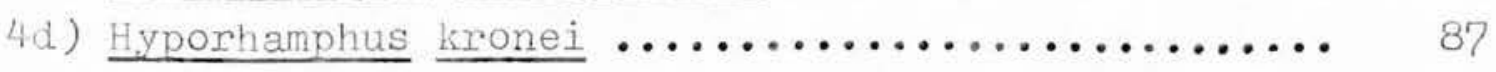

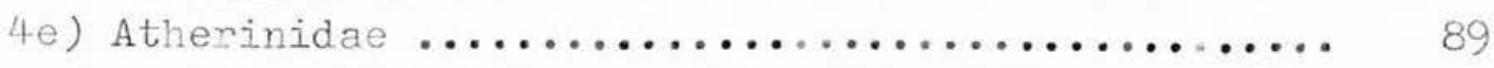


4t) Syngnathus folletti................... 91

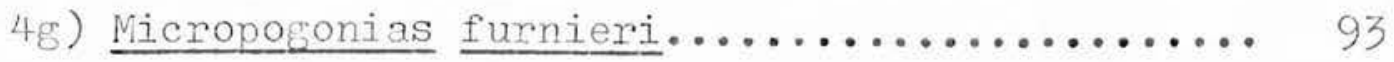

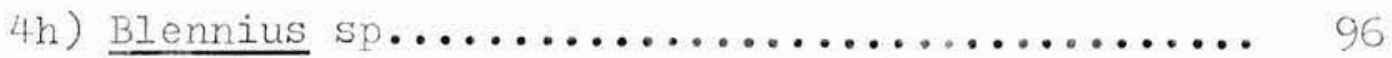

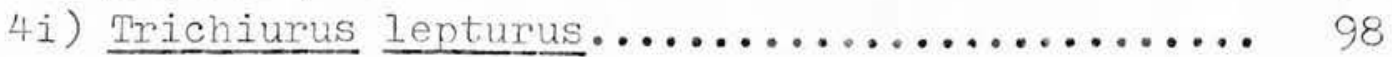

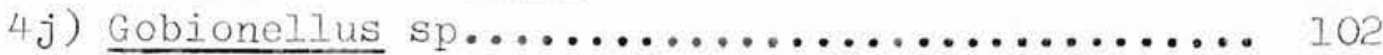

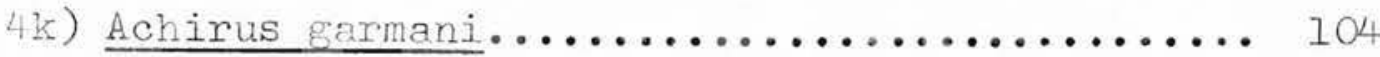

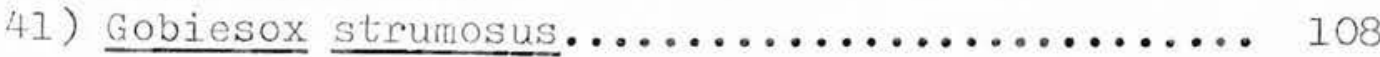

5) Coexistencia espacial de las especies más abun

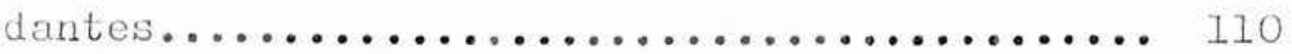

6) Coeficiente de afinidad entre las larvas más

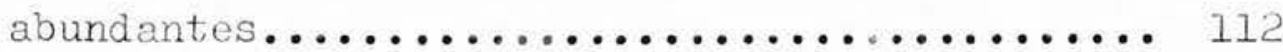

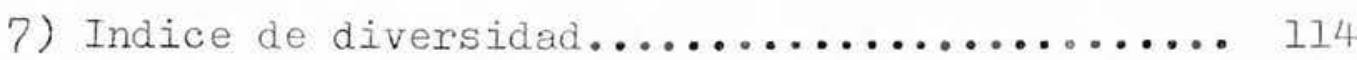

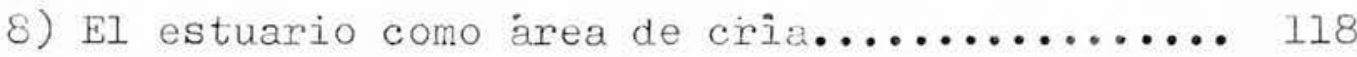

PARTE C: DISTRIBUCION VERTICAL DIL ICTIOPLANCTON

1) Distribución del ictioplancton en relacion con

los factores ambientales.................. 120

la) Análisis de los gradientes en el plano vertical 120

lb) Variaciones del numero de huevos............ 126

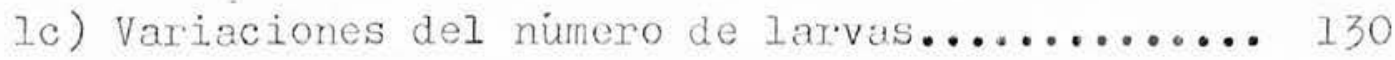

ld) Analisis de las muestras diurnas y nocturnas para los tres niveles de profundidad........ 145

$\mathrm{V}$ - CONCLUSIONES

A - Generalidades del ictioplaneton estuarial.... 150

B - Distribución horizontal ................. 150

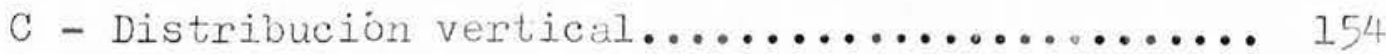

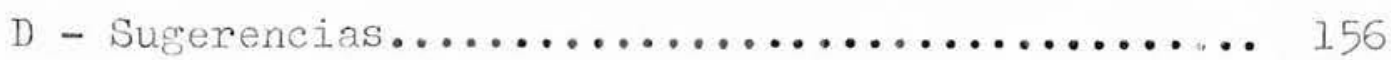

VI - AGRADECIMIENTOS...................... 157

VII - BIBLIOGRAFIA...................... 158 
El material de estudio se obtuvo con una red de tipo cónica, en lances horizontales de 5 minutos de dura ción y con malla de 500 . Se efectuaron 26 cruceros desde el 15/12/75 hasta el 10/11/78 con un total de 671 estaciones. Por otro lado, con el objeto de analizar la distribución vertical, se utilizó un sistema de 3 redes que colectaban pasivamente en tres niveles distintos de profundidad, durante 12 horas diurnas y 12 nocturnas. Los muestreos se realizaron a intervalos de 7 dias, durante las cuatro épocas del año. Se efectuó un total de 19 muestreos desde el $17 / 11 / 76$ hasta el 27/10/77.

Fueron identificadas y descriptas para el área, en etapa de huevo las especies: Brevoortia pectinata, Lycengraulis grossidens, Micropogonias furnieri, Trichiurus lepturus y Achirus garmani; en etapa de larva: Brevoortia pectinata, Lycengraulis grossidens, Parapimelodus valen ciennis, Hyporhamphus kronei, Syngnathus folletti, Micropogonias fumieri, Macrodon ancylodon, Paralonchurus brasiliensis, Umbrina canosai, Cynoscion striatus, Trichiu rus Iepturus, Achirus garmani y Gobiesox strumosus; Lar vas a nivel de género: Blennius y Gobionellus y a nivel de Familia: Atherinidae. El porcentaje de huevos no identificados fue de $1,2 \%$ y el de larvas fue de 2,4\%.

Se observó que la diversidad del estuario es muy baja y que el número de individuos de las especies que lo utilizan como área decría es grande. El ambiente típico utilizado como área de cría es el que registra salinidades de $\mathrm{O}$ a $5 \%$.

A nivel de huevos la especie más abundante fue M. furnieri con un $89 \%$ sobre el total. En cuanto a las larvas los mayores registros correspondieron a I. grossidens con el 44\% y a $\underline{B}$. pectinata con el 20\%, mientras que M. Iurnieri se presentó en un 13\%. El área de distribu ción de $\underline{B}$. pectinata y $\underline{I}$. grossidens iue el mayor y ambas presentaron altos coeficientes de afinidad.

Las larvas de $\underline{B} \cdot$ pectinata $y \underline{I}$ - grossidens pre sentaron una constancia de casi el 100\% en todos los rangos de salinidad y temperatura, com mayores registros entre 0 y $5 \%$ y temperaturas de 240 y 2690 . $\underline{P}$. valenciennis 
se presentó siempre en las salinidades mínimas y temperaturas más elevadas. Los aterínidos fueron más abundantes en salinidades de 5 a $20 \%$ y temperaturas de 20 a $25 \mathrm{C}$, a pesar de tener una moderada frecuencia en todos los ran gos de salinidad y temperatura. M. furnieri se registró en todas las amplitudes de temperatura y salinidad, presentando mayores registros en los más altos valores de es tos parámetros. Los otros Sciaenidae en número reducido fueron característicos de aguas de alta salinidad al igual que $\underline{\text { T. }}$ lepturus. Las larvas de Gobionellus sp. en pequeño número, mostraron preferencias por bajas salinidades mien tras que aparecieron en todos los registros de temperatura por su largo período reproductivo. A. garmani y $\underline{\text { G.stru }}$ mosus se presentaron en densidades mínimas, limitando $1 \bar{a}$ interpretación sobre su comportamiento.

En relación a la distribución vertical se ob servó que B. pectinata, I. grossidens y $\underline{P} \cdot$ valenciennis , están presentes principalmente entre media agua y superfi cie y efectúan una migración para aguas intermedias duran te el día, principalmente cuando la columna de agua está estratificada. Las larvas de Atherinidae que mostraron una marcada preferencia por aguas de profundidades médias, tienden a migrar a aguas más profundas durante el día. Cuando la columna de agua es homogénea las larvas de M. furnieri se presentaron principalmente en aguas superficiales. Cuando existe estratificación, sus mayores regis tros se presentaron en aguas profundas al acompañar la penetración de agua de origen marino.Las larvas de $\underline{T} \cdot \underline{I} \underline{\underline{p}}$ turus que tanto de día como de noche presentaron mayores registros en aguas profundas, independientemente de las características de la columna de agua indican su incapacidad de flotar en un ambiente que no le es propicio.tas larvas de Gobionellus sp. en aguas homogéneas presentan una acentuada tendencia por aguas superficiales indepen dientemente de la incidencia de luz o no.

En definitiva, considerando la fuerte corrien te que se registra en el canal de acceso del estuario, existen larvas, que venciendo la resistencia del medio, se mantienen en determinadas profundidades y también efectúan una migración nictimeral. 


\section{II - INTRODUCCION}

\section{A - INPORTANCIA DE LOS BIOTOPOS ESTUARINOS}

Ios estuarios y aguas costeras tienen una importante función como área de cría para las larvas y juveniles de peces. Estos se congregan en esas áreas y se benefician con la posibilidad de abundante alimento y protección de predadores. Se gún Clark ( 1967) y Mc Hugh ( 1966, 1967), más del 70\% de juveni les de peces de especies de importancia comercial en el Atlántico Norte-Occidental, tienen una parte de su vida relacionada con estuarios.

Las especies que utilizan el estuario como área de cría son de origen marino, dulceacuícola y las típicamente es tuarinas. Pocas especies pertenecientes a los grupos de Anguilli formes, Clupeiformes, Perciformes y Gadiformes existen en los es tuarios porque tienen adaptaciones especificas, mientras que, Ios Salmoniformes, Atheriniformes y Gasterosteiformes, tienen adapta ciones básicas que les permiten su existencia en dichos ambien tes.

Según Mc Hugh ( 1966), alta mortalidad de animales marinos es bastante común en ambientes estuarinos, estando éstos sujetos a amplias variaciones en sus abundancias. Bruscos cambios de salinidad, temperatura, contenido de oxígeno y composición química del agua ocurren contínuamente, provocando en estos organismos un "stress" fisiológico muy grande. A pesar del alto costo fisiológico, estas especies son compensadas por la abun dancia de alimento y protección.

La distribución y abundancia de los huevos y lar vas de peces están condicionadas principalmente por la temperatu ra, salinidad y predación. Otros agentes controladores son: la turbidez, la iluminación y en muchos casos la polución, dado que Ios estuarios son utilizados por las ciudades para eliminar sus productos de deshecho.

En diciembre de 1975, la Universidad de Rio Gran de inició el "Projeto Lagoa", bajo la coordinación del Lic. Jorge P. Castello. Dicho proyecto tenía como objetivos la caracteri zación del régimen hidrodinámico del área estuarial de Lagoa dos Patos y estudiar su influencia sobre la distribución espacial y temporal de la fauna, asi como su papel en los ciclos de vida de las diferentes especies de peces, crustáceos y moluscos de impor tancia económica y ecológica. 
Considerando el desenvolvimiento de una gran actividad pesquera en la región y la carencia total de investiga ciones sobre el ictioplancton en dicha área estuarial, se incluyó este tema en dicho proyecto. En el transcurso de su realiza ción se publicaron "Relulorios" con los primeros datos referen tes a la distribución cuali-cuantitativa del material ictioplanc tónico correlacionándolos con los factores ambientales: tempera tura y salinidad (Castel10, 1976a,b,c,d, I977a,b, 1978 a,b).

Simultáneamente se instaló un sistema de redes en el canal de entrada para obtener filtrados pasivos de planc ton a diferentes niveles de profundidad. El objetivo de este sis tema de muestreo era analizar el ictioplancton en toda la columna de agua ya que en el Projeto Lagoa las muestras eran de super ficie.

En el transcurso de su realización se efectuó un estudio sobre el crecimiento y metamorfosis de Brevoortia pec tinata y Iycengraulis olidus (Weiss e Krug, 1977). Estas dos especies son características de ambientes estuarinos, principal mente en su etapa larval.

También se realizó un trabajo comparativo entre

Lycengraulis olidus, de hábitos estuarinos, Anchoa marinii, de ambientes costeros y Engraulis anchoita, típicamente marina ( Weiss e Feijó de Souza, 1977).

B - GENERALIDADES DE LAGOA DOS PATOS

Lagoa dos Patos está situada en el Estado de Rio Grande do Sul de Brasil. Es en América del Sur la mayor área lagunar. El sector sur, desde Ilha da Feitoría hasta su desembocadura presenta características tipicamente estuariales. Este sector que representa aproximadamente la décima parte de la laguna (900 $\mathrm{Km}^{2}$ ), está localizado entre 310 44' N y 320 14' S de lati tud y 51워' E y 520 15' W de longitud ( $H i$. 1.).

Esta laguna es la principal cuenca receptora de Ias aguas fluviales que drenan la altiplanicie del Estado de Rio Grande. El canal que descarga en el mar las aguas provenientes del vasto sistema lagunar formado por ésta ( $10.360 \mathrm{Km}^{2}$ ) y por Lagoa Mirim ( $3.749 \mathrm{~km}^{2}$ ) tiene un ancho de $750 \mathrm{~m}$ en la desembocadura y una profundidad media de $15 \mathrm{~m}$.

Estudios realizados por Malaval (1916) durante 
un período de 6 años, indicaron que en cada período anual, en 108 días fue registrada penetración de agua marina con una me dia de $6.767 \mathrm{~m}^{3} / \mathrm{s}$, en 205 días se observó desague con una media de $8.651 \mathrm{~m}^{3} / \mathrm{s}$ y en 52 día las aguas no mostraron un movimiento definido.

La observación diaria del comportaniento hi dráulico del canal reveló que los flujos de entrada tienen una duración media de 18 a 24 horas, habiendo en los períodos de sequía prolongados, entradas de agua que duran de 5 a 9 días y desagues de invierno que tienen una duración de 10 a 19 días.

La constante inversión del sentido de la corriente en el canal provoca una variación de niveles con una constante reposición de las masas de agua, hasta que el siste ma alcanza una nueva situación de equilibrio por la propia compensación hidráulica. En general la situación de desague supera en 200\% a los períodos de penetración de agua (Herz , 1977)

\section{C - OBJETIVOS}

Los objetivos del presente trabajo son los si guientes:

- Identificar y describir los huevos y larvas planctónicas presentes en el área.

- Analizar la penetración de los huevos y lar vas y la influencia de los factores ambientales.

- Analizar la distribución cuali-cuantitativa, espacial y temporal de los huevos y larvas.

- Estudiar el comportamiento individual de las especies y sus relaciones interespecíficas.

- Analizar las fluctuaciones cuali-cuantitativa en la distribución vertical y la influencia de la salinidad y temperatura.

- Analizar la función del estuario como área de cría para las especies con huevos y larvas planctónicas y proveer las bases para un futuro monitoreo del área. 
III - MATERIAI Y METODOS

\section{A - METODOLOGIA DE CAMPAÑA}

El área de estudio ( Fiğ. 1) está comprendida en tre el canal de acceso y una línea imaginaria que une Ilha da Feitoría y Ponta dos Lençois. Se contó con la Lancha "Squalus"de la Universidad de Rio Grande, que tiene una eslora de $12 \mathrm{~m}$ y un calado de $90 \mathrm{~cm}$, Io que permitió realizar colectas en aguas rela tivamente someras. Con esta embarcación se realizaron los 24 pri meros cruceros, que desde 1 a primavera de 1975 hasta el verano de 1978 cubrieron en forma relativamente contínua todas las esta ciones del año ( Tabla 1). Los últimos dos cruceros, el 25ㅇ y 26\% fueron realizados en la primavera de 1978 con la Lancha "Larus", también de la Universidad, de $15 \mathrm{~m}$ de eslora y un calado de 1,45m. El total de muestras colectadas fue de 671 (Tabla 1).

El numero de estaciones por crucero fue de 20 a 30, en las cuales se determinó la temperatura y salinidad de la columna de agua por intermedio de un termo-salinómetro de in ducción. Ias estaciones no fueron realizadas en locales fijos porque uno de los objetivos del "Projeto Lagoa" era el levanta miento de sedimentos y fauna bentónica.

Las muestras de plancton se obtuvieron con una red de tipo cónica de $70 \mathrm{~cm}$ de diámetro de boca y malla de $500 \mu$. El volúmen de agua filtrado por la red se obtuvo por medio de un flujómetro, a excepción de los tres primeros cruceros en los que por falta de éste, el volúmen filtrado fue calculado considerando el área de la boca de la red y la distancia recorrida, en base al tiempo y la velocidad del arrastre. Los lances con 5 minutos de duración fueron realizados en la superficie, horizontal mente y a una velocidad de 2 nudos. Todos los lances fueron realizados durante el día.

Para analizar la distribución vertical del ictio plancton fueron instalados, en dos puntos del Canal de entrada, dos conjuntos de redes dispuestas en forma similar al sistema ideado por Graham y Venno (1968). En la Fig. 2 se presenta un esquema del sistema utilizado. Las redes se dispusieron a $1 \mathrm{~m}, 6 \mathrm{~m}$ y $11 \mathrm{~m}$ de la superficie. La profundidad máxima de las estaciones era de $13 \mathrm{~m}$. El cabo que sujetaba las redes era fijado en el fon do por intermedio de un ancla y suspendido por una boya. 
Las redes con una malla de $500 \mu$ filtraron pasivamente, siendo orientadas por intermedio de la aleta direccional colocada en la parte superior del aro de cada red. De cada estación se obtuvo una muestra diurna y otra nocturna ( cada una de 12 horas) para cada estrato, totalizando en cada colecta 12 muestras. Se tomó la temperatura y salinidad a cada metro de profundidad, al colocar las redes y al retirar el material.

Las salidas, 19 en total, se efectuaron a inter valos regulares de 7 días, durante las cuatro épocas del año, desde el 17 de noviembre de 1976 hasta el 27 de octubre de 1977 ( Tabla 2).

Conociendo la inestabilidad de un estuario, 12 horas contínuas de filtración sin flujómetro no es la metodología indicada, pero se efectuó ante la imposibilidad de aplicar otro tipo de muestreo. De todas maneras, a pesar del tipo de muestreo, sus resultados reflejarán las conuiciones del ictio planctor y del ambiente.

\section{$B$ - TECNICAS DE ESTUDIO}

El material ictioplanctónico fue fijado en formol al 5\% neutralizado, y examinado bajo microscópio estereoscó pico dotado de escala micrométrica.

Para la identificación de los huevos se utiliza ron en algunas oportunidades gonadas maduras, próxinas a deso var, como en el caso de Micropogonias furnieri y Achirus garma ni. En la primera especie, por ser sus huevos más difíciles de identificar, se midió el diámetro y la gota de aceite de aproxí madamente 4.000 huevos, colectados en diferentes épocas y salinidades, y se calculó su distribución de frecuencias.

En el caso de Iycengraulis grossidens se midió el eje mayor (E) y el eje menor (e) de cada huevo, y se obtuvo su volúmen ( $V=4 / 3 \bar{\pi} \cdot \mathrm{E} / 2 \cdot \mathrm{e} / 2 \cdot \mathrm{e} / 2)$ y excentricidad:

$\left(K=\frac{(E / 2)^{2}-(e / 2)^{2}}{(E / 2)^{2}}\right)$, para precisar mejor el diagnóstico $y$ poder diferenciarlos de los huevos de otros engraulídeos que ha bitan el área costera. Las fórmulas se obtuvieron de Sadosky y Guber (1960). 
En las restantes especies, cuya identificación fue menos complicada se midieron los diámetros y gotas de los huevos y se estudió su distribución de frecuencias.

En cuanto a las larvas, partiendo del juvenil identificado se efectuó una serie completa de las diferentes $\underline{e}$ tapas de crecimiento hasta la recién eclosionada. Dicha serie se tiñó con alizarina según el método de Hollister ( 1934) pa ra determinar la secuencia de osificación. En estos casos se $\underline{e}$ laboró una tabla de caracteres merísticos para una mejor deter minación.

En especies como Lycengraulis grossidens y Bre voortia pectinata, que sufren un proceso de metamorfosis, sé elaboró una tabla morfométrica, donde se tomaron las proporcio nes morfológicas para su comparación dada su gran semejanza en la primera etapa de vida.

Con las larvas de las especies más abundantes se utilizó el coeficiente de afinidad de Fager (1963) y Ionghurst (1964): $\frac{\mathrm{A}}{\mathrm{a} \cdot \mathrm{b}}-\frac{1}{2 \sqrt{\mathrm{b}}}$ donde, $\mathrm{A}$ : es el número de estaciones donde las especies a y b están juntas.

El Índice de diversidad utilizado fue el de Margalef (1958): $D: \frac{S-1}{\lg n}$ donde, $S:$ número de especies y
$n:$ número de individuos.

Ias larvas pertenecientes a la Familia Atheri nidae no fueron identificadas a nivel de especie por ser éste un grupo muy complejo y el poco conocimiento que existe en es ta área.

En las colectas pasivas de plancton a tres ni veles de profundidad, las larvas de $\underline{B}$ - pectinata y $\underline{I}$ grossidens, fueron muy dañadas debido a su permanencia en la red; consecuentemente, en el item de distribución vertical éstas figuran como pertenecientes al SO. Clupeoidei.

Las larvas de Macrodon ancylodon, Paralonchurus brasiliensis, Cynoscion striatus y Umbrina canosai, por presentarse en número muy reducido fueron agrupadas en la Fa milia Sciaenidae en las correspondientes tablas y gráficos. 


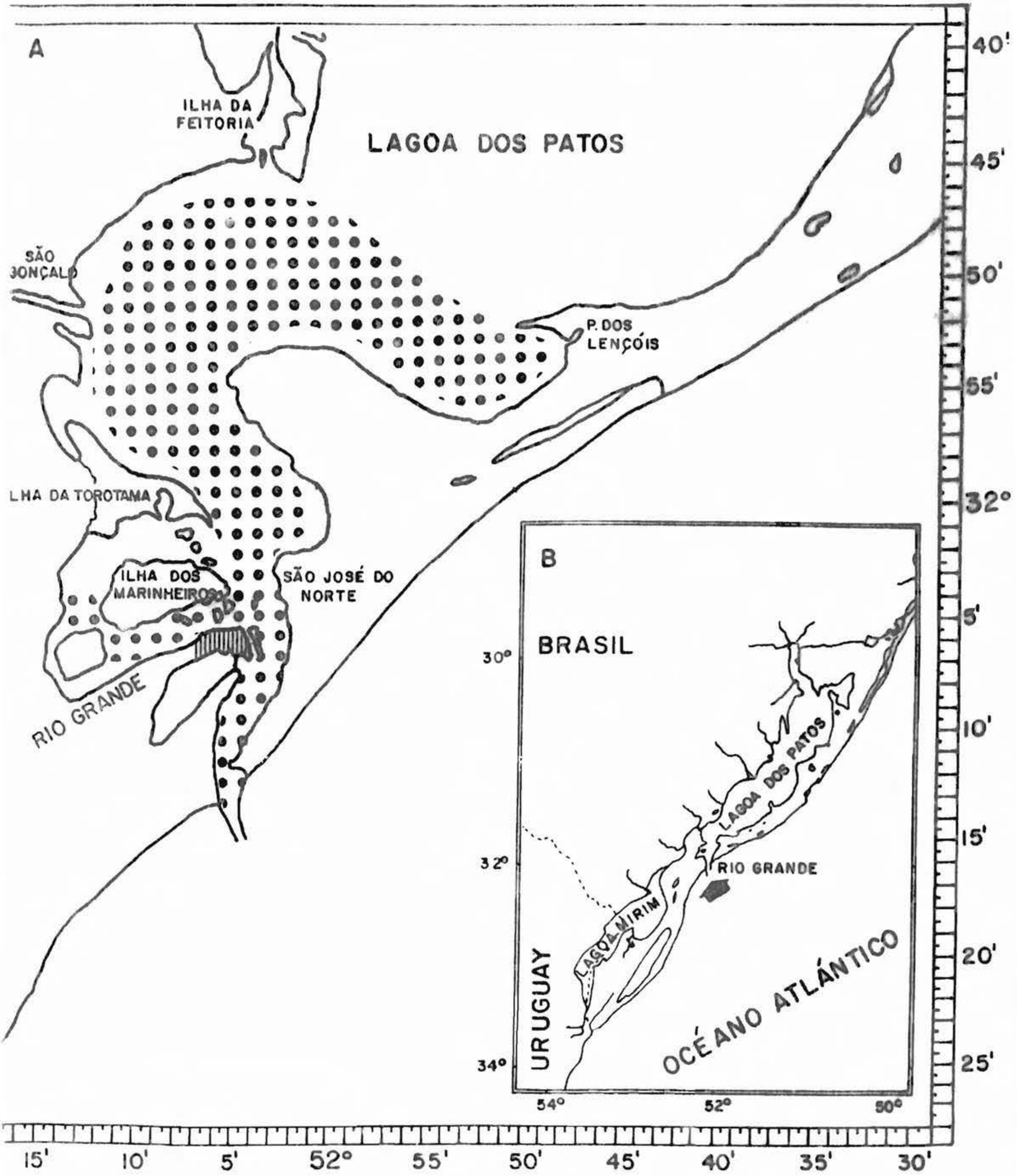

'í. I: Area estuarial de Lapoa dos ratos (A); localización de Lagoa dos tatos y Lagoa hirim (B). 


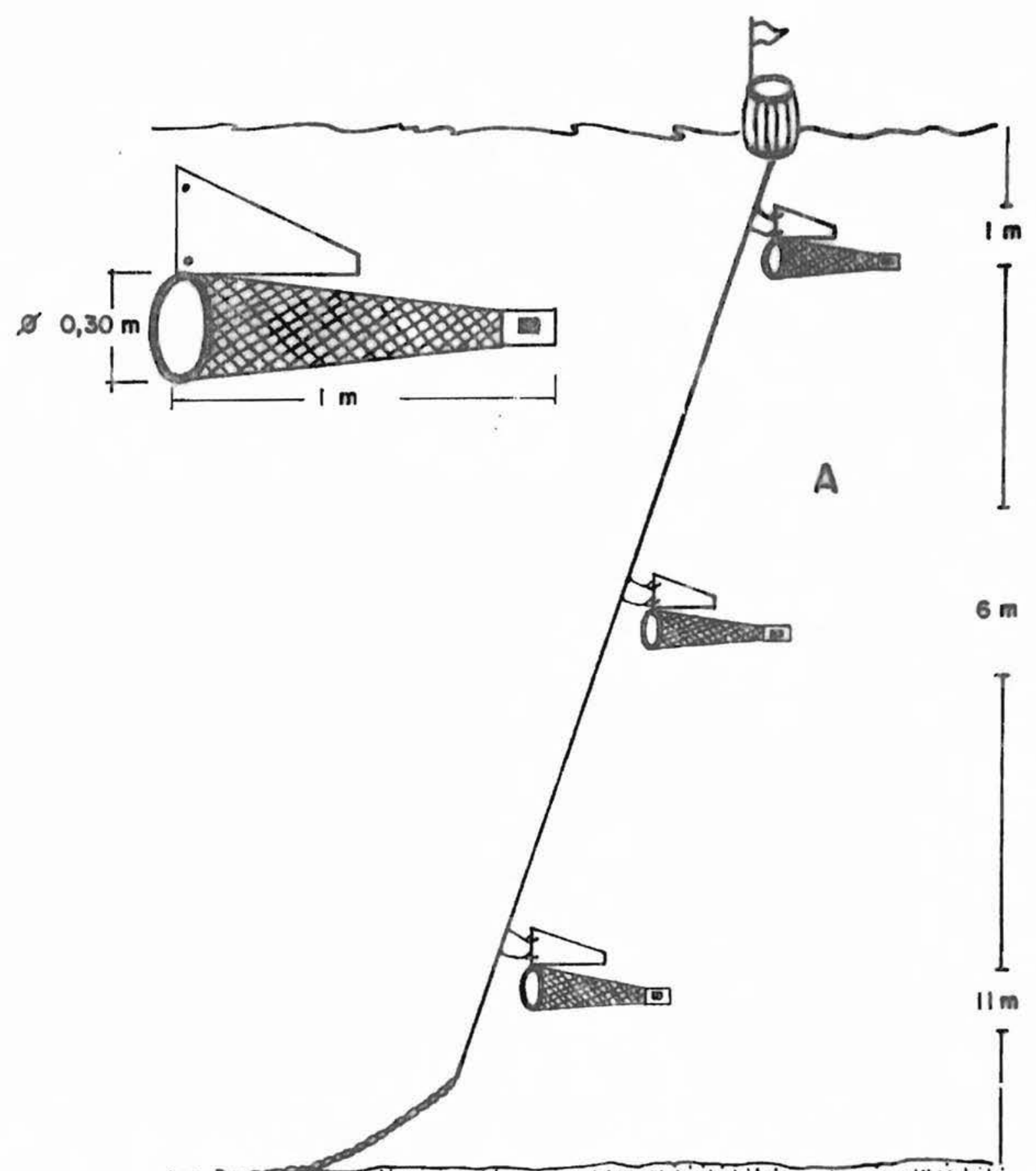

Fig. 2: Esquema del sistema pasivo de colecta de plancton para distintas prolundidades utilizado en el es tuario (modificado de Graham \& Venno, 1968). 
Tabla 1: Datos correspondientes a cada crucero y media del núnero de huevos y larvas por $100 \mathrm{~m}^{3}$.

\begin{tabular}{|c|c|c|c|c|c|}
\hline CRUCERO & FECHA & EPOCA & No EST. & № HUEVOS & № LARVAS \\
\hline 1 & $08 / 12-11 / 12 / 75$ & P & 20 & 16,4 & 121,2 \\
\hline 2 & 08/01-10/01/76 & V & 23 & $2.056,3$ & 112,6 \\
\hline 3 & $26 / 01-29 / 01 / 76$ & V & 30 & 912,0 & 32,9 \\
\hline 4 & $16 / 02-24 / 02 / 76$ & V & 19 & 0,1 & 12,7 \\
\hline 5 & $05 / 04-09 / 04 / 76$ & 0 & 23 & 14,3 & 7,8 \\
\hline 6 & $26 / 04-30 / 04 / 76$ & 0 & 34 & 1,1 & 15,7 \\
\hline 7 & $19 / 05-26 / 05 / 76$ & 0. & 45 & 33,8 & 24,0 \\
\hline 8 & $15 / 06-18 / 06 / 76$ & 0 & 30 & -- & 42,9 \\
\hline 9 & $10 / 08-13 / 08 / 76$ & I & 18 & -- & 6,8 \\
\hline 10 & $27 / 09-03 / 10 / 76$ & $\mathrm{P}$ & 35 & 0,4 & 1,6 \\
\hline 11 & $19 / 10-22 / 10 / 76$ & $\mathrm{P}$ & 24 & 324,9 & 3,9 \\
\hline 12 & $09 / 11-11 / 11 / 76$ & $P$ & 26 & $1.265,5$ & 23,6 \\
\hline 13 & $29 / 11-04 / 12 / 76$ & P & 37 & 102,9 & 42,9 \\
\hline 14 & $20 / 12-22 / 12 / 76$ & V & 18 & 0,2 & 55,5 \\
\hline 15 & $10 / 01-13 / 01 / 77$ & V & 24 & 0,5 & 27,9 \\
\hline 16 & $24 / 01-27 / 01 / 77$ & V & 25 & 523,9 & 31,8 \\
\hline 17 & $08 / 03-12 / 03 / 77$ & V & 18 & 150,1 & 3,7 \\
\hline 18 & $30 / 03-04 / 04 / 77$ & 0 & 34 & 70,2 & 20,7 \\
\hline 19 & $02 / 06-06 / 06 / 77$ & 0 & 26 & -- & 15,0 \\
\hline 20 & $26 / 07-28 / 07 / 77$ & I & 16 & -- & 5,2 \\
\hline 21 & $13 / 09-16 / 09 / 77$ & I & 28 & -- & 0,9 \\
\hline 22 & $09 / 11-11 / 11 / 77$ & $P$ & 23 & 5,0 & 28,3 \\
\hline 23 & $04 / 01-13 / 01 / 78$ & V & 22 & 121,9 & 21,2 \\
\hline 24 & $26 / 02-02 / 03 / 78$ & V & 23 & 19,9 & 21,1 \\
\hline 25 & $26 / 09-29 / 09 / 78$ & $\mathrm{P}$ & 23 & 4,7 & 25,8 \\
\hline 26 & $08 / 11-10 / 11 / 78$ & $\mathrm{P}$ & 27 & 296,0 & 8,9 \\
\hline
\end{tabular}


Tabla 2: Número de huevos y larvas capturadas en cada estrato y en cada muestreo.

\begin{tabular}{|c|c|c|c|c|c|c|c|c|}
\hline \multirow{3}{*}{$\begin{array}{l}M \\
\mathrm{U} \\
\mathrm{E} \\
\mathrm{S} \\
\mathrm{T}\end{array}$} & \multirow{3}{*}{ FECHA } & \multirow{3}{*}{$\begin{array}{l}\mathrm{E} \\
\mathrm{P} \\
\mathrm{O} \\
\mathrm{C} \\
\mathrm{A}\end{array}$} & \multicolumn{6}{|c|}{ ESTRATO } \\
\hline & & & \multicolumn{3}{|c|}{ HUEVOS } & \multicolumn{3}{|c|}{ IARVAS } \\
\hline & & & $\operatorname{lm}$ & $6 \mathrm{~m}$ & $11 \mathrm{~m}$ & Im & $6 \mathrm{~m}$ & $11 \mathrm{~m}$ \\
\hline 1 & 17.11 .76 & $\mathrm{P}$ & 1 & 1 & 7 & 1.288 & 1.890 & 1.102 \\
\hline 2 & 24.11 .76 & $\mathrm{P}$ & 26.128 & 10.340 & 7.463 & 103 & 26 & 37 \\
\hline 3 & 29.11 .76 & $\mathrm{P}$ & 1.894 & 15.249 & 3.193 & 371 & 767 & 337 \\
\hline 4 & 08.12 .76 & $\mathrm{P}$ & 7.440 & 4.854 & 13.852 & 343 & 366 & 571 \\
\hline 5 & 15.12 .76 & V & 1 & 49 & 93.333 & 40 & 843 & 406 \\
\hline 6 & 22.12 .76 & V & 95 & 487 & $7 \cdot 329$ & 1.121 & 1.212 & 1.799 \\
\hline 7 & 29.12 .76 & V & 86.726 & 85.666 & 62.965 & 231 & 290 & 180 \\
\hline 8 & 05.01 .77 & V & 271 & 874 & 1.328 & 418 & 269 & 20 \\
\hline 9 & 19.01 .77 & V & --- & --- & 46 & 106 & 51 & 117 \\
\hline 10 & 13.04 .77 & 0 & 1 & --- & --- & 131 & 80 & 48 \\
\hline 11 & 19.04 .77 & 0 & --- & --- & --- & 794 & 346 & 205 \\
\hline 12 & 28.04 .77 & 0 & --- & --- & ---- & 29 & 36 & 36 \\
\hline 13 & 06.07 .77 & I & ---- & $-\cdots$ & --- & 256 & 114 & 159 \\
\hline 14 & 13.07 .77 & I & $-\cdots$ & --- & --- & 10 & 51 & 44 \\
\hline 15 & 20.07 .77 & I & --- & $-\infty$ & ---- & 24 & 9 & 24 \\
\hline 16 & 20.09 .77 & $P$ & ---- & 1 & --- & 3 & 2 & 2 \\
\hline 17 & 13.10 .77 & $\mathrm{P}$ & 317 & 408 & 472 & 310 & 343 & 192 \\
\hline 18 & 20.10 .77 & $\mathrm{P}$ & 15 & 14 & 8 & 166 & 91 & 38 \\
\hline 19 & 27.10 .77 & $\mathrm{P}$ & 987 & 786 & 997 & 4 & 4 & 4 \\
\hline
\end{tabular}


IV - RESULTADOS Y DISCUSION

$\underline{\underline{P A R T E}} \stackrel{\mathrm{A}}{=}$

DESCRIPCION DE IAS ESPECIES 
Las especies identificadas y descriptas fueron:

HUEVOS $\frac{\text { Brevoortia pectinata }}{\text { Iycengraulis grossidens }}$

Brevoortia pectinata

Iycengraulis grossidens

Parapimelodus valenciennis

Hyporhamphus kronei

S.yngnathus folletti

Micropogonias furnieri

LARVAS Macrodon ancylodon

Paralonchurus brasiliensis

Umbrina canosai

Cynoscion striatus

Trichiurus lepturus

Achirus garmani

Gobiesox strumosus

Identificados a nivel de género, fueron:

Blennius sp.

Gobionellus sp.

A nivel de Familia: Atherinidae.

Por no ser identificadas a nivel de especies estas últimas larvas no fueron descriptas. Las descripciones de los huevos y larvas dependió en algunos casos de la canti dad de material disponible, y en otros casus de la importancia económica y biológica. 
Los huevos de esta especie fueron identificados en las aguas costeras del Sur de Brasil por Weiss et all. (1976). Los valores de diámetros obtenidos por estos autores fueron de 1134 a $1404 \mu$ con una media de $1260 \mu$ para la primavera de 1971. Estos diámetros son semejantes a los obtenidos en el presente trabajo en los meses de octubre, noviembre y mayo de 1976 en diferentes rangos de salinidad (Fig. 3). Los menores diámetros se obtuvieron en los meses de enero y marzo con una media de 1042 y $1063 \mu$ respectivamente.

La disminución del tamaño del huevo con el aumento de la temperatura ya fue observado por diversos investigadores y en diferentes especies de peces, ( Blaxter y Hem pel, 1963; Zijlstra, 1969; Hempel y Blaxter, 1967; etc.). El djámetro del huevo de una especie puede variar a través de un cradiente de temperatura latitudinal o estacional. En este caso el aumento de la temperatura en la época de verano determina una disminución del huevo en un 15\% en relación con los diámetros obtenidos en octubre o mayo. Evidentemente de los huevos de menor tamaño, desarrollados a mayores tempe raturas, nacerán larvas menores, que son compensadas por abundante alimento en el plancton. De los huevos de épocas Irias nacerán larvas más capacitadas para soportar un ambien te desfavorable. Por otro lado, temperaturas frias provocan un desarrollo demorado y favorecen la asimilación de las sus tancias alimenticias del vitelo, obteniéndose larvas mejor desarrolladas.

Efectuando el análisis de la varianza para los diámetros de los huevos en salinidades de 27 a $30 \%$ y de 23 a 26\% respecto al mes de muestreo, se obtuvo: $F=1,3278$ y $F=0,2974$ respectivamente. Dado que $F$ es menor a $F_{0,95}$ se acepta la hipótesis de igualdad de las muestras. Este resul tado es consecuencia de que la suma de los cuadrados dentro de cada mes es mayor que la suma de cuadrados entre meses. A pesar de que el análisis de la varianza no evidencia la varia ción del diámetro del huevo, biológicamente el hecho es razonablemente evidente.

El tamaño de la gota de aceite fue de 108 a a $162 \mu$, no presentando variación con cambios de la temperatura. 
Ia descripción del desarrollo embrionario y larval de esta especıe sobre material del mismo estuario fue efectuado por Weiss y Krug, 1977. La Fig. 4 fue tomada de estos autores. un resúmen de las cauacterísticas más importantes, indica que:

El huevo es tipicamente planctónico, transparente y sin pigmentación. El vitelo se dispone desde la par te inferior de la cabeza hasta el tercio anterior del cuerpo. La gota se sitúa en el extremo ventro-posterior. Las aletas pectorales están bien desarrolladas y aún membranosas. La aleta embrionaria es amplia y nace detrás de la cabeza, rodeando todo el cuerpo hasta el ano que se dispone cerca del extremo caudal ( $85 \%$ del largo total).

El vitelo es consumido totalmente a $10 \mathrm{~s} 5 \mathrm{~mm}$, cuando tiene la boca funcional y los ojos pigmentados. Sobre la aleta embrionaria se observan los primeros radios de la aleta dorsal y caudal. Las pectorales están más desarroIladas.

A Ios $10 \mathrm{~mm}$ la aleta embrionaria desaparece por completo, observándose la aleta dorsal con 10 radios, la anal con 11 y 1 a caudal con 19 radios principales. Las pectorales están más desarrolladas pero todavía membranosas. El tracto digestivo sigue recto hasta el ano, estando éste situado a un $80 \%$ del largo total. In la parte ventral apare cen una serie de melanóforos y otra serie entre el intestino y el cuerpo. En ese momento se observan 42 miómeros, sien do este el número definitivo.

A Los $15 \mathrm{~mm}$ tiene características muy semejantes a los juveniles. Las aletas tienen el número definitivo de radios, siendo, 14 en 1 a dorsal, 19 en 1 a caudal y 7 en las ventrales las cuales se forman entre 10 s 13 a $14 \mathrm{~mm}$ de largo. Las pectorales recién comienzan a osificar sus radios La pigmentación es más acentuada, presentando la misma característica que la larva de $10 \mathrm{~mm}$; solamente aparecen unos tènues melanóforos en el hocico y sobre la caudal. El tracto digestivo continúa siendo recto y la posición del ano se encuentra a un $72 \%$ del largo total.

I adquiriendo características tîpicas de juvenil. La distancia preanal está a 59 o 60\% del largo total. A pesar de conside rarse juvenil, la altura del cuerpo recién se estabiliza en tre 10 s 60 a $70 \mathrm{~mm}$ de largo. 


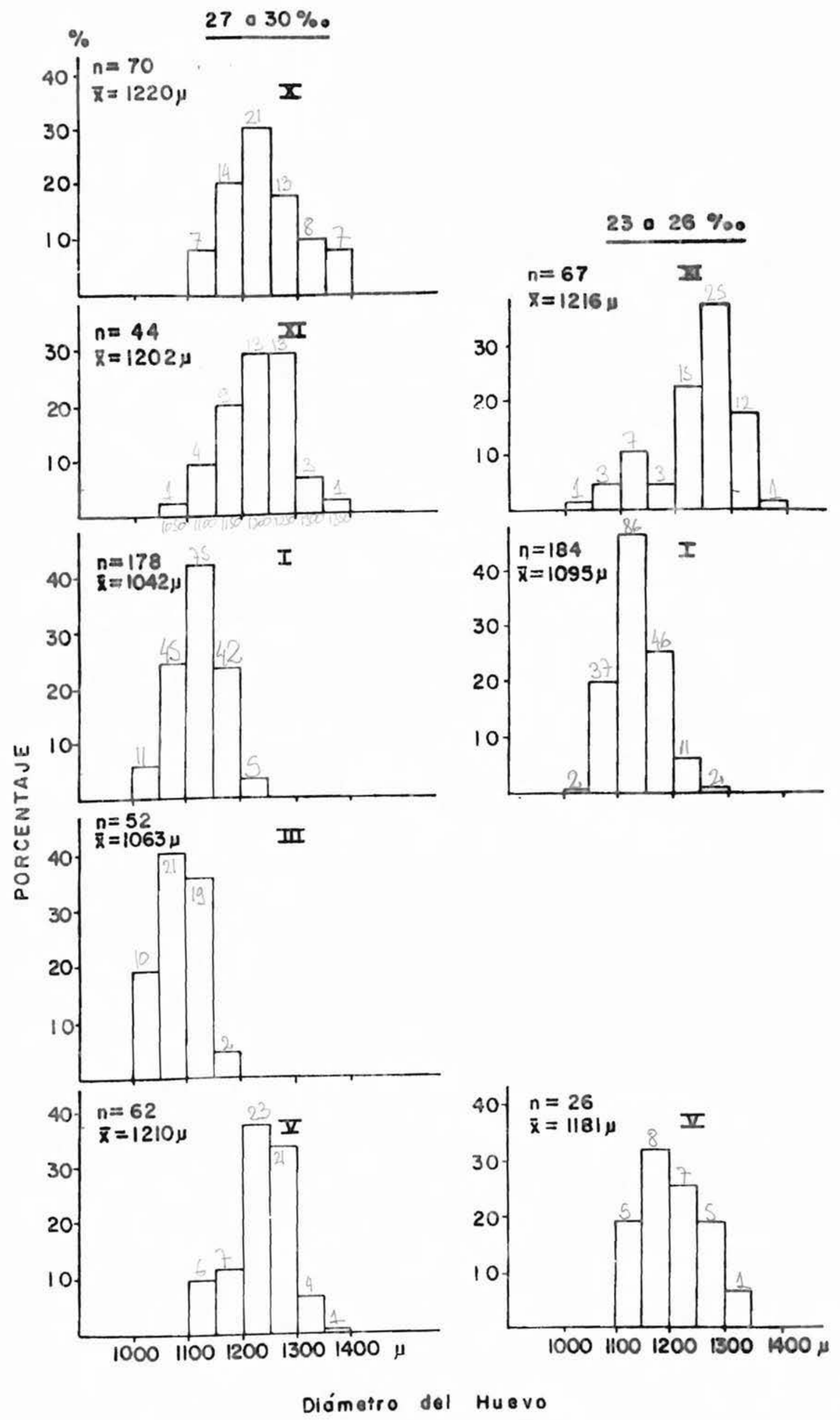

Tí. 3 : Distribución de frecuencias de huevos de B. nectinata 

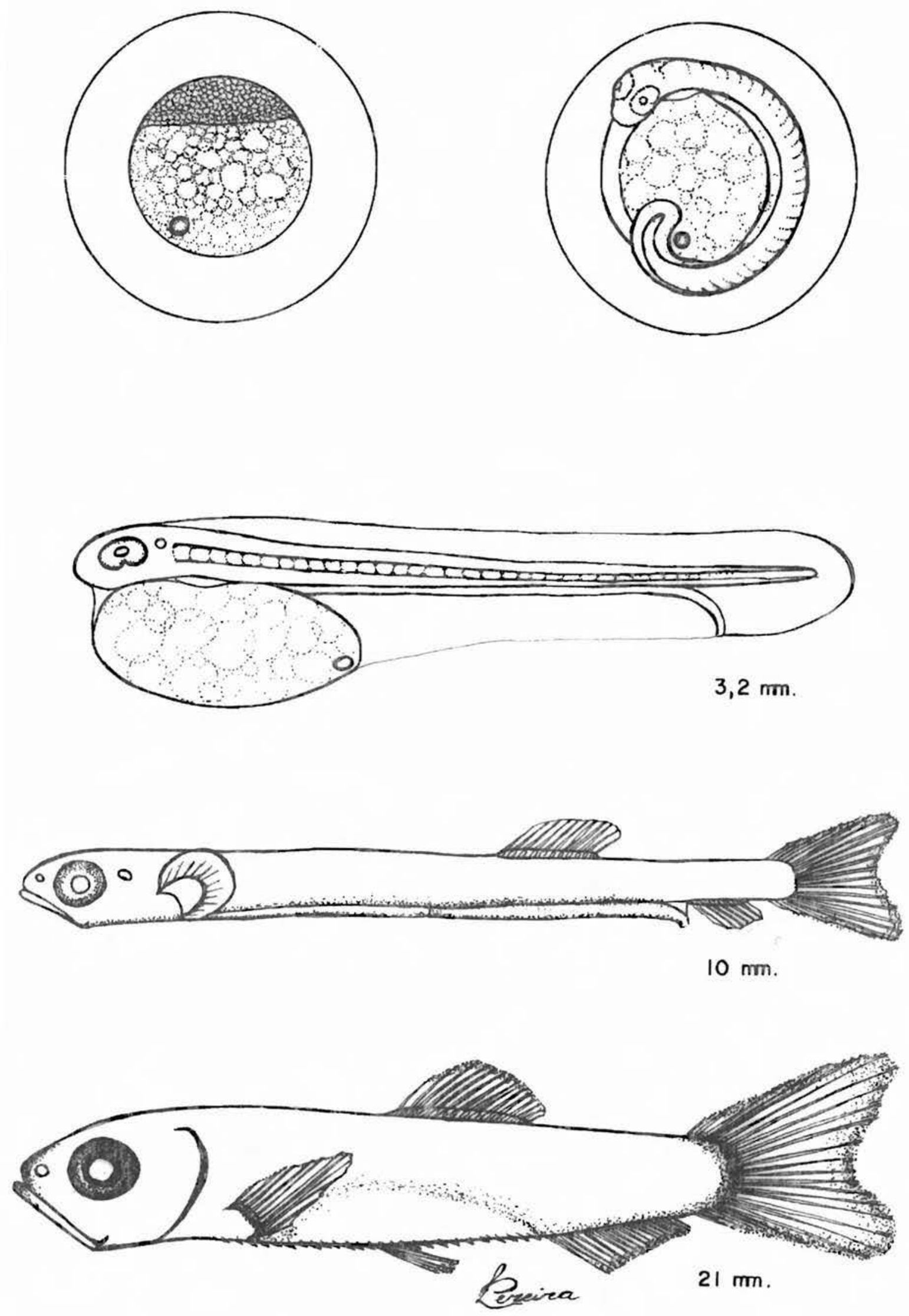

Fis. 4 : Desirrolio ewbrionario y 14rval is Srevoortia pectinata. ( Tomado de Veiss e frug, 2977). 


\section{2 - LYCENGRAULIS GROSSIDENS}

Los huevos fueron identificados por Weiss et all (1976) para el área costera del sur de Brasil. Las dimen

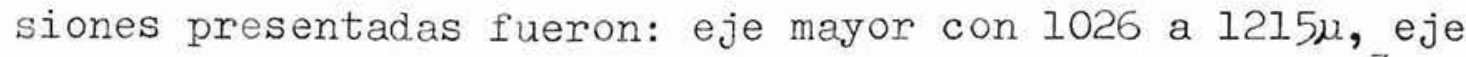
menor con 756 a $945 \mu$ y el volúmen de 0,3380 a $0,5680 \mathrm{rm}^{3}$.

La Fig. 5 presenta la distribución de frecuen cias del eje mayor, eje menor, volúmen y excentricidad en salinidades mayores a $30 \%$, entre $27 \%$ y $30 \%$ y entre $23 \% 0$ y 26\%o, obtenidos en la primavera de 1976. Fue éste el único pe ríodo en que se colectó un número relativamente abundante de huevos, no teniendo posibilidad de comparar con otras épocas del año.

Los valores medios de eje mayor, menor y volú men coincider con los obtenidos por los autores citados anteriormente. Llama la atención la gran amplitud de variación que existe en la excentricidad de estos huevos, a pesar de que las medias oscilan apenas entre 0,62 y 0,60.

El exámen de las larvas presentes en el estua rio realizado por Weiss y Krug (1977) y continuado en el presente estudio indicaron que el único engraulídeo que utiliza esta área para su desarrollo es I. grossidens, descartando la posibilidad de que la amplia variación de la excentricidad es té dado por la presencia de otro huevo de la misma Fanilia. Posiblemente ésta sea una característica propia de la especie y la influencia de un ambiente inestable.

La Fig. 6 presenta los estadios más caracte rísticos del desarrollo embrionario y larval de ésta especie tomados de Weiss y Krug (1977).

Las características más importantes en cuanto a su descripción son:

Los huevos son planctónicos, transparentes, sin gota de aceite, vitelo segmentado en vacuolas pequeñas y espacio perivitelino pequeño.

La larva nace con 3mm, muy poco desarrollada, transparente y sin pigmentación. El vitelo se dispone en la parte ventral, debajo de la cabeza hasta la mitad del cuerpo. La aleta embrionaria, estrecha, nace detrás de la cabeza y rodea todo el cuerpo hasta el ano, situado cerca de la aleta caudal ( $70 \%$ del largo total). Los miómeros, en número aproximado de 35, continúan su formación. 
A los $5 \mathrm{~mm}$ ya consumió totalmente el vitelo. Tie ne la boca funcional y los ojos pigmentados. Sobre la aleta em brionaria se esbozan los radios de las aletas dorsal y caudal. Las pectorales todavía son membranosas. El tracto digestivo es recto hasta el ano, que se dispone todavía a un 70\% del largo total.

A Ios $10 \mathrm{~mm}$ presenta las aletas dorsal, caudal $y$ anal bien formadas con vestigios de la aleta embrionaria. Las ventrales todavía no se formaron y las pectorales ya tienen algunos radios. El tracto digestivo sigue recto, observándose la vejiga natatoria entre el intestino y el cuerpo, aproximadamente a la mitad del mismo. El número de miómeros visibles ya es el definitivo (45). El ano está más distante del hocico, a un $73 \%$ del largo total.

Con $20 \mathrm{~mm}$ se parece bastante al juvenil. Las ale tas tienen practicamente el número definitivo de radios. Las ventrales que nacen cuando la larva alcanza los 14 a $15 \mathrm{~mm}$, ya están bien desarrolladas. El tracto digestivo continúa recto, estando el ano a un 65\% del largo total. Aparecen una serie de melanóforos en la parte ventral que se dispone en dos hileras paralelas desde la parte inferior de la mandíbula hasta la aleta pectoral y desde la mitad de la anal hasta el inicio de la caudal.

A los $30 \mathrm{~mm}$ presenta características semejantes a la anterior con un aumento de la pigmentación, observándose melanóforos en la parte superior y ventral de la cabeza y ro deando el borde póstero-inferior del opérculo. Dos hileras pâ ralelas de melanóforos se inician detrás de la cabeza y continúan dorsalmente hasta la aleta caudal, que rodean por su base y continúan ventralmente hasta el ano. El tracto digestivo comienza su metamorfosis, formándose el estómago y los ciegos pi Ióricos. La distancia pre-anal disminuye a un 53\% del largo to tal.

A los 40mm termina su metamorfosis, adquiriendo las caracterîsticas tîpicas de juvenil. Las aletas tienen su número definitivo de radios, teniendo la dorsal 16 radios, la anal 25 a 26, las ventrales ?, las pectorales 15 a 16 y la caudal 19 radios principales. Ia distancia pre-anal está a un $50 \%$ del largo total. Ia altura del cuerpo en proporción con el largo ya es la definitiva, o sea que inicia su crecimiento iso métrico. 

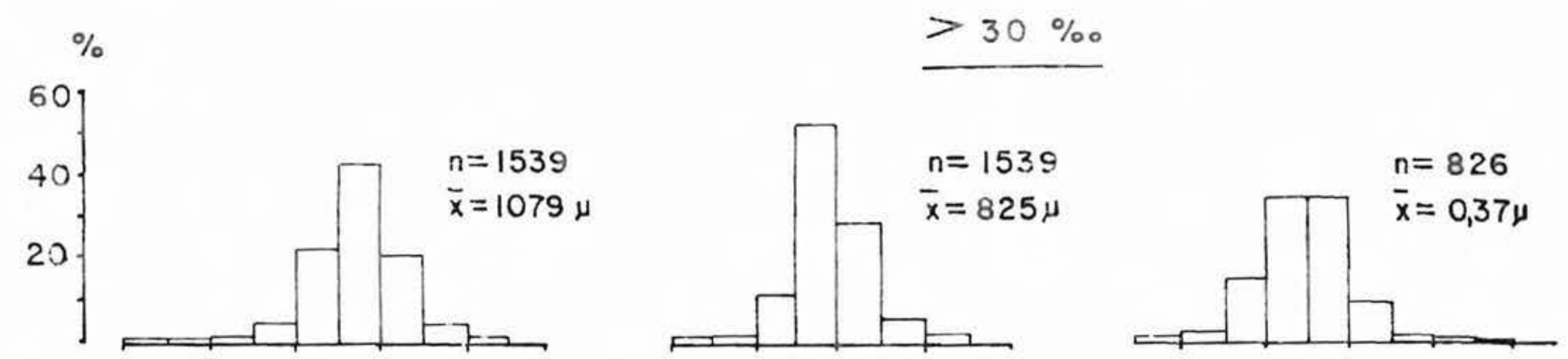

$27-30 \%$ 。
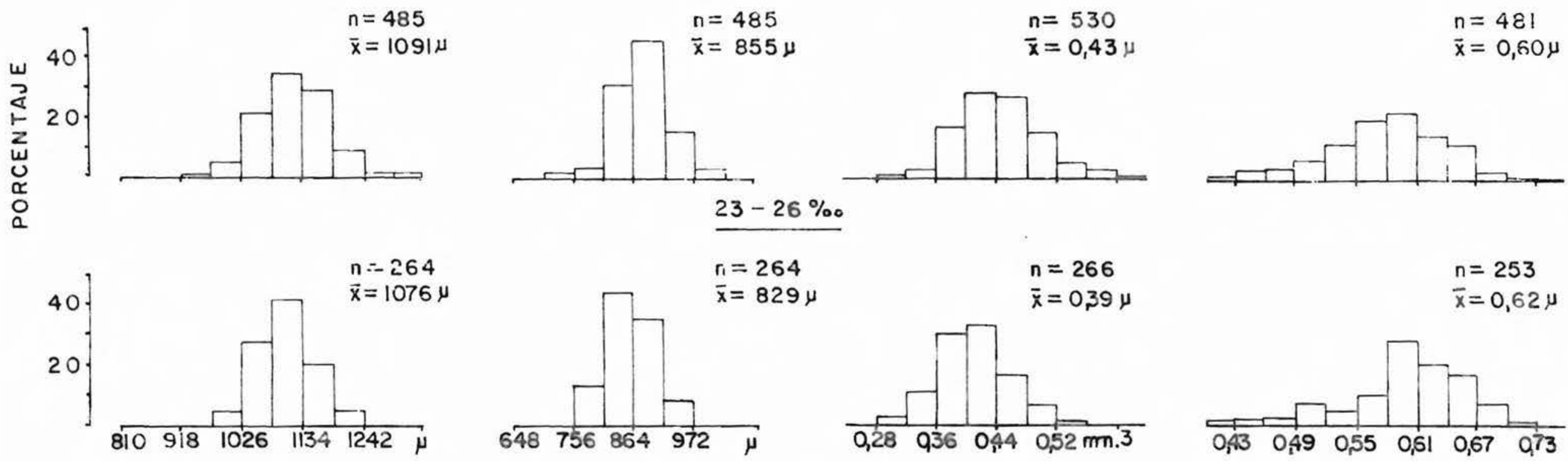

eje mayor

eje menor
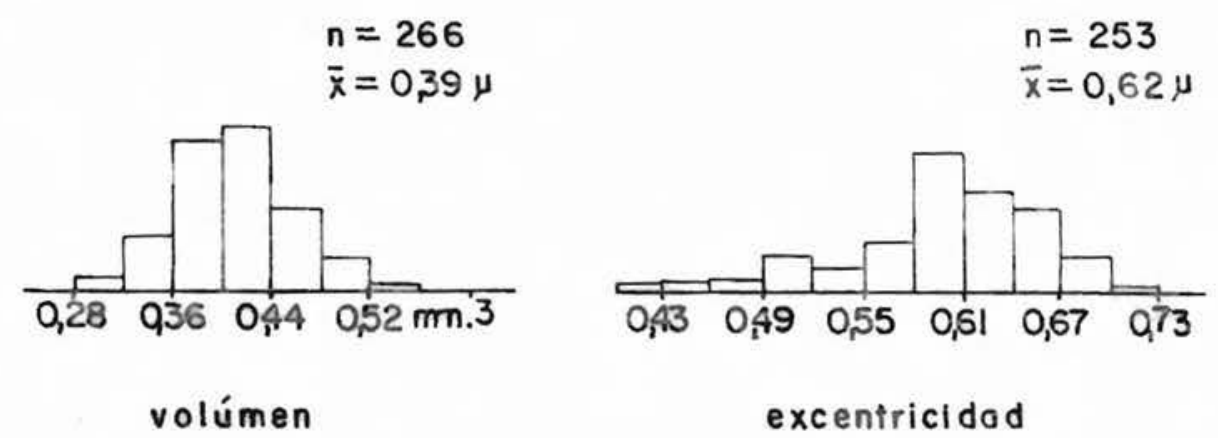

Fig. 5: Distribución de frecuencias da eje mavor, eje menor, vol'men

$\mathrm{V}$ excentricidan de huevos de $\mathrm{I}$. grossidens en diferentes sa-

inidades, para la primavera de 1775 . 

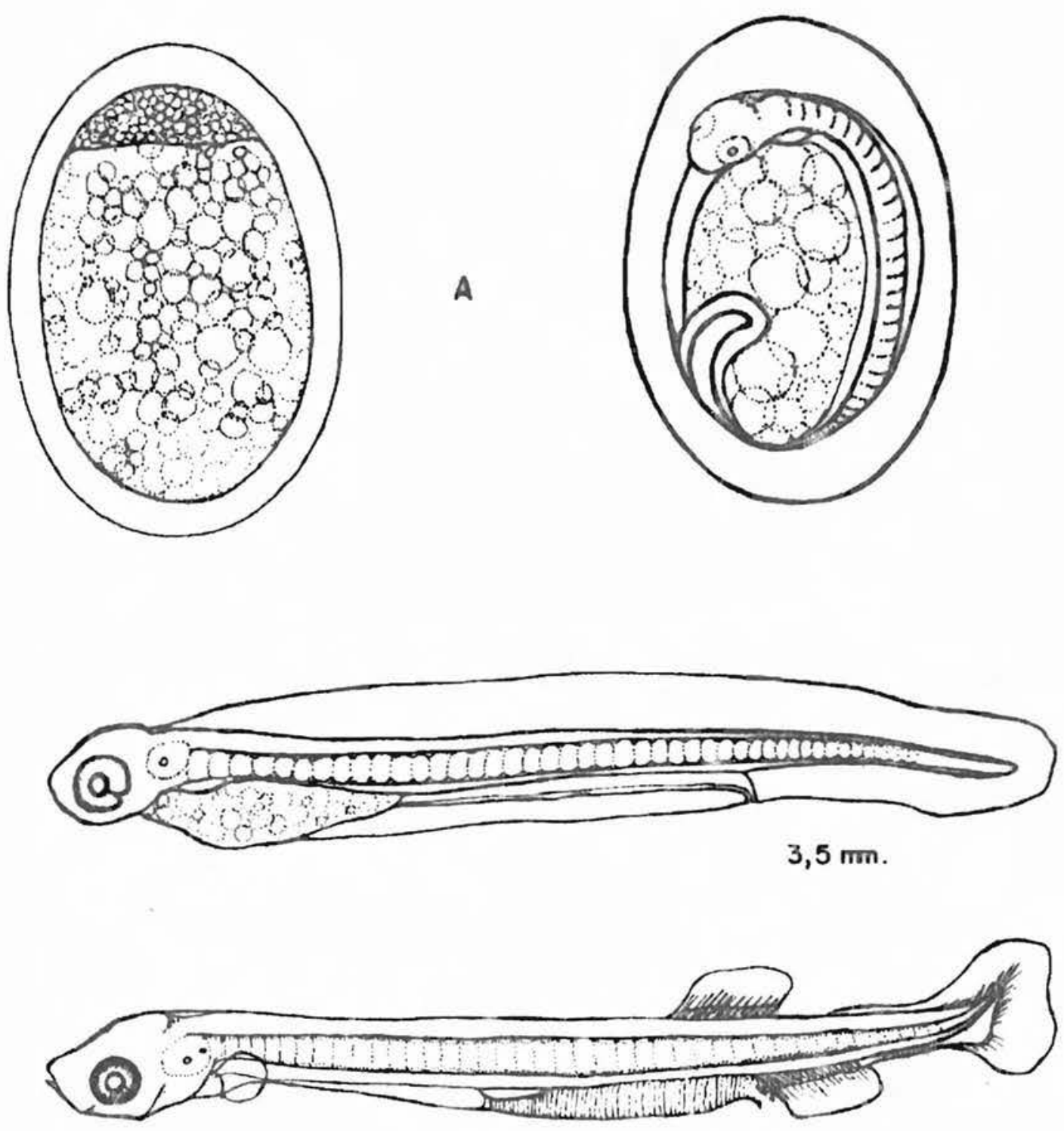

$11 \mathrm{~mm}$.

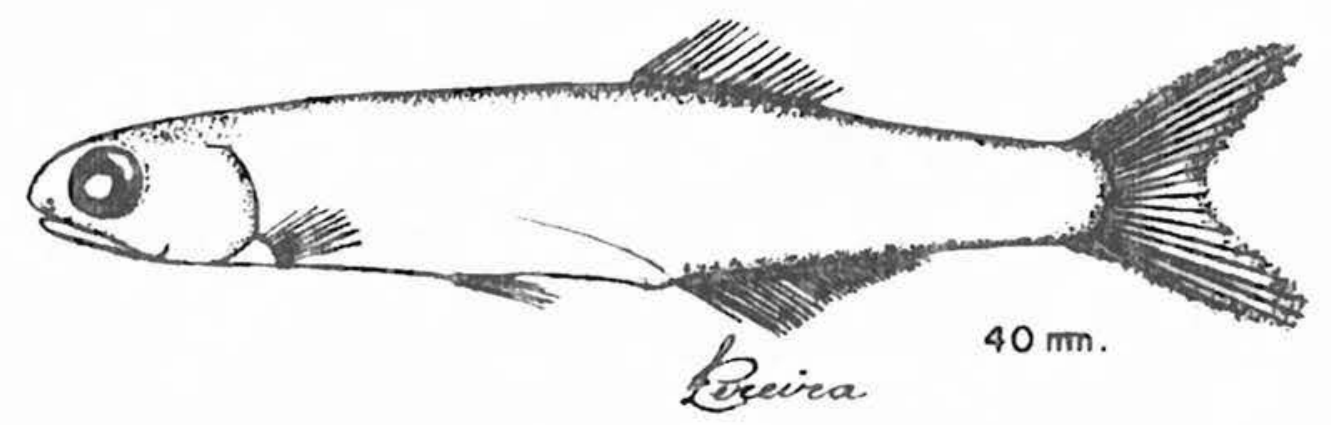

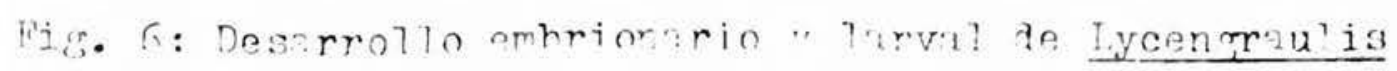

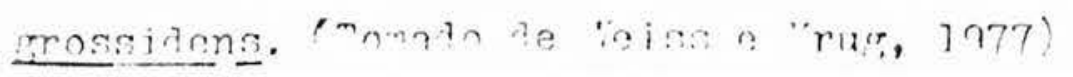




\section{3 - PARAPIMELODUS VALENCIENNIS}

La menor larva encontrada fue de $8 \mathrm{~mm}$. Fn este estadio carece totalmente de pigmentación, a excepción de los ojos que presentan una leve pigmentación marrón claro. El tracto digestivo está practica mente formado y la boca es funcional, no presentando vestigios de vitelo. La notocorda es bien visible cur vándose hacia arriba en el extremo caudal. El número de miómeros posibles de contar son aproximadamente 28. Presenta restos de la aleta embrionaria en la parte posterior del tronco y bajo el intestino. No hay vesti gios de las aletas dorsales ni ventrales. Las pectorales son sumamente pequeñas y membranosas. Sobre la ale ta embrionaria se observan 14 radios que corresponden a la aleta caudal y unos 5 radios comienzan a insinuar se en la anal. Ios tres pares de barbillas está bien desarrolladas, lo que facilita su identificación.

A los $22 \mathrm{~mm}$ presenta todas las características del juvenil. Los ojos están completamente pigmenta dos y se observa un pronunciado aumento del número de melanóforos por todo el cuerpo, acentuándose en la par te dorsal del tronco y cabeza. La distancia pre-anal representa un 53\% del largo total. Todas las aletas es tán bien desarrolladas, presentando la primera dorsal II - 6, (Ia segunda dorsal es adiposa), la anal II -15, la ventral 6, la pectoral I - 7 y la caudal 16. El número de miómeros es de 37 a 38. Los barbillones están más desarrollados.

Tamaños mayores a 22mm sólo fueron encontra dos en raras ocasiones en el plancton. 

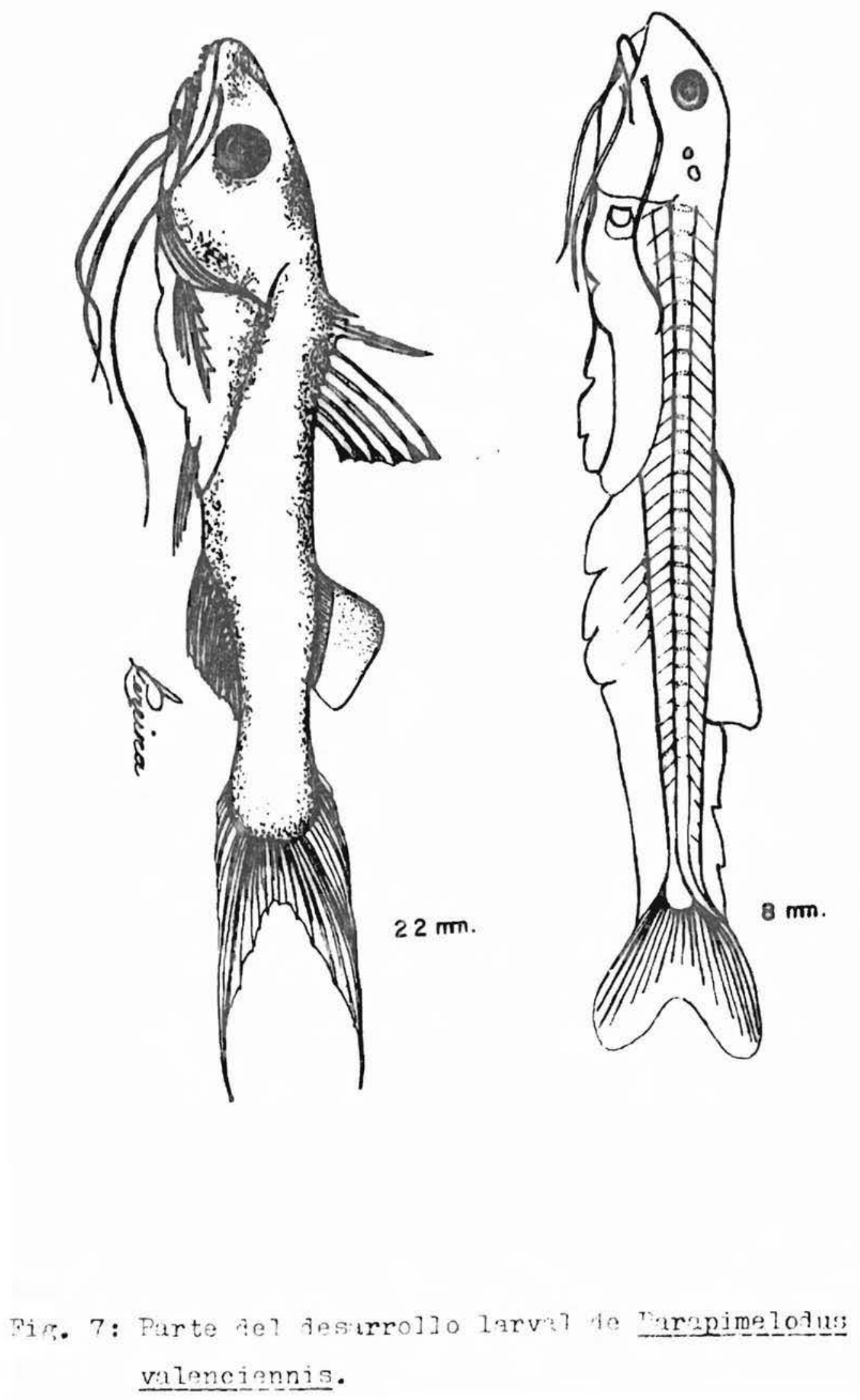
4 - HYPORHAMPHUS KRONEI

A travéz de una gónada en avanzado estado de maduración, se observaron los fillamentos de la cáscara del huevo. Estos filamentos, que inician su formación en ovocitos bien pe queños ( $135 \mu$ ) están presentes en pequeño número y son muy lar gos ( Fig. 8). A travéz de los filamentos los huevos se unen entre sí y a la vegetación sumergida. Hildebrand y Schroeder (1928) caracterizan los huevos de Hyporhamphus unifasciatus del Atlántico Norte como semiflotantes, teniendo éstos un esca so número de filamentos y muy largos.

En las muestras de plancton las larvas más peque ñas fueron de $7 \mathrm{~mm}$. En este estadio la larva presenta vestigios de las aletas dorsal, caudal y anal. Las pectorales son relati vamente grandes y membranosas. El tubo digestivo es recto y de semboca en el ano ubicado a un 63\% del largo total. La mandíbú la se presenta un poco sobresaliente en comparación con la maxila Los ojos grandes son muy pigmentados. Presenta una doble hilera de melanóforos en el dorso del cuerpo, desde la cabeza hasta la aleta caudal. La pigmentación en la parte dorsal del tubo digestivo es muy intensa. Melanóforos agrupados aparecen detrás del ojo y en el hocico.

Con $17 \mathrm{~mm}$ las proporciones del cuerpo se mantienen, apareciendo un mayor número de radios en las aletas, pero todavía no completos. Comienzan su desarrollo las ventrales.La mandíbula ya inició su crecimiento alométrico proyectándose hạ cia adelante. Los ojos acentuaron su pigmentación al igual que el resto del cuerpo. Se visualizan 34 miómeros abdominales y 20 caudales, șumando un total de 54 miómeros.

A los $24 \mathrm{~mm}$ las aletas completaron su número de radios teniendo la dorsal 16, la anal $16 \mathrm{yla}$ pectoral 11. Ia $\underline{a}$ lometría de la mandíbula ya es bien manifiesta. La pigmentación está bien definida, observándose una doble hilera dorsal, otra ventral y otra lateral. Se acentuó la pigmentación en la cabeza, principalmente en la parte dorsal.

A excepción de la mandíbula, que continúa con su crecimiento alométrico, las características morfológicas del cuerpo son iguales a los adultos. 

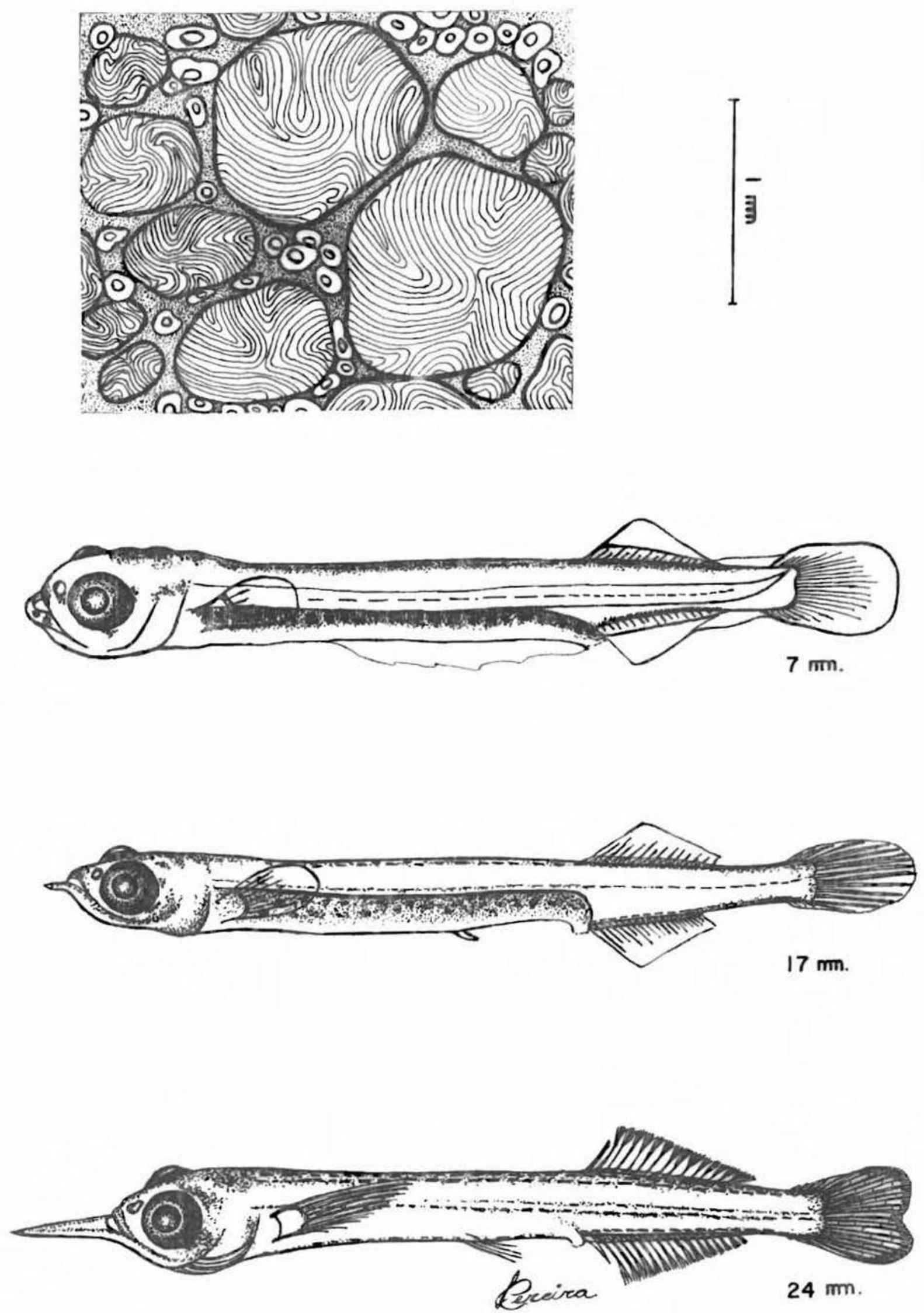

Hig. 8: A: Huevos ováricos, B: desamrollo larval de 


\section{5 - SYNGNATHUS FOLLETTI}

I os huevos de esta especie son incuba-dos en un par de pliegues ventrales del macho, hasta que el embrión consume todo el vitelo y comienza su alimentación externa.

La menor larva colectada en las mues tras de plancton fue de lomm. Esta larva tiene seme janza con los adultos a pesar de no haber completado todo su desarrollo. Los escudos cutáneos que for man los anillos del cuerpo están presentes pero no completos, principalmente la parte que cubre el tubo digestivo es rudimentaria. Las aletas pectorales, dorsal y caudal no tienen el número definitivo de radios y presentan restos de la aleta membranosa. La anal es incipiente. Los ojos están bien pigmenta dos y tienen melanóforos distribuídos homogéneamente por todo el cuerpo (Fig. 9).

A los $24 \mathrm{~mm}$ ya tienen el número total de escudos, presentando una media de 16 torácico-abdomi nales y 38 caudales, sierilo el total 5\%. Ta aleta dorsal presenta unos 39 radios y la caudal 10. Las pectorales y anal todavía son membranosas. La pigmen tación continúa homogénea por todo el cuerpo.

El juvenil de $42 \mathrm{~mm}$ tiene una pigmenta ción característica que consiste en una série de ban das transversales a lo largo de todo el cuerpo y que persiste en la fase adulta. 

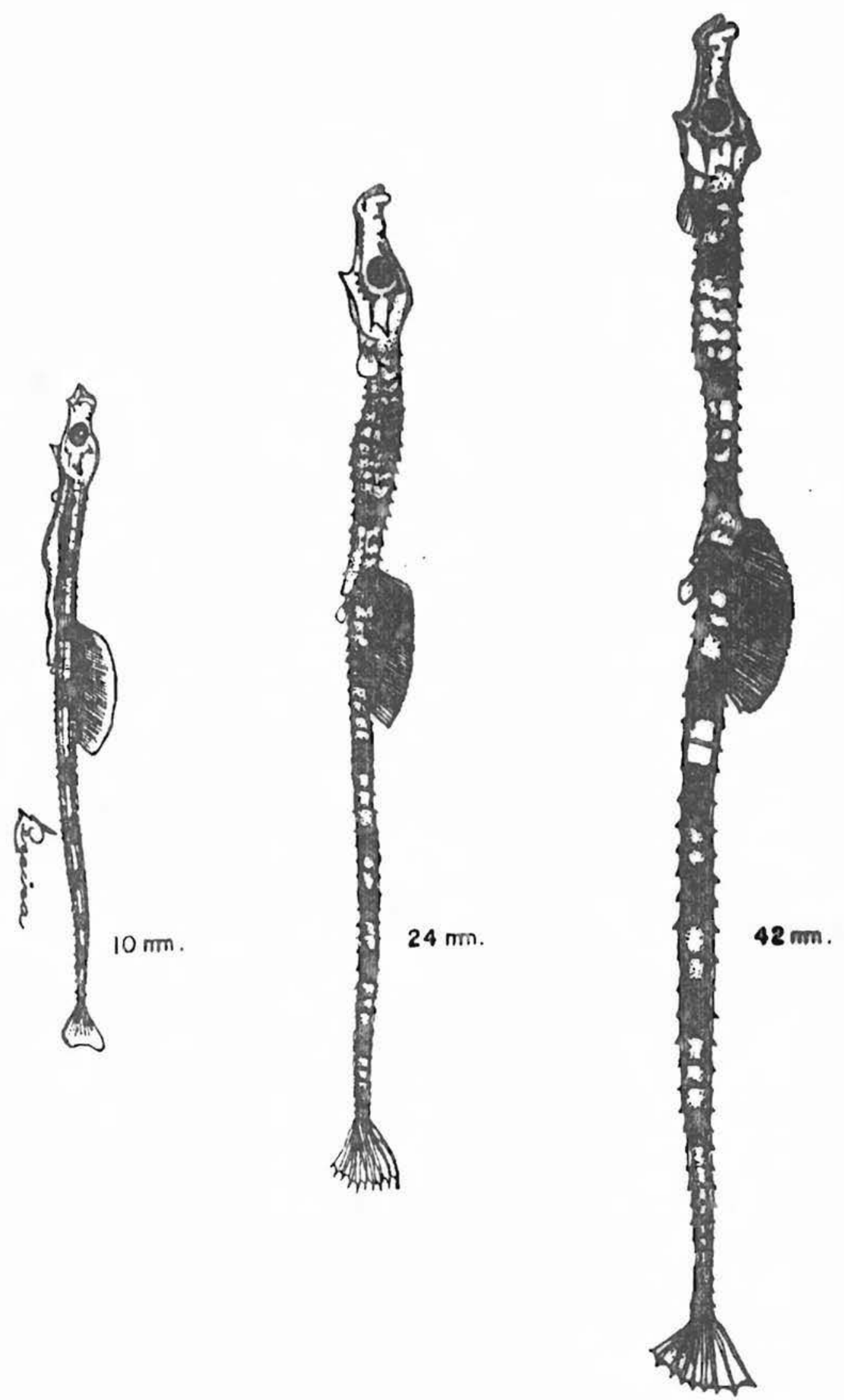

in. 9: Sonmatius folletti: A: lenra de $10 \mathrm{~mm}$; B: larva de 


\section{6 - MICROPOGONIAS FURNIERI}

EI huevo de esta especie tiene las caracterîs ticas típicas de Ia Familia Sciaenidae. Es redondo, con espa cio perivitelino relativamente pequeño, gota de aceite grande ( $279 \mu$ en media) y ligeramente amarillenta; el vitelo es transparente y presenta una estructura alveolar. El diámetro varía, dependiendo de Ia época, entre 730 a 1053 . La Fig.10 muestra la distribución de frecuencias de los diámetros en diferentes meses para salinidades de 27 a $30 \% 0$ ( 1 a columna) y 22 a 26\%o ( 2 a columna). Se observa una disminución del tâ maño a medida que avanza la época de desove.

En el análisis de la varianza para los diámetros de los huevos en las distintas salinidades respecto al mes de muestreo, se obtuvo: $F=2,4432$ para salinidades de 27 a $30 \%$ y $F=1,0237$ para las salinidades menores. Siendo estos valores de $F$ menores a $F_{O}, 95$ se acepta la hipótesis de igualdad de las muestras. Al igual que el caso de $\underline{B}$ - pectinata este resultado es consecuencia de que la suma de los cuadrados dentro de cada mes es mayor que la suma de los cuadrados entre meses.

Para obtencr resultados más precisos se aplicó el Test de "t" entre los diferentes meses para los dos rangos de salinidad, obteniéndose los siguientes resultados:

S\%o Oct/Nov. Oct/En. Oct/Mar. Nov/En. Nov/Mar. En/Mar.

$\begin{array}{rrrrrrr}27- & 20,28 & 45,00 & 39,98 & 11,88 & 10,04 & 0,217 \\ 30 & (\mathrm{SS}) & (\mathrm{SS}) & (\mathrm{SS}) & (\mathrm{SS}) & (\mathrm{SS}) & (\mathrm{NSS}) \\ & & & & & \\ 22- & 5,52 & 15,67 & 5,11 & 9,58 & 10,23 & 19,58 \\ 26 & (\mathrm{~S}) & (\mathrm{SS}) & (\mathrm{S}) & (\mathrm{S}) & (\mathrm{SS}) & (\mathrm{SS})\end{array}$

siendo SS: altamente simnificativo, S: significativo $y$ NS: no significativo para $95 \%$.

A través de este Test de "t", se observa que la disminución del huevo en el decorrer del tiempo es en sene ral altamente significativa, mientras que el aumento observado entre encro y marzo es altamente simnifieativo para salini dades entre 22 - 26\% y no 10 es para salinidades mayores. 
La Fig. Il muestra el desarrollo embrionario desde el estadio de 4 blastómeros ( Fig. 1lA). In este esta dio la gota de aceite continúa amarillenta, sin pigmentación al igual que el resto del huevo. En la formación de la blás tula se observan pequeños cromatóforos en la gota de aceite ( Fig. IlB), los cuales aumentan en el estadío de gástrula ( Fig. IlC). Ya en la néurula aparecen pequeños melanóforos sobre el dorso del embrión y la gota más pigmentada ( Fig. 11D). El embrión ya es visible en el estado de cierre del blastóporo, observándose la formación de los primeros mióme ros y en el ojo la fisura coroidea que llega hasta la pupila ( Fig. IlE). La pigmentación se intensifica en la parte superior de la cabeza, dorso del cuerpo y parte caudal. Cuando la larva está por eclosionar ( Fig.llF) con la cauda Iibre en el espacio perivitelino, se pueden contar entre 8 a 10 miómeros. La pigmentación se intensifica con las mis mas características.

En la Fig. 12 se observa la larva en el momento de salir del huevo. Ia larva recién nacida (Fig.I2B) tiene aproximadamente $2 \mathrm{~mm}$. El vitelo se dispone en la parte ventro-anterior desde el inicio de la cabeza hasta el ano, semitransparente y sin pigmentación. La gota se localiza en su extremo posterior. Se observan los ojos con la fisura y con inicios de pigmentación. Detrás de la cápsula ótica, en linea recta se observan cuatro protuberancias sensoriales. La aleta embrionaria estrecha nace detrás de la cabeza y ro dea todo el cuerpo hasta la boca. Se observan entre 17 a 18 miómeros.

A $\operatorname{los} 2,5 \mathrm{~mm}$ ( Fig. 12) se observa una gran disminución del vitelo, la boca no funcional, los ojos bien pigmentados sin la fisura coroidea y las protuberancias sen soriales todavia visibles. Aparecen pequeños melanóforos so bre la cabeza, en la parte ventro-caudal, atrás del ano y en la parte ventral del vitelo.

A los $3 \mathrm{~mm}$ presenta todavía restos del vitelo y de la gota de aceite ( Fig. 13). Ia boca comienza a ser funcional en posición oblícua. Se observan las narinas y otolitos bien diferenciados. La aleta pectoral está más desarrollada. Ya se cuentan 25 miómeros que son los definitivos. Presenta un melanóforo bien estrellado en la parte dor so-posterior de la cabeza, otros tenues en la parte ventro- 
anterior y una serie en la parte ventral del tronco. Con $4 \mathrm{~mm}$ el intestino está bien desarrollado. Persisten todavia las protuberancias sensoriales; los miómeros están bien visibles y sobre la aleta embrionária se insinúan los radios de la caudal (Fig. 13).

A los $8,5 \mathrm{~mm}$ presenta características propias de juvenil. El pre-opérculo está bien osificado con tres dientes principales bien desarrollados, en tanto que el opérculo presenta en la parte superior una pequeña care na dentada ( Fig. 13). Las aletas dorsal, anal, caudal y pectoral, a pesar de no tener el número definitivo de radios, estan bien formadas, mientras que las ventrales recién se esbozan. El melanóforo, localizado en la parte ven tral del intestino, es bien definido, y comienzan a aparecer varios distribuidos por el tronco.

A los $11 \mathrm{~mm}$ las aletas presentan el número definitivo de radios, teniendo la primera parte de la dorsal X y la segunda parte I - 27 a 29, la anal II - 8, la pectoral 18 y la ventral I - 5. 11 número de vértebras es 25. Los melanóforos aumentan en número y tamaño.

Con $20 \mathrm{~mm}$ presenta caracteristicas muy similares a la anterior con una mejor formación de las aletas, inclusive de la ventral. Iá boca adquiere una posición horizontal, con tres pares de pequeños barbillones en la par te inferior de la mandíbula. La pigmentación está bastante acentuada con melanóforos grandes ( Fig. 14).

A los $30 \mathrm{~mm}$ ya no se observa la carena denta da en el pre-opérculo (Fig. 14). Los melanóforos aumentan en número y disminuyen en tamaño, distribuyéndose principalmente por encima de la cabeza y del tronco.

Con $40 \mathrm{~mm}$ la pigmentación presenta las carac terísticas tipicas del adulto, con las bandas de melanóforos verticales en el tronco. Desde este momento no sufre más modificaciones en su morfología y pigmentación.

En cuanto a su desarrollo tiene mucha semejanza con la espécie del Atlántico Norte, Micropogon undulatus, principalmente en la primera etapa de vida (Hildebrand y Cable, 1930). 


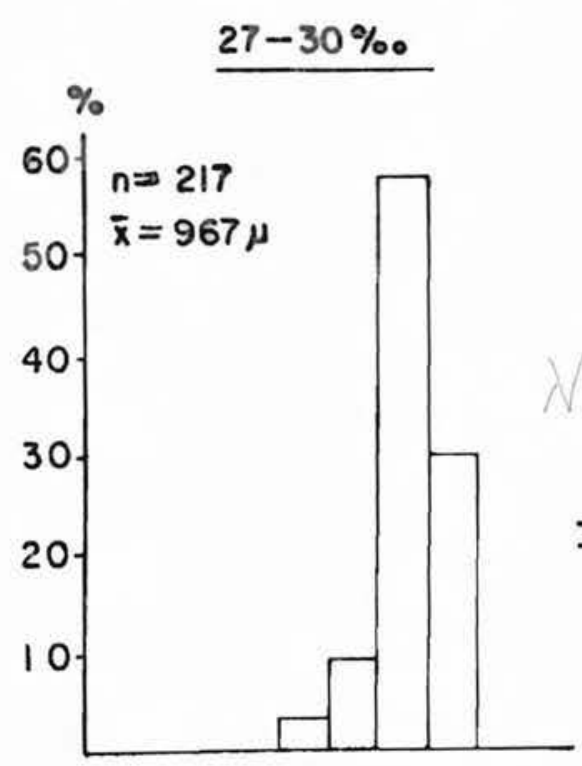

$22-26 \%$
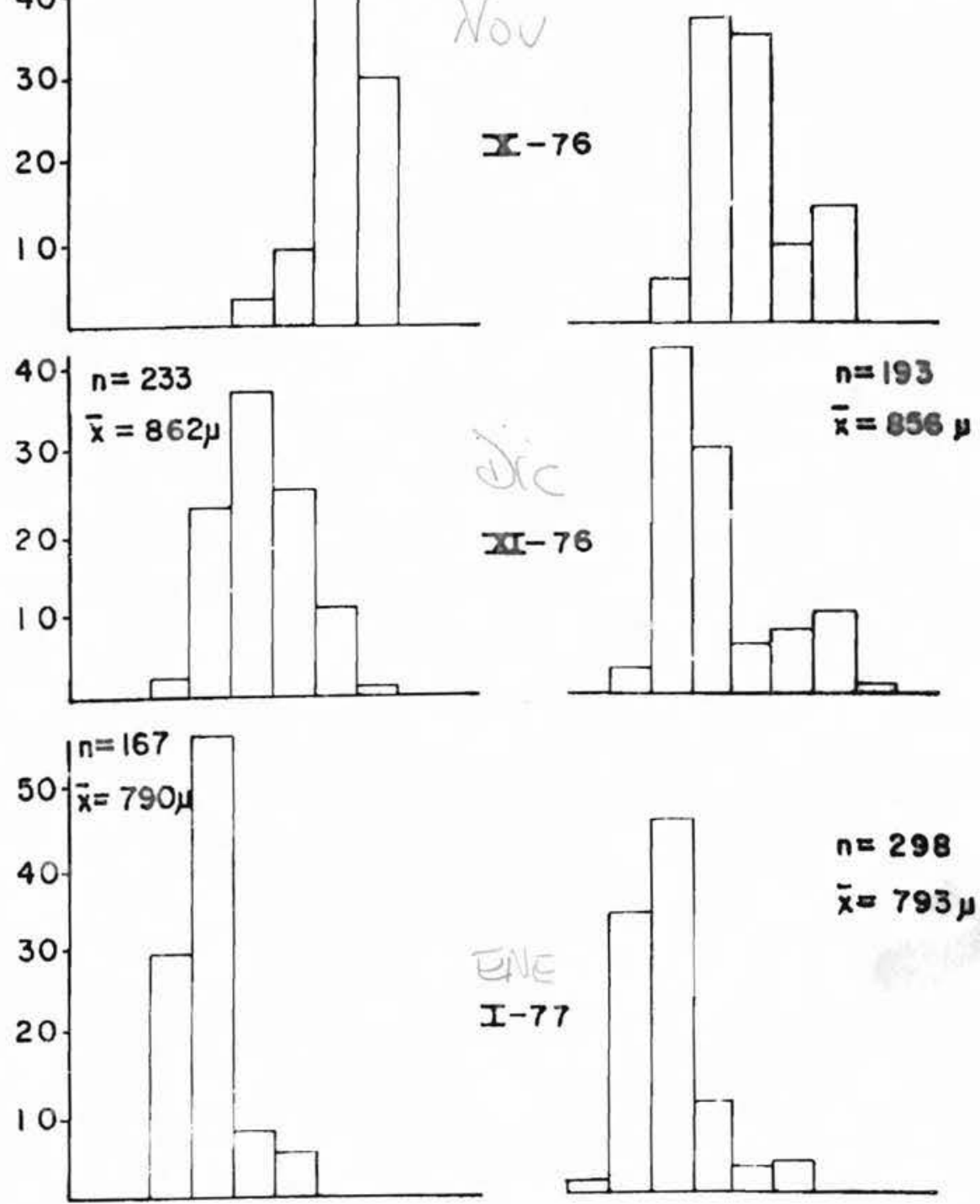

50 - $n=113$
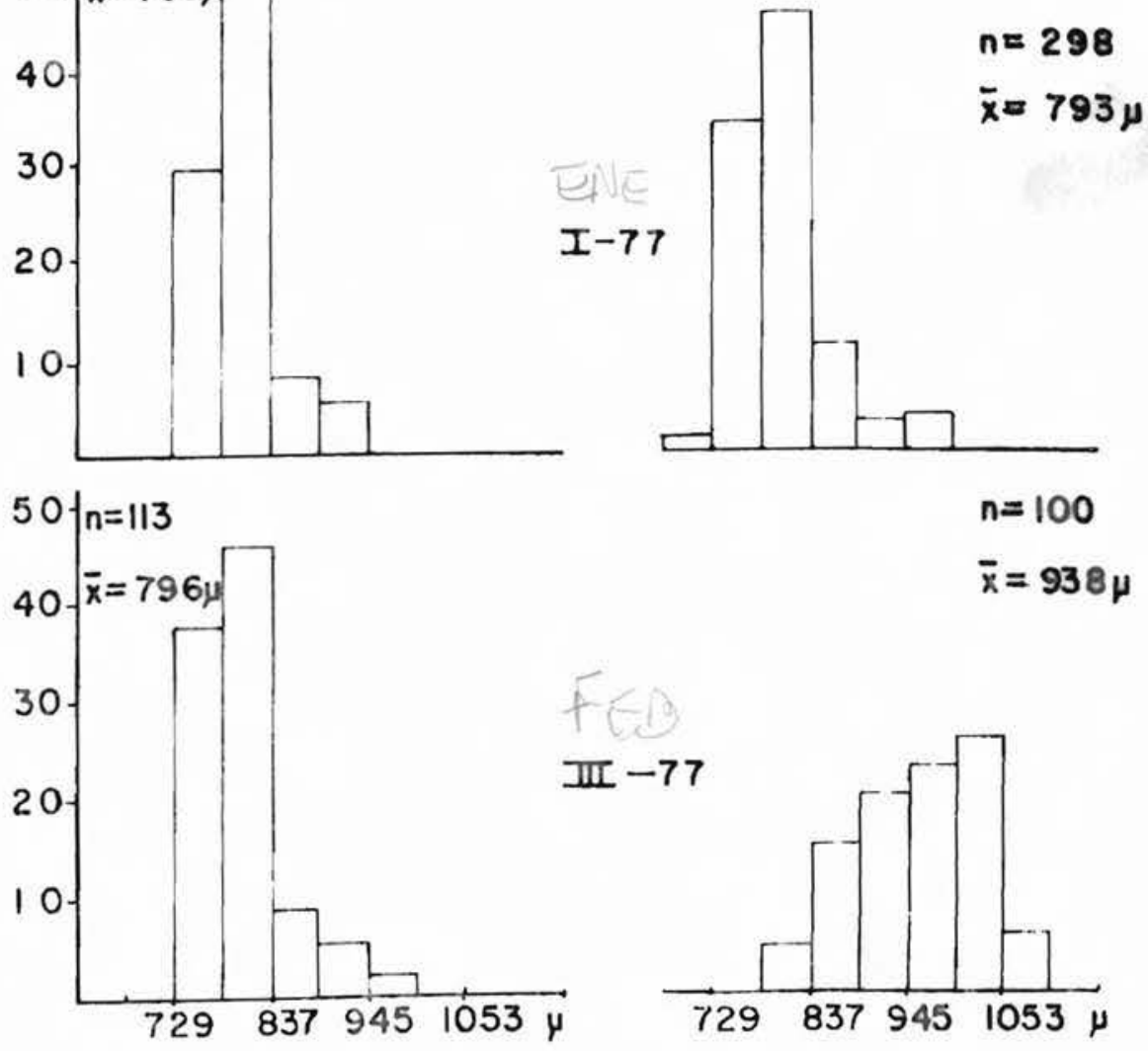

$n=100$
$\bar{k}=901 p$

$x-76$
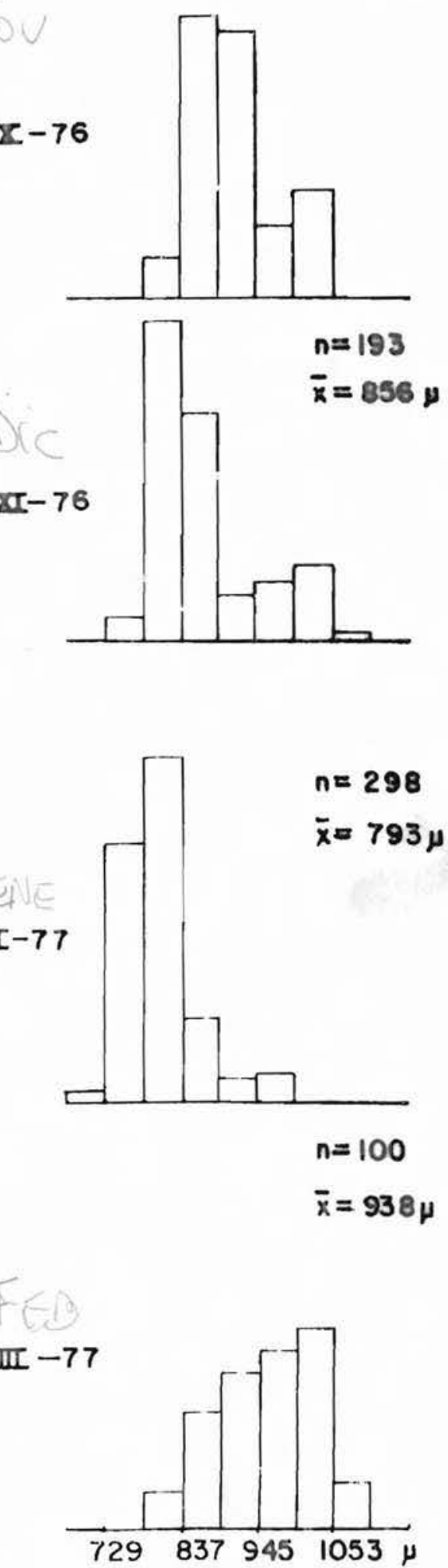

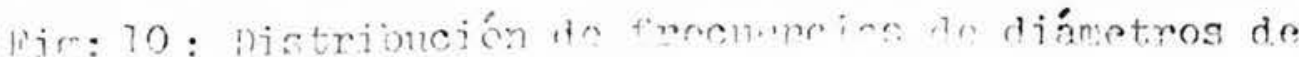



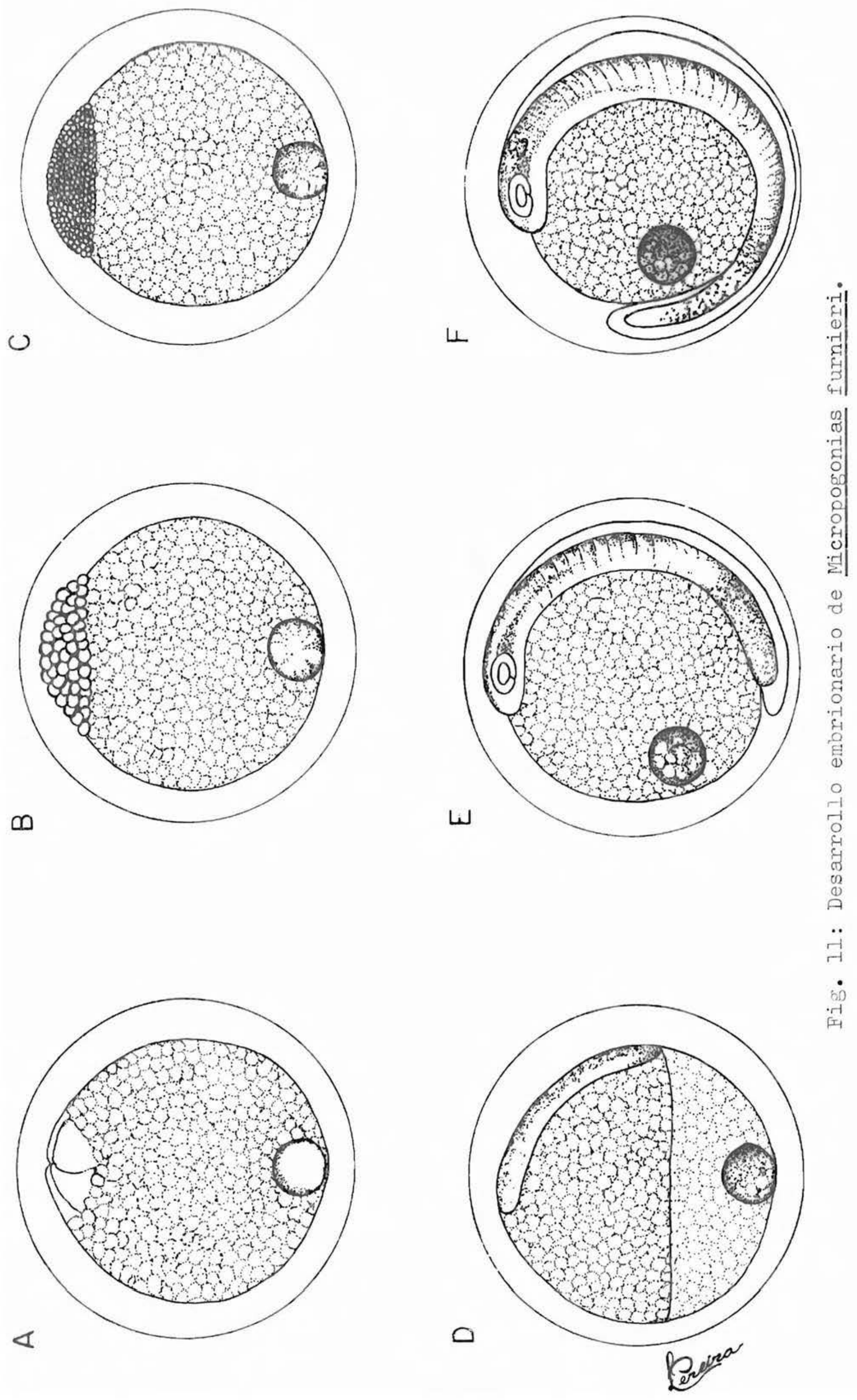

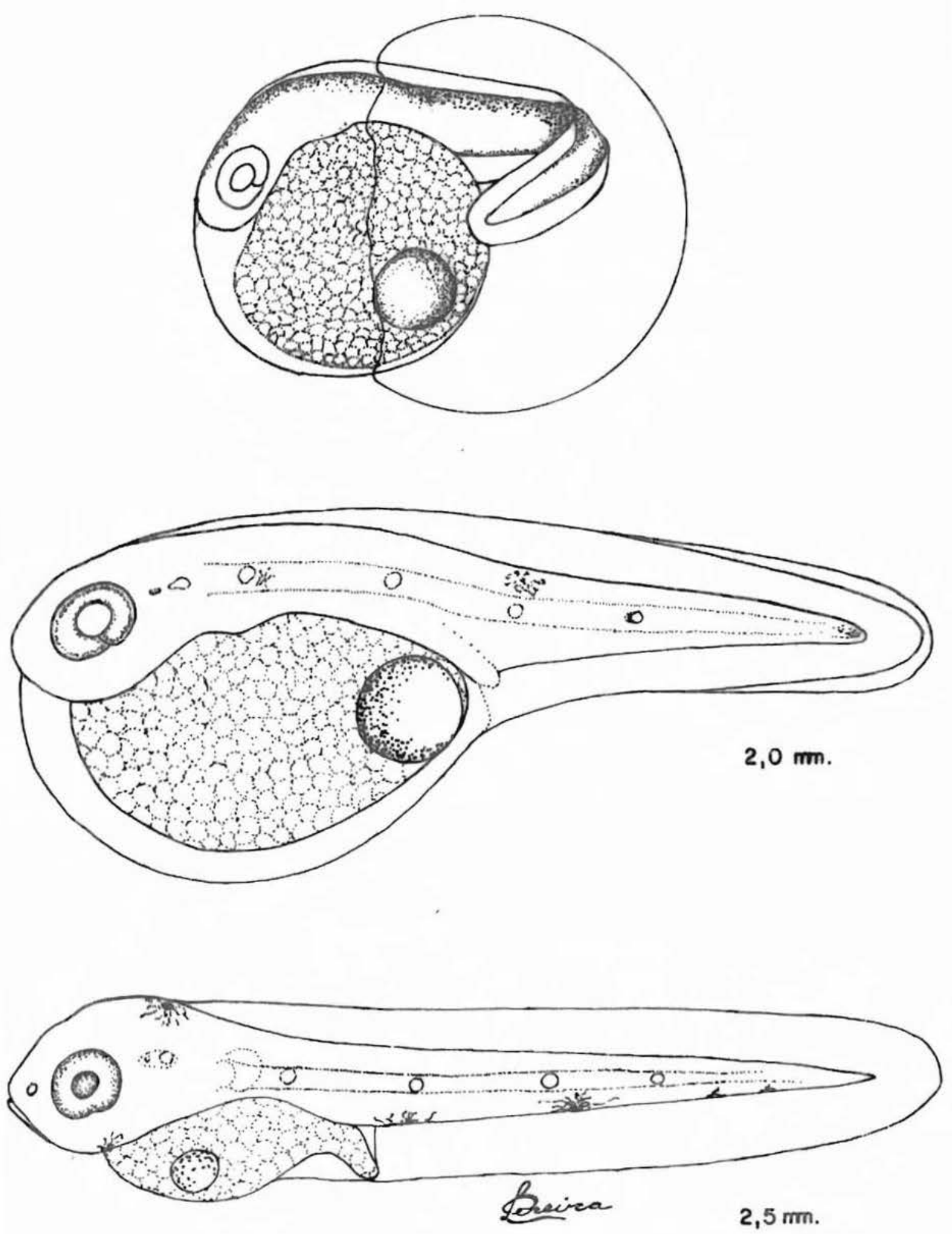

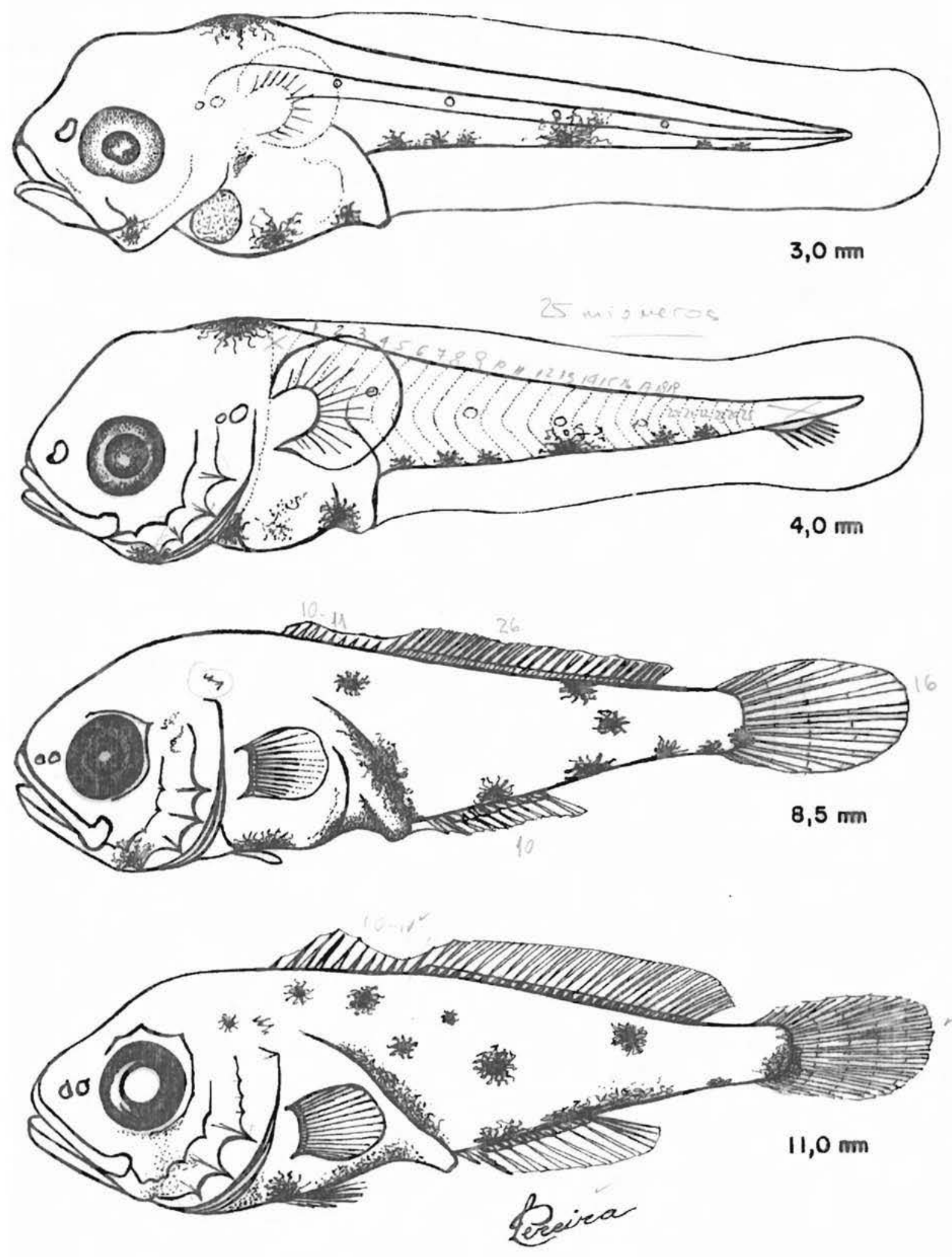

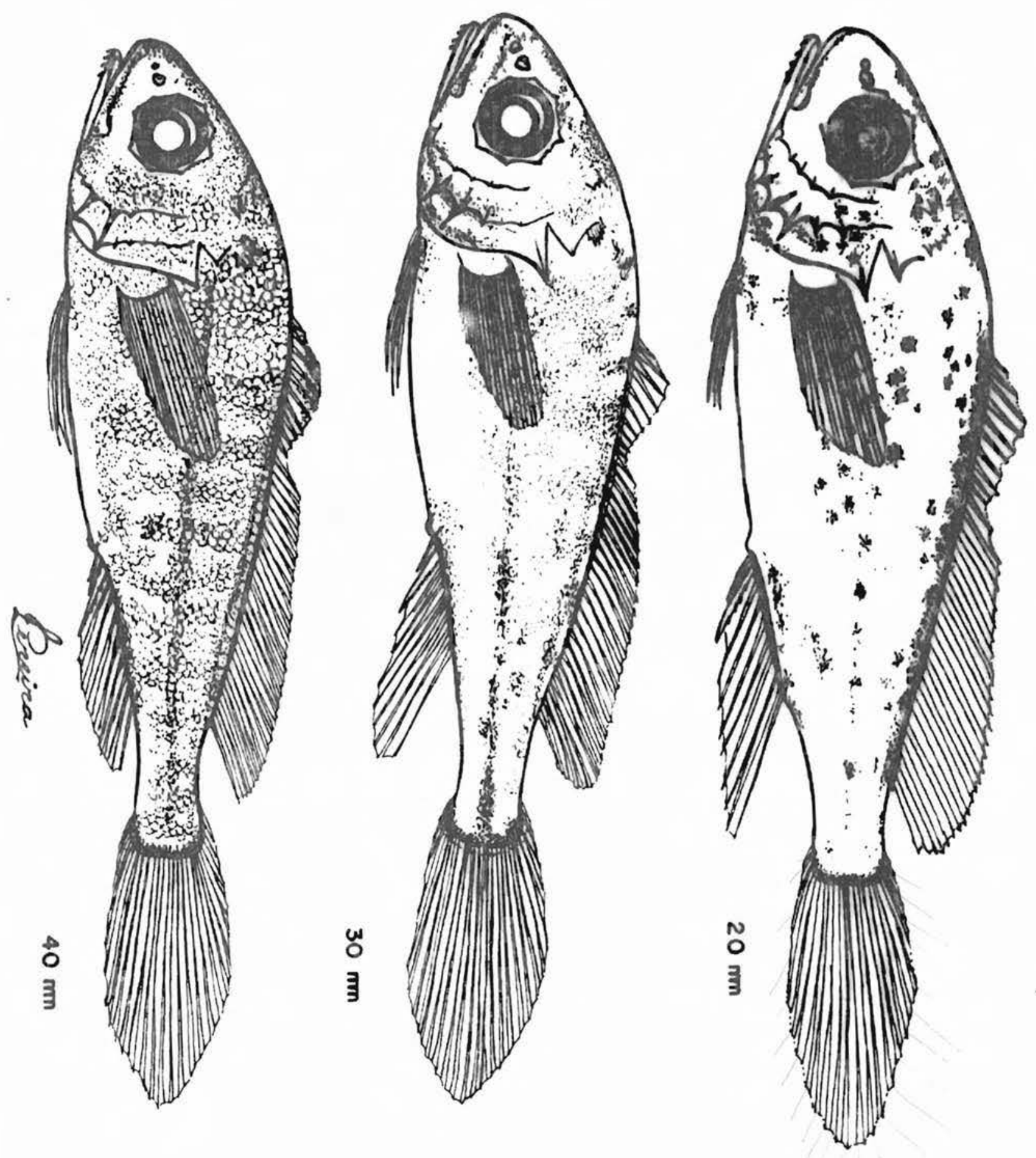

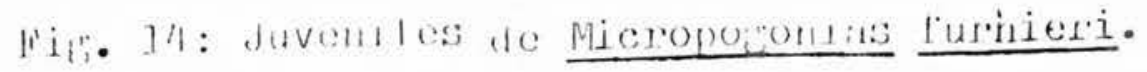




\section{7 - PARALONCHURUS BRASTIIENSIS}

Los huevos de esta especie no fueron identificados, y la larva de menor tamaño encontrada es de $3 \mathrm{~mm}$. Esta larva no presenta restos de vitelo, la boca funcional es le vemente oblicua y el aparato digestivo está bien formado. Se visualizan unos 28 miómeros. La aleta embrionaria es amplia y sobre ella se esbozan los radios de las aletas dorsal, a nal y caudal. La pectoral pequeña es membranosa con indicios de la formación de radios. Es totalmente despigmentada a excepción de los ojos que inician su pigmentación (Fig. 15).

A Ios $7 \mathrm{~mm}$ las aletas están bastante desarrolla das y practicamente con el número definitivo de radios. Ia parte anterior de la dorsal presenta $X$ radios, la parte pos terior I-30, la anal II-7, la ventral I-5 y la pectoral 18 a 19 radios. El número de miómeros es el definitivo, 11 abdomi nales y 19 caudales. El opérculo bien osificado comienza a formar las espinas. Los ojos están bien pigmentados y sobre la cabeza y el cuerpo aparecen grupos de melanóforos bastante tenues.

A los $13 \mathrm{~mm}$ (Fig. 15) se asemeja a un juvenil.Las aletas están bien formadas así como el opérculo. La pigmenta ción es más intensa, comenzando a disponerse los melanóforos en bandas sobre el tronco, intensificándose en el hocico y la cabeza. Inician su desarrollo las barbillas mentonianas . Las estructuras del opérculo están bien definidas.

Con $15 \mathrm{~mm}$ (Fig. 16), es practicamente un juvenil a pesar de presentar un cuerpo robusto y la cabeza redondeada. La boca adquiere una posición más inferior y las barbi llas más pronunciadas se disponen en 3 a 4 pares anteriores y unos 10 pares en la mandíbula inferior. La pigmentación del cuerpo está en general más pronunciada.

A los $25 \mathrm{~mm}$ presenta una cabeza aguzada con la bo ca en posición inferior y horizontal. Las barbillas en igual número están más desarrolladas. La pigmentación se presenta en bandas bien características por el tronco.

Con 40mm, morfológicamente, es igual al adulto. La cabeza y cuerpo se han afinado. Las barbillas y opérculo bien desarrollados. La pigmentación del cuerpo presenta las características bandas transversales propias de la especies. 

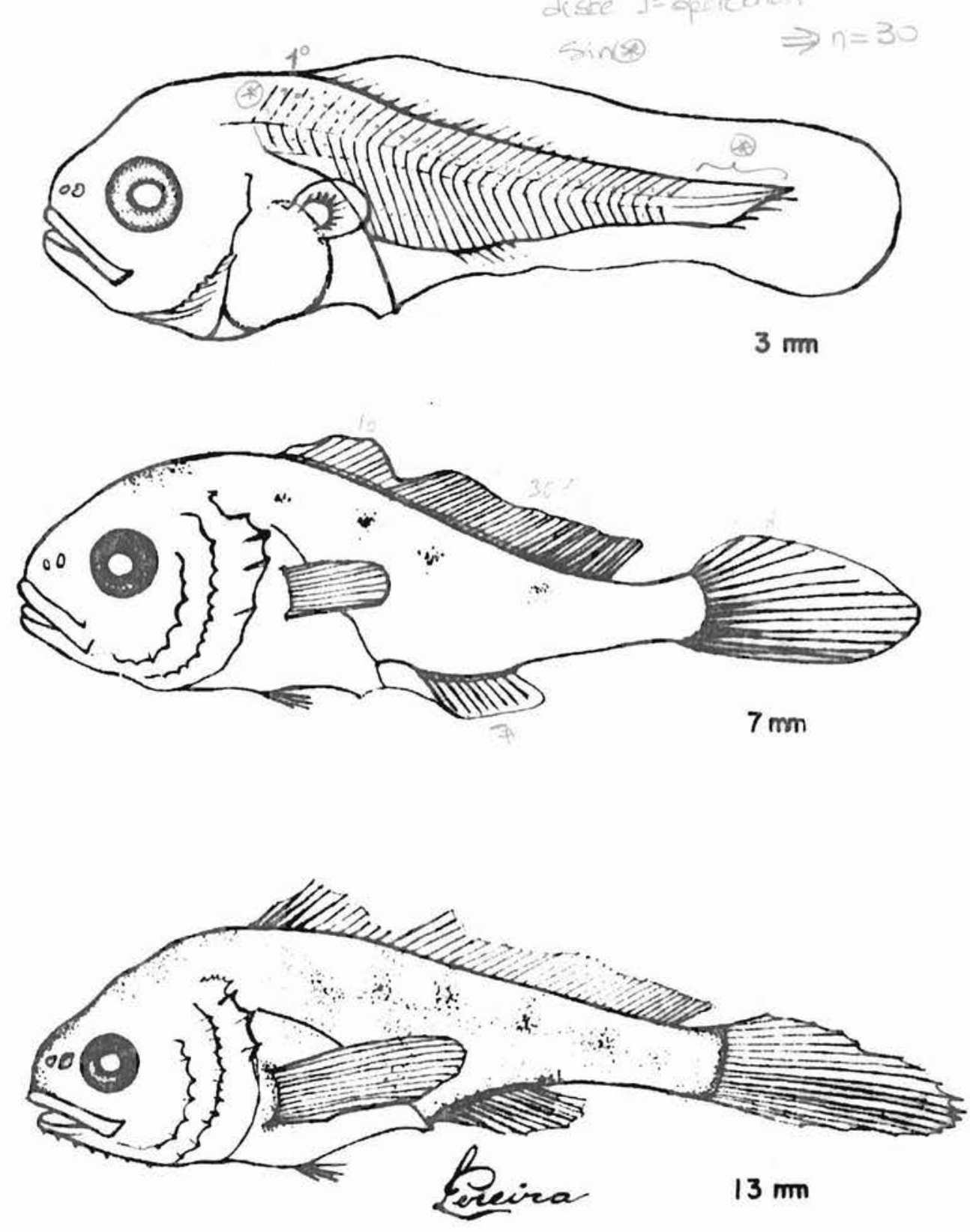

Fig.15: Desarrollo larval de Paralonchurus brasiliensis. 

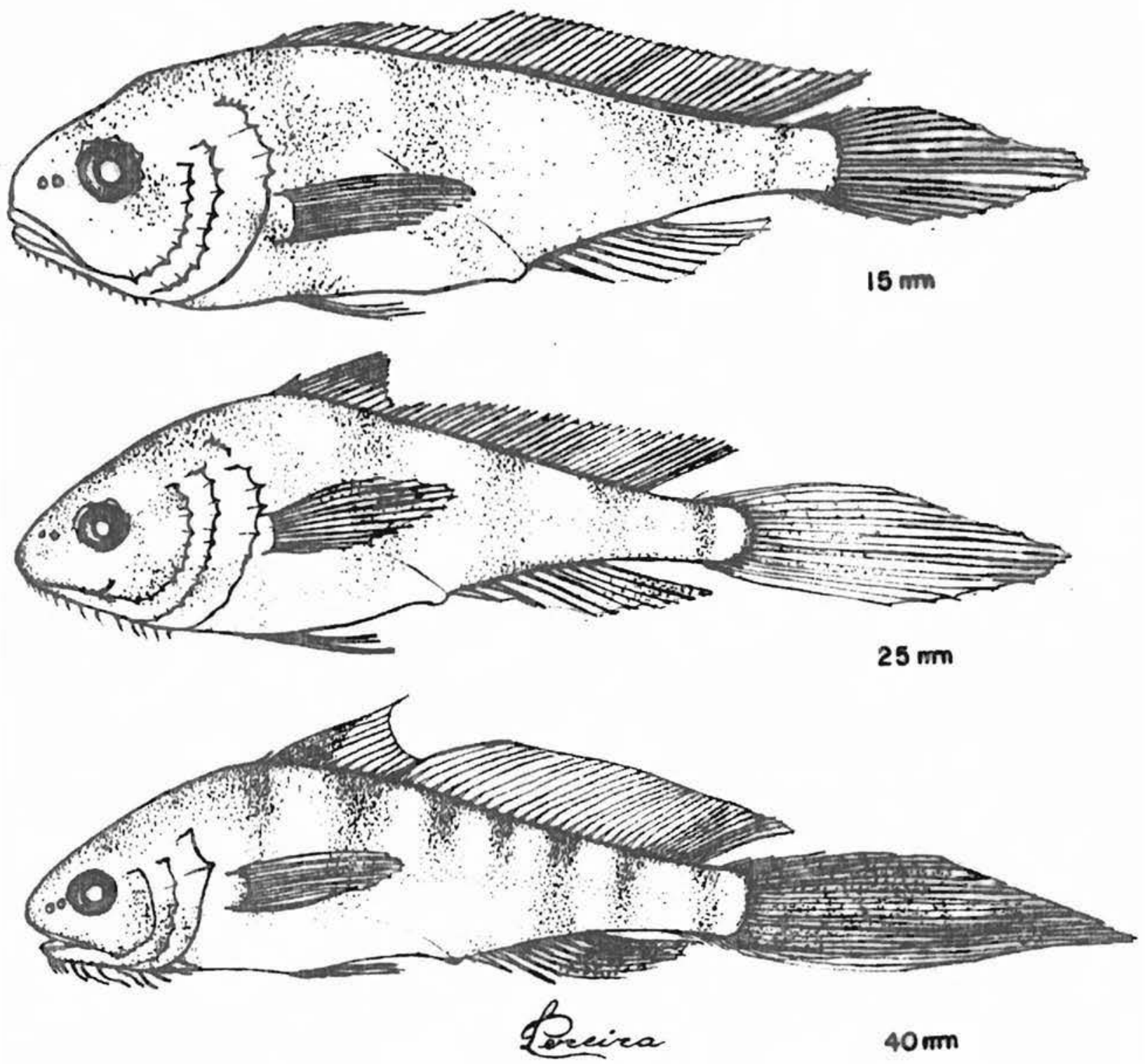

Fig. 16: Larvas y juvenil de Paralonchurus brasiliensis. 
No fueron identificados los huevos de esta especie. La larva más pequeña tiene $4 \mathrm{~mm}$ con 1 i geros restos de vitelo. La cabeza es bastante robusta presentando el ano en el tercio anterior del cuerpo.El tronco es afinado hacia la región caudal, observándose la notocorda recta y unos 23 a 24 miómeros. La aleta embrionaria no es muy amplia $y$ no se visualizan radios. Las pectorales son membranosas y pequeñas. La cabeza es bastante característica, presentando una cresta en la parte dorsal y otra encima de los ojos. El pre-opér culo es espinoso y presenta 3 dientes bien pronunciados. La boca tiene posición oblícua y la mandíbula levemente sobresaliente. Los ojos grandes comienzan a pigmentarse y aparecen 4 grupos de melanóforos en la parte dorsal, posterior y ventral del tracto digestivo. (Fig. 17).

A Ios $7 \mathrm{~mm}$ el cuerpo es más robusto presentando restos de la aleta embrionaria sobre la cual se visualizan radios de la dorsal, caudal y anal. Las pectorales continúan siendo membranosas con algu nos radios. No hay indicios de las ventrales. La cresta dorsal en relación al tamaño del cuerpo es menor, mientras que la cresta que está ubicada sobre los ojos y los dientes delpre-opérculo continúan sobresalientes. Los ojos son menores en comparación con el tamaño del cuerpo y pigmentados. Ios melanóforos, más abundantes y dispersos, se localizan en la parte inferior y superior del tracto digestivo. Aparecen otros pequeños en el extremo de la mandíbula y en la parte inferior del tronco a la altura de la aleta anal.

Con 15mm las crestas en proporción con el cuerpo son menores, al igual que los dientes del pre-opérculo. Aparece otra cresta en la parte supe rior del opérculo. La mandíbula está proyectada ante riormente con los dientes bien visibles. Los ojos peque ños están bien pigmentados. Ias aletas están con los ra 
dios completos, teniendo la parte anterior de la dorsal X, la parte posterior I - 27 a 28 , la anal II -8 a 9, la ventral I - 5, la pectoral 18 a 19 y la caudal 19 radios. El número de vértebras es 25 ( 14 torácicas y 11 abdominales).

Con $24 \mathrm{~mm}$ todavía presenta la cres ta dorsal aunque reducida. Las espinas pre-operculares siguen bien manifiestas, al igual que la cresta sobre el opérculo. Ia forma del cuerpo se asemeja al juvenil. La pigmentación se acentuó con melanóforos dispersos en la región dorsal del tronco, cabeza, ną xila y mandibula ( Fig. 18).

Con $30 \mathrm{~mm}$ presenta los últimos ves tigios de la cresta dorsal de la cabeza y la localizada sobre el opérculo. Las características genera les se mantienen iguales, con la única diferencia de la pigmentación que se intensificó en la región dor sal del tronco, parte de la mandíbula y maxila. Se intensifican los pigmentos sobre las aletas dorsal, anal y caudal.

Finalmente a los $45 \mathrm{~mm}$ desaparece totalmente la cresta de la cabeza y la del opérculo, manteniéndose los dientes del opérculo, con lo cual presenta las características definitivas de la especie. 

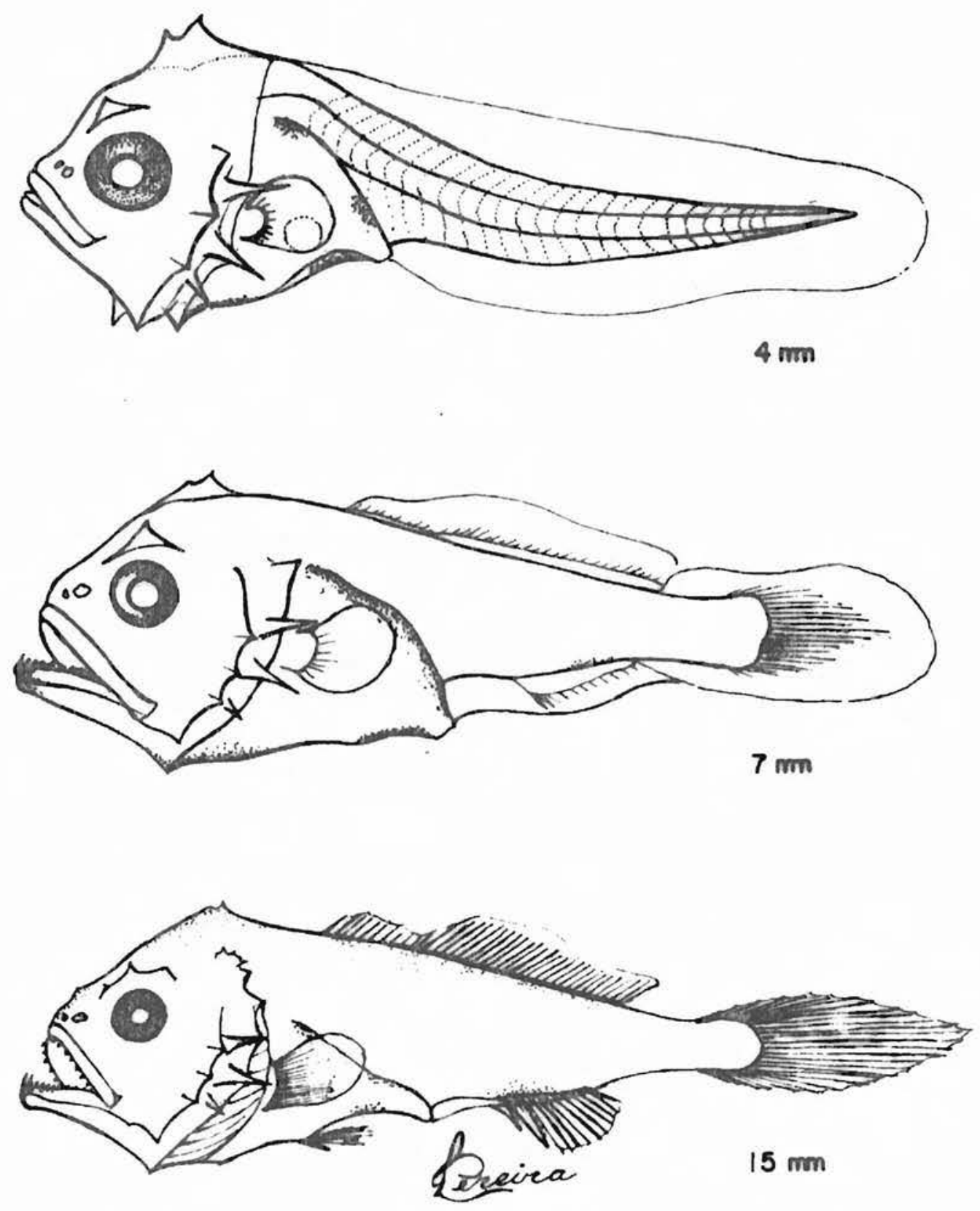

Fic. 17: Desarrollo larval de Macrodon ancylodon. 

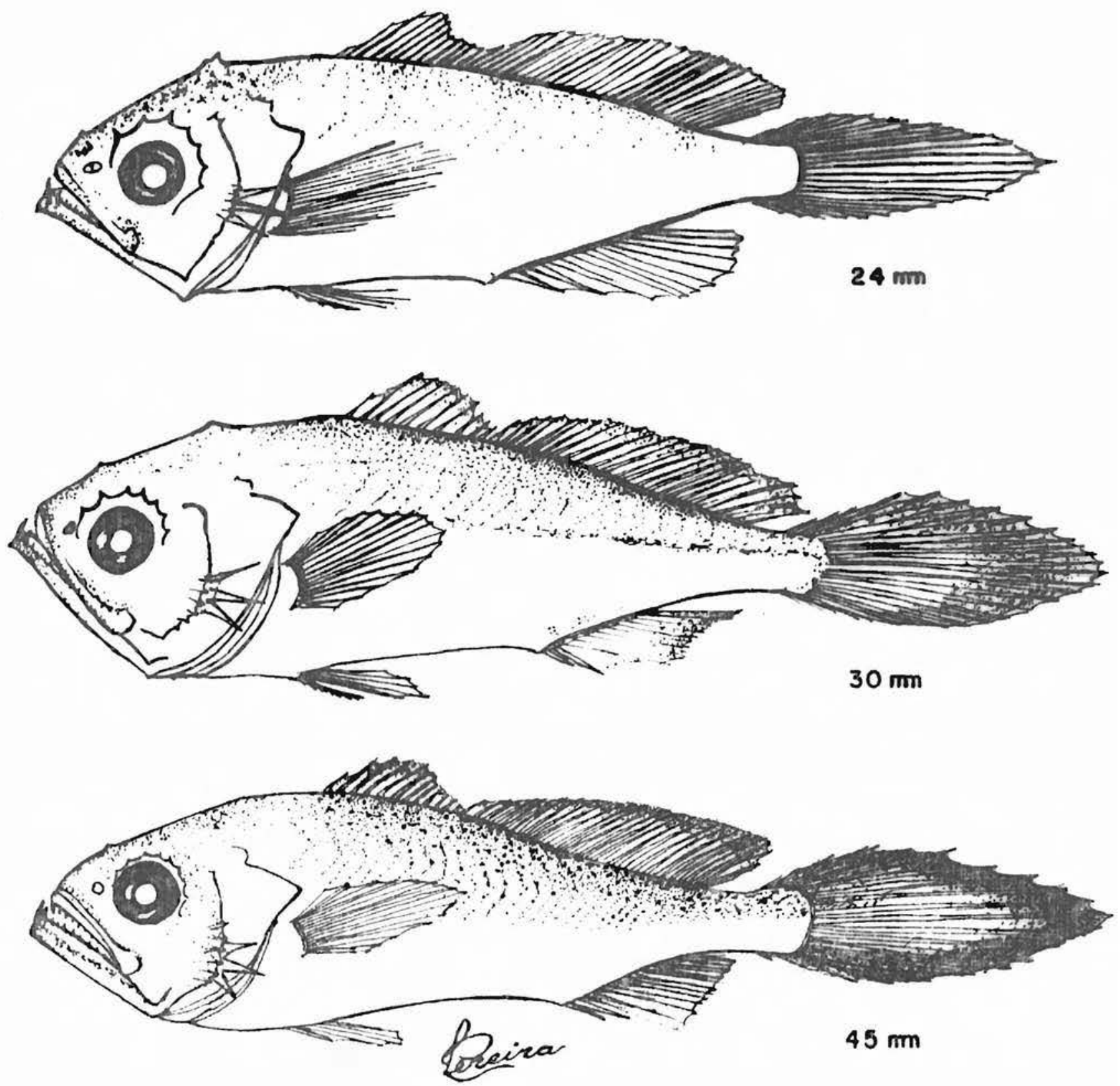
En relación a esta especie el material colectado fue escaso. La larva identificada de menor tamaĩo tiene IOmm. A pesar de que morfológicamente no sea parecida al adulto tiene todos los caracteres merísticos que facilitan su identifi cación. La parte anterior de la aleta dorsal tiene $\mathrm{X}$ radios, la parte posterior I - 24, la anal II - 8, la pectoral 18, la ventral I - 5 y la caudal 19. Los miómeros son 24 ( 10 abdominales. y 14 caudales). La cabeza es abultada con ojos bien grandes y pigmentados. Ia boca tiene una posición oblícua y el opérculo y pre-opérculo son bastante dentados. El ano está ubicado aproximadamente en la mitad del cuerpo. Seis grupos de melanóforos se disponen en la región dorso-posterior del tubo digestivo, otros grupos se ubican en la vase de la aleta anal y en la base de la dorsal en su extremo posterior. Algunos melanóforos se hallan dispersos en la región dorso-anterior de la cabeza y maxila (Fig. 19).

Con $22 \mathrm{~mm}$ se observa que la parte anterior del cuerpo continúa siendo robusta, los ojos grandes, la boca oblicua y las aletas mejor desarrolladas. La pigmentación se intensifico en grupos de melanóforos dispersos por el tronco, cabeza, hocico, opérculo y la parte dorsal del tracto digestivo.

A los $30 \mathrm{~mm}$, la región del cuerpo sobre la cabeza está achatada, observándose que la parte más alta del cuer po está a nivel del inicio de la dorsal. El ojo continúa siendo grande, el opérculo menos dentado y la boca no tan oblicua presenta la barbilla mentoniana. La pigmentación se acentúa por to do el cuerpo a excepción de la parte ventral del abdomen.

Con 40mm la forma del cuerpo es muy parecida a la del adulto, la boca adquirió una posición horizontal. Los ojos continúan siendo grandes, el opérculo menos espinoso y la pigmentación es abundante y más difusa por todo el cuerpo a excepción de la región abdominal. La barbilla mentoniana es bien notoria, roma y corta.

Comparando la Umbrina canosai con la $\underline{U}$. coroi des de Ubatuba, São Paulo (Matsuura y Nakatani, 1979 ), se ob= serva mucha semejanza, difiriendo principalmente en las caracte rísticas de la pigmentación y el número de radios. 

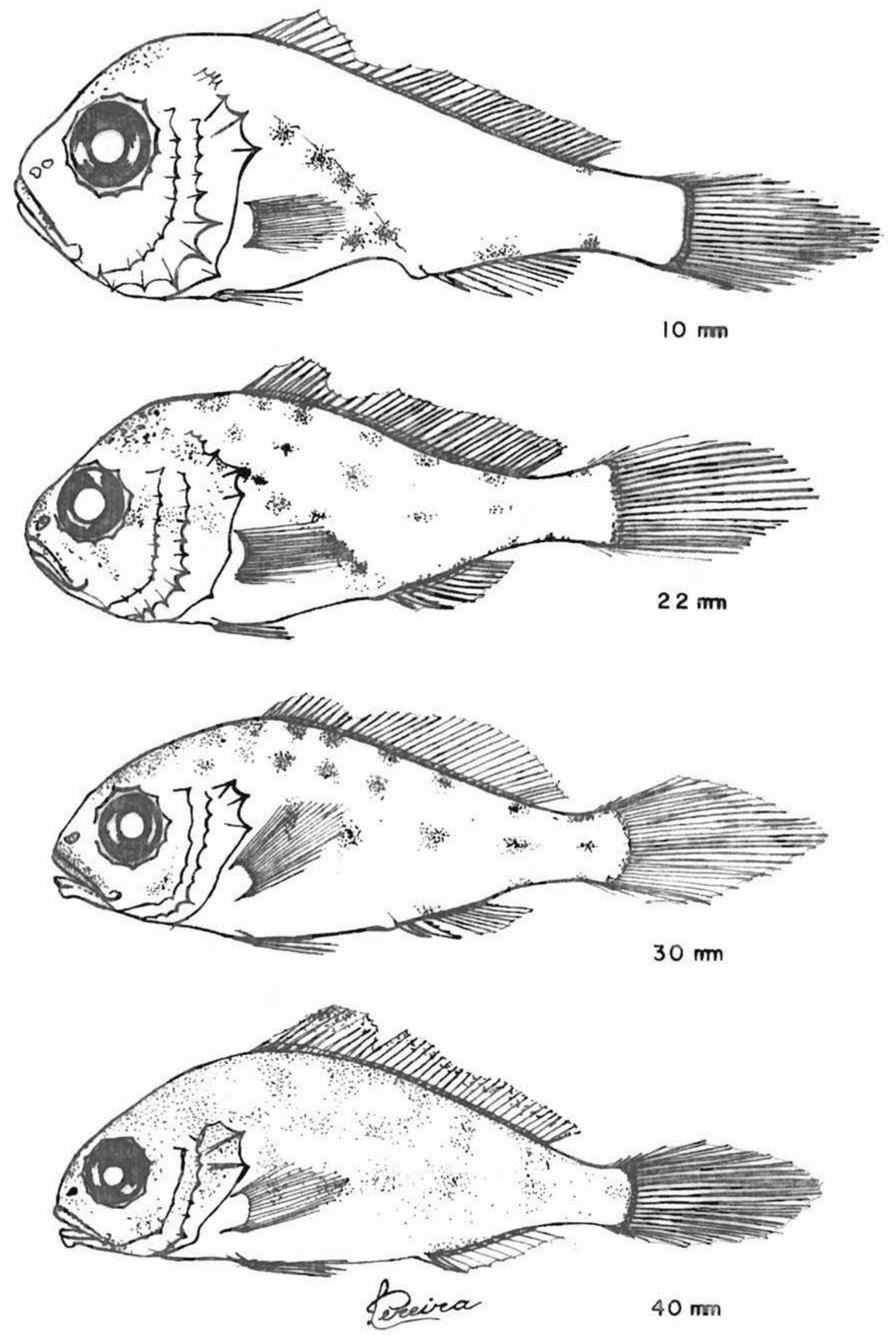
Los huevos no fueron identificados. La larva de menor tamaño identificada tiene $4 \mathrm{~mm}$. No presenta restos de vitelo y la boca y tubo digestivo son funcionales. Ia cabeza no muy grande, tiene la boca con una posición pronunciadamente oblicua y numerosos dientes. Los ojos son grandes e inician su pigmentación. El opérculo y pre-opérculo presentan bordes lisos. Sobre la aleta embriona ria no muy amplia, se observan los primeros radios de la anal. Las pectorales pequeñas, son membranosas. La notocorda es bien visible y no se curva en el extremo caudal. Se visualizan entre 22 a 23 mió meros. La pigmentación se caracteriza por grupos de melanóforos en la region dorso-posterior del tracto digestivo, 4 grupos en la par te ventral del tronco, 1 en la mitad superior del tronco, I mayor en la región dorsal antes del inicio de la aleta embrionaria y 1 en el borde postero-inferior del opérculo ( Fig. 20).

Con $17 \mathrm{~mm}$ presenta un cuerpo robusto con las ale tas totalmente formadas provistas del numero definitivo de radios. La parte anterior de la dorsal tiene $\mathrm{X}$ radios, la posterior I - 20, la anal II - 8, la pectoral 16, la caudal 19 y la ventral I - 5. El número de miómeros es 25 ( 11 abdominales y 14 caudales). El opércu彑 lo y pre-opérculo son muy dentados, presentando una carena en la parte superior. Ios ojos están totalmente pigmentados y los melanóforos se ubican en dos bandas verticales, una a la altura de la par te anterior de la dorsal y otra al inicio de la anal. Dos agrupacio nes de melanóforos se ubican en la región dorsal de la cabeza, respectivamente sobre el opérculo y el ojo. Otros melanóforos disper sos se distribuyen por el opérculo, pre-opérculo y hocico (Fig. 20).

A los $22 \mathrm{~mm}$ se modificó levemente la forma del cuerpo, las aletas están bien desarrolladas y el opérculo continúa con sus dientes pronunciados. 'La pigmentación está bien acentuada, iniciando desde la región dorsal del tronco hacia la ventral, la formación de 4 bandas de melanóforos al igual que la región del opérculo, pre-opérculo y boca.

Con $35 \mathrm{~mm}$ el borde del opérculo y pre-opérculo tienen dientes poco pronunciados. Se observa una carena dentada desde la maxila hasta el ojo por la parte media dorsal del hocico. Las bandas de melanóforos están distribuídos por todo el tronco principalmente en la parte superior. La cabeza está practicamente cubierta de melanóforos ( Fig. 21).

A Ios 48mm la forma del cuerpo se asemeja a la del adulto; la forma del opérculo, las bandas de pigmentación del tronco y las escamas indican que no van a existir más variaciones en su morfología. 

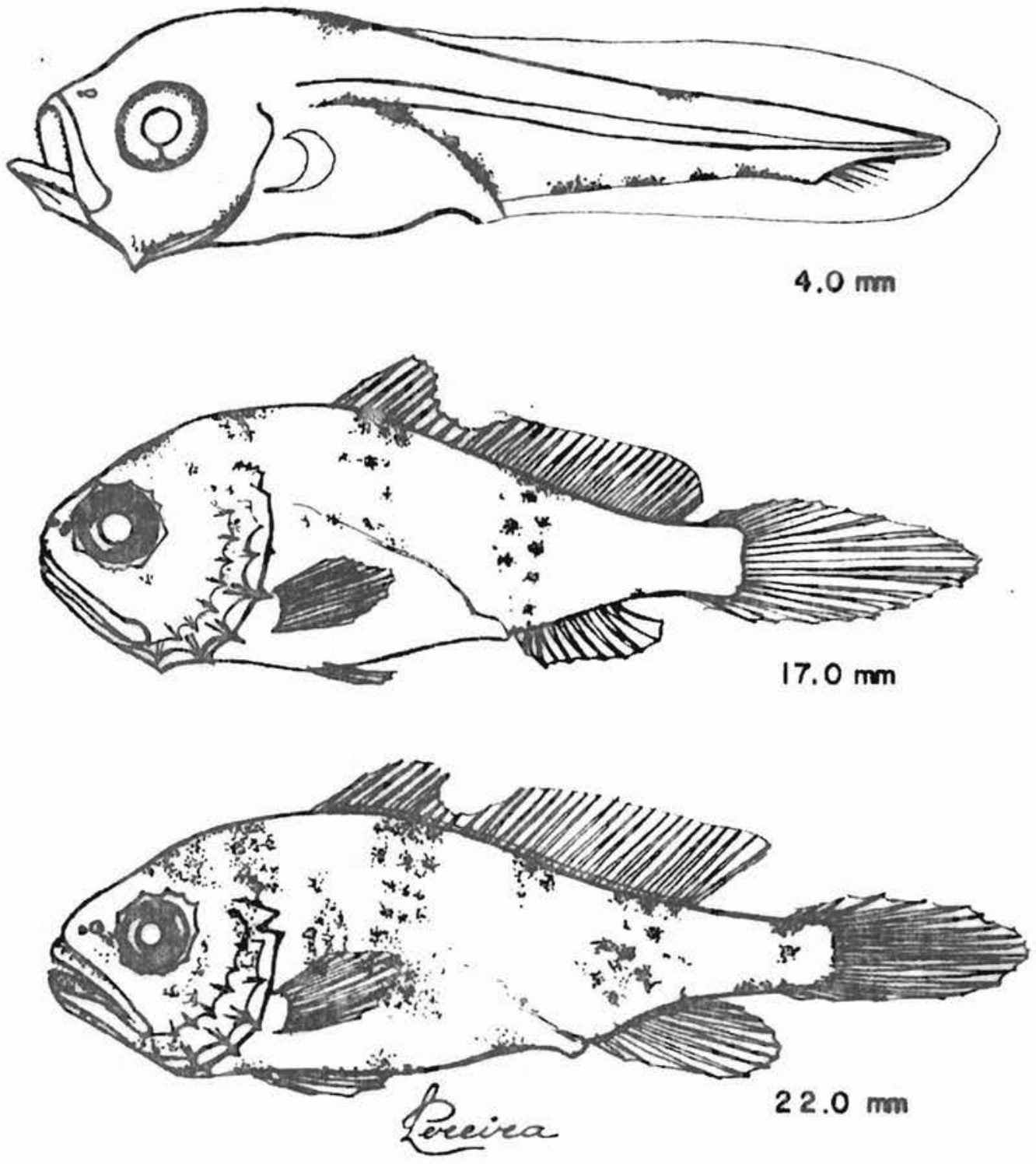

Fig. 20: Desarrollo larval de Cynoscion striatus. 

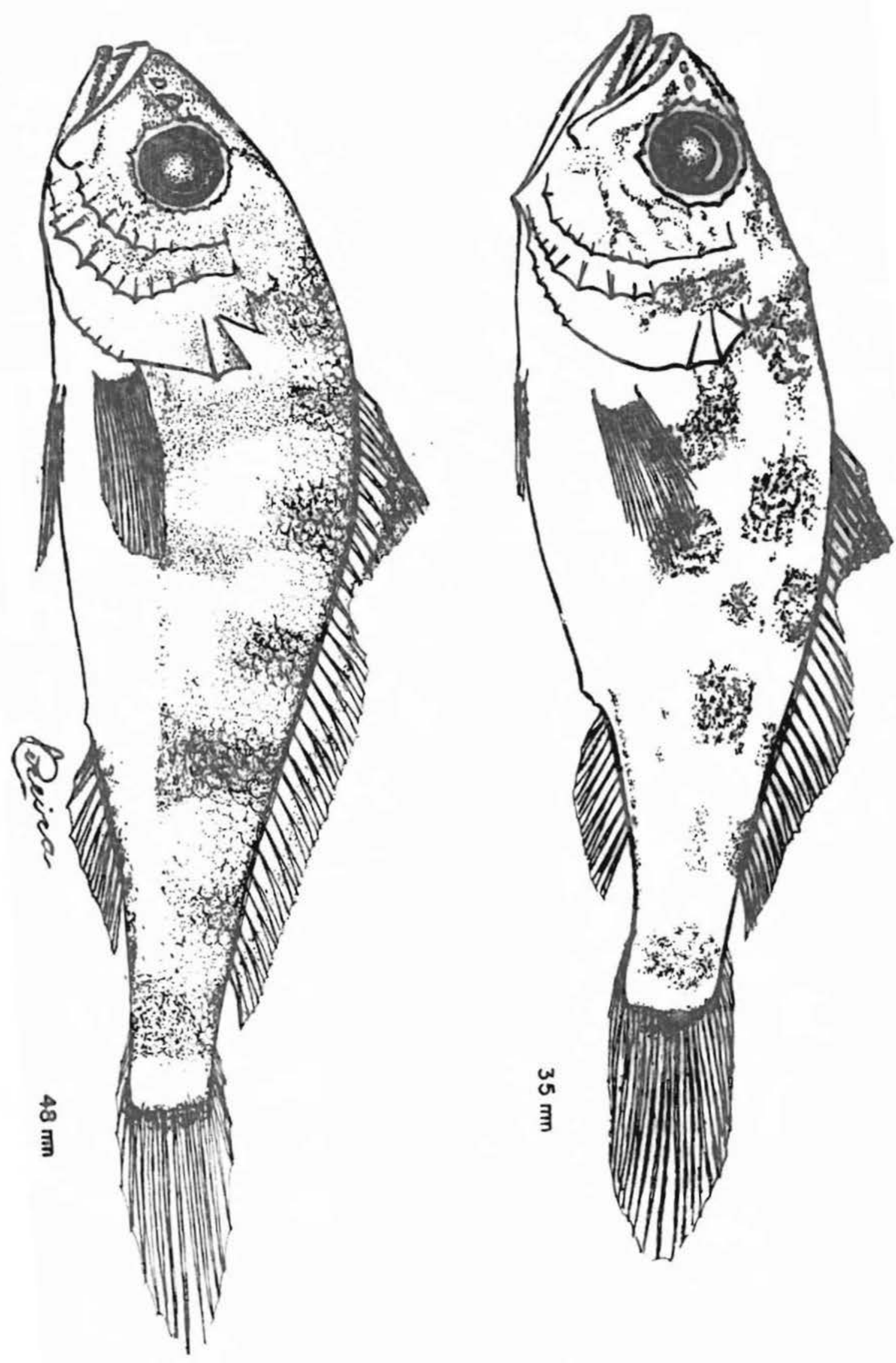


\section{1 - TRICHIURUS LEPTURUE}

Tus huevos de esta especie ya fueron identificados y descriptos por otros autores. Según Tsukahara (1962) sus huəvos son pelásicos y se djstribuyen en el mar a media agua. 'lienen entre 1,7 a $1,9 \mathrm{~mm}$ de diámetro, una mem brana fina, transparente, incolora, sin esculturas, vitelo levemente amarillo y transparente, la gota de aceite de 0,4mm de diámetro es de color anarillo cobrizo, y el espa cio perivitelino es pequeño. La descripción efectuada por

- este autor coincide perfectanente con las características encontradas en el material aquí obtenido a excepciónde las medias de los diámetros de los huevos, que son mayores. Ia media obtenida de 66 b huevos es de $2,039 \mathrm{~mm}$, oscilando entre 1,890mm y 2,214mm ( Fig. 22 B).

Durante el desarrollo embrionario este autor observó pequeños melanóforos distribuidos irregularmente sobre la sota do aceite, cabeza y en la parte dorsal y ventral de la aleta embrionaria, hecho no observado en el material en esturio ( Hig. $22 \mathrm{~A}$ ).

Cuando la larva eclosiona, presenta, según el. mismo axtor, 2 giujos de melanóforos ramificados en el margen de la aleta embrionaria, uno dorsal y otro ventral, otros dispersos en la cabera y una série en la parte media del tronco, asi como en la gota de aceite. En este estudio solamente se obcervó la presencia de un grupo de melanófo ros en la aleta embrionaria ventral yen el tercio posterior de $\perp$ cuerpo (Fig. 22).

La larva recién eclosionada tiene entre b y $6 \mathrm{~mm}$. Hil número de miómeros visibles es de aproximadamente 110. La boca no es funcional, los ojos están totalmente des pigmentados, La gota de acelte está ubicada en la parte pos terior del vitelo, La aleta embrionaria es amplia y las pec torales están poco desarrollatas.

A medida que va creciendo, el cuerpo se va comprimiendo, la cabeza se alarga y se van formando los prí meros radios de la aleta dorsal desie la parte anterior, co mo se puede observar en 1 a FIg. 22. Con llmm la aleta em brionaria persiste en la parte tinal de la dorsal, en la anal y caudal. A pesar de no haber completado todas sus a $\perp$ tas, su mortolopía es mug semejante al adulto. A excepción de la pigmentación, todas las características morfológicas corresponden con las observadas por 'lsukahara ( op. cıt). 

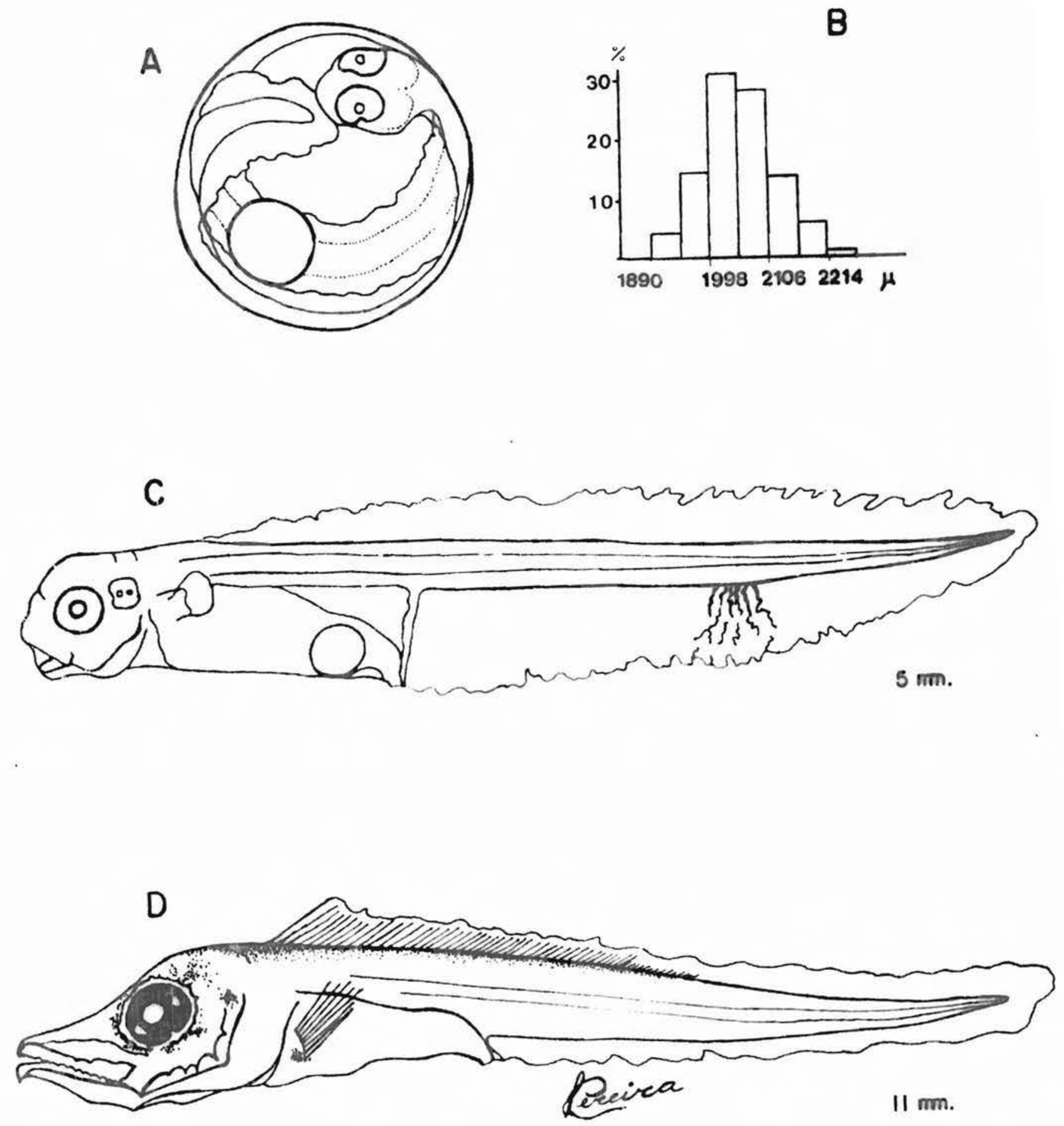

Fip. 22: Trichiurus 1epturus: A: huevo, 13: distribución de frechencias de diámetros de huevos, C: 1arva de smm, D: Larva de 1 Lmm. 
Los huevos de esta especie son redondos, con un diámetro oscilando entre $972 \mu$ a $1161 \mu$. La cáscara no tiene esculturas, el espacio perivitelino es reducido y el vitelo no es segmentado, a pesar de ser su superficie irregular. Pre senta varias gotas de aceite ( promedio de 14) de distintos tamaños y levemente amarillas (Fig. 24). No se observa ninguna pigmentación.

La distribución de frecuencias del diámetro del huevo a diferentes salinidades en el verano de 1976 se presenta en la Fig. 23. Se observa un ligero aumento de la me dia a medida que la salinidad disminuye. Es evidente que este aumento del volúmen del huevo es producido simplemente por ós mosis. A pesar de esta evidencia, con el análisis de la varian za para los diámetros en diferentes salinidades, se obtuvo un $F=1,0026$ que es menor a $F_{0,95}$ por lo que se acepta la hi pótesis de igualdad de las muestras. Al igual que en $\underline{B}$. pecti nata y $\underline{M}$. furnieri este resultado es consecuencia de que la suma de cuadrados dentro de cada salinidad es mayor que la sú ma de cuadrados entre diferentes salinidades.

El poco material impidió efectuar un análisis de las distribuciones de frecuencias de los diámetros de los huevos obtenidos en diferentes épocas.

Il desarrollo embrionario se presenta en la Fig. 24. En el estadio de néurula aparecen pequeños cromatófo ros en el dorso del embrión. Esta pigmentación va aumentando a medida que el embrión se va desarrollando hasta que está por eclosionar ( Fig. 24 D, E y F).

Cuando está por nacer se observan unos 10 mió meros, la aleta embrionaria que rodea todo el cuerpo es peque ña y los ojos son despigmentados, con la fisura coroidea que llega hasta la pupila.

La larva recién eclosionada tiene 2,6mm de largo. Presenta la típica sobresaliencia del mesencéfalo y una aleta embrionaria bien amplia. El ano forma un ángulo rec to con el cuerpo, desembocando en el borde libre de la aleta embrionaria a un $43 \%$ del largo total.

A $\operatorname{los} 3,6 \mathrm{~mm}$ ( Fig. 25) el vitelo está casi to talmente consumido, presentando restos de gotas de aceite. La 
prominencia del mesencéfalo es bien notoria. La parte final del tubo digestivo termina en un marcado ángulo recto en re lación con el tronco de la larva. Ia pigmentación del cuerpo es muy difusa y tenue, los ojos comienzan su pigmentación presentando todavía la fisura coroidea. Ia aleta embrionaria es bien amplia y las pectorales poco desarrolladas. En la par te posterior del recto se esboza la vejiga natatoria.

A los 4,2mm ( Fig. 25) tiene la boca y aparato digestivo funcional y los ojos completamente pigmentados, a pesar de presentar vestigios de la fisura coroidea. Se pueden contar 10 miómeros pre-anales y 15 post-anales. Pequeños melanóforos se distribuyen por la parte dorsal y ventral del cuerpo, parte inferior del tracto digestivo $y$ en la mandíbula.

Las pectorales presentan mayor desenvolvimiento. Por encima de los ojos, sobre el hueso parietal y el pterótico, presenta tres crestas semejantes a las que po see A. Iineatus, que habita en aguas costeras del Atlántico Norte y aguas tropicales. Según estudios realizados por Hou de et all. (1970) y Futch el all. (1972), forman parte del sistema laterosensorial.

Con 6,2mm la larva está muy desarrollada y pronta para metamorfosearse. La distancia pre-anal disminuye a un $40 \%$ del largo total con la consecuente disminución. del número de miómeros pre-anales ( 8 miómeros pre-anales y 18 post-anales). No fue observado el tentáculo dorsal obser vado por Houde et all. (1970) en A. Iineatus; éste está soportado por el 30 radio de la dorsal, presentando un largo mucho mayor que Ios restantes. A. garmani presenta un penacho anterior formado por radios de mayor tamaño, siendo el tercero y cuarto radio los que duplican su longitud (Fig.25). Los restantes radios de la dorsal ( 50 en media) son normales. La aleta anal está formada por 42 radios y la caudal por 18. La pigmentación es más intensa, observándose melanó foros por todo el cuerpo, concentrados principalmente en la parte dorsal y ventral del tronco. Otras diferencias entre estas especies se refieren al tamaño de los huevos y larvas: Ios de $\underline{A}$. Iineatus miden en promedio $740 \mu$ eclosionando una larva de $1,6 \mathrm{~mm}$ de largo y su metamorfosis se inicia entre Ios 3,0 a 3,2mm. Es interesante el hecho de que mientras la diferencia del diámetro de los huevos es de un 26\%, en la larva recién nacida la diferencia aumenta a un 38\%, y en el momento de la metamorfosis la larva de $\underline{\text { A }}$ garmani practica- 


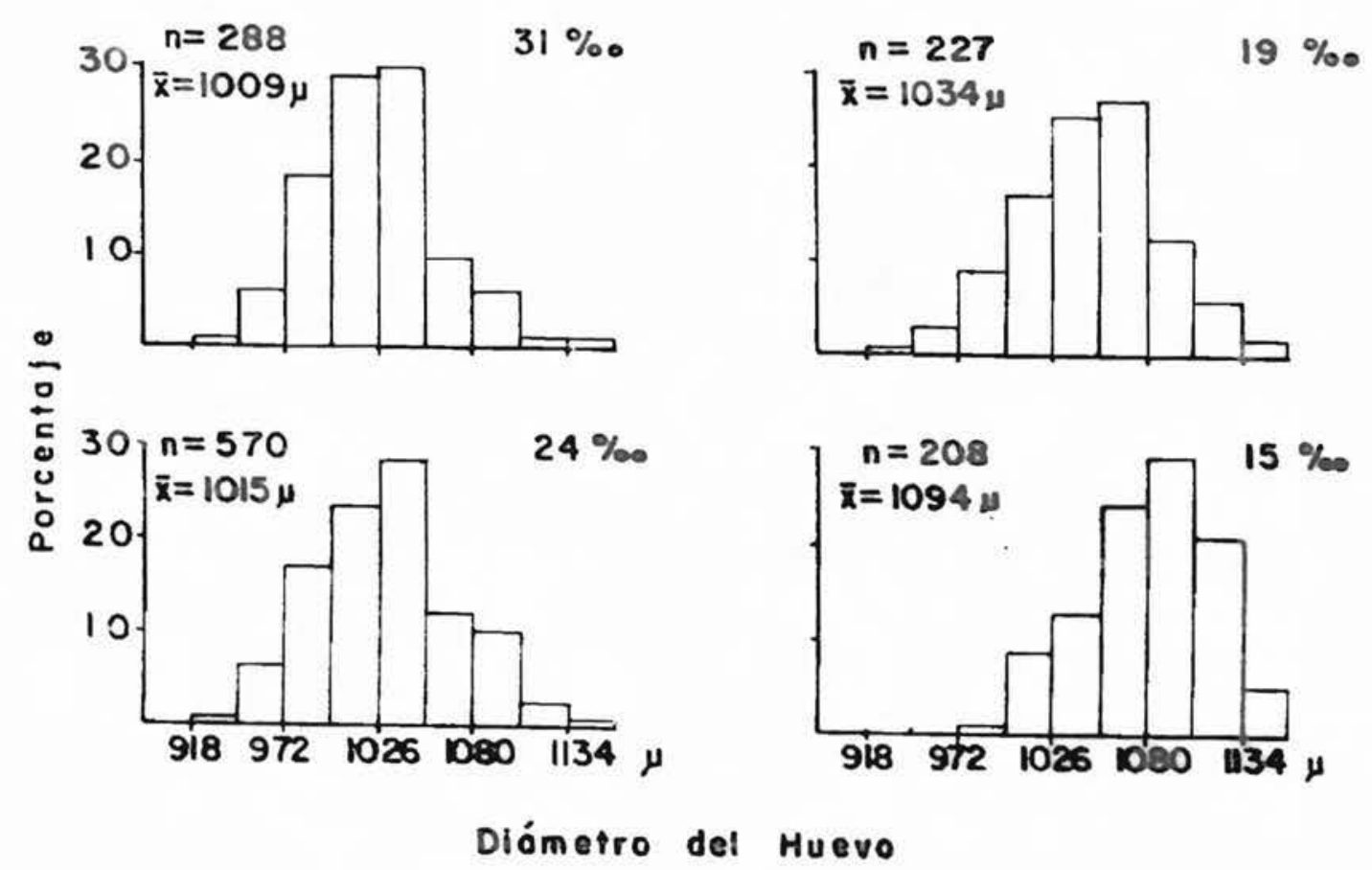

Fig. 23 : Distribución de frecuencias del diémetro del huevo de $\underline{A}$. Sarmani en diferentes salinidades. 

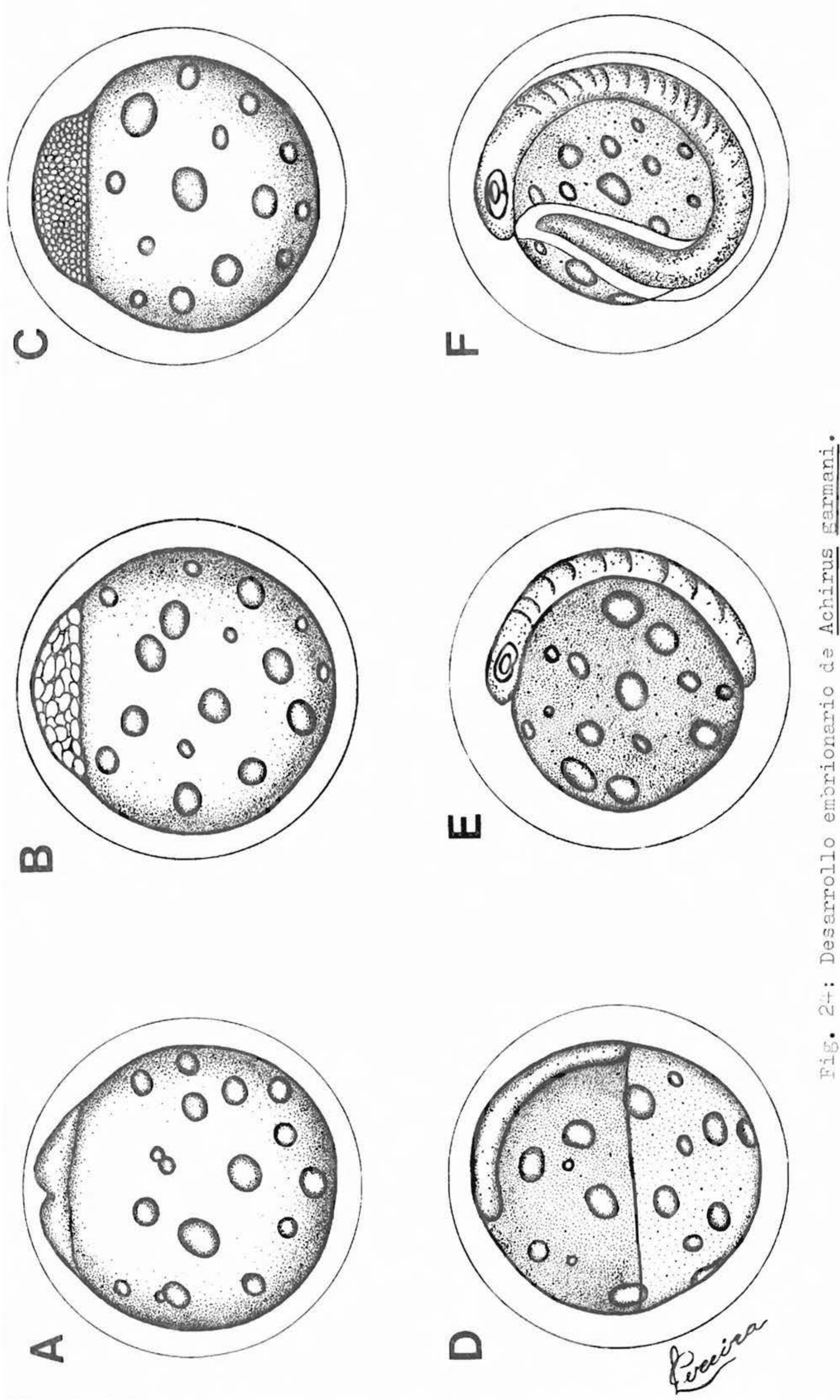

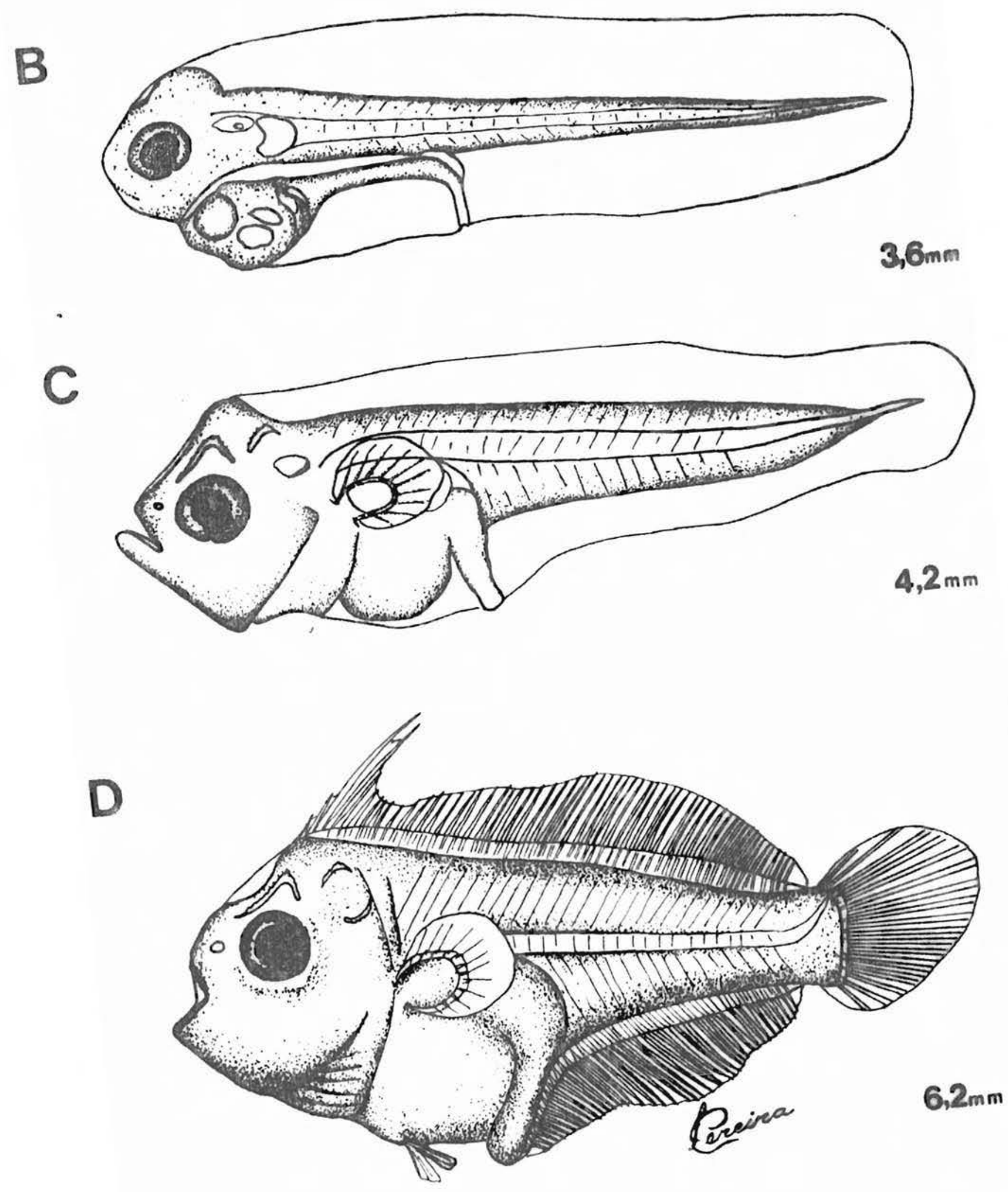

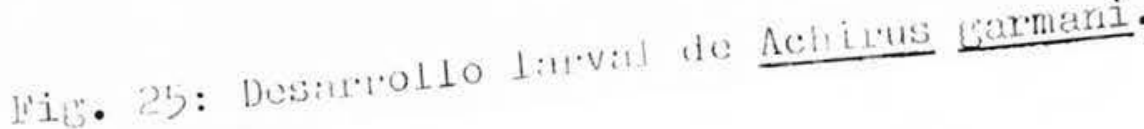


Según Kunyan (1961), los huevos de esta especie son demersales, depositados en una masa adhesiva en la concavi dad de ostras vacias y cuidados por el macho. Son estéricos o le vementë elípticos con un diámetro de 750 a $940 \mu$. La membrana es finamente rugosa y muy adhesiva. El vitelo es grande y presenta entre 70 a 80 gotas de aceite de 20 a $100 \mu$ de diámetro. El espacio perivitelino es aproximadamente de un $15 \%$ a un $20 \%$ del diáme tro.total del huevo.in el presente estudio no tue posible obte ner huevos de esta especie principalmente por sus caracteristi cas bentónicas.

Las larvas menores presentes en las muestras de plancton, tueron de 3,Omm, mostrando todavía el saco vitelino en la parte ventro-anterior del cuerpo (Fig. 26). Según Runyan (1961), la larva eclosiona con 3,21nm en promedio y experimentos efectuados por saksena y Joseph (1972), mostraron que eclosiona con 2,7mm. La aleta embrionaria no es muy amplia y las pectoraLes están bien desarrolladas. Se visualizan unos 30 a 35 miómeros. Los ojos están bastante pigmentados y presentan 2 series de melanóforos en la parte dorsal y ventral del cuerpo terminanao puco después del ano, quedando la parte caudal, aleta embriona ria y pectorales despigmentadas. La parte anterıor del cuerpo presenta gran cantidad de pequeños melanóforos dispersos Pig. 26).

A los $3,5 \mathrm{~mm}$ el vitelo está totalmente consumido y la boca es funcional. Los ojos están totalmente pigmentados y la pigmentación general del cuerpo se acentúa manteniendo las mismas características que con 3,Omm. Se visualizan los primeros radios de 1 a aleta dorsal y caudal sobre la aleta embrionaria y en las pectordes.

El estado larval es considerado desde 1 os $3,9 \mathrm{~mm}$ (Runyan, 1961) nasta los 9mm ( Dovel, 1463). Los ejemplaces de este tamaño son difíciles de encontrar en las muestras de p $\perp$ ancton porque adquieren prontamente hábitos bentónicos. vurante es te período no presenta características muy importantes a excep-ción de una intensificación de la pigmentación en todo el cuerpo. Ia formación de las aletas dorsal, anal y caudal y la aparición de las ventrales se produce aproximadamente a los lomm. Con $12 \mathrm{~mm}$ ya es un juvenil con las características típicas del adulto ( Fig. 26). 

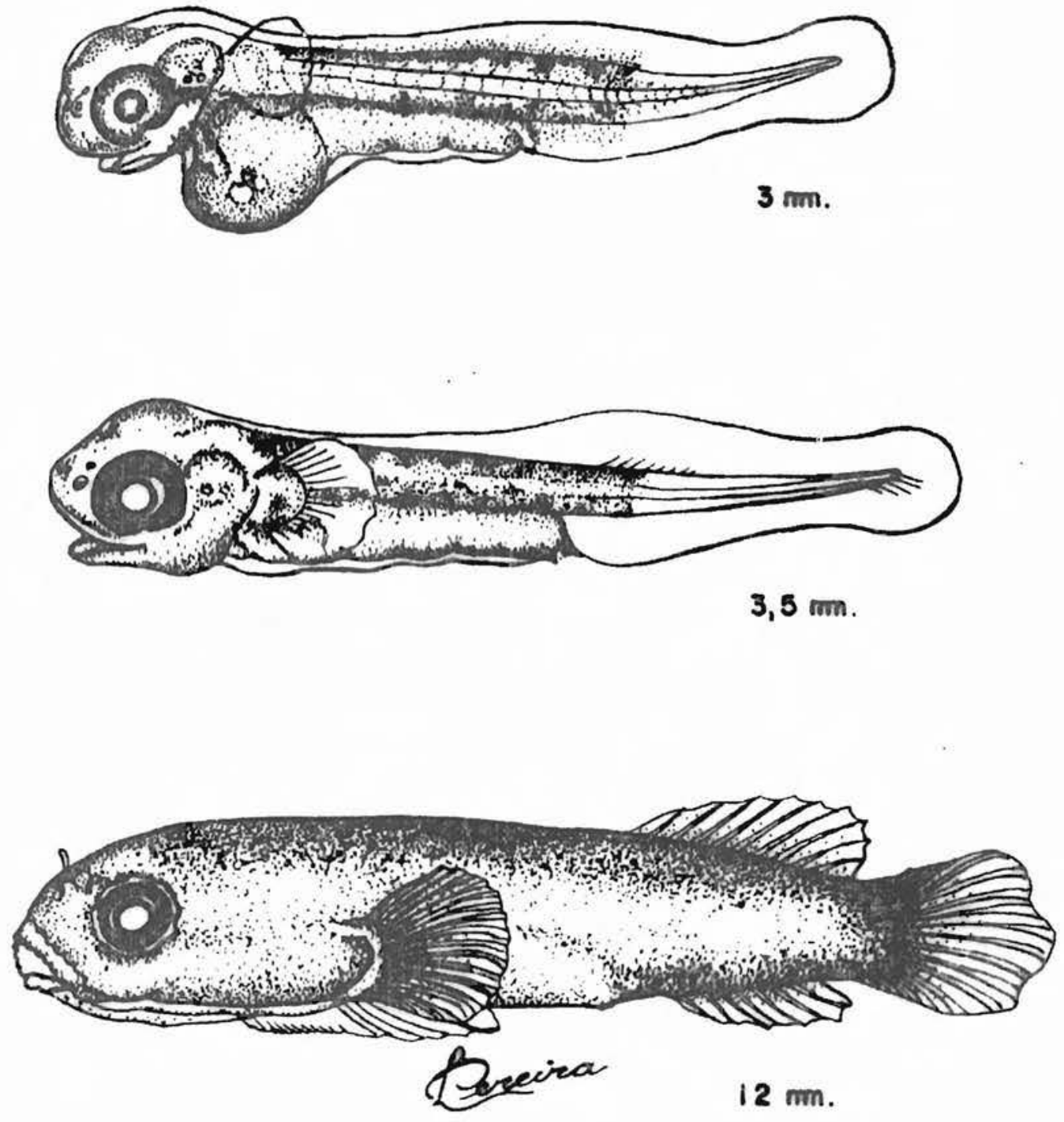

Iif. 26: Desarrolio Iarval de Gobiesox strumosus. 

$\underline{\underline{P} A R \text { T E }} \stackrel{\underline{B}}{\underline{\underline{B}}}$

DISTR IBUCION HORIZONTAL DEL ICTIOPIANCTON 


\section{1 - FLUCTUACIONES CUANTITATIVAS EN RELACION CON LOS}

\section{FACTORES AMBIENTALES}

En la Fig. 27A se observan las oscilaciones de los valores mediosde temperatura y salinidad, en el transcurso de los 3 años de estudio. Comparando los valores obtenidos en la secuencia estacional se observa que las medias de la temperatura se mantienen constantes en los tres años. Por el contrario, las medias de la salinidad presentan oscilaciones totalmente aleatorias, principalmente al final de la primavera, en el verano y otoño, mientras que el invierno y principios de primavera se caracteriza por valores mínimos a causa del alto índice plu viométrico como fue demostrado por Castello y Mbller(1978) en un análisis estadístico a través de 10 años. También es evidente que las marcadas oscilaciones de la salinidad en las diferentes épocas son provocadas por el comporta miento hidráulico del angosto canal de entrada, con bruscos cambios de los flujos de agua bajo condiciones espe ciales de lluvias y vientos como fue observado por Mala val (1916).

Analizando la penetración de los huevos (Fig. 27 B) en relación con la temperatura se observa que en general, un aumento de ésta, acompaña un aumento de la densidad numérica de los huevos.

Se puede observar también que, a pesar de estar en plena época de reproducción ( verano), existen disminuciones notables del número de huevos como ocurre en el 4으, 14으 y 150 crucero. Estas disminuciones son provocadas por una inversión en el flujo de agua en el canal de entrada, produciéndose un desague que arrastra el mate rial planctónico hacia aguas costeras adyacentes. Obser vándose asî que, de una media de 912 huevos/100m ${ }^{3}$, en el tercer crucero con una salinidad media de $21,8 \%$, se obtenga 16 días después, en el cuarto crucero, una media de 0,1 huevos $/ 100 \mathrm{~m}^{3}$, con una salinidad de $3,3 \% 0$.

Otro hecho similar se observa en el otoño de 1976, en el que la penetración del agua marina está acompañada por un importante ingreso de huevos: en el quin to crucero, 14,3 huevos/100m ${ }^{3}$ y 33,8 huevos/100m ${ }^{3}$ en el 
séptimo crucero, con salinidades de 12,4\% y 15,7\% respec tivamente. Opuestamente en el sexto crucero, la disminución de la salinidad se correlaciona con el bajo número de 1,1 huevos/100m $\mathrm{m}^{3}$.

En el otoño siguiente ocurrió algo semejante: el décimo octavo crucero registró 70,2 huevos/100m ${ }^{3}$ y una salinidad de $19,5 \%$ y el décimo noveno crucero no registró huevos y una media de la salinidad de 2,5\%o.

De lo expuesto se deduce que la presencia de Ios huevos planctónicos en el estuario es regida principalmente por los flujos de penetración de agua marina, por ser todos de origen marino y debido a su carácter pasivo de transporte. Por esta causa, no se puede afirmar que la au sencia de los mismos en el estuario durante el invierno indique que las especies no desoven, dado que esta época se caracteriza principalmente por desagues prolongados. En ca da ciclo anual se observan dos picos de abundancia, regis trándose el de mayor densidad en primavera y verano, y otro con densidades menores en otoño.

Las larvas, por el contrário, presentaron una distribución independiente de las temperaturas y salinida des medias del estuario. A pesar de observarse los mayores registros en primavera, verano y otoño, existen en estas épocas disminuciones independientemente de la temperatura co mo se observa en el 4으,5으, 13으, 17으, cruceros. Tampoco los aumentos o disminuciones de la salinidad muestran fluctua ciones numéricas de las larvas, observándose una distribu ción totalmente aleatória. Ts evidente que las larvas muestreadas son de especies con hábitos diferentes ( marinas, estuarinas u oligohalinas) que utilizan esta área para criar. se - Consecuentemente, al considerarlas en un todo, se enmascaran las características propias de cada especie que utiliza este estuario.

Los valores obtenidos en la Tabla 1, muestran una disminución paulatina en el número de los huevos y de las larvas desde la primavera de 1975 a la primavera de 1978. Por ser éste el primer registro del ictioplancton en el área se torna difícil su explicación, principalmente si se considera su inestabilidad. Futuros estudios y monitoreos podran esclarecer si es un problema inherente a las especies - al ambiente en sí, dado su carácter portuario. 

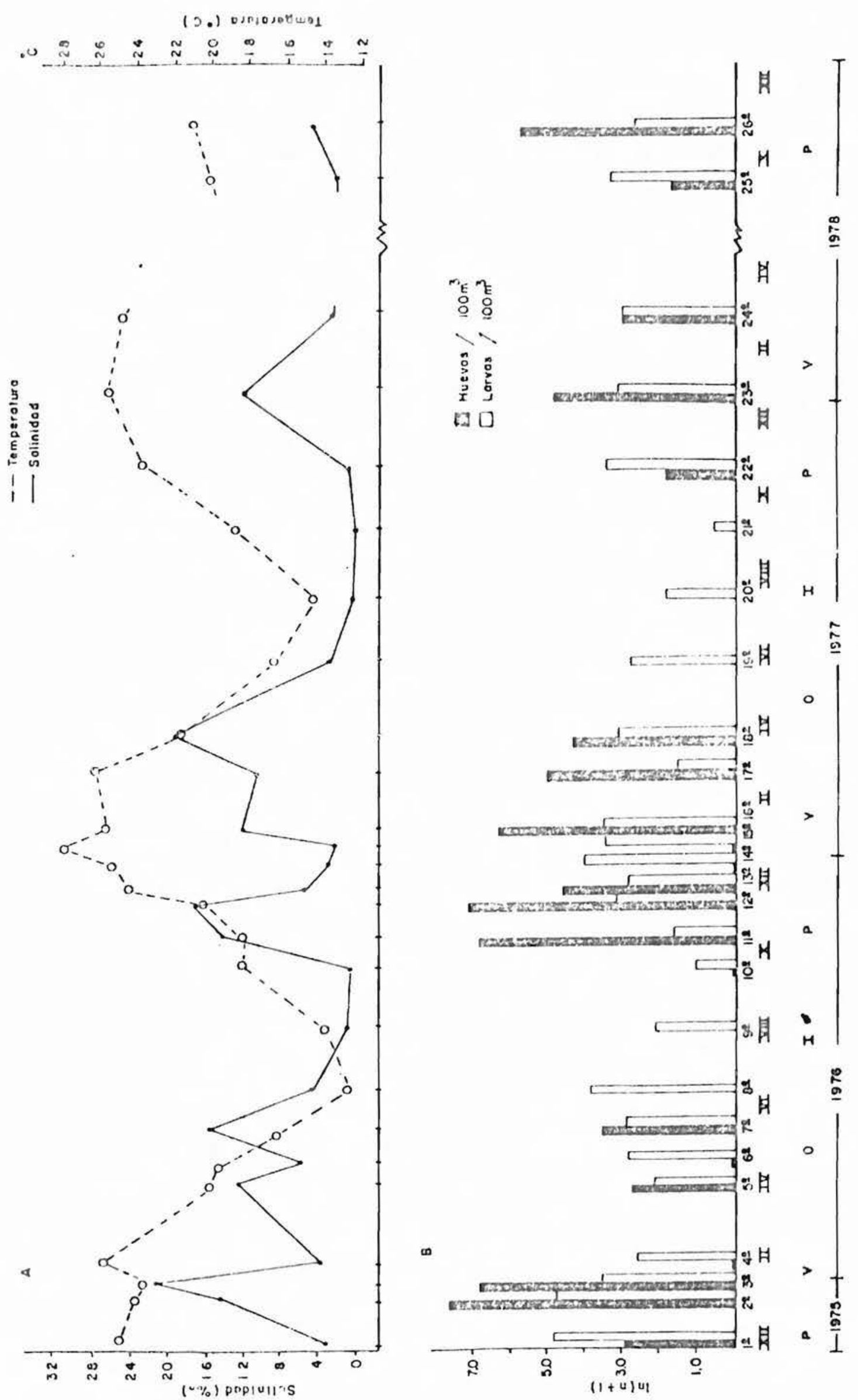

Fig. 27: A - Medias de temperaturas y salinidades por crucero; B - Medias de huevos y larvas por crucero. 
El total de huevos colectados en los 26 cruceros fue de $148.836,6$ por $10 \mathrm{~m}^{3}$, de los cuales el $89 \%$ correspondió a la corvina ( Micropogonias furnieri), mostrando una dominancia total sobre cualquier otra especie ( Tabla 3 ).

Los huevos restantes ( $10,2 \%)$, pertenecieron en orden de importancia numérica al linguado ( Achirus garmani), a la manjuba ( Iycengraulis grossidens), a la lacha ( Brevoortia pectinata) y al pez sable ( Trichiurus lepturus). El 1,2\% no fue identificado.

A pesar de ser los huevos de $\underline{M}$. furnieri tan nu merosos, su distribución fue limitada, presentándose en solo el 32,4\% de las estaciones. Las otras especies tuvieron una distribución todavia menor, siendo más limitada la de $\underline{\text { T. leptu }}$ rus a sólo el 4,8\% de estaciones positivas.

La composición por especie de las larvas es to talmente diferente a la de los huevos. De un total de 16.712,2 larvas $/ 10 \mathrm{~m}^{3}$, I. grossidens representó el $44 \% \mathrm{y} \mathrm{B}$. pectinata el 20,1\%, estando en tercer lugar $\underline{M}$. furnieri con $13,1 \%$. Esta diferencia entre la abundancia de huevos y larvas está dada por las características propias de cada especie. El elevado número de huevos de $\underline{M}$. furnieri dentro del estuario está indicando que los adultos desovantes se encuentran en áreas adyacentes o en el mismo canal de entrada con condic í nes propicias. Por el contrario, los desovantes de L. grossidens y B. pectinata están en áreas más alejadas, penetrando en el estuario, fundamentalmente como larvas. La alta frecuencia de larvas de estas 2 últimas especies se debe en parte a que presentan un tiempo de vida planctónico más prolongado.

En la Tabla 3 se puede apreciar que si bien $\underline{B}$. pectinata tiene menor número de larvas que $\mathbf{I}$ - grossidens, el número de estaciones positivas es mayor, indicando una distribución más amplia, en tanto que la scuunda estaría en un área más restringida.

Las larvas de $\underline{\mathbb{M}}$ - furnieri tienen una vida planctónica mucho más breve, ya que rapidamente adquieren hábitos bentónicos. Un hecho similar ocurre con $\underline{A}$. Sarmani, que presen tando un total de $6.898,1$ huevos/100m ${ }^{3}$, apenas llegan a presen $\operatorname{tar} 185 / 100 \mathrm{~m}^{3}$ de individuos en estado larval. 
Tabla 3: Composición por especie para el total de cruceros por $100 \mathrm{~m}^{3}$ de agua filtrada

\begin{tabular}{|c|c|c|c|c|}
\hline & ESPEC IE & TOTAL $\left(100 \mathrm{~m}^{3}\right)$ & $\%$ & $\%$ est. \\
\hline \multirow{6}{*}{$\begin{array}{l}\text { UR } \\
0 \\
p \\
\text { pla } \\
D \\
\text { 出 }\end{array}$} & Brevoortia pectinata & $2.063,8$ & 1,4 & 16,0 \\
\hline & Iycengraulis grossidens & $4.105,9$ & 2,8 & 7,1 \\
\hline & Micropogonias furnieri 13 & $133.712,6$ & 89,8 & 32,4 \\
\hline & Trichiurus Iepturus & 235,1 & 0,2 & 4,8 \\
\hline & Achirus garmani & $6.898,1$ & 4,7 & 11,6 \\
\hline & Otros & $1.821,1$ & 1,2 & 13,8 \\
\hline \multirow{14}{*}{ 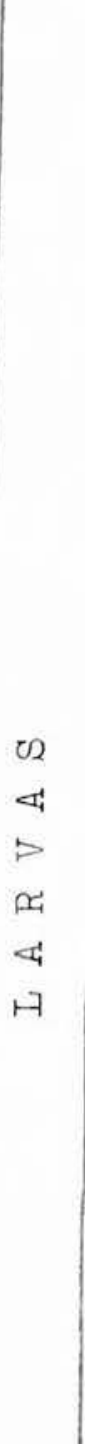 } & Brevoortia pectinata & $3.359,3$ & 20,1 & 58,0 \\
\hline & Lycengraulis grossidens & $7.347,1$ & $4.4,0$ & 53,0 \\
\hline & Parapimelodus valenciennis & is 950,2 & 5,7 & 7,7 \\
\hline & Hyporhamphus kronei & 142,6 & 0,9 & 4,4 \\
\hline & Atherinidae & $1.132,2$ & 6,7 & 29,3 \\
\hline & Syngnathus folletti & 182,5 & 1,1 & 11,8 \\
\hline & Micropogonias furnieri & $2.195,6$ & 13,1 & 24,0 \\
\hline & Macrodon ancylodon & 81,4 & 0,5 & 3,4 \\
\hline & Paralonchurus brasiliensis & 4,0 & 0,1 & 0,2 \\
\hline & Blennius sp. & 194,4 & 1,2 & 10,6 \\
\hline & Trichiurus lepturus & 22,8 & 0,1 & 1,4 \\
\hline & Gobionellus sp. & 295,3 & 1,8 & 15,0 \\
\hline & Achirus garmani & 184,8 & 1,1 & 11,0 \\
\hline & Gobiesox strumosus & 216,6 & 1,3 & 9,5 \\
\hline & Otras & 403,4 & 2,4 & 15,4 \\
\hline
\end{tabular}


Otro ejemplo son Macrodon ancylodon y Paralonchurus brasiliensis, ambos sciaenidae, que a pesar de ser abundantes en el estuario como juveniles, sus larvas planctónicas son ocasionales en el canal de entrada ( 0,5 a $0,1 \%$ del total de larvas). Es probable que la primera etapa de vida planctónica de estas especies ocurra en el mar.

Dentro de las especies con huevos bentónicos, como Hyporhamphus kronei, Blennius sp., Gobionellus sp., Gobiesox strumosus y las pertenecientes a la Fam. Atherinidae, las únicas verdaderamente representativas fueron las últimas, tanto en número como en distribución. Las larvas del bagre de agua dulce ( Parapimelodus valenciennis), fueron capturadas en número relativamente grande a pesar de presentarse en pocas estaciones $(4,3 \%)$. Las larvas del pez aguja ( Syngnathus folletti), por el contrario, se presentaron en número reducido pero con mayor distribución. Finalmente las larvas

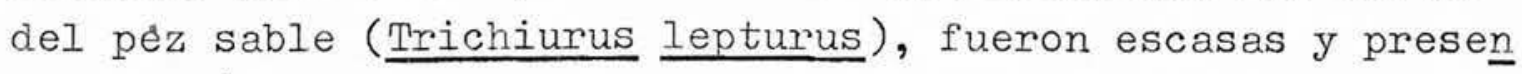
tes en número reducido de estaciones.

3 - VARIACION CUANTITATIVA ESTAC IONAL DE LAS ESPECIES

\section{A) HUEVOS}

La Fig. 28 presenta la dislribución cuantitativa de Ios huevos de cada especie en diferentes épocas. Ia superficie de cada círculo representa la densidad total de és tos y cada sector es proporcional a las abundancias de cada especie. Ia Tabla 4 muestra las medias del número de huevos y larvas de las especies en cada época y la Tabla 5 dá los valo res de temperatura y salinidades mínimas, máximas y medias re gistradas para cada período.

Comparando por épocas, se observa respecto a las primaveras que, la correspondiente a 1976 presentó el mayor número y diversidad de huevos, época ésta caracterizada por la salinidad media más alta $(9,6 \%$ ) y la temperatura media me nor $(19,8$ 으).

En orden de número y diversidad le sigue la pri mavera de 1978, correspondiéndole en este caso también el sé gundo lugar respecto a las salinidades más altas $(6,2 \%)$ y tem peraturas más bajas (20,8으).

Finalmente las primaveras de 1975 y 1977 presen taron los menores índices de abundancia y diversidad, caracte 
Tabla 4: Media del numero de huevos y laxvas ( $x 100 \mathrm{~m}^{3}$ ) para cada periodo.

\begin{tabular}{|c|c|c|c|c|c|c|c|c|c|c|c|}
\hline \multirow{2}{*}{$E S P E C I E$} & \multicolumn{2}{|l|}{1975} & \multicolumn{2}{|c|}{1976} & \multirow[b]{2}{*}{$P$} & \multicolumn{4}{|c|}{1977} & \multicolumn{2}{|c|}{1978} \\
\hline & $\mathrm{P}$ & $\mathrm{V}$ & 0 & I & & V & 0 & I & $\mathrm{P}$ & V & $P$ \\
\hline B. pectinata & - & 3,8 & 0,8 & - & 8,4 & 8,9 & 1,8 & - & - & 0,5 & 0,1 \\
\hline I. grossiders & - & - & 14,1 & - & 32,2 & - & 0,3 & - & - & - & - \\
\hline M. furnieri & 16,1 & 935,7 & 2,5 & - & 389,9 & 162,7 & 29,0 & - & 4,3 & 57,2 & 178,7 \\
\hline T. lepturus & - & 2,0 & - & - & 0,1 & 0,7 & 0,3 & - & - & 0,1 & 0,1 \\
\hline A. Garmani & 0,3 & 76,2 & 0,4 & - & 4,0 & 5,0 & 1,3 & - & - & 10,2 & 3,0 \\
\hline Otros & 0,1 & 5,0 & 0,3 & - & 8,8 & 5,1 & 0,9 & - & 0,7 & 1,2 & 0,2 \\
\hline B. pectinata & 35,5 & 2,4 & 8,5 & 4,1 & 3,8 & 2,7 & 5,6 & 2,3 & 10,3 & 1,1 & 2,9 \\
\hline I. grossidens & 74,5 & 30,7 & 6,6 & 1,5 & 7,0 & 22,1 & 2,6 & 0,1 & 2,7 & 1,0 & 1,0 \\
\hline P. valenciennis & 6,5 & 0,1 & - & 0,1 & 5,0 & 0,1 & - & - & 12,7 & - & - \\
\hline H. kronei & 0,1 & 0,5 & 0,1 & - & 0,1 & 0,1 & - & - & - & 2,2 & - \\
\hline Atherinidae & 4,1 & 0,6 & 2,8 & 1,0 & 0,4 & 0,2 & 0,2 & 0,3 & 0,9 & 1,4 & 9,4 \\
\hline S. folletti & 0,1 & 0,2 & 0,3 & - & 0,1 & 0,4 & 0,3 & 0,1 & - & 0,1 & 1,1 \\
\hline M. furnieri & 0,2 & $12, ?$ & 0,1 & - & 1,0 & 2,6 & 6,2 & - & 0,5 & 13,7 & - \\
\hline Blennius sp. & - & 0,3 & 0,7 & - & 0,1 & 0,1 & $0,1$. & - & 0,1 & 0,2 & - \\
\hline T. Iepturus & - & 0,1 & - & - & 0,1 & 0,1 & 0,1 & - & - & - & - \\
\hline Gobionellus sp. & 0,1 & 1,3 & 0,1 & 0,2 & 0,1 & 0,9 & 1,4 & 0,4 & 1,0 & 0,1 & - \\
\hline A. garmani & - & 0,2 & - & - & 0,4 & 0,1 & - & - & - & 0,5 & 0,1 \\
\hline G. strumosus & - & 1,2 & 0,7 & 0,1 & 0,1 & 0,1 & 0,2 & - & - & - & 0,2 \\
\hline Otras & 0,1 & 1,1 & 0,4 & - & 0,4 & 0,6 & 0,2 & - & 0,2 & 0,7 & 2,5 \\
\hline
\end{tabular}


Tabla 5: Salinidades y temperaturas minimas, máximas $\mathrm{y}$ medias registradas para cada época.

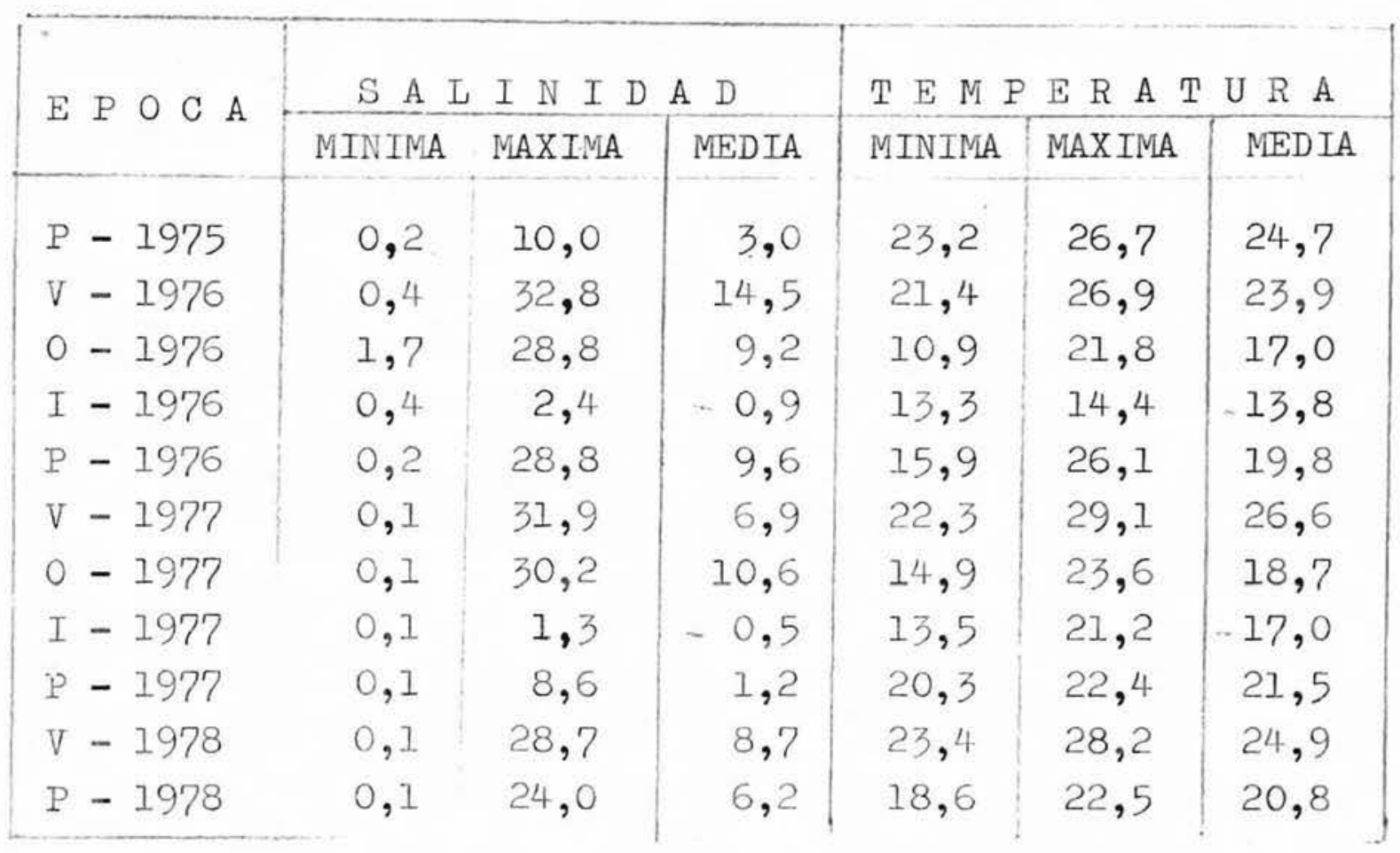



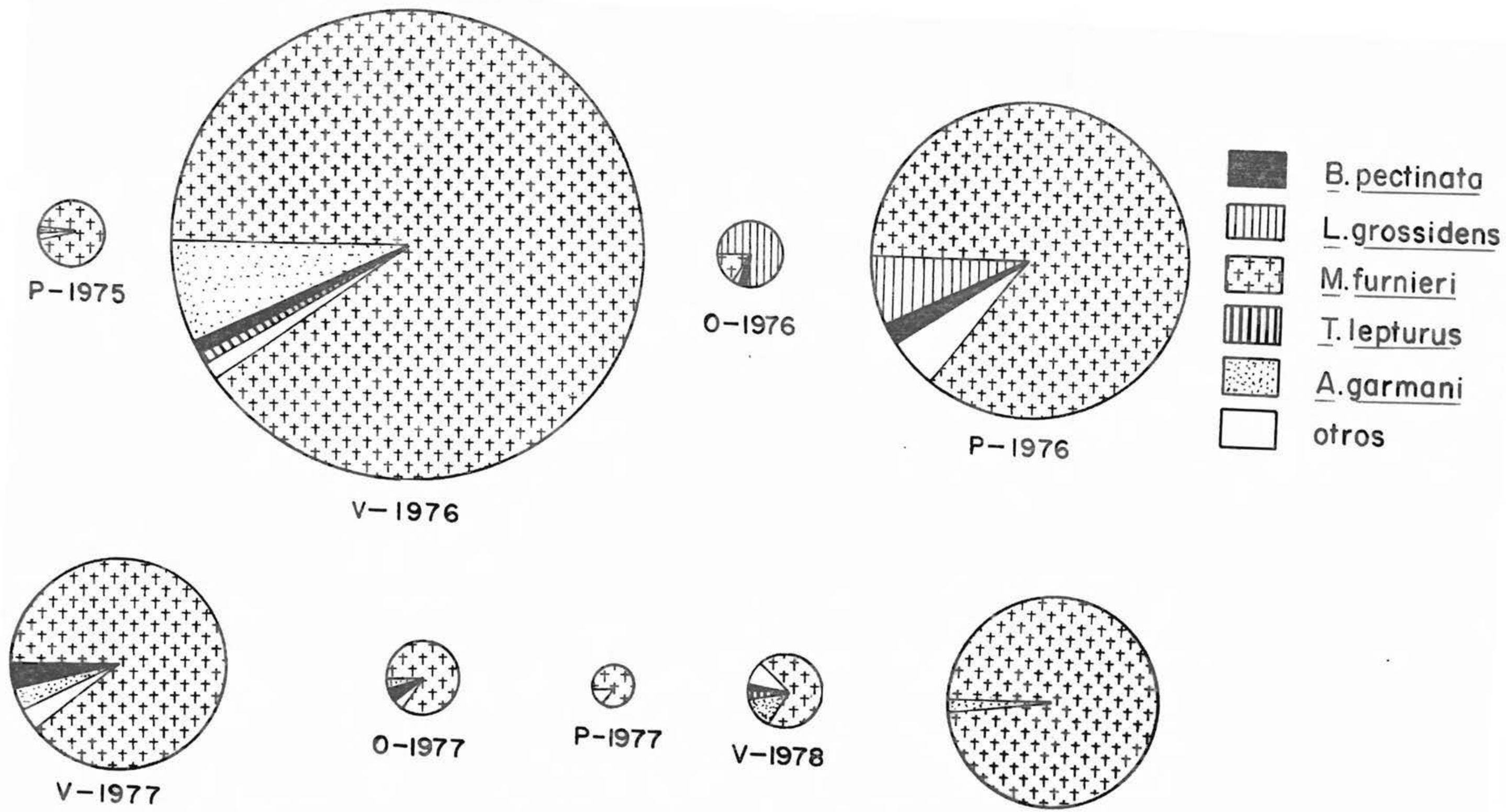

Fig. 28:

$$
P-1978
$$

halladas ( escala: un fínoumes de las diferentes especies 
rizadas éstas por presentar las medias de salinidad más bajas y temperaturas más altas.

Es importante resaltar en este caso que estos dos últimos períodos primaverales están representadas por un único crucero realizado en cada uno. En estas dos circunstancias, se dá la coincidencia de presentar el estuario condiciones de desague, explicando la baja abundancia de huevos. En todos los casos la especie más representada fue M. furnieri. El verano de 1976, con medias de salinidades de $14,5 \%$ y temperaturas de 23,9 oC presentó el mayor número y di versidad. En abundancia corresponde el segundo lugar al verano de 1977, que a pesar de presentar valores medios de salini dad de 6,9\%o, presentó los máximos registros ( $31,9 \% 0)$. Estos valores elevados de la salinidad indican la penetración en el estuario de una masa de agua marina, responsable de la entrada de una media de 183 huevos/100m ${ }^{3}$.

En forma coherente las temperaturas mínimas acompañan los más altos valores de salinidad. Por ejemplo, los mínimos de temperatura se presentaron en el verano de 1976 con 21,4으, el de 1977 con 22,3으 y el mayor en 1978 con valo res de 24,9 으 (Tabla 5).

También en este caso la especie mejor representada fue $\underline{\text { M. }}$ furnieri.

La época otoñal presentó las mismas característí cas en relación con las temperaturas y salinidades, a pesar de presentar una penetración de huevos menor.

La única excepción en que huevos de otras espe cies superaron la abundancia de los huevos de $\underline{M}$. furnieri $\left(2,5\right.$ huevos/100m $\left.{ }^{3}\right)$ fue en el otoño de 1976, en que I. grossidens presentó valores de 14,1 huevos $/ 100 \mathrm{~m}^{3}$.

B - IARVAS

Ia Fig. 29 presenta la abundancia y diversidad de las larvas para las diferentes épocas.

Se observa que la primavera de 1975 fue numéri camente, la más representativa. Las salinidades medias fueron de 3,0\% y las temperaturas de 24,700. En orden de importane. cia se presentaron $\underline{I} \cdot \underline{\text { grossidens }}, \underline{B}$ - pectinata, $\underline{P} \cdot \underline{\text { valencie- }}$ nnis y Atherinidae. La menor salinidad media se registró en la primavera de $19 \%$ ( $0,2 \% 0)$, asociada, aunque en menor nú- 
mero, a las mismas especies practicamente, siendo $\underline{P}$ - valenciennis, un pequeño bagre de hábitos dulceacuícolas, que represen tó casi el 50\%. En la primavera de 1978, las salinidades medias aumentaron a $6,2 \% 0$, desapareciendo $\underline{\mathrm{P}} \cdot \underline{\text { valenciennis y aumentan- }}$ do la proporción de Atherinidae. La primavera de 1976, con salinidades mayores $(9,6 \%$ ) como consecuencia de la entrada de aguas marinas ( el máximo registro fue de 28,8\%0), presentó las mismas especies que en 1975, más la presencia de larvas de M. furnieri y A. garmani. Con respecto a la presencia de huevos, la primavera de 1976 fue la más representativa tanto en número como en diversidad.

En relación a los veranos, la estación más impor tante en número como en especies, fue la de 1976, caracterizada por la media de salinidad más elevada ( 14,5\%o) y la amplitud máxima ( 0,4\% a 32,8\%). El verano de 1977 le sigue en or den de importancia, apreciándose que la salinidad media disminuye y también la proporción de larvas de ㅆ. furnieri. Finalmente, el verano de 1978 cori salinidades mucho mayores presenta menor incidencia de larvas $\mathrm{y}$ mayor diversidad, siendo $\mathbb{M}$. furnieri la especie: con mayor representatividad (13,7 larvas $\left.100 \mathrm{~m}^{3}\right)$.

A pesar de que en otoño las salinidades medias fueron de 9,2\% y 10,6\%०, la presencia de huevos fue muy limí tada, estando las larvas por el contrario bien representadas. En 1976 predominó $\underline{B}$. pectinata y en segundo lugar I. grossidens. En 1977 la mayor abundancia correspondió a M. furnieri, coincidiendo con la mayor salinidad $(10,6 \%)$.

La época invernal, caracterizada por salinidades mínimas y ausencia de huevos, presentó el menor Índice de larvas, predominando siempre $\underline{B}$. pectinata.

Es evidente que la variación cuantitativa estacional de las larvas, al igual que la de los huevos, depende de los factores ambientales.

Las densidades de las diferentes especies está condicionada a la entrada o salida de agua en el estuario. Altas salinidades van acompañadas por un gran número de huevos y larvas de espécies como ‥ furnieri, $\underline{\text { T. }}$ lepturus y $\underline{\text { A. }}$ garmani. Bajas salinidades están asociadas con baja densidad de huevos o ausencia, y larvas de especies como $\underline{B}$. pectinata, I. grossidens y $\underline{\mathrm{P}}$. valenciennis. 0 sea que la variación cualicuantitativa depende de la época, de las condiciones ambienta les en el momento en que se realiza el muestreo, y del ciclo biológico de la especie. 


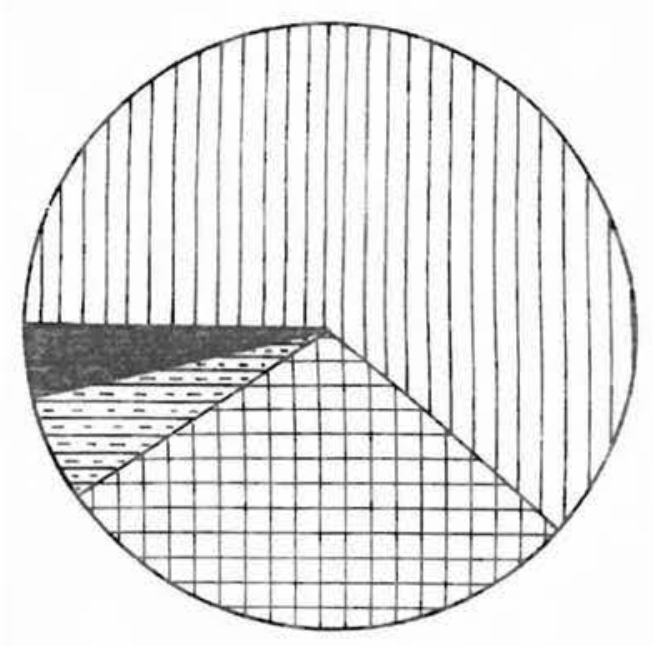

$P-1975$

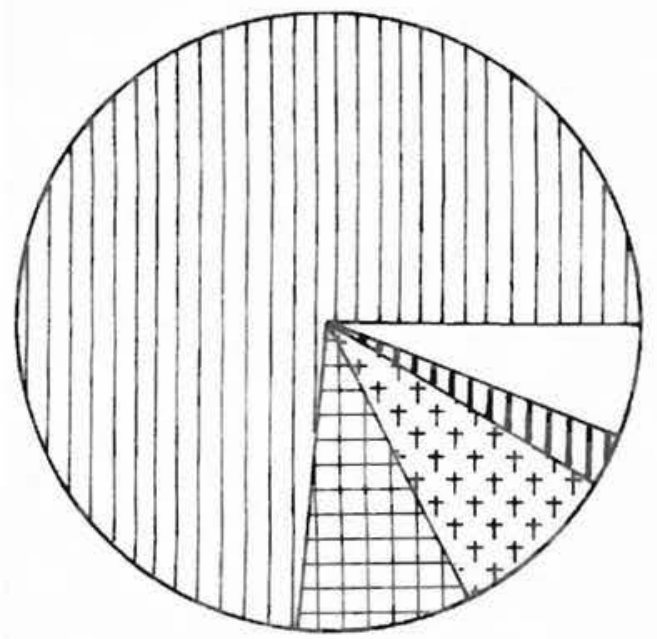

$v-1977$
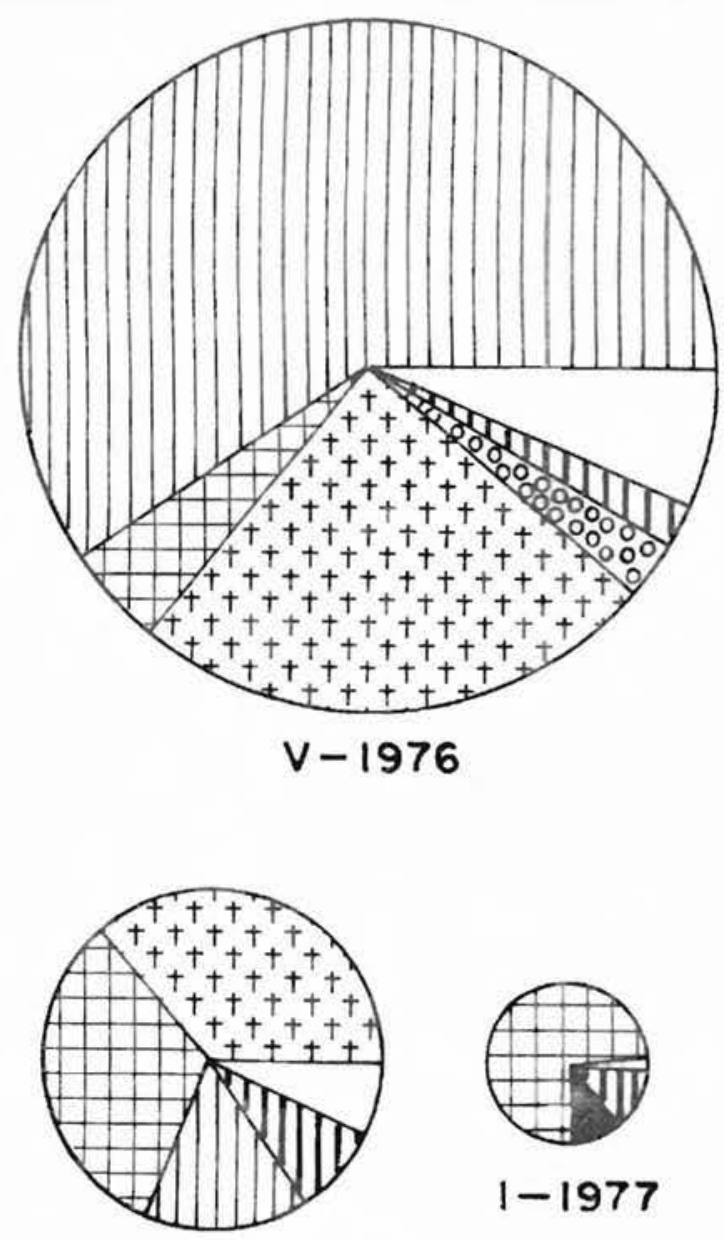

$0-1977$

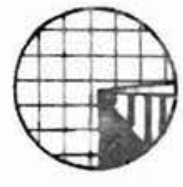

$1-1977$
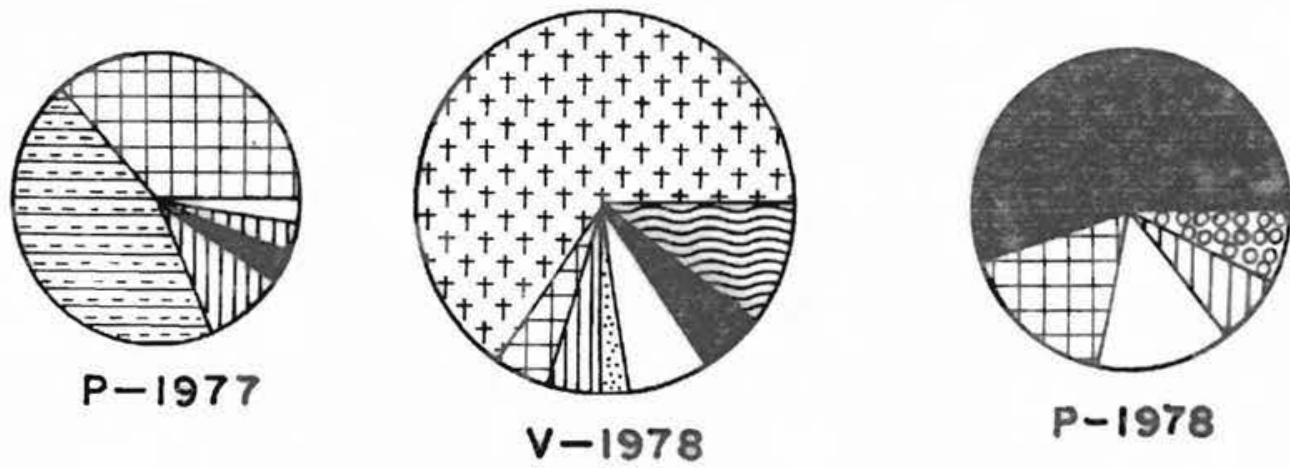

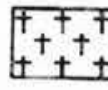

एक

ए1

M. furnieri

A. garmani

B. pectinata

Fis 29:

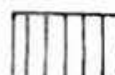

IIIII

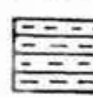

\section{L.grossidens}

Gobionellus sp

P. valenciennis

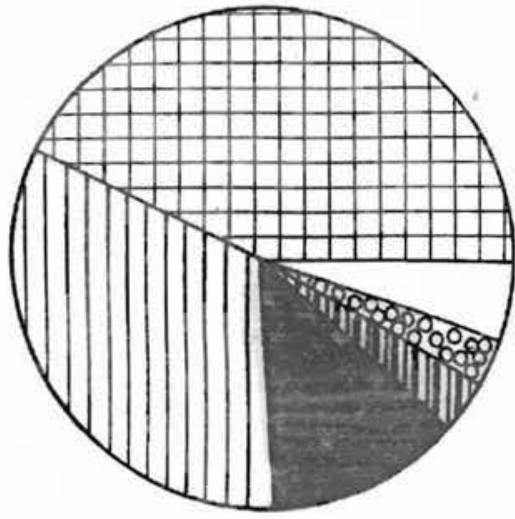

$0-1976$

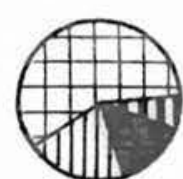

$1-1976$

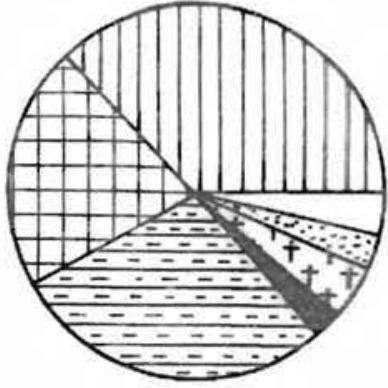

$P-1976$

\section{H. kronei}

\section{Atherinidoe}

000 0000

G. strumosus

Blennius sp

otros

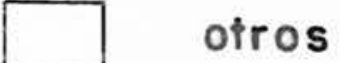

lat ladas: (escala: un círculo de $53 \mathrm{~mm}$ de diámetro representa 100 larvas). 
4 - ANALISIS INDIVIDUAL DE LA DISTRIBUCION TEMPORAL EN REIACION CON TIA SAIIINIDAD Y TEMPERATURA

En las Fig. 30, 31 y 32 se graficaron las temperaturas y salinidades de superficie correspondientes a las estaciones de cada crucero.

Se pueden observar en las mismas los valo res elevados de temperatura en verano y los bajos re gistros en invierno, su aumento en el transcurso de la primavera y su disminución a medida que avanza el otoño.

En relación con la salinidad se observa en la época invernal la predominancia de aguas oligo halinas como producto de un fuerte desague del estua rio producido por las intensas lluvias y vientos pro picios. En las tres épocas restantes se observan diversas condiciones: ya sea un intenso desague, una fuerte penetración de agua marina, y situaciones intermedias.

De modo general, se observó que el 53\% de las veces se registraron entradas de agua de origen marino, y el 47\%, condiciones de desague.

Por otro lado, las aguas estuarinas son más afectadas por los cambios estacionales de la tem peratura en comparación con el mar, debido a ser menos profundas y al aporte de aguas continentales. En consecuencia, en la primavera y en el verano las aguas de menor salinidad son las más cálidas, e inver samente, en otoño e invierno las más cálidas corresponden a las de origen marino. 


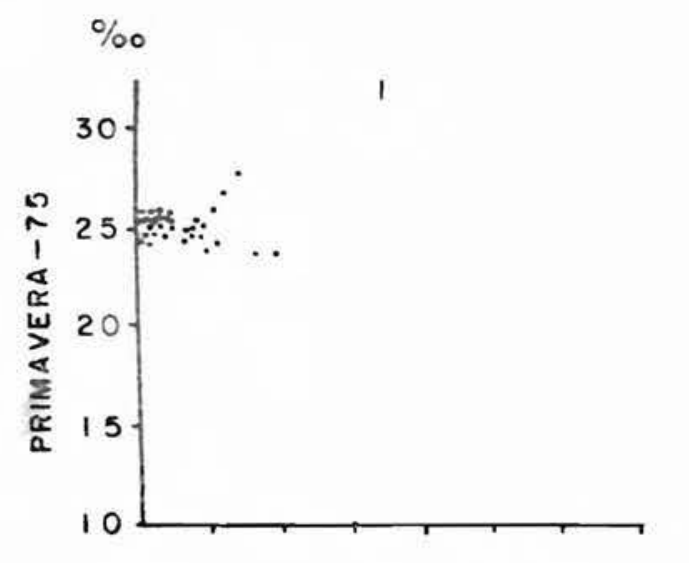

Fig. 30: Temperaturas y salinidades de superficie correspondientes a cada estación de los 8 primeros cri ceros.
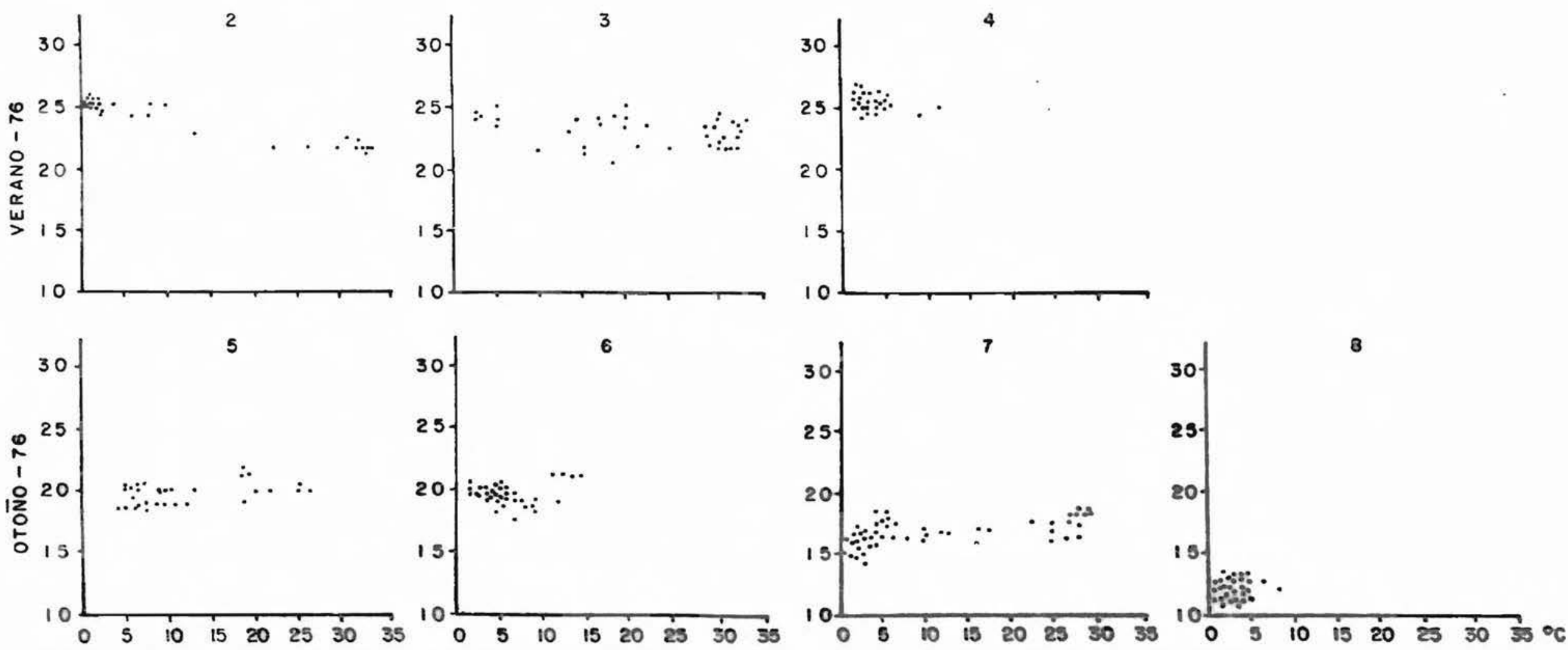


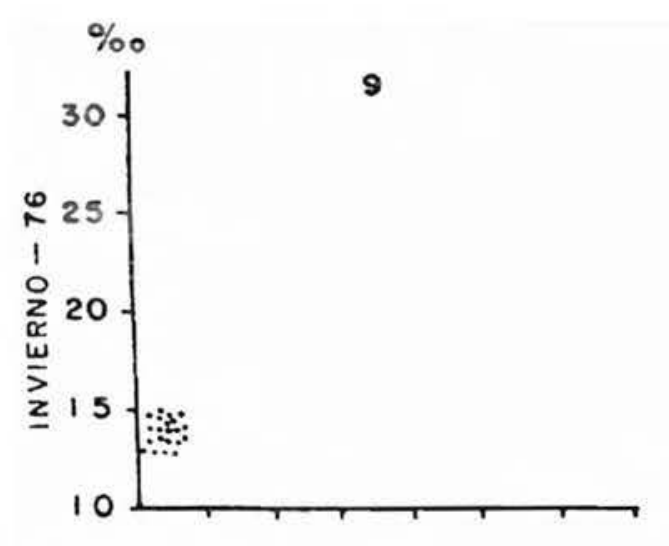

\section{Fif. 31: Jemperaturas y salinidades de superficie correspon-} dientes a cada estación del $9^{\circ}$ al $17^{\circ}$ ericero.
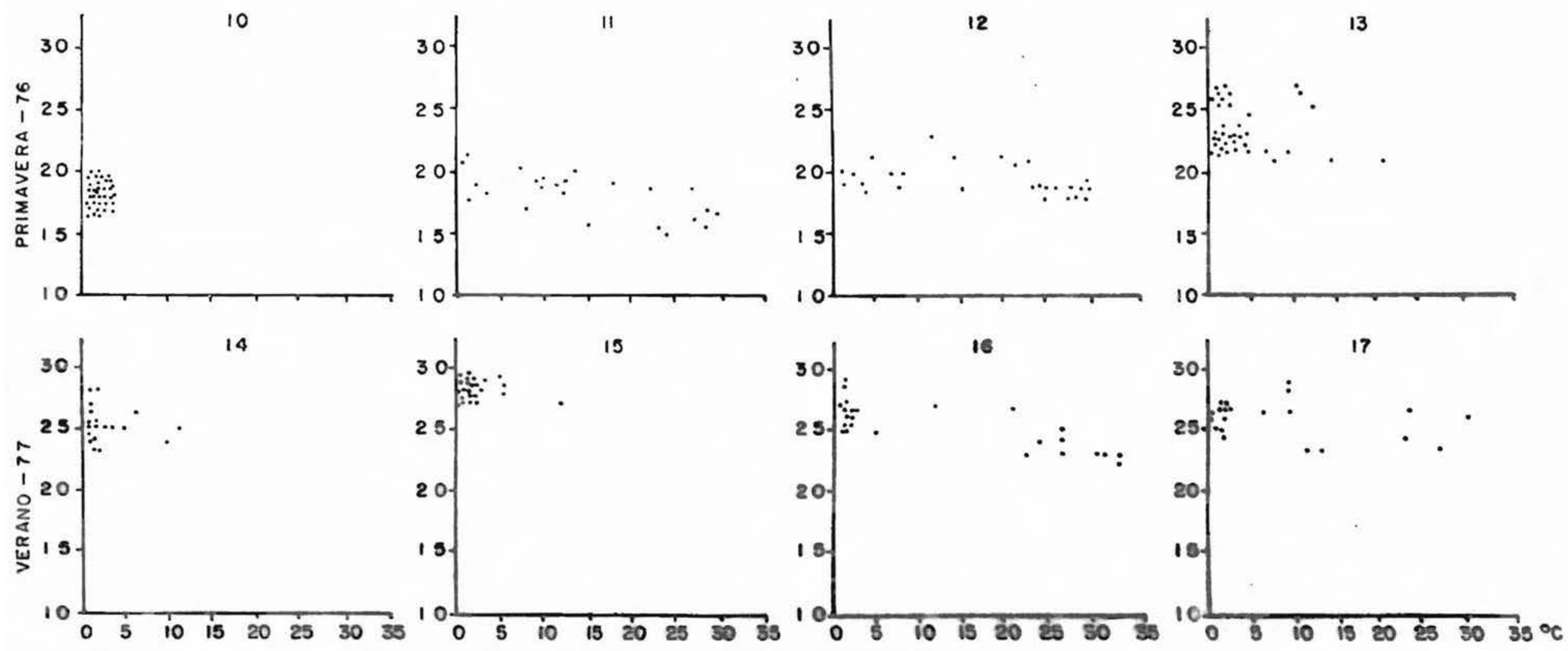
$4 a-$ BREVOORTIA PECTINA'IA

Si bien los huevos de $\underline{B}$. pectinata fueron escasos tuvieron relativa constancia. Se observó su ausencia en los cruceros de invierno y las primaveras de 1975 y 1977, donde se registraron salinidades mínimas ( Fig. 33). Los máximos registros de huevos ocurrieron en la primavera de 1976 y el verano de 1977 con densidades medias de 8,4 y 8,9 huevos/100m 3 respec tivamente ( Tabla 4), circunstancias en que estuvieron presentes en salinidades menores a 5\%o. Este hecho muestra que la ca pacidad eurihalina de esta especie es alta.

En relación con la temperatura se observa que las mayores densidades se presentaron en las aguas más frías en primavera y verano y en las más cálidas en otoño, por ser éstas las de origen marino. (Fig. 33).

Sus larvas ( Fig. 34), estuvieron presentes en to das las épocas del año y en número mucho mayor que los huevos. Sus mayores abundancias se registraron en primavera de 1975 , otoño de 1976 y primavera de 1977 ( T'abla 4).

A la inversa de lo que acontece con los huevos, mostraron en todos los casos una tendencia a distribuirse en a guas de menores salinidades, a pesar de que sus presencias en aguas de mayores salinidades son importantes. En cuanto a Ia temperatura, se observa una tendencia a aumentar su número en aguas más cálidas en primavera y verano y a disminuir en otoño e invierno.

En la Fig. 35 se presentan las distribuciones de frecuencias de los largos totales de las larvas capturadas en diferentes salinidades y diferentes épocas de 1976. En el vera no, otoño y primavera se observa el aumento del número y del tamaño de las larvas con la disminución de la salinidad. En in vierno solamente se registraron valores de salinidad menor a 5\%, observándose larvas desde $6 \mathrm{~mm}$ a más de $16 \mathrm{~mm}$.

A través de las observaciones realizadas se pueden obtener las siguientes conclusiones:

a) el desove de esta especie se realiza en aguas marinas, alejadas del área estuarial.

b) Las larvas penetran en el estuario en diferentes estadios de desarrollo y procuran aguas de menor salinidad, - sea las más internas.

c) el área de crecimiento de las larvas correspon de a aguas internas, oligohalinas, donde se registran los ejem plares de mayor tamaño ( Fig. 35). 
d) Ia presencia de huevos y larvas recién eclosionadas de 4 a $6 \mathrm{~mm}$ de largo, registradas en salinidades menores a 5\%o (Fig. 34), indican que la capacidad eurihalina del primer estado de vida de esta especie es alto. Esta observación indicaría que el hecho de que los desoves se realizen en aguas típicamente mari nas es inherente a la población adulta desovante, más que al desa rrollo embrionario y larval, que procisi de aguas oligohalinas.

e) Ia presencia de larvas de $6 \mathrm{~mm}$ de largo durante to do el año, indica un desove practicamente contínuo. A travéz del análisis de gónadas se constató la presencia de hembras en estado avanzado de madurez durante todo el año (Haimovici, comunicación personal).

Por los datos obtenidos, es posible que este desove tenga uno o dos picos de mayor intensidad, ya sea en primavera o primavera y otoño. Este hecho es difícil de comprobar en el estua rio, dada las condiciones ambientales inestables y su influencia en Ia penetración de los huevos y larvas.

Los antecedentes bibliográficos referentes a esta es pecie se reducen al hallazgo de huevos en el plancton en aguas de plataforma entre Ios 290 30' y 310 o0'S (Weiss et all, 1976), entre fines de octubre y noviembre de 1971. Según estas autores 1 a densidad numérica de huevos aumentó cn el mes de noviembre, siendo registrado el mayor número en aguas más cercanas a la costa.EI hecho apoyaría parte de las conclusiones obtenidas en este análisis, en cuanto a la presencia de un desove intenso en primavera y la tendencia de Ios adultos a concentrarse en aguas costeras, 10 . cual facilitaría la penetración de las larvas al estuario.

La otra especie presente en el Atlántico Sur es $\underline{B}$. aurea (Agassiz) 1892, que segun Reintjes(1969), podría ser junto a ésta, una única especie con variantes geográficas por estar toda vía imperfectamente estudiadas.

Ciechomski (1968) observó la presencia de huevos de B. aurea en el plancton costero frente a Mar del Plata en 1966, en el mes de octubre, noviembre y diciembre solamente. Cassia et all (1979) llegaron a una conclusión semejante estudiando la reproducción y fecundidad de esta especie.

Reintjes(1969) realizó una sinopsis biológica con B. tyrannus del Atlántico Norte, observando que los adultos desovan principalmente en el mar, bahias o estrechos y que sus lar vas migran a estuarios, donde se transforman en juveniles, perma neciendo allí por 6 u 8 meses. Ello indica que tendria un compor tamiento semejante a la especie aquí considerada. 


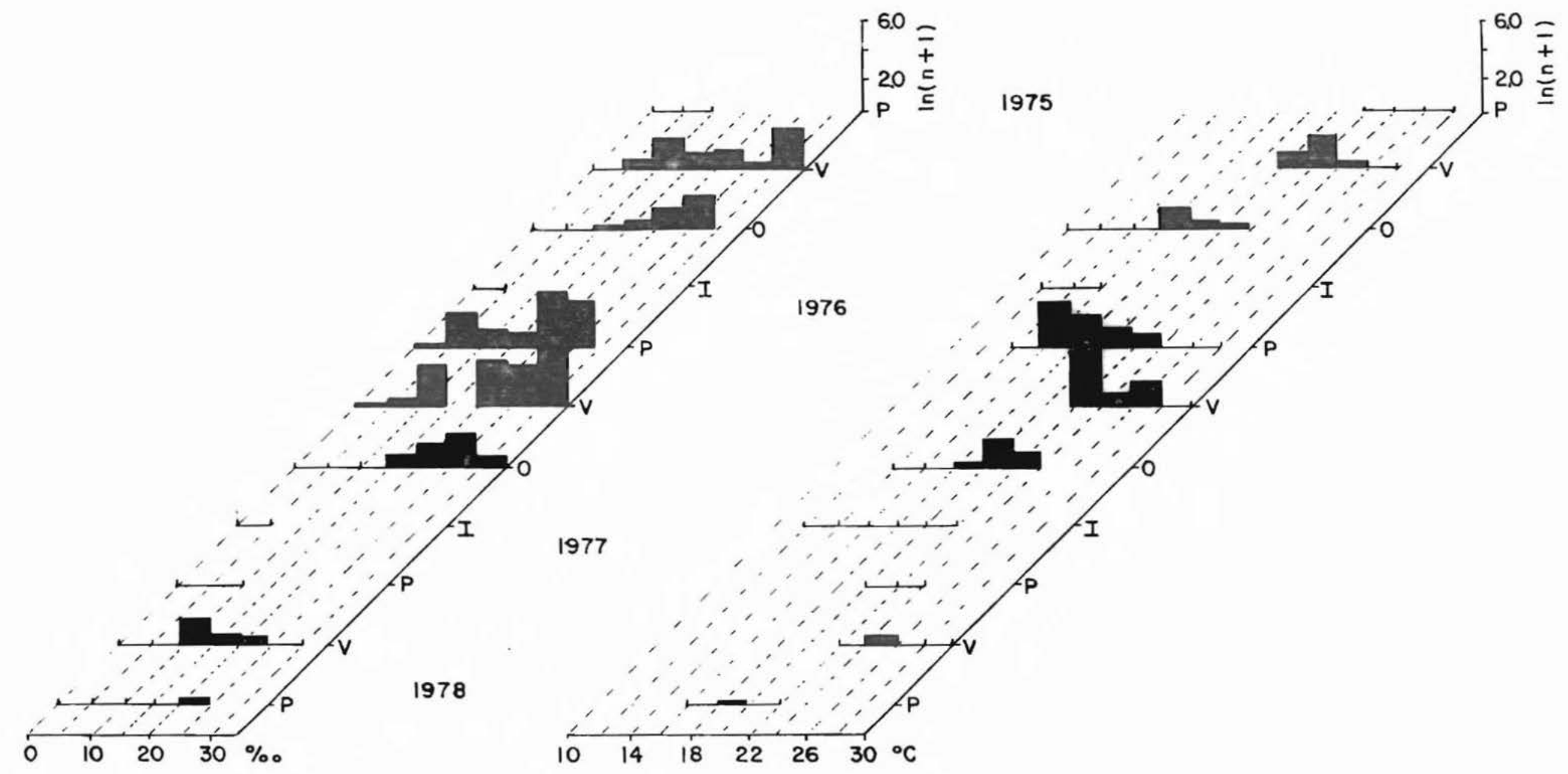

Fig. 33 : Distribución de huevos de $\underline{B}$. pectinata ( $n=n$ o de hurvos $/ 100 \mathrm{~m}^{3}$ ) para las diferentes salinidades y temperaturas en cada época. 


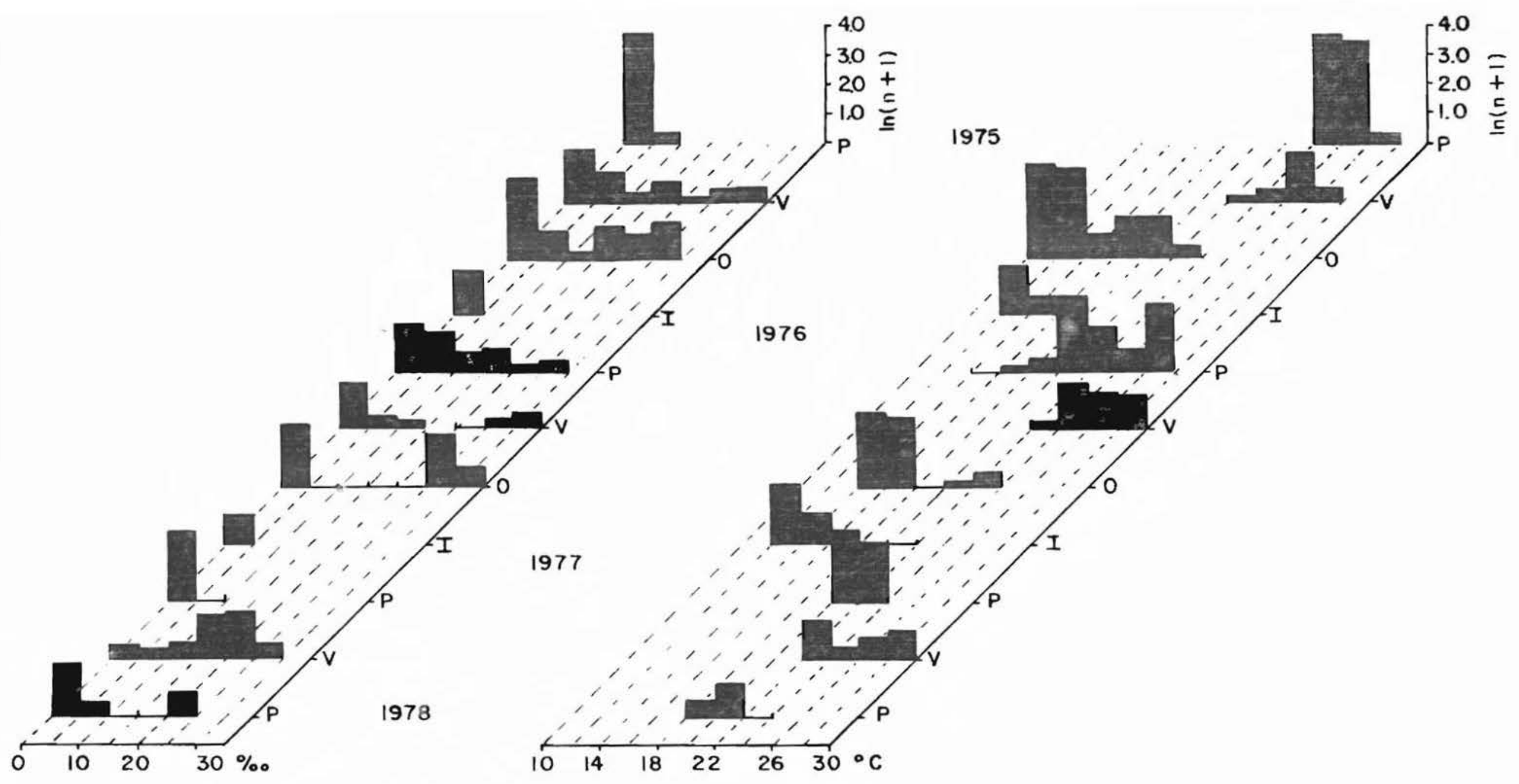

FiE. 34 : Distribución de larvas de $\underline{B} \cdot$ Dectinata $\left(n=n\right.$ o de larvos $/ 100 \mathrm{~m}^{3}$ ) para las diferentes salinidades y temperaturas en cada época. 

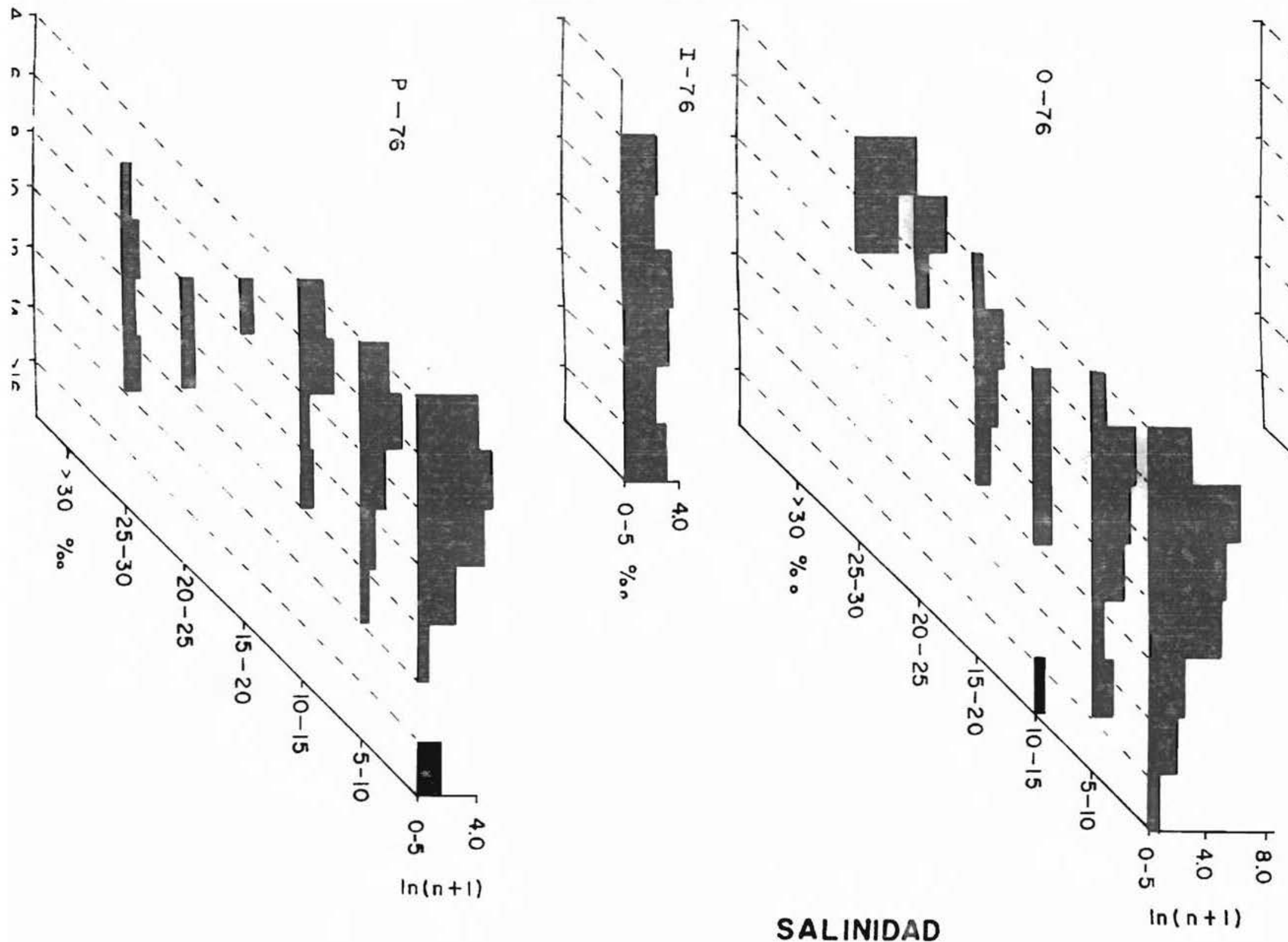

$<$
1
के

SALINIDAD

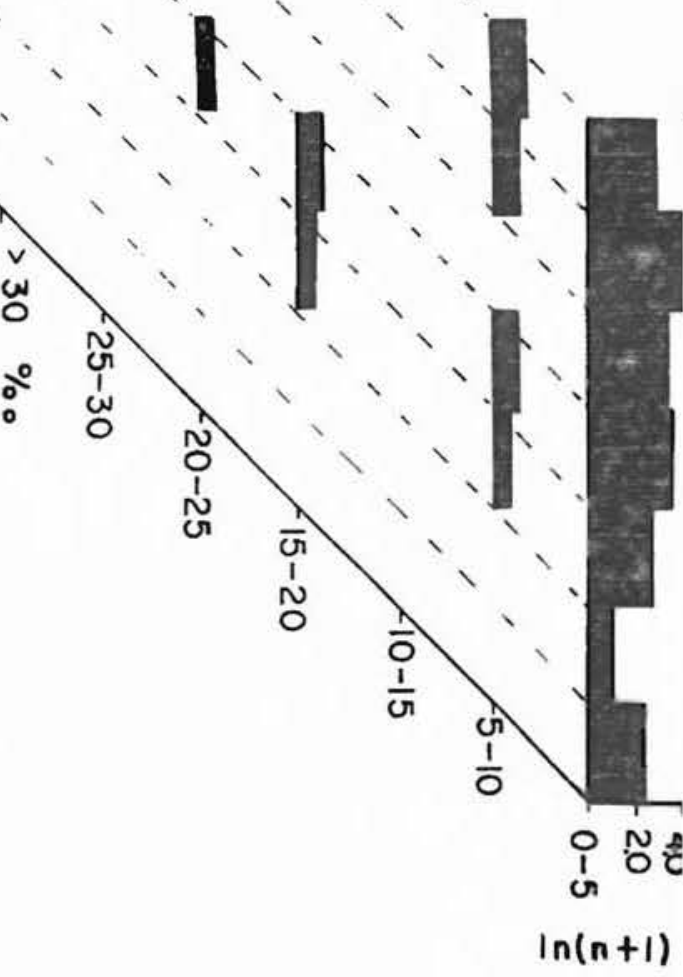

Fis. 35 : Distribución de frecuencias para larvas de B. pectinata

en las diferentes selinidades $\nabla$ épocas del año. 
4b - LYCENGRAULIS GROSSIDENS

Los huevos de $\underline{\text { }}$ grossidens estuvieron presentes en las muestras en solo 3 ocasiones: otoño y primavera de 1976 y otoño de 1977. El mayor registro ocurrió en la primavera de 1976, con una média de 32,2 huevos/100m ${ }^{3}, y$ el menor en otoño de 1977 , con sólo 0,3 huevos/100m ${ }^{3}$ (Tabla 4).

Las mayores abundancias se registraron en las aguas con mayores salinidades y temperaturas más frias en primavera y más cálidas en otoño, o sea que, siendo de origen marino, la especie presenta las mismas características que B. pectinata (Fig. 36).

Sus larvas estuvieron presentes en todo el año, y Ios mayores registros corresponden a la primavera y verano, y los menores en invierno. Estuvieron presentes en todos Ios rangos de salinidad $y$ en todas las épocas, con marcada tendencia a aumentar su número en aguas de menor salinidad (Fig. 36); esta tendencia se ve reflejada en presentar mayores registros en aguas más cálidas en primavera y verano y más frías en otoño e in vierno ( aguas dulceacuícolas).

Las distribuciones de frecuencias de los largos totales de las larvas capturadas en diferentes salinidades y épocas de 1976 están representadas en la Fig. 37. En todos los casos los mayores registros y mayores tamaños están en salinidades menores a 5\%o, a pesar de observarse algunas larvas de 13 a $15 \mathrm{~mm}$ en salinidades mayores.

Comparando esta especie con $\underline{B}$. pectinata se observa un comportamiento muy similar, por lo que, las conclusiones obte nidas son semejantes, con algunas pocas excepciones:

a) por la escasés de huevos en el canal de acceso y Ia abundancia y tamaño de las larvas al entrar al estuario, se dẹ duce que el desove ocurre en aguas alejadas del área estuarial.

Al respecto, análisis realizados por el Oceanólogo L. C. Krug (comunicación personal), indican que durante casi todo el año existen estadios de maduración y post-desovados; en ningún caso registró hembras en desove. Estos hechos reforzarían la suposición de que las hembras procurarían áreas alejadas para desovar.

b) al igual que B. pectinata; las larvas penetran al estuario y procuran aguas internas registrándose las mayores densidades numéricas y tamaños en aguas con menor salinidad; en esta especie la penetración se realiza en estadio de desarrollo más avanzado que la anteriormente mencionada. 
c) el area donde se realiza el crecimiento comprende aguas más internas del estuario.

in dos cruceros realizados en otoño y primavera en aguas internas entre Ilha da Feitoría y São Lourenzo, se obtuvie ron larvas de $\underline{B}$. pectinata y $\underline{\text { L }}$ grossidens. Las distr1buciones de frecuencias de largos totales se presentan en 1 a Fig. 38. Las salinidades registradas fueron siempre entre 0 a $5 \%$. Las dos es pecies presentaron caracteristicas iguales, registrándose todos los tamaños.

Weiss y Krug (1977) observaron un notable paralelis mo entre las dos especies, en cuanto a los habitats preferidos en las diferentes etapas de su vida larval y juvenil. También en ese mismo estudio observaron que la metamorfosis de L.grossidens concluye entre los 35 a $40 \mathrm{~mm}$ y en B. pectinata entre los 20 a $25 \mathrm{~mm}$, siendo en esta etapa en que dejarian sus hábitos planctóni cos. Ubservaron también que la presencia de Larvas de $\underline{B}$. pectina ta en el plancton se $\perp$ imita a ejemplares menores a $20-25 \mathrm{~mm}$ y dé I. grossidens a menores de $35-40 \mathrm{~mm}$. Posiblemente el mayor tiem po de vida planctónıca de esta última especie se traduzca en una aparente mayor abundancia.

d) La presencia de huevos y larvas de todos los tamaños en salinidades desde 34 " hasta $0 \%$, evidencia la alta capacidad eurihalina de esta especie.

e) Ia presencia continua de las larvas en todo el a ño indicaría también en este caso un desove prolongado, con la presencia de larvas de pequeño tamaño en todas las épocas, Inclu sive en invierno. La disminuclón del número de Larvas en invierno puede deberse a su difícil acceso por los flujos de agua, aun que una real disminución del desove puede tambièn ser la causa. Castello y Krug (1978), que realizaron un estudıo sobre los tipos de otolitos de esta especie, observaron 4 diferentes grupos de descendientes. Estos grupos corresponderian a 1) verano-principios de otoño, 2) fin de otoño-principios de in vierno, 3) fin de invierno y 4) primavera, indicando que existe un desove contínuo durante todo el año.

Estos resultados contradicen a los estudios realizados sobre esta especie por Fuster de Plaza y Boschi (1961) quienes indican los meses de octubre y noviembre como época de reproducción, y que ésta efectuaría una migración ascendente hacia el río de la Plata y los grandes tributarios de este sistema hidrográfico, para desovar. 


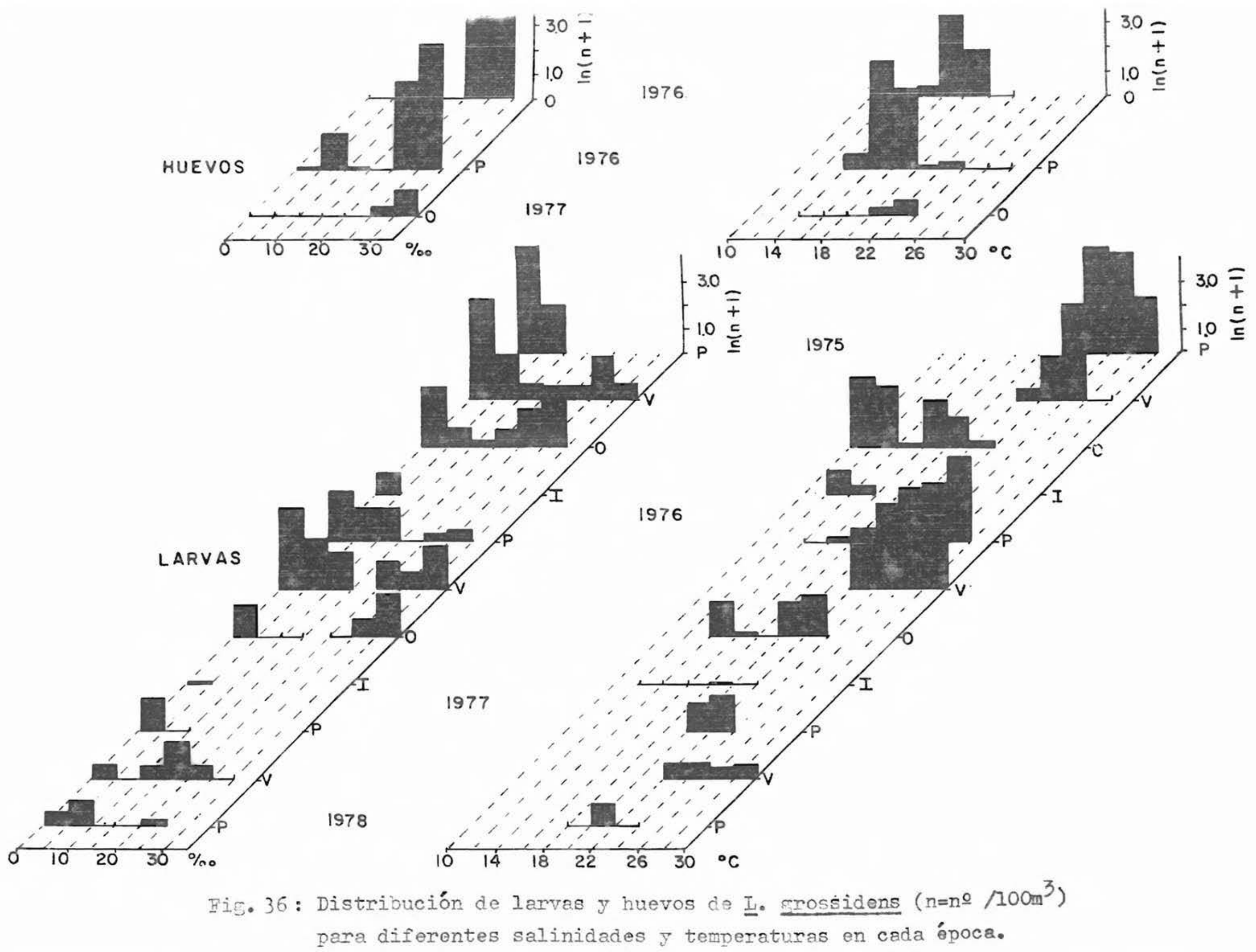



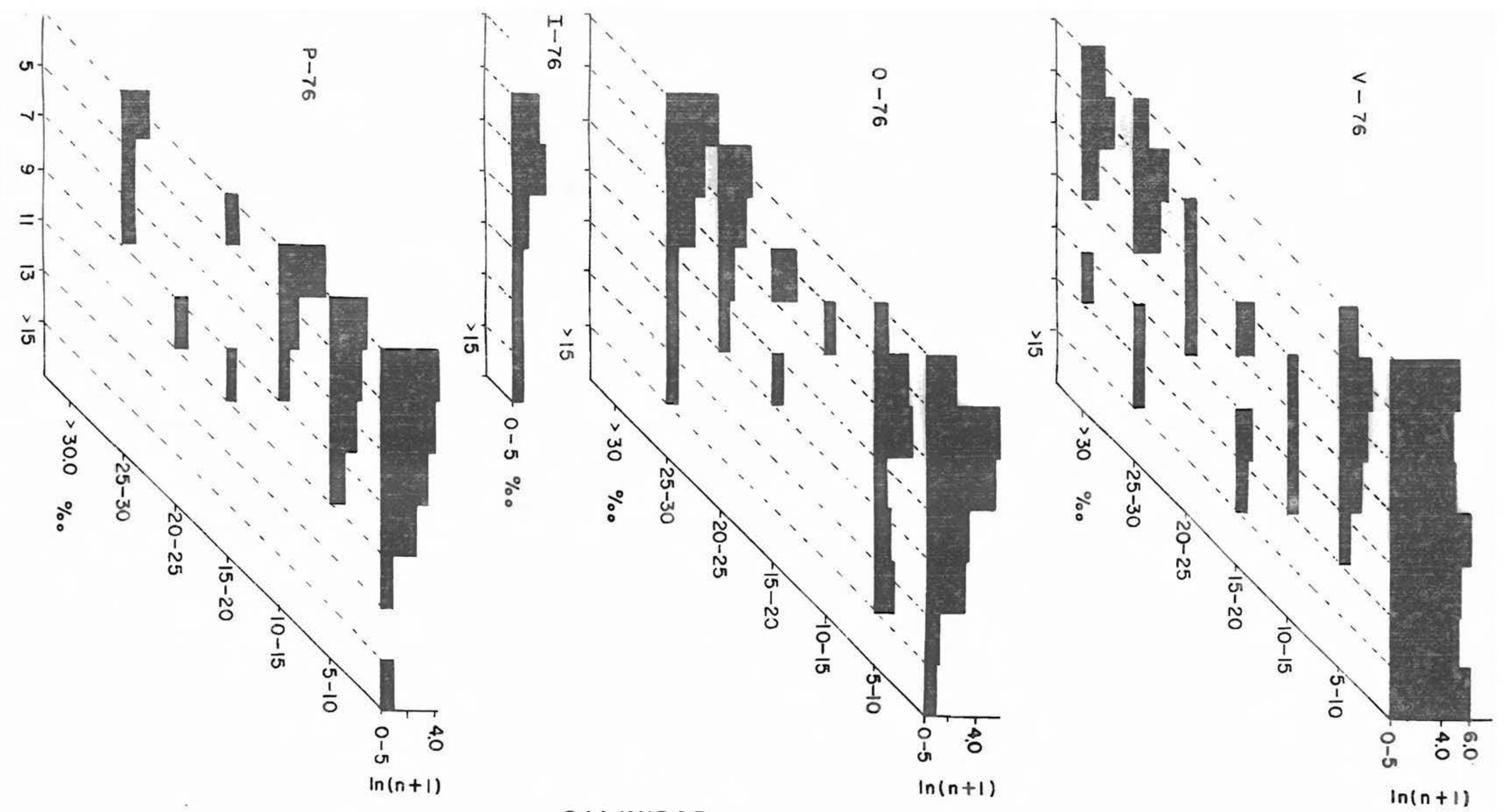

Fig. 37 : Distribución de frecuencias para larvas de I. Erossidens en las diperentes salinidades y épocas del año. 


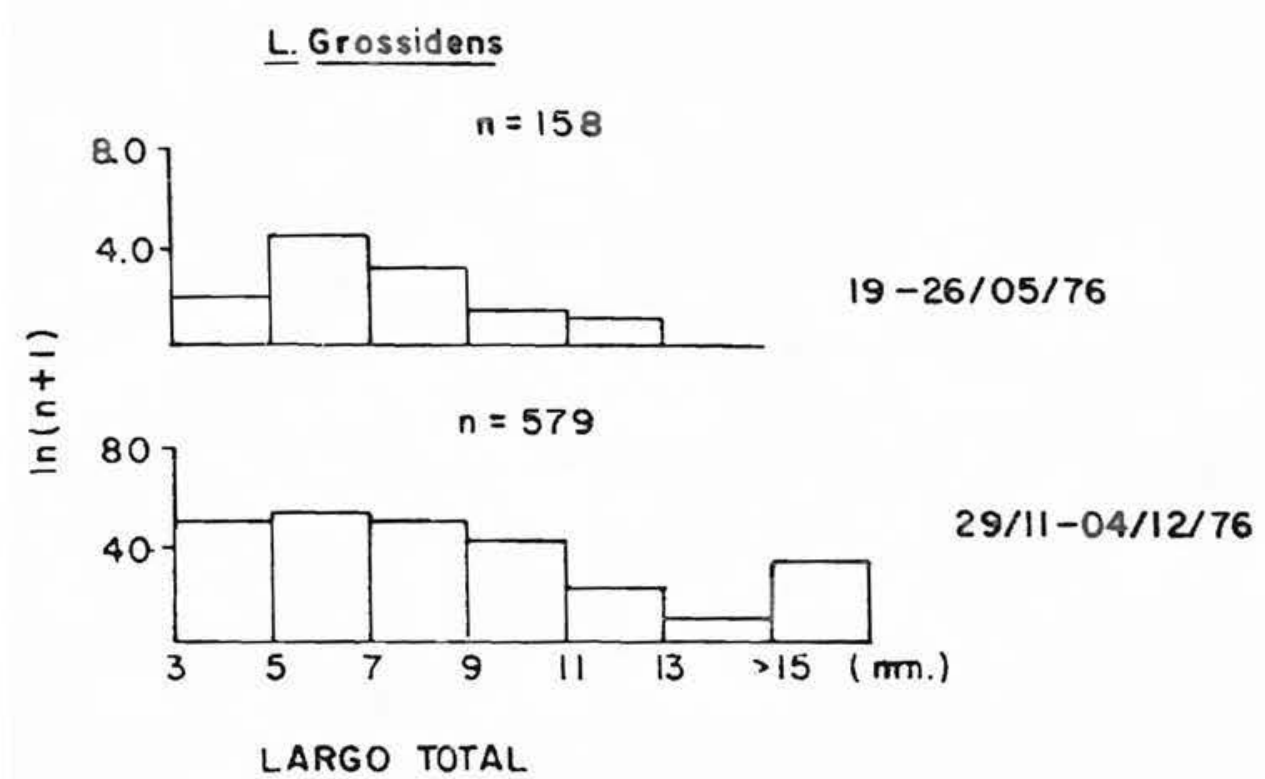

B. Pectinata

$n=180$

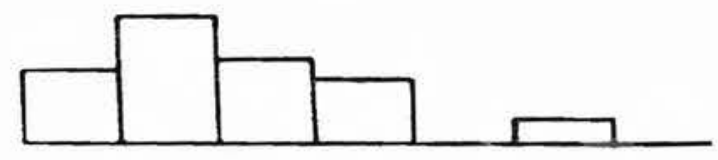

$n=165$

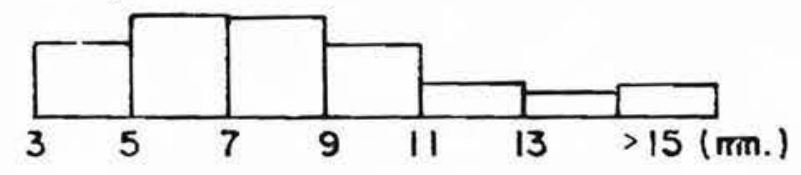

LARGO TOTAL

Fig. 38: Distribución de frecuencias de larvas de $\underline{\text { L. grossidens }}$ y $\underline{\text { B }}$ pectinata para el área comprendida entre Ilha da Feitoría y São Lourenço. 
Sus larvas se presentaron en todas las ocasiones en aguas oligohalinas, generalmente en momentos en que se producía la descarga del estuario, llegando en algunos casos a presentarse en el canal de acceso. Ello indicaba que eran arrastradas de su lugar de origen por la fuerte co rriente. En todos los casos sus tamaños no pasaban de los $20 \mathrm{~mm}$, o sea que su capacidad nadadora para vencer la corrien te era reducida.

La presencia de estas Iarvas se registró principalmente en primavera y verano y, en el invierno de 1976, con una média de 0,1 larvas/100m ${ }^{3}$, con ejemplares de $5 \mathrm{~mm}$ de largo total. Las mayores abundancias se registraron en las primaveras, con un máximo de 1.2,7 larvas/100m ${ }^{3}$ en 1977 (Tabla 4 ).

Por ser de origen dulceacuícola, sus mayores registros ocurrieron en las salinidades mínimas ( Fig. 39). En relación a la temperatura se observa que en primavera ocuparon casi todos los rangos registrados en cada época. En verano presentaron preferencia por aguas más cálidas y de forma inversa en invierno.

Según Ringuelet et all. (1967) el "bagarito o porteñito" es de régimen planctívoro, se reproduce a fin de la primavera y vive en ambientes lagunares. Aparentemente, es una especie con una neta dominancia numérica entre los bagres lagunares en Argentina. Estas observaciones corresponden con este estudio, ya que se presentó siempre en aguas oligohalinas y sus mayores abundancias se registraron en primavera, siendo que las observaciones para verano e invier no fueron minimas.

Observaciones realizadas por Candia et all. (1968), indicaron una relación de hembras y machos de 2 a 1 , siendo el porcentaje de hembras maduras en la época de deso ve del 90\%; ello hace que esta especie se constituya una verdadera plaga para la pesca profesional en el área de la costa del Rio de la Plata. Observaron también en el período de desove una migración a aguas más profundas en las zonas de Punta Lara, Boca Cerrada y Magdalena. La baja densidad de larvas obtenidas en el presente estudio se debe a ser és ta un área típicamente estuarina, y es muý posible que en a guas mas internas su número aumente. 


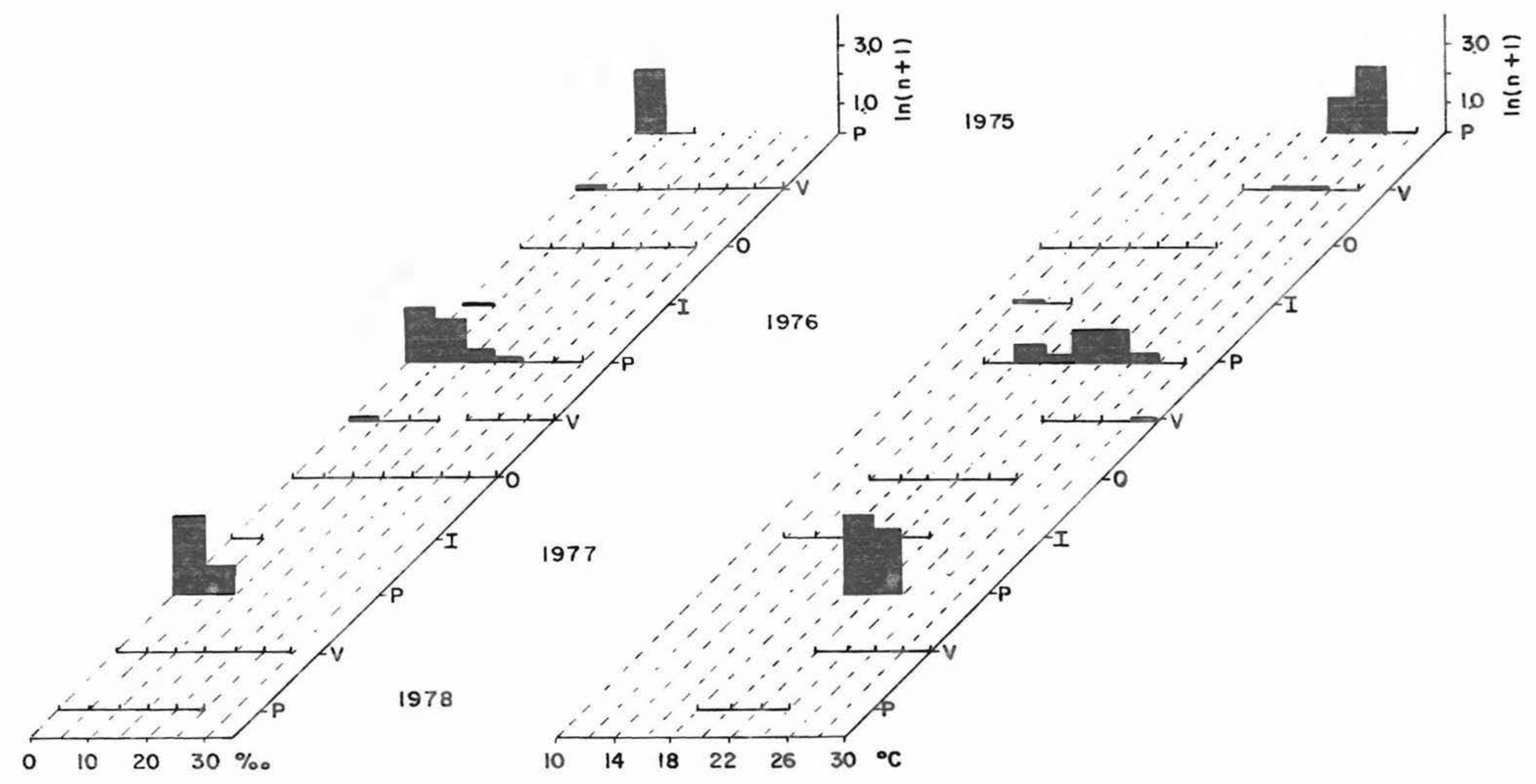

Ziff. 39: Distrihución de larvas de $\underline{P}$. valenciennis ( $n=n$ o de larvas/100m ${ }^{3}$ ) pera las diferentes selinidades y temperaturas en cada época. 
Las larvas de esta especie estuvieron presentes en primavera, verano y otoño en reducido número; la mayor densidad se registró en el verano de 1978 con 2,21ar vas/100m ${ }^{3}$ estando éstas en las salinidades y temperaturas mínimas registradas para ese perídodo, de $0 \%$ a $5 \%$ y $220 \mathrm{C}$ a 24으 respectivamente ( Fig. 40).

En todos los casos hubo registros de larvas en las salinidades minimas. En el otoño de 1976 se presentaron en salinidades de 20 a $25 \%$ y en el verano del mismo año en salinidades mayores a $30 \%$. Por presentar una distribución un tanto aleatoria en relación a aguas de origen marino o dulceacuícola, no se observó ninguna preferencia por temperaturas determinadas.

Según la bibliografĺa existente, las especies pertenecientes a esta Faminia producen huevos pelágicos y demersales. La especie Hyporhamphus unifasciatus del Atlán tico Norte tiene huevos de un dímetro medio de 2,0mm, transparentes, sin gota de aceite y con varios filamentos muy largos en el corion (Hildebrand y Schroeder, 1928). Es tos filamentos sirven para unirse entre ellos y a las plan tas acuáticas quedando, según este autor, en una posición semiflotante. Los desoves ocurren en aguas rasas entre la vegetación. Según Dovel (1971), sus larvas fueron encontra das en salinidades de 0 a 12\%o. Breder y Rosen ( 1966) y Schwartz (1962), registraron el desove de esta especie en la época de verano en la Bahía de Chesapeake.

De acuerdo con los resultados obtenidos en el presente estudio, el verano es la época más importante para su reproducción, a pesar de que su período de desove se extiende desde la primavera hasta el otoño. 


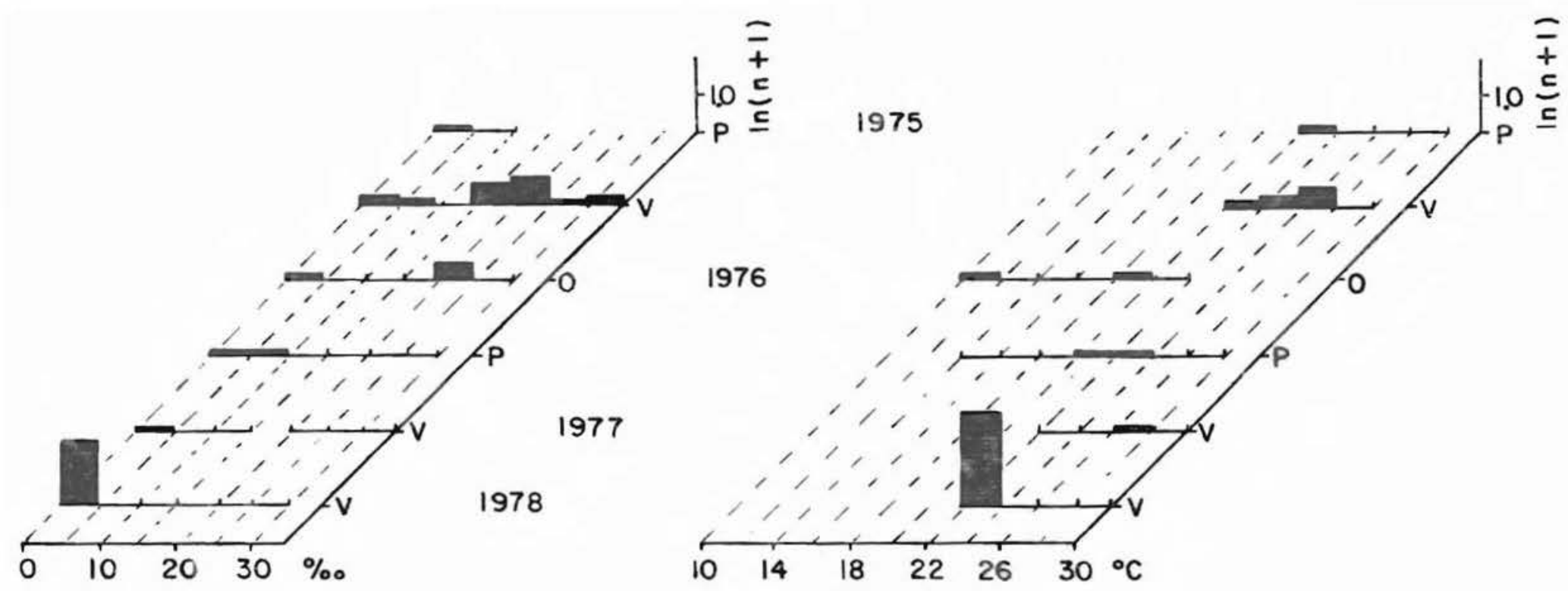

Fif. 40 : Distribución de larvas de H. kronei ( $n=n$ e de lervas / 100m ${ }^{3}$ ) para las diferentes salinidades $y$ temperaturas en cada época. 


\section{$4 e-$ ATHERINIDAE}

Lo peces pertenecientes a la Familia Atherinidae son pequeños y habitan tanto en agua dulce como salobres o costeras. Su taxonomía, en América del Sur, no fue todavía estudiada suficientemente, por 10 que se realiza aquí una breve descripción acerca de su presencia y características en relación con la salinidad y temperatura.

Sus larvas estuvieron presentes en todas las épocas del año, sin excepción. Los mayores registros se observaron en la primavera de 1978 con 9,4 larvas/100m ${ }^{3}$ y en la primavera de $1975 \mathrm{con} 4,1$ larvas/100m ${ }^{3}$, en las restantes épocas del año sus densidades fueron bastante meno res ( Fig. 41, Tabla 4).

El mayor número siempre se registró en aguas de salinidades mínimas a pesar de presentarse un número mínimo de individuos en salinidades mayores de 30\%o. In cuanto a la temperatura sus preferencias no son muy definidas, observándose en algunas épocas mayor número en aguas cálidas y en otras a la inversa.

Al desconocerse la identidad taxonómica de las especies aqui consideradas es imposible obtentr cualquier conclusión. En el caso de ser una única especie ésta tendría una alta capacidad eurihalina, pero en el caso contrario los resultados estarían enmascarados. Es eviden te que ésta o éstas especies utilizan el estuario en una fase temprana de su vida dado su contínua presencia en to das las épocas del año. 


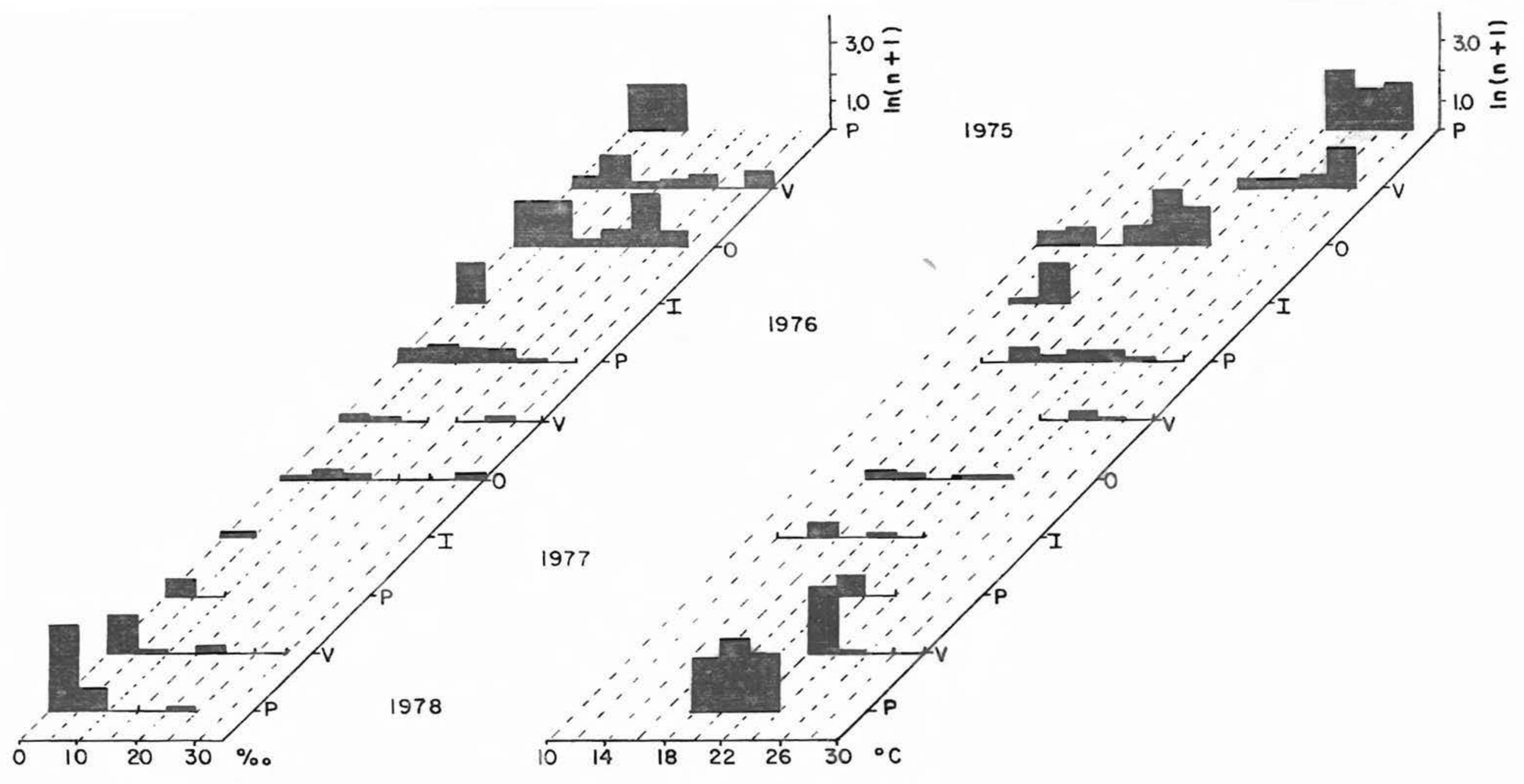

Fin: 41 : Distribución de larvas de Atherinidae ( $n=n$ o de larvas / 100 $\mathrm{m}^{3}$ ) para las diferentes salinidades y temperaturas en cada época. 
$4 f$ - SYNGNATHUS FOILETTI

Las larvas y juveniles de $\underline{S}$. folletti se presentaron de forma constante en las muestras de planc ton, faltando solamente en el invierno de 1976 y en la primavera de 1977. Estuvieron presentes en número reducido, obteniéndose la media máxima para el área de 1,1 larvas/100m en Ia primavera de 1978 (Tabla 4). Mostraron en general una capacidad eurihalina y euritérmica alta ( Fig. 42), no observándose preferencia por cualquier gradiente de estos parámetros. Por la alta constancia de las larvas y juveniles presentes se deduce que el período reproductivo es largo.

Según citan Figuereido y Menezes (1980),

esta especie es muy común en el sur de Brasil y abundan te en las costas de Rio Grande do Sul, en profundidades de 10 a $30 \mathrm{~m}$. Señalan también, que soportaría gran varia ción de la salinidad, dado el registro de capturas efeç tuadas en la desembocadura del Rio de la Plata. El examen bibliográfico leveló ausencia de datos sobre esta especie, y debido a la escasa información obtenida en este estudio, se torna difícil obtener conclusiones acerca de sus hábitos reproductivos, más si se tiene en cuenta la incubación paterna durante la primera etapa de vida. 


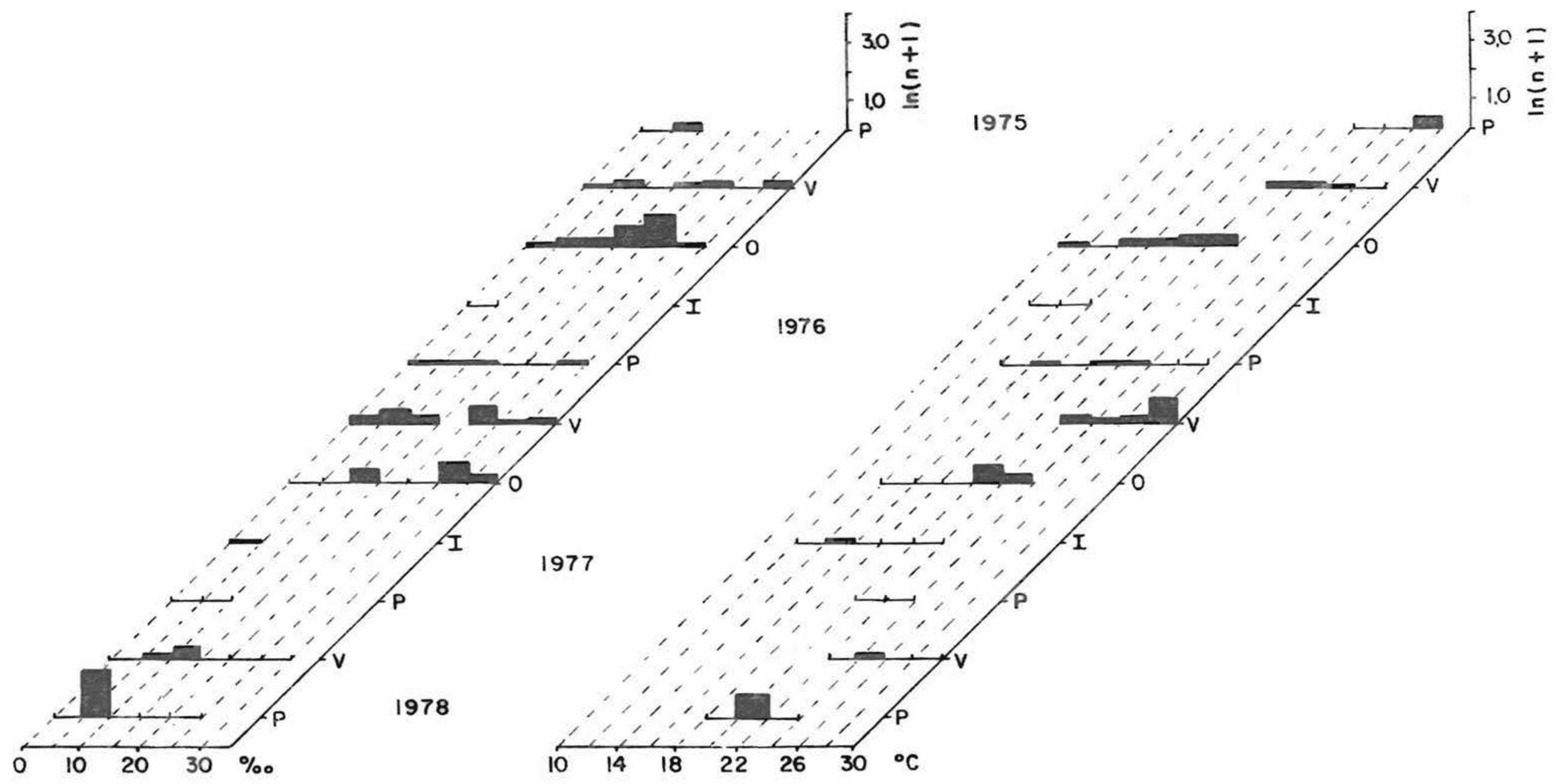

Fig. 42: Distribución de larvas de $\underline{\text { S }}$ folletti ( $n=n=$ de larvas/100m ${ }^{3}$ ) para las diferentes salinidades y temperaturas en cada época. 
Los huevos de esta especie fueron los más abundantes, presentes en elevado nûmero en todas las épocas, a excep ción del invierno. El mayor registro se observó en el verano de 1976 con una media de 935,7 huevos/100m ${ }^{3}$ (Tabla 4). Sus larvas que, por el contrario no fueron las más abundantes ni las más constantes, esturiẹcon ausentes en el invierno y en la primavera de 1978. Los mayores registros se obtuvieron en verano de 1978 , con una media de 13,7 larvas/100m ${ }^{3}$ y en el ve rano de 1976 con 12,7 larvas/100m ${ }^{3}$.

Los huevos presentaron sus mayores densidades numé ricas en aguas de alta salinidad a pesar de caracterizarse por una alta capacidad eurihalina. En las primaveras y veranos se presentaron en mayor número en aguas más frias y en otoño en aguas más cálidas, todas ellas de origen marino (Fig. 43).

Sus larvas, a pesar de ser menos abundantes, mostraron la misma tendencia en su distribución que los huevos, mostrando también una alta capacidad eurihalina ( Fig. 44).

La especie del Atlántico Norte, Micropogon undulatus, desova en una ampiia área de aguas costeras ( Hildebrand y Cable, 1930; Bearden, 1964; Pearson,1929; Wallace, 1940). Al sur de Cape Hatteras el desove ocurre desde setiembre a marzo ( Hildebrand y Cable, 1930; Pearson, 1929. etc) a veces se extiende hasta mayo ( Ilildebrand y cable, 1930) o junio (Parker, 1971). Al norte de Cape Hatteras generalmente desova entre agosto y diciembre (Wallace, 1940; White y Chittenden, 1976; Pearson, 1941). La larva pasa los primeros estadios en el mar, entrando a estuarios con 8 a $15 \mathrm{~mm}$ de longitud (Bearden, 1964). Las larvas y juveniles están en salinidades de 0 a 21\% y temperaturas de 0 a $240 \mathrm{C}$ en Bahía de Chesapeake (Dovel, 1971).

Lras grandes densidades de huevos en el área en estudio indica que los adultos desovantes están en aguas muy próximas o en el propio canal cuando las condiciones lo permi ten. El bajo registro de larvas está dado posiblemente por su corto periodo de vida planctonica. Se desconoce el comportamiento de esta especie en el mar, pero es evidente por los registros obtenidos en este estudio que el perîodo de desove del adulto y la capacidad curihalina de los huevos y larvas de M. furnieri son mayores que en la especie de hemisferio norte. 


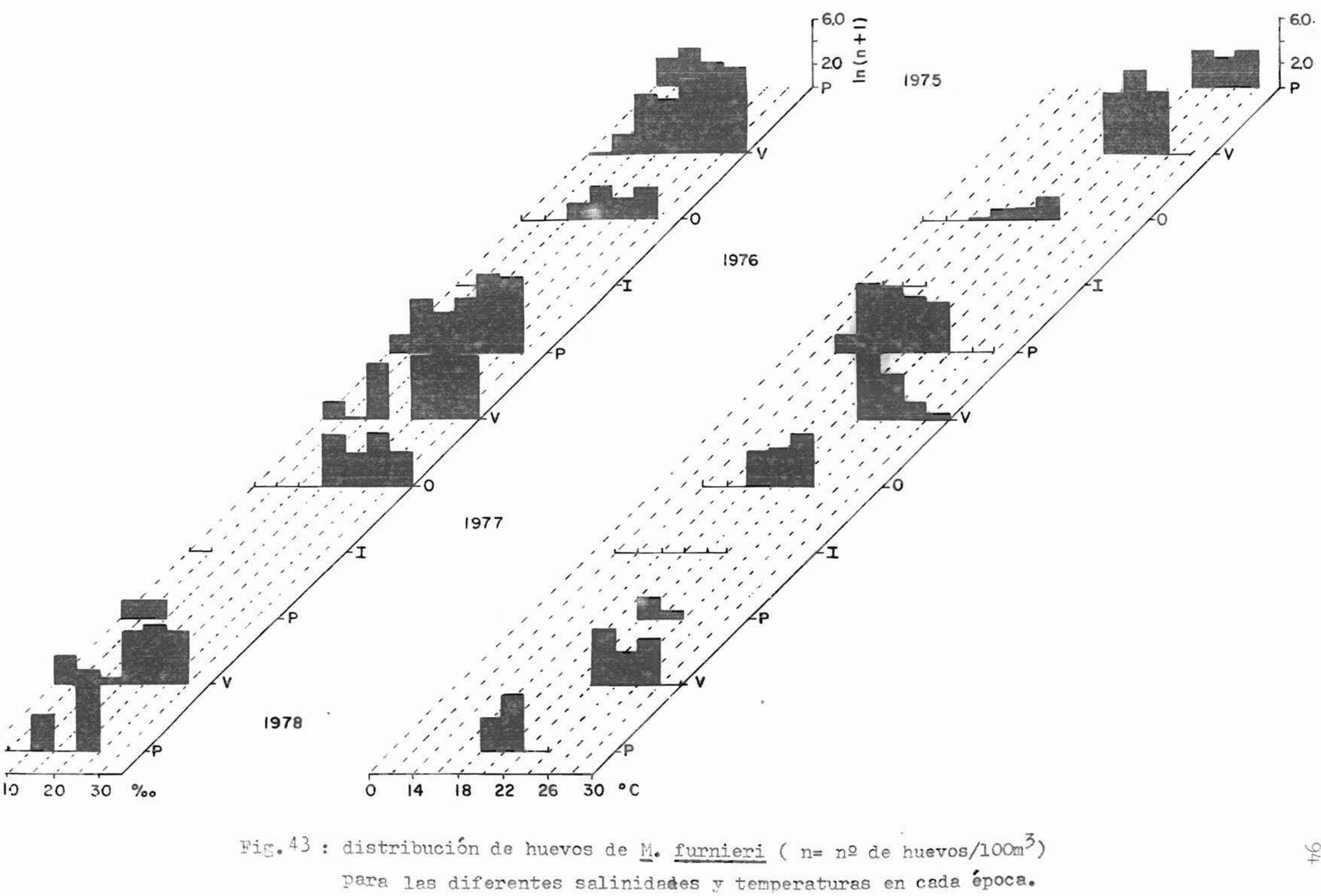




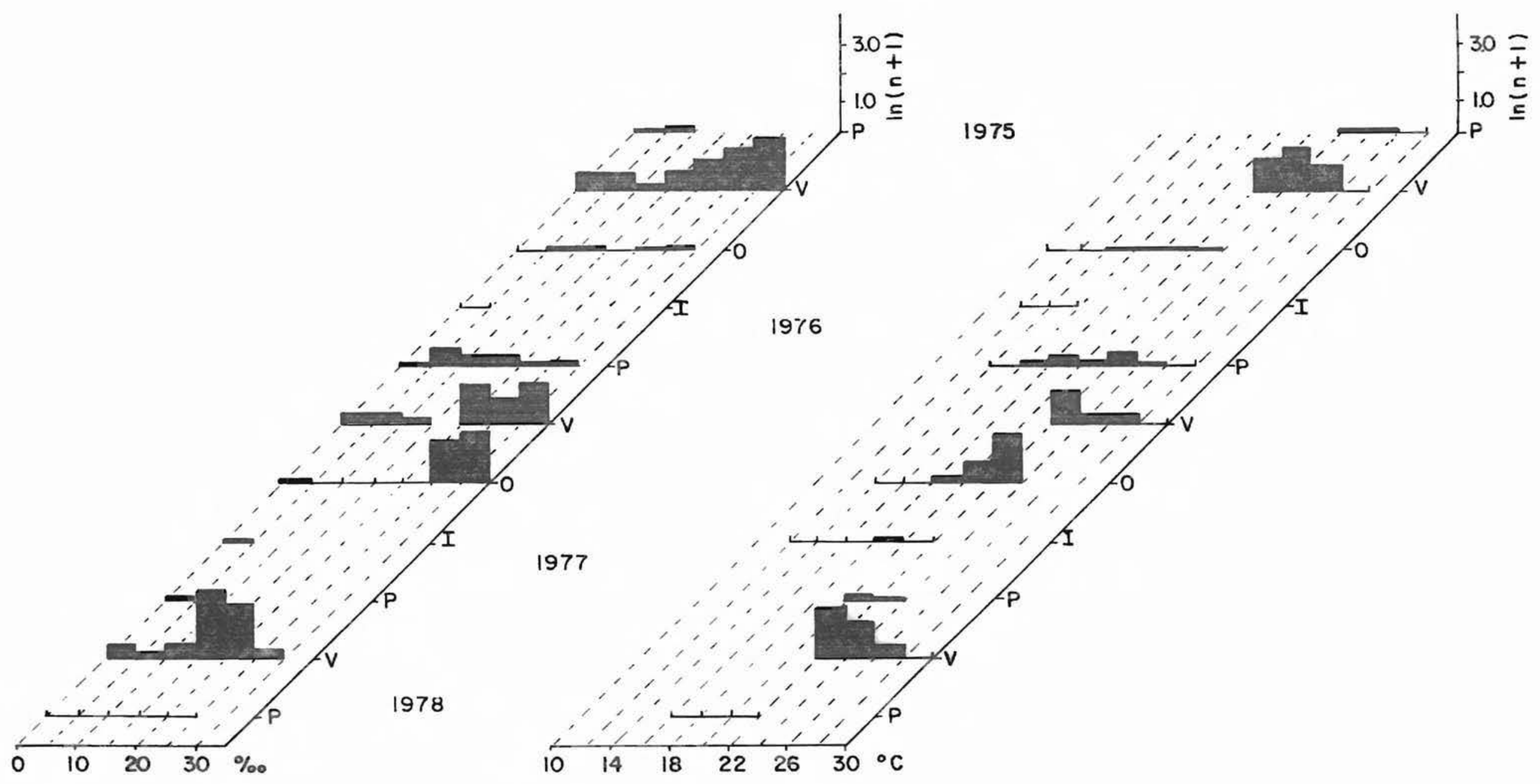

Fig. 44 : Distribución de larvas de M. furnieri ( $n=n$ o de larvas/100m ${ }^{3}$ ) para las diferentes salinidades y temperaturas en cada época. 
Sus larvas fueron encontradas constantemente en las muestras de plancton, estando ausentes en los in viernos y las primaveras de 1975 y 1978. Se presentaron en densidades minimas, observándose el máximo para el â rea, en el otoño de 1976 con 0,7 larvas/100m 3 (Tabla 4 ). A pesar de ser eurihalinas, en todos los casos mostraron preferencias por aguas de mayor salinidad, llegando a es tar presentes en salinidades de 0 a $5 \%$ en el verano, otoño y primavera de 1976. Por presentar mayor número en aguas de origen marino fueron más abundantes en aguas de bajas temperaturas en verano y primavera, y en aguas más templadas on otoño (Tiß. 45).

Dado que no fueron identificadas a nivel de especie, se desconoce si las larvas corresponden a una o más; no obstante ello se aprecia su preferencia por águas de origen marino.

La bibliografia referente a la Familia Blennii dae, (Randall, 1968; Hildebrand y Schroeder, 1928; Cervigon, 1966; Tavolga, 1954, Briggs, 1974, etc.) indica que son peces marinos de aguas tropicales y habitan nive les de poca profundidad. Algunas especies se presentan en aguas templadas, y otras entran en estuarios y llegan a agua dulce. Muchas especies depositan los huevos en valvas de moluscos, y otras los guardan en lugares protegidos y los cuidan hasta su eclosion. En el presente estudio no se obtuvo ninguna evidencia sobre los hábitos reproductivos de este género. 


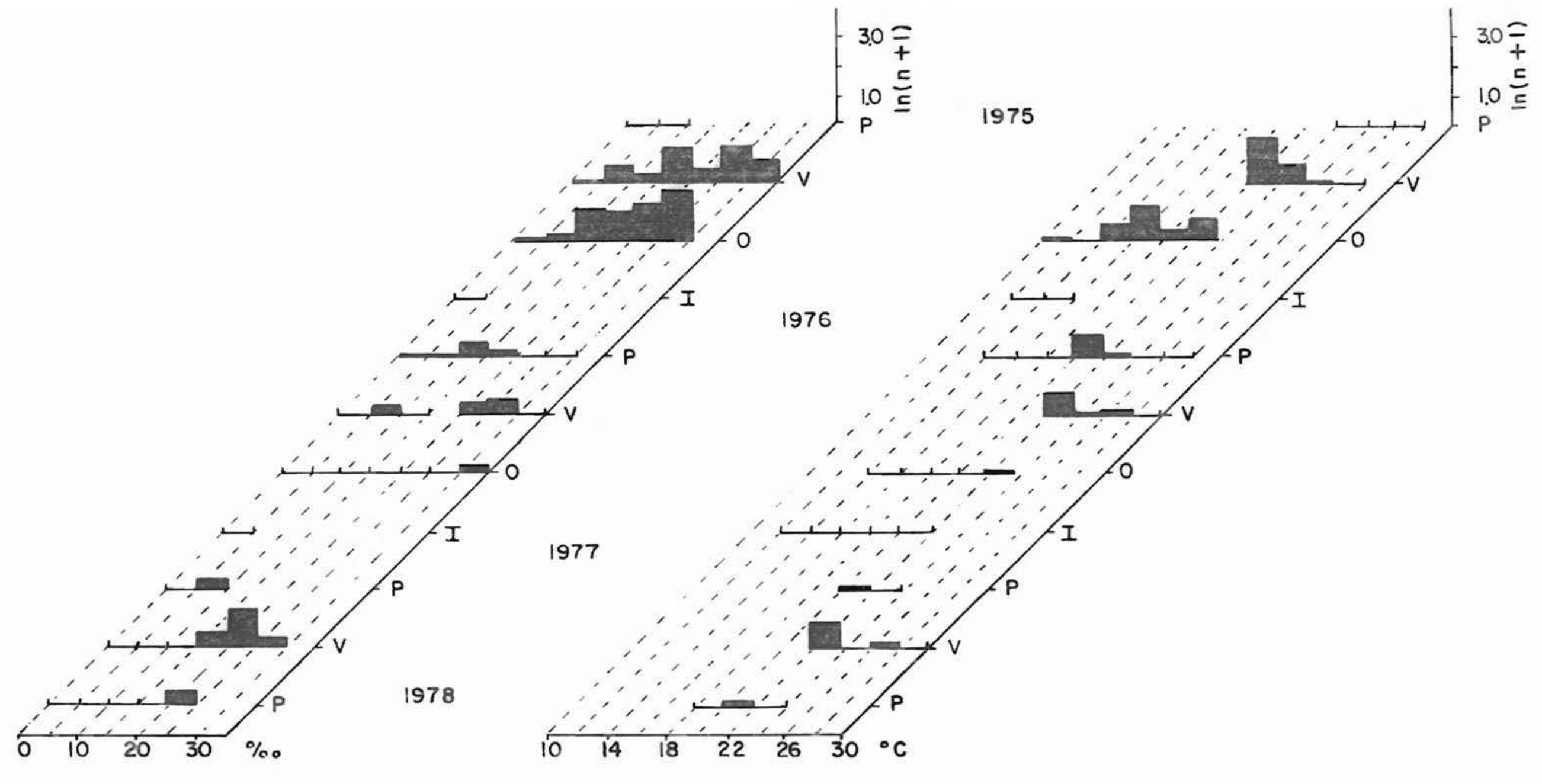

Fig. 45 : Distribución de larvas de Blenius sp. ( $n=n$ o de larvas $\left./ 100 \mathrm{~m}^{3}\right)$ para las diferentes salinidades $\mathrm{y}$ temperatures en cada época. 
Los huevos de esta especie se presentaron en densidades pequeñas y en pocas ocasiones. El mayor regis tro sc observó on el verano de 1976 con una media de 2 huevos $/ 100 \mathrm{~m}^{3}$. Se presentaron en algunas primaveras, vera nos $\mathrm{y}$ otoños de los diferentes años, indicando un prolon gado período de desove ( Tabla 4).

Ia menor salinidad registrada con huevos de esta especie fue de 20,0\% , aumentando su número con el de ésta. En lo referente a temperatura, acompaña las aguas de origen marino, siendo mínimas en verano y primavera y altas en otoño (Fig. 46).

Los menores registros de larvas fueron ( 0,1 larvas/100m ${ }^{3}$ ) en el verano y primavera de 1976 y verano y otoño de 1977. Los mayores registros se observaron en aguas de salinidades elevadas ( mayores a 20\%o) con una única excepción en salinidades de 5 a $10 \%$ (Fig. 47). En cuanto a la temperatura se observa el mismo comportamien to que los huevos. Este hecho se debe a que las larvas eran pequeñas ( menores a $10 \mathrm{~mm}$ ) y se presentaron en las mismas muestras que los huevos.

EI hecho de que los huevos y larvas de esta especie esten siempre presentes en aguas de alta salinidad indicaria una capacidad eurihalina limitada. Por otro lado, si se tiene en consideración la falta de larvas de mayor tamaño, se deduciría que $\underline{\text { T. }}$ lepturus no utiliza el cstuario como árca de cría, sino que sus huevos y larvas son arrastrados por la corriente cuando los adultos están desovando en aguas próximas al acceso.

Los registros de huevos obtenidos en aguas de plataforma frente a Rio Grande do Sul (Weiss el all.1976) mostraron una amplia distribución en la primavera de 1971.

Estudios realizados por otros investigadores en esta misma especie indican una amplia distribución en todos los océanos con excepción de aguas cálidas y del Pacífico. Los adultos son bentopelágicos y se distri buyen en aguas do plataforma entre 1 os 300 a 500m ( Parin y Bekker, 1973), entrando en estuarios a principios del invierno en Australia (Scott et all. 1974). En Ioui 
siana son abundantes entre $10 \mathrm{~s} 6$ a $46 \mathrm{~m}$ en febrero y marzo, octubre y noviembre $y$, de mayo a julio, migrando a aguas más profundas en otoño ( Dawson, 1967). Según Musick (1972),1a especie está asociada a salinidades entre 16\%0 y 35\% . EI desove ocurre en aguas con profundidades mayores a $46 \mathrm{~m}$ en el Golfo de Mexico (Dawson, 1967). En Japón ocurre en los meses de julio y agosto (Tsukahara, 1961); en el Noroeste de Africa en mayo a octubre (Wojcie chowsky, 1972) y, en el este de China en abril a agosto (Yamada, 1971).

Los juveniles son más abundantes entre Ios 27 y $46 \mathrm{~m}$ cerca de Louisiana (Dawson, 1967) y según Gunter (1948), pasan a aguas internas de bahías como área de cría durante el verano y retornan al Golfo de México al final del verano. Juveniles de 50 a 200mm de largo fueron colectados en aguas de profundidades de 15 a $20 \mathrm{~m}$ en el ca nal de entrada del estuario y en aguas costeras con salinidades siempre mayores a $35 \%$. Además, estudios actuales efectuados por el Laboratório de Ictioplancton de la Uni versidad de Rio Grande, Brasil, están registrando larvas mayores a IOmm en aguas de plataforma frente a Rio Grande do sul, hecho que dá más evidencias de que esta especic on este úca $\mathrm{se}$ desarrolla en a juas tipicamente mari nas y que su ingreso en el estuario es ncasional. 


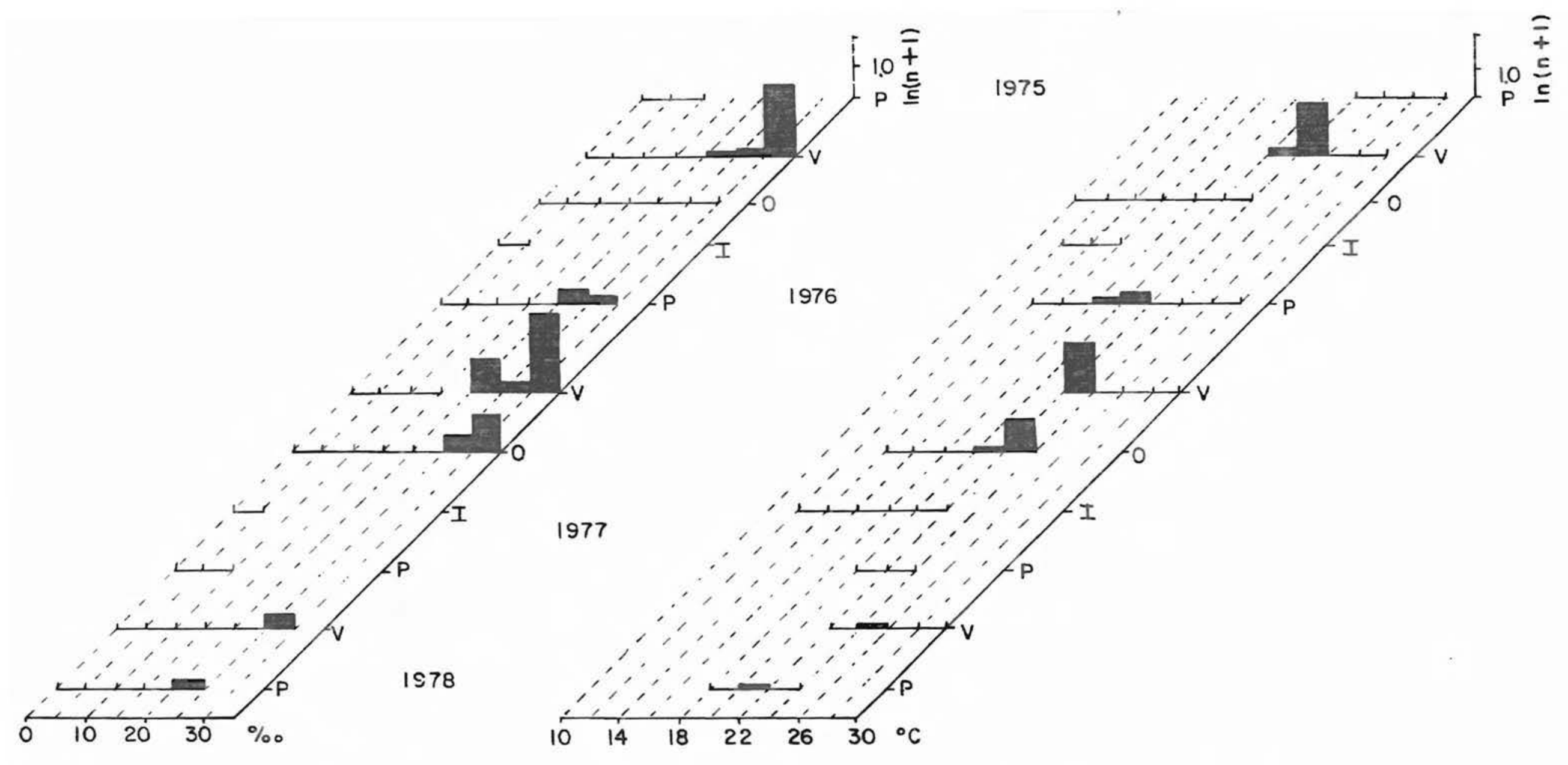

Fig. 46: Distribución de huevos de $\mathrm{T}$ - lecturus $\left(n=\mathrm{n}\right.$ o de huevos $/ 100 \mathrm{~m}^{3}$ ) para las diferentes salinidades y temperaturas en cada época. 

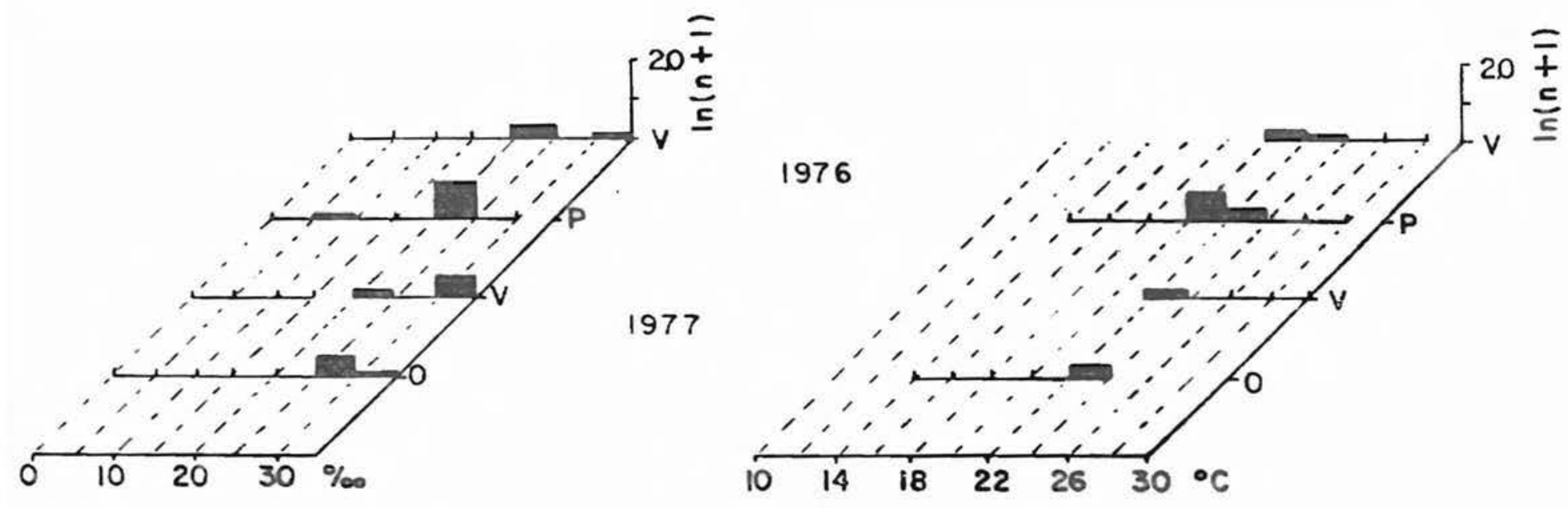

FiE. 47: Distribución de larvas de T. leptumus ( $n=n$ e de larvas/100m ${ }^{3}$ ) para las diferentes salinidades 7 temperaturas en cada época. 


\section{$4 j-$ GOBIONELTUS SP.}

Las larvas del gènero Gobionellus, estuvieron presentes con una elevada frecuencia. A excepción de la primavera de 1978, estuvieron en todas las épocas restantes. Los mayores registros se observaron en el verano y otoño a pesar de que la máxima densidad fue solamente de 1,4 larvas/100m ${ }^{3}$ ( Tabla 4).

La distribución de estas larvas fue totalmente aleatoria, hallándose presente en distintas salinidades y temperaturas, o sea que su distribución en el estuario es independiente de los parámetros aquí considerados (Fig. 48).

Posiblemente este resultado obtenido se deba a que o bien sea una especie con alta tolerancia termo-halina y su distribución esté regida por otros parámetros físicos o biológicos, o bien que se trate de más de una especie. Como los adultos pertenecientes a este género no fueron todavía correctamente identifi cados en este área, se hace imposible el diagnóstico a nivel de larva.

Según datos bibliográficos ( Hildebrand y Schroeder, 1928; Dawson, 1969; Dawson, 1967, etc.), Ios huevos de este género son elípticos, demersales y se adhieren a distintos objetos sumergidos. En este estudio no fueron hallados, por lo que no se pudo tener elementos de juicio sobre su comportamiento o su determinación. 


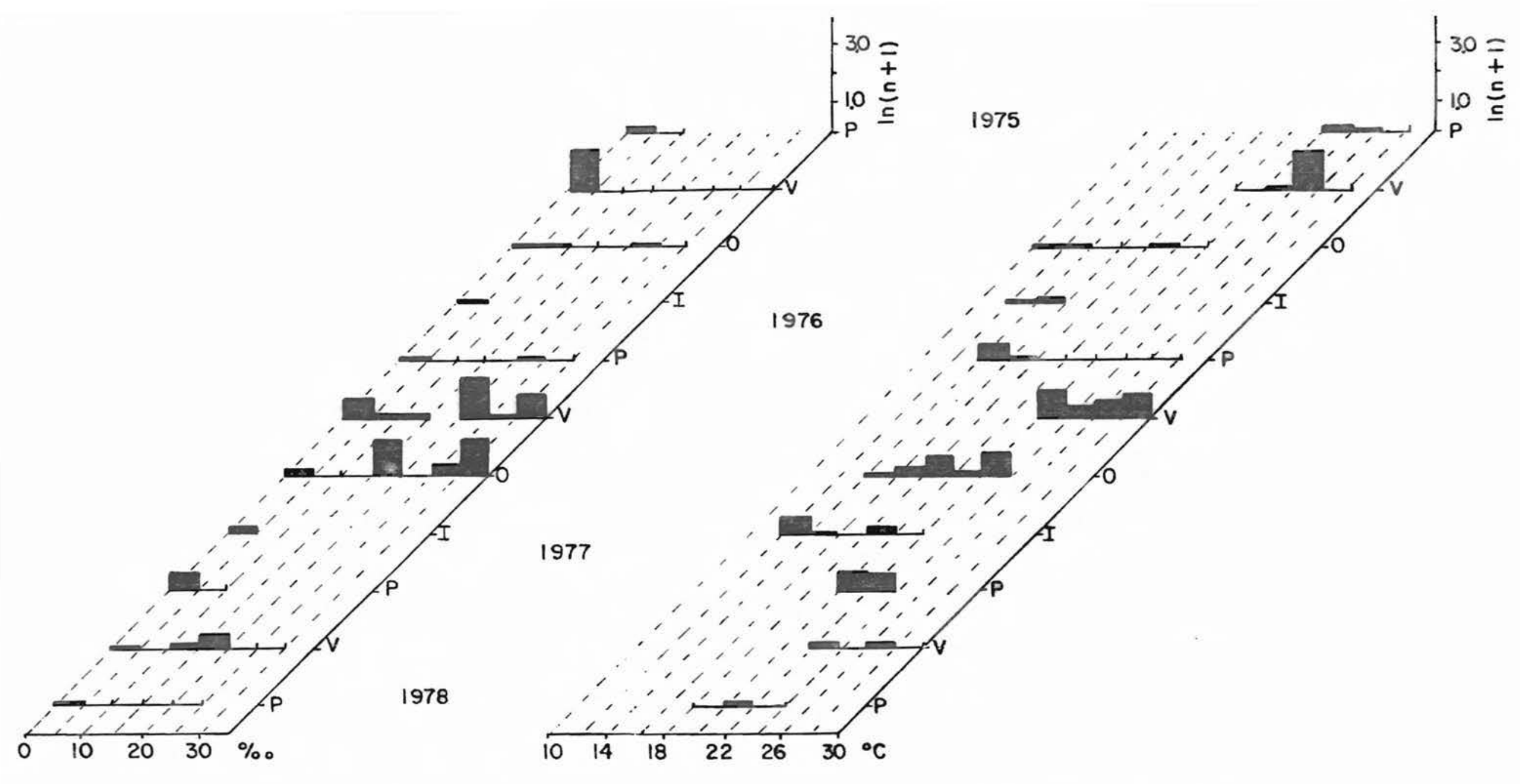

Fig. 48: Distribución de larvas de Gobionellus sp. (n= ne de larvas/100m ${ }^{3}$ ) para las diferentes salinidades y temperaturas en cada época. 
$4 \mathrm{k}-\underline{\text { ACHIRUS }}$ GARMANI

Los huevos de esta especie se registraron en todas las épocas del año, a excepción de los inviernos y la primavera de 1977. El mayor número fue observado en el verano de 1976 con una media de 76,2 kuevos/100m 3 (Tabla 4). Al igual que los huevos de otras especies, los mayores registros se presentaron en aguas de alta salinidad, observándose en algunos casos, como en la pri mavera de 1975 y primavera y verano de 1976, huevos en a guas oligohalinas ( Fig. 49).

Con relación a la temperatura se observa la misma característica ya citada para los huevos de otras especies, es decir: temperaturas más frías en primavera y verano y más cátidas en el otoño.

En cuanto a las larvas, sus registros fueron mínimos: entre 0,1 a $0,5 / 100 m^{3}$ en la primavera y verano de 1976 y 1978 y el verano de 1977 ( Tabla 4). Se observó una leve preferencia por aguas de mayor salinidad, a pesar de estar presente en todos los rangos de ésta, asi como por aguas más frias (Fig. 50).

Por los mínimos registros y por los pequeños tamaños de larvas colectados se infiere que el tiempo de vida planctónica de esta especie es muy corto.

Según estudios efectuados por Weiss y Haimovi ci ( Ms), los adultos y juveniles en el época invernal restringen su distribución a las aguas más costeras del estuario, donde la salinidad no pasa 10 s $2 \%$. A medida que avanza la primavera su distribución se amplía, siendo capturados en aguas con salinidades de 0,5\%o a 34\%o ; en el verano aunenta el número de ejemplares en aguas de mayor salinidad y disminuye nuevamente en oton̄o. Con res pecto a la temperatura, durante el invierno se localizan en aguas con 13으 a 14으 y en el verano, al ampliar su

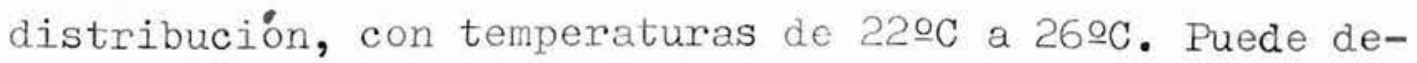
ducirse que los adultos se desplazan hacia aguas de mayor salinidad en el comienzo de su ciclo anual reproductivo, desovando en ellas y que los huevos y larvas son transportados por la corriente hacia el interior del estuario. 
No se ha observado la presencia de esta especie en aguas marinas, 10 que indica que es de hábitos ti picamente estuarinos.

Ia especie Achirus lineatus está ampliamente distribuída desde Florida a Uruguay por la costa Atlánti ca, y el Golfo de México ( Briggs, 1958) y es citada para aguas estuarinas (Reid, 1954; Springer y Woodburn, 1960; Tabb y Manning, 1961). Futch (1970), en base a larvas y juveniles de esta especie capturadas en Tampa Bay, observó que el desove está provablemente, confinado a áreas costeras desde abril hasta noviembre, cuando la temperatura es mayor a $20 \% \mathrm{C}$, encontrando las máximas cap turas entre junio y julio. Comparando con dichos resulta dos, se observa una gran coincidencia, principalmente en Io que respecta a la época de reproducción ( primavera, verano y oton̈o) y de la mayor intensidad de desove ( verano). 


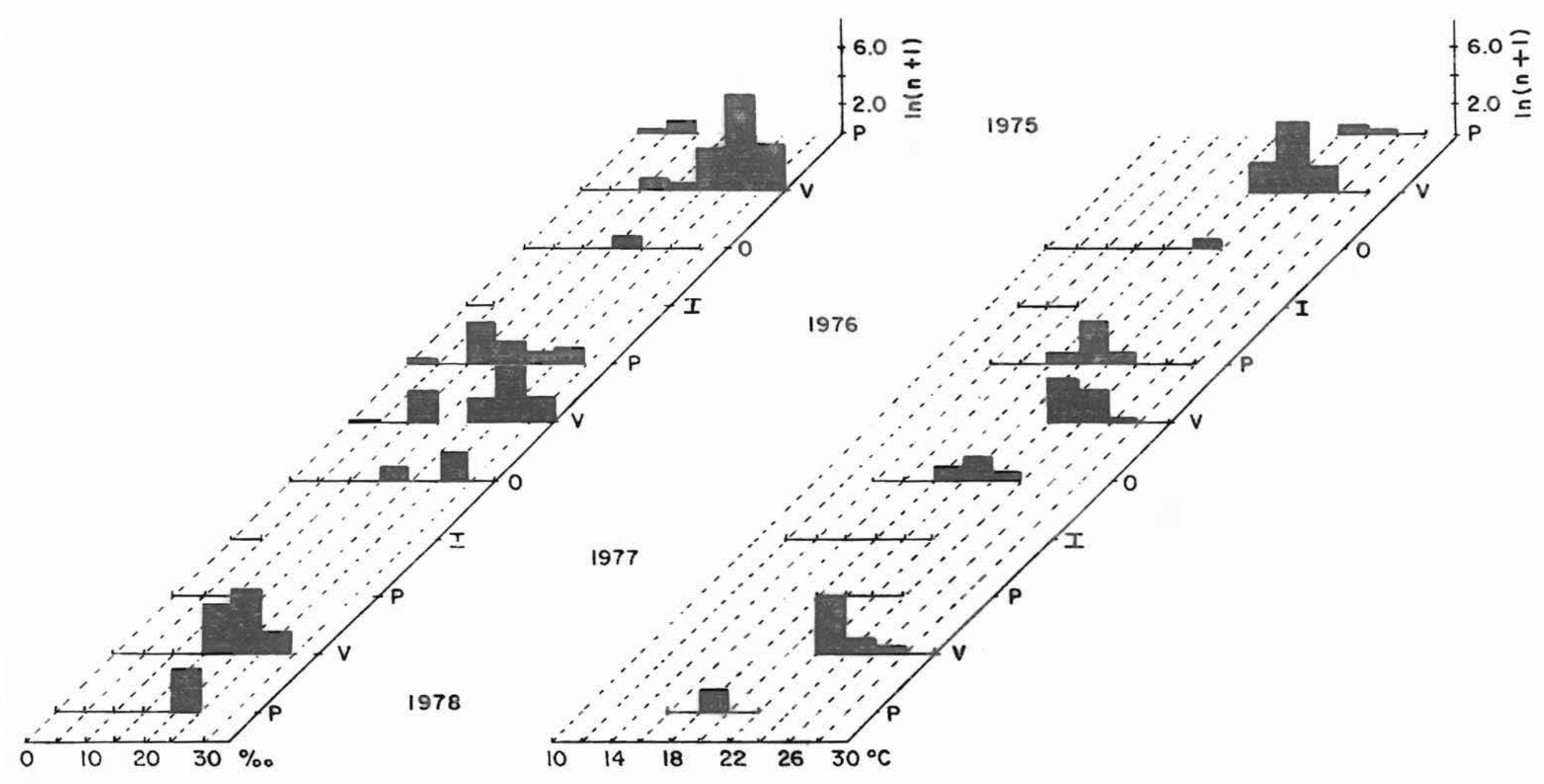

Fig. 49: Distribución de huevos de A. garmani ( $n=n$ o de huevos / 100m ${ }^{3}$ ) para las diferentes salinidades $\mathrm{y}$ temperaturas en cada época. 


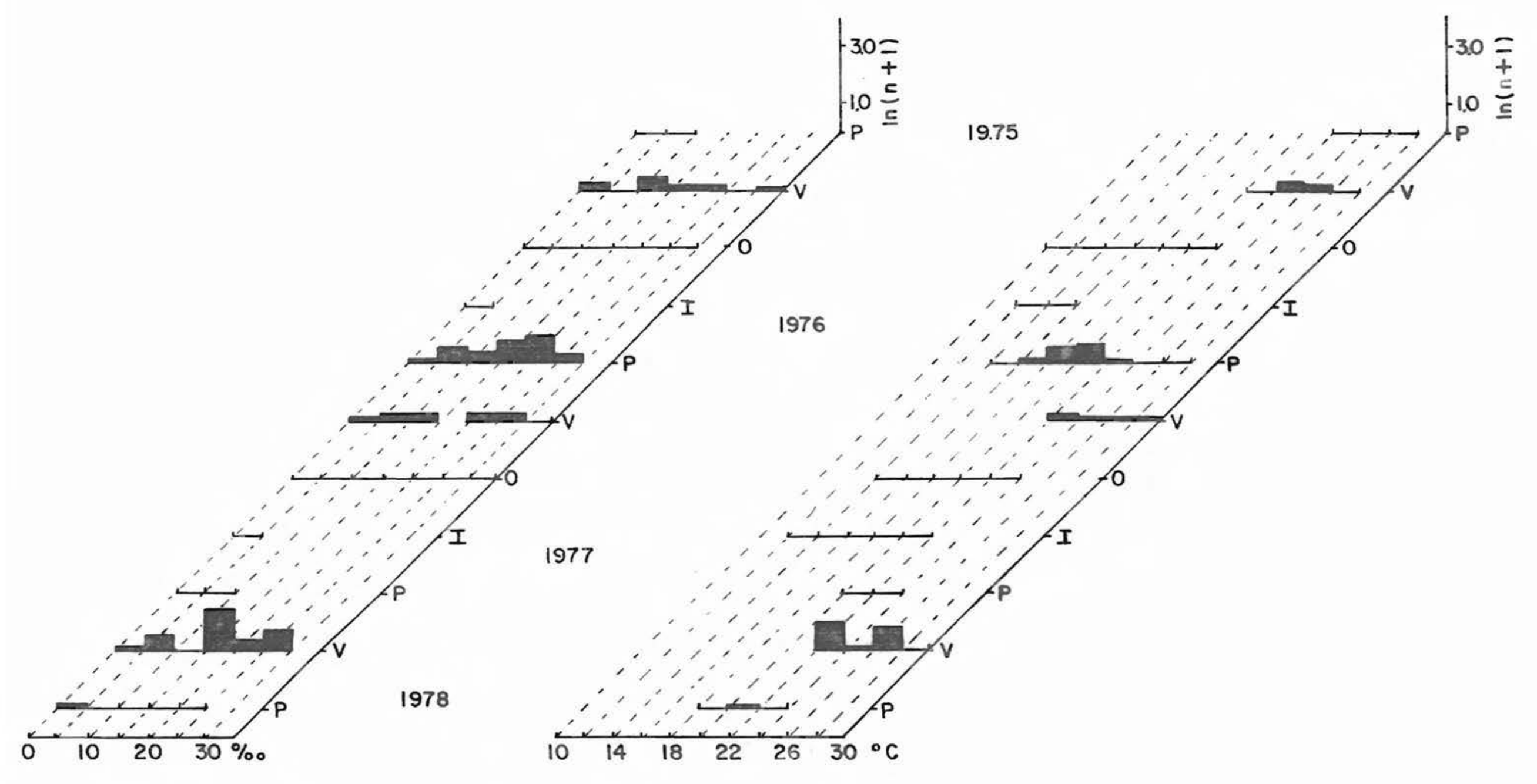

Fig.50: Distribución de larvas de $\underline{A}$. germani $\left(n=n\right.$ o de larvas/100m ${ }^{3}$ ) para las diferentes salinidades y temperaturas en cada época. 
Las larvas de esta especie se presentaron en forma frecuente pero siempre en número reducido. En el año 1976 estuvo presente en todas las estaciones, con mayor abundancia en verano ( 1,2 larvas/luom ${ }^{3}$ ) y otoño $\left(0,7\right.$ larvas/100m $\left.{ }^{3}\right)$. Se registró también su presencia en verano y otoño de 1977, así como en primavera de 1978 (I'abla 4).

En relación con la salinidad, se caracterzó por estar en mayor número en aguas saladas, a pesar de estar presente también en aguas mas dulces, como se observó en otoño de 1976 ( Fig. 51). En relación con la temperatura se observó preferencias por temperaturas me nores en verano, mayores en otoño e intermedias en primavera.

Los adultos son pequeños habitantes de aguas salobres que viven entre piedras y moluscos con hábitos sedentarios (Runyan, 1966). No eslí aduplado para vivir en aguas oceánicas abiertas y no existen registros para aguas dulces.

Según Mc Hug (1967) esta especie es endémica del estuario de Chesapeake. Dovel (1971) la caracterizó como una especie típicamente estuarina, encontrando sus larvas desde mayo a septiembre en la Bahía de Chesapeake en aguas de salinidades no muy bajas ( 4 a 19\%0) y temperaturas de 17 a 2700 . Estas características coinciden con los datos obtenidos en este análisis, a excepción de que sus larvas fueron halladas durante todo el año, 10 cual indica un desove contínuo. 


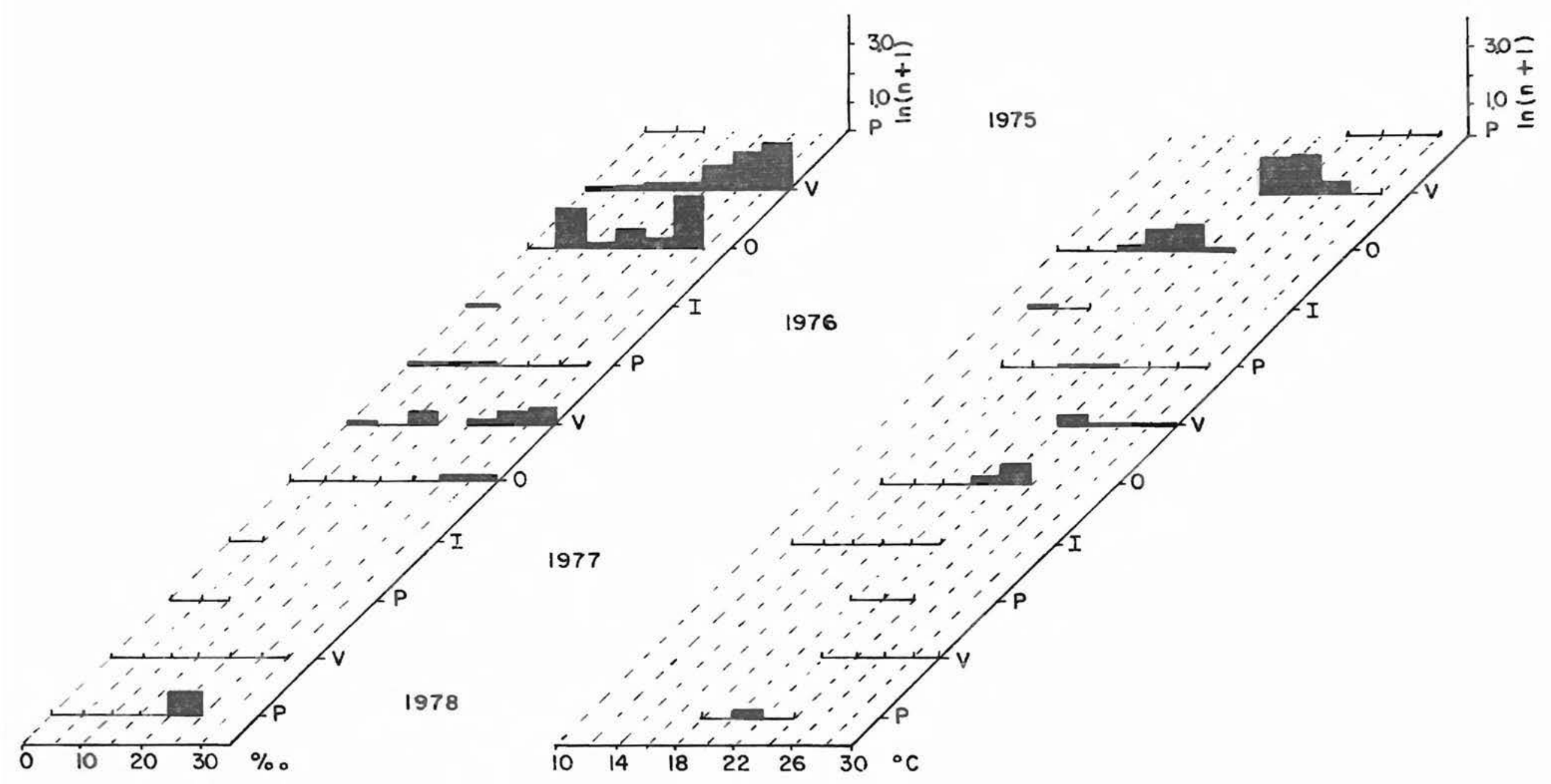

Fig. 51: Distribución de larvas de $\underline{G}$. strumosus ( $n=n$ o de larvas/100m ${ }^{3}$ ) para las diferentes salinidades y temperaturas en cada época. 
5 - COEX ISTENCIA ESPACIAI DE IAS ESPECIES MAS ABUNDANTES

De 671 estaciones observadas en el total de los cruceros, las especies más frecuentes en las muestras fueron: $\underline{B}$ - pectinata con $54 \%$ de estaciones positivas, I. grossidens con 49\%, M. furnieri con 25\% y Atherinidae con 28\%. Con el objetivo de analizar la coexistencia entre ellas y tomando como base $\underline{B}$. pectinata por ser la más representativa, se calculó el número de estaciones en que estaban juntas. Los resultados se presentan en la tabla siguiente, donde se indica el número de estaciones positi vas de las especies y el numero de estaciones en que comparten, con los respectivos porcentajes. La Fig. 52 presenta el área de distribución de cada especie y la superposición de las áreas de las especies copresentes.

B. pectinata L. grossidens M. furnieri Atherinidae B. pectinata 360 (total)

I. grossidens $224(68 \%) 331$ (total)

M. furnieri $80(53 \%) \quad 92(61 \%) \quad 152$ (total)

Atherinidae $115(61 \%) \quad 98(52 \%) \quad 32$ ( $17 \%) 190$ (total)

Se observa que: a) todas las especies compar ten más del $50 \%$ de estaciones con $\underline{B}$. pectinata; b) que $\underline{M}$. furnieri y Atherinidae comparten más del 50\% con L. grossi dens y c) que Atherinidae y $\underline{M}$. furnieri ;omparten solamente el $17 \%$ de sus estaciones.

La elevada constancia de $\underline{B}$ - pectinata y $\underline{\text { L }}$. grossidens determina su alta coexistencia, mientras que $\underline{M}$. furnieri y Atherinidae presentan una alta coexistencia con las dos primeras, pero no entre sî. Estos valores estarian indicando características de comportamiento similar en algunos casos y opuestos en otros, como se observa con las dos últimas especies.

Ia coexistencia de Ias larvas de diferentes especies puede ser consecuencia de su afinidad por determi nados ambientes, pero siendo el estuario un lugar de transición estarían obligadas a compartir el mismo área. 


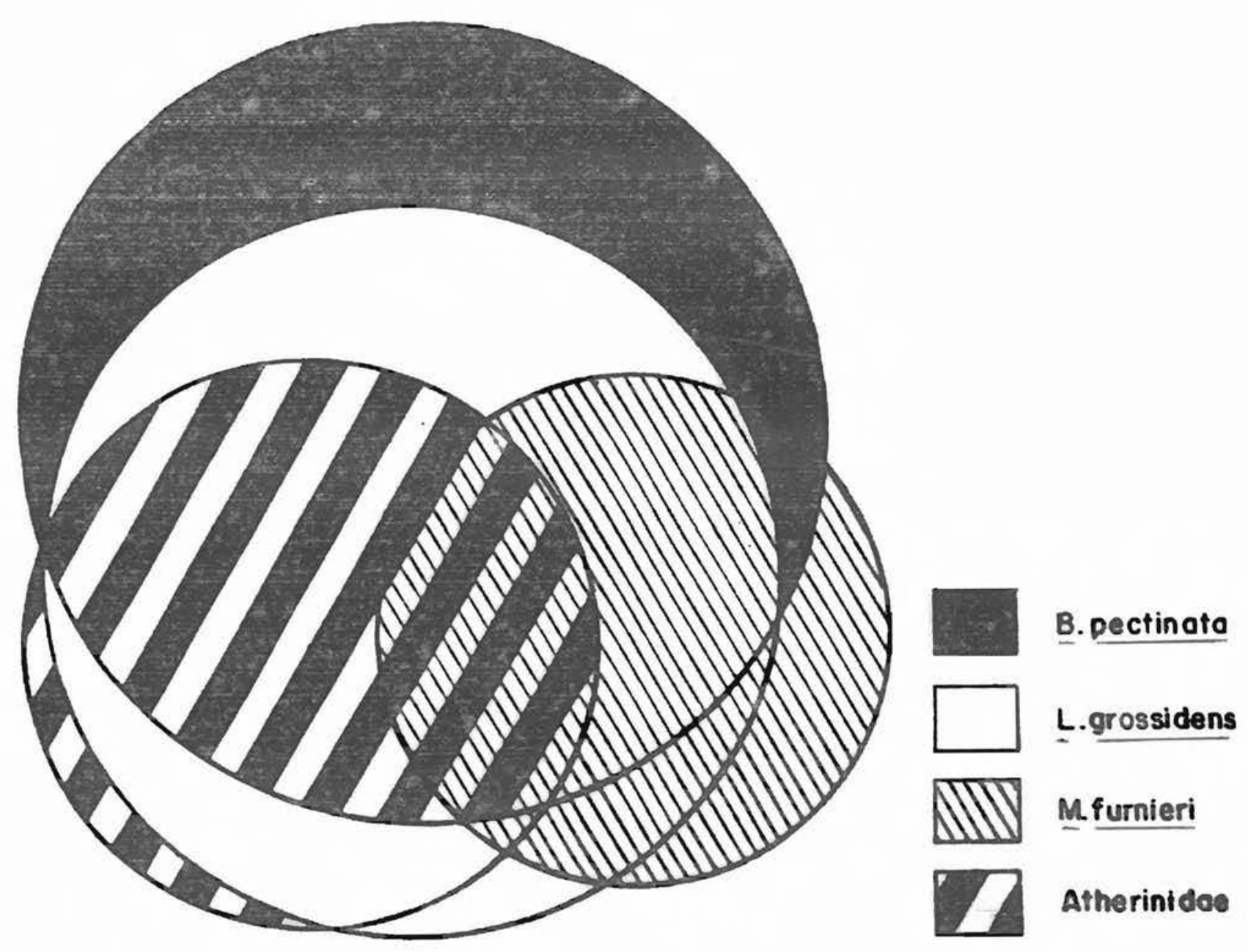

Mig. 52: Jistribución espacial y superposición de áreas de las especies mas abundantes, (escala: un círcuio de $31 \mathrm{~mm}$ representa 170 estaciones positivas). 
$6-$ COEF ICIENTE DE AFINIDAD ENTRE IAS LARVAS MAS ABUNDANTES

Para saber si la alta coexistencia observada en las especies está asociada con su afinidad por deteminados ambientes y épocas reproductivas, se utilizó el coeficiente de afinidad de Fager (1963) y Longhurst (1964).

Se demostró que entre $\underline{B}$ - pectinata y I. grossidens existe afinidad en 14 de los 26 cruceros (Tabla 6). Este coeficiente aumenta con el número de cruceros, y en valor absoluto si se consideran las larvas presentes en sa linidades menores a 5\%o, y disminuye en salinidades mayores. El aumento de la afinidad en aguas oligohalinas ( más internas del estuario), está indicando sus preferencias por el mismo tipo de ambiente, hecho explicable por ser am bas del Sub Orden Clupeoidei con un período larval planctó nico prolongado y ser filtradoras de plancton.

EI coeficiente entre $\underline{B}$. pectinata y $\underline{M}$. fur nieri fue en general mínimo, a excepción del 130 y 230 cru ceros, que arrojaron valores mayores a 0,50 .

Valores semejantes se obtuvieron con $\underline{B}$ - pectinata y Atherinidae, en las que, a excepción del 60 cru cero ( coeficiente de 0,72 ), la media fue de 0,40 .

Los coeficientes obtenidos entre $\underline{\text { M. }}$ furnieri y Atherinidae fueron en todos los cruceros menores a 0,50 ; - sea que a pesar de que éstas están presentes en un número elevado de estaciones, sus densidades son mínimas, indi cando que la alta coexistencia espacial es consecuencia de que el estuario sea un área de transición para diferentes ambientes.

M. furnieri tiene un periodo planctónico lar val muy corto, adquiriendo rápidamente hábitos bentónicos. Atherinidae tiene huevos bentónicos y larvas con un periodo planctónico limitado, adquiriendo el juvenil hábitos pe lágicos costeros. Estas características y la falta de afinidad entre ellas, hacen suponer que sus preferencias son diferentes. 
Tabla 6: Coeficientes de afinidad entre larvas de $\underline{B}$. pectinata y I. grossidens para los diferentes cruceros, en el total de estaciones, en estaciones con salinidades me nores a $5 \%$ y mayores a $5 \% 0$.

\begin{tabular}{|c|c|c|c|}
\hline Crucero & $\begin{array}{c}\text { Total de } \\
\text { est. }\end{array}$ & $\begin{array}{c}\text { Est. con } \\
<5 \% 0\end{array}$ & $\begin{array}{c}\text { Est. con } \\
>5 \% 0\end{array}$ \\
\hline 1 & 0,77 & 0,76 & 0,55 \\
\hline 2 & 0,75 & 0,51 & 0,66 \\
\hline 3 & 0,02 & 0,15 & 0,08 \\
\hline 4 & 0,55 & 0,63 & - \\
\hline 5 & - & $\div$ & - \\
\hline 6 & 0,58 & 0,66 & 0,29 \\
\hline 7 & 0,66 & 0,77 & 0,49 \\
\hline 8 & 0,79 & 0,90 & - \\
\hline 9 & 0,57 & 0,57 & - \\
\hline 10 & - & - & - \\
\hline 11 & 0,30 & 0,58 & 0,16 \\
\hline 12 & $0,51$. & 0,54 & 0,59 \\
\hline 13 & 0,82 & 0,85 & 0,53 \\
\hline 14 & 0,56 & 0,50 & 0,65 \\
\hline 15 & 0,63 & 0,69 & - \\
\hline 16 & 0,68 & 0,69 & 0,40 \\
\hline 17 & 0,17 & 0,23 & - \\
\hline 18 & 0,18 & 0,20 & 0,27 \\
\hline 19 & 0,87 & 0,86 & - \\
\hline 20 & - & - & - \\
\hline 21 & - & - & - \\
\hline 22 & 0,73 & 0,73 & - \\
\hline 23 & 0,46 & 0,61 & 0,33 \\
\hline 24 & - & - & - \\
\hline 25 & - & - & - \\
\hline 26 & - & - & - \\
\hline
\end{tabular}


Un ecosistema estuarial se caracteriza por su baja diversidad específica como consecuencia de la alta inestabilidad ambiental, hecho ya demostrado por varios autores en diferentes lugares ( Dahlberg y Odum, 1970; Boesch, 1972; Allen y Horn, 1975; Moore, 1978).

Considerando que respectivamente, el número de huevos y larvas no identificado es mínimo ( $1,2 \%$ y 2,4\% del total), se aplicó el índice de diversidad de Margalef (1977). Los resultados obtenidos indican valores muy bajos especialmente para los huevos. Observando la Tabla $7 \mathrm{y}$ com parando dichos valores con las temperaturas y salinidades medias, se observan casos en que el índice más elevado de 0,54 ( 180 crucero) va acompañado de una salinidad media de $19,5 \%$ y una temperatura media de $21,50 \mathrm{C}$, mientras que otro valor alto, como el obtenido en el 100 crucero de 0,48, Ia media de la salinidad fue de $0,5 \%$ y la temperatura de 18,20 C. Lo mismo ocurre con las larvas: un valor máximo de I,82 de diversidad ( 4 o crucero) va acompañado de una tempe ratura media de $25,1 \cong \mathrm{C}$ y $3,3 \%$ de salinidad y otro valor al to de 1,76 en el 30 crucero tiene una media de 23,15으 de temperatura y $21,8 \%$ de salinidad.

Es posible que la inestabilidad del ambiente se refleje en las variaciones de los indices de diversidad. Además de la alta inestabilidad, característica de todo estuario, se tiene que considerar que su canal posee un ancho de solamente $700 \mathrm{~m}$ en la desembocadura, por el cual descarga en el mar las aguas provenientes del vasto sistema lagunar formado por Lagua dos Patos y Lagoa Mirim. La forma de embu do del área estuarial provoca fuertes corrientes en el canal de entrada, dando mayor inestabilidad al ecosistema y provablemente pocas especies puedan realmente adaptarse y penetrar en determinadas épocas y condicioneis.

Según Remane (1971) el número de especies dis minuye desde $\mathrm{e}$ inar hacia las aguas mixohalinas y aunenta nuevamente en aguas típicamente dulces. Este hecho también fue observado por Boesch ( 1974) en la fauna bentónica, que es una comunidad sésil y más estable. 
Tabla 7: Indice de diversidad para huevos y larvas en cada crucero, con las correspondientes medias de tempe ratura y salinidad.

\begin{tabular}{|c|c|c|c|c|}
\hline CRUCERO & HUEVOS & LARVAS & ToC & $\%$ \\
\hline 1 & 0,17 & 0,90 & 24,7 & 3,0 \\
\hline 2 & 0,28 & 1,53 & 24.3 & 14,1 \\
\hline 3 & 0,29 & 1,76 & 23,2 & 21,8 \\
\hline 4 & - & 1,82 & 25,1 & 3,3 \\
\hline 5 & 0,52 & 1,54 & 19,9 & 12,4 \\
\hline 6 & 0,15 & 1,11 & 19,5 & 5,8 \\
\hline 7 & 0,47 & 1,02 & 16,2 & 15,7 \\
\hline 8 & - & 0,84 & 12,1 & 4,0 \\
\hline 9 & - & 1,04 & 13,8 & 1,0 \\
\hline 10 & 0,48 & 1,82 & 18,2 & 0,5 \\
\hline 11 & 0,22 & 1,56 & 17,8 & 14,1 \\
\hline 12 & 0,39 & 1,10 & 19,8 & 17,5 \\
\hline 13 & 0,51 & 1,51 & 23,1 & 5,5 \\
\hline 14 & - & 1,01 & 25,0 & 2,8 \\
\hline 15 & - & 0,92 & 27,6 & 2,0 \\
\hline 16 & 0,32 & 1,67 & 25,3 & 12,0 \\
\hline 17 & 0,26 & 1,74 & 25,7 & 10,2 \\
\hline 18 & 0,54 & 1,49 & 21,5 & 19,5 \\
\hline 19 & - & 0,50 & 16,2 & 2,4 \\
\hline 20 & - & 0,68 & 14,1 & 0,6 \\
\hline 21 & - & 1,44 & $18, ?$ & 0,4 \\
\hline 22 & - & 0,93 & 21,5 & 1,2 \\
\hline 23 & 0,38 & 1,15 & 25,3 & 12,6 \\
\hline 24 & 0,32 & 0,49 & 24,6 & 4,8 \\
\hline 25 & - & 0,32 & 20,2 & 4,2 \\
\hline 26 & 0,33 & 1,10 & 21,2 & 7,0 \\
\hline
\end{tabular}


La clasificación de aguas salobres sugerida en el "Symposium on the classification of brackish waters", 1958 ("The Venice System"), fue: aguas oligohalinas con salinidades de 0 a $5 \%$, mesohalinas con $5 \%$ a $18 \%$ y polihalinas de $18 \% 0$ a $30 \% 0$. Considerando esta clasificación, en la Fig. 53 se representó los valores de diversidad y el numero de individuos obtenidos en los diferentes valores de salinidad y temperatura. Se observa que el índice de diversidad disminuye gradualmente en las aguas polihalinas, mesohalinas y de forma abrupta, en aguas oligohalinas. El número de individuos también presenta una gradual disminución desde las aguas con 30\%, observándose luego un valor máximo en aguas oligohalinas. Evidentemente las larvas que continuan siendo planctónicas en este ambiente son numéricamente importantes y representadas por pocas especies como son B. pectinata y I. grossidens.

Analizando el comportamiento de las larvas con la temperatura se observa que la diversidad decrece gradualmente en las temperaturas más elevadas $\mathrm{y}$, de forma brus-

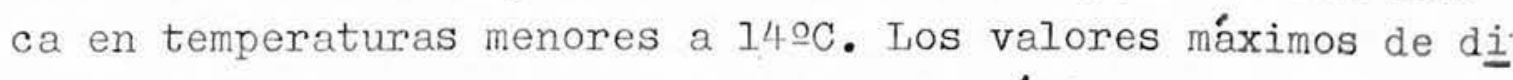
versidad obtenidos en las temperaturas máximas, es consecuen cia de un mayor número de especies desovantes, mientras que en temperaturas de 22 으 los mayores registros de larvas corresponden a las especies típicas del estuario (

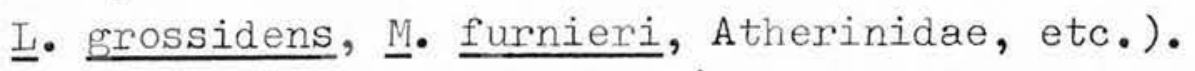

La disminución de la temperatura provoca una gradual disminución del número de larvas. En temperaturas menores a $14 \mathrm{C}$ se observa un leve aumento ocasionado por las larvas que están presentes en la época invernal (B. pectinata, I. grossidens y Atherinidae, principalmente).

El comportamiento de los huevos es diferente. $\mathrm{E} 1$ Indice de diversidad disminuye gradualmente en aguas polihalinas y mesohalinas y aumenta en las aguas oligohalinas, mientras que su número disminuye acentuadamente desde salini dades de 30\%0 a 0\%o. Dado que de las 5 especies presentes, 4

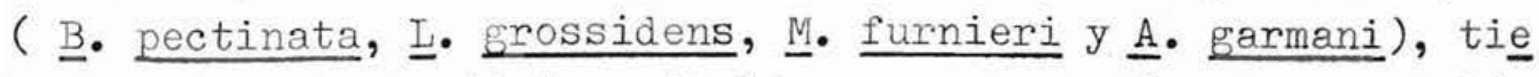
nen una alta capacidad eurihalina, su presencia en aguas oligohalinas en pequeño número, se refleja en un aumento del índice de diversidad.

El Índice de diversidad de los huevus es mayor en las temperaturas medias al igual que el número, mostrando que las temperaturas medias (20 - 22oㅡ) son las más propicias para todas las especies. 
HUEVOS
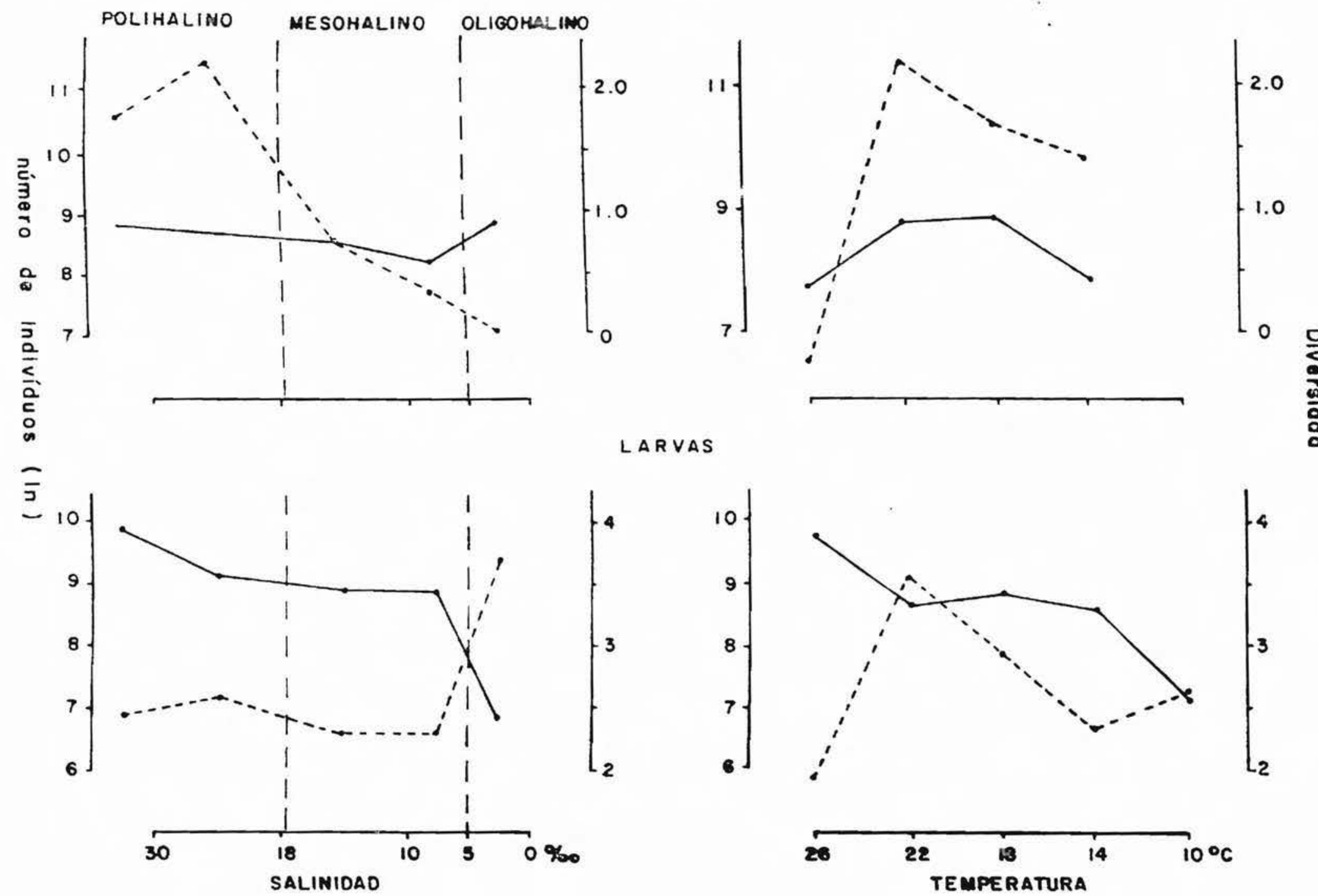

$\frac{0}{\vdots}$

iig. 53: húmero de individuos ( - - -) y divorsidad ( - - ) de huevos y larvas en diferentes salinidades y temperaturas. 


\section{8 - EI ESTUARIO COMO AREA DE CRIA.}

El área de cría descripte como " zona crítica por Massman (1963) es referida al área con salinidades de 1 a $15 \%$ o entre 5\% a 15\% (Massman, 1964). Dovel(1971) ubicô el área de cría en Chesapeake Bay en aguas con salinidades entre 0 a 11\%o, donde encontró el 95\% del total de larvas.

En el presente estudio se obtuvo:

$\mathrm{S} \% \mathrm{O}$

$\%$ larvas

$\%$ huevos

$$
\begin{array}{rr}
0 & -5 \\
5 & -10 \\
10 & -20 \\
20 & -30 \\
30
\end{array}
$$$$
75,6
$$$$
0,8
$$$$
4,5
$$$$
1,6
$$

$$
4,6
$$$$
3,5
$$

8,0

66,6

7,3

27,5

1 número de larvas está indicando en este estuario que, el área de alimentación y cría está vinculado a acuas con salinidades mínimas ( de 0 a 5\%o), mien tras que la primera etapa de vida embrionaria transcurre principalmente en salinidades mayores a $20 \%$. 

$\underline{\underline{P}} \underline{\underline{A}} \stackrel{\text { R }}{=} \stackrel{\mathrm{T}}{=} \stackrel{\mathrm{E}}{=} \underline{\mathrm{C}}$

DISTRIBUCION VERTICAL DEL ICTIOPLANCTON 


\section{1 - DISTRIBUCION DEL ICTIOPIAANCTON EN RETACION CON LOS FACTORES AMBIEITALES.}

Considerando las amplias variaciones de las corrientes, la falta de flujómetro impide efectuar una distribución cuantitativa real; a pesar de ésto, se analizan las abundancias de los huevos y larvas a título comparativo.

\section{la - ANALISIS DE LOS GRADIENTES EN EL PLANO VERTICAL.}

En la Fig. 54 se representó el núméro de huevos y larvas que colectó cada par de redes (media de las 2 estaciones: São José do Norte y Cocuruto) en los tres estratos ( $1 \mathrm{~m}, 6 \mathrm{~m}$ y llm de profundidad) en cada muestra, realizado en las diferentes épocas. En la parte superior de cada gráfico se representó la salinidad y temperatura media para cada estrato. Los valores de temperatura y salinidad estan dados. en las Tablas 8 y 9 yel número de huevos y larvas en la Tabla 2.

Analizando la temperatura a lm de profundidad se observa que responde en general a las variaciones estacionales, - sea que aumenta en primavera (de 1976) teniendo un máximo en el verano, disminuye en otoño e invierno y aumenta nuevamente en la siguiente primavera (de 1977). Sc observa también peque ñas disminuciones temporales con el aumento de la salinidad y pequeños aumentos con la disminución de ésta. Este hecho respon de a que las aguas marinas son más frías que las de origen continental.

En cuanto a la salinidad, ésta responde al esquema presentado para la distribución horizontal (Fig. 27). Presenta una gran inestabilidad en los meses de primavera y verano con grandes oscilaciones, siendo más estable en otoño e invierno, con presencia de valores bajos.

A $6 \mathrm{~m}$ de profundidad las temperaturas practicamente no sufren variación, mientras que la salinidad se modifica en la primavera de 1976 y más suavemente en el verano de 1977. Aumenta la salinidad en el 30 muestreo de 12,0\% a 29\%o, acompañada de una leve disminución de la temperatura de 21,00 a $20,00 \mathrm{C}$.

Otro cambio de importancia se registró en el 8 으 muestreo, donde 1 a salinidad de $6,0 \% 0$ a $1 \mathrm{~m}$ de profundidad, aumenta a $13 \% 0$ a $6 \mathrm{~m}$, no observándose practicamente modificación con la temperatura. 
Si se analizan los datos obtenidos para $11 \mathrm{~m}$, se pueden apreciar, a excepción del otoño de 1977, modificaciones muy importantes.

En el 30 muestreo continúa estable hasta el fondo después de incrementarse a $27 \%$ a $6 \mathrm{~m}$. En el 50 y 60 de salinidades de $4 \%$ a $3 \% 0$ registradas a $6 \mathrm{~m}$, aumentan a $22 \%$ y $17 \%$ respec tivamente, acompañadas por una disminución de la temperatura de 24 으 a 23 으.

De forma similar se presenta en el 80 muestreo, en el que la salinidad de $13 \% 0$ aumenta a $21,0 \%$ y la temperatura de 24, 0 o disminuye a 23,0 으.

En el 9ㅇ, que presentaba una columna de agua homogénea de $0,6 \%$ a $0,8 \%$ hasta 10 s $5 \mathrm{~m}$, aumenta a 9,0\% a 10 s $11 \mathrm{~m}$.

En otoño y parte del invierno mostraron condiciones estables en toda la columna de agua. El muestreo 140 realizado a mediados del mes de julio, presentó una elevación de la salini dad en las aguas mas profundas: de 1,0\%o a 6m, pasó a 18,4\% a $11 \mathrm{~m}, 11$ egando a $24,4 \% 0$ a $13 \mathrm{~m}$. La temperatura en este caso presen tó una disminución muy leve de 16,0 a $15,5 \mathrm{C}$.

Finalmente la primavera de 1977 , presentó condiciones ambientales más estables en toda la columna de agua.

Analizando la secuencia estacional, se observa la pre sencia de huevos en primavera, verano y otoño, mientras que las larvas están presentes durante todo el año.

La abundancia de los huevos está regida principalmente por la salinidad, o sea por la entrada de agua marina; en términos generales presenta las mismas características encontradas en la distribución horizontal, o sea que en plena época de desove los flujos y reflujos de agua de origen marino o mixohalino condi cionan la presencia y abundancia de éstos.

Estas condiciones se reflejan tanto en aguas superficiales como profundas, observándose un aumento del número de huevos cuando las condiciones ambientales lo permiten. Por ejemplo en el 5ㅇ muestreo, se colectaron a $1 \mathrm{~m} 1$ huevo, a $6 \mathrm{~m} 49$ huevos y a IIm 93.33 huevos presentando cada estrato salinidades de $2 \% 0,4 \% 0$ y $22 \%$ respectivamente.

En el 20 muestreo, con una columna de agua más homogẹ nea, variando las salinidades de 20,0\% a 24,0\%०, la abundancia de huevos fue de $26.128,10.340$ y 7.463 para los tres niveles men cionados.

Al igual que lo observado para la distribución horizontal, los huevos por ser todos de origen marino y de flotación pasiva cstan sujetos a entrar en el estuario, según los flujos de 

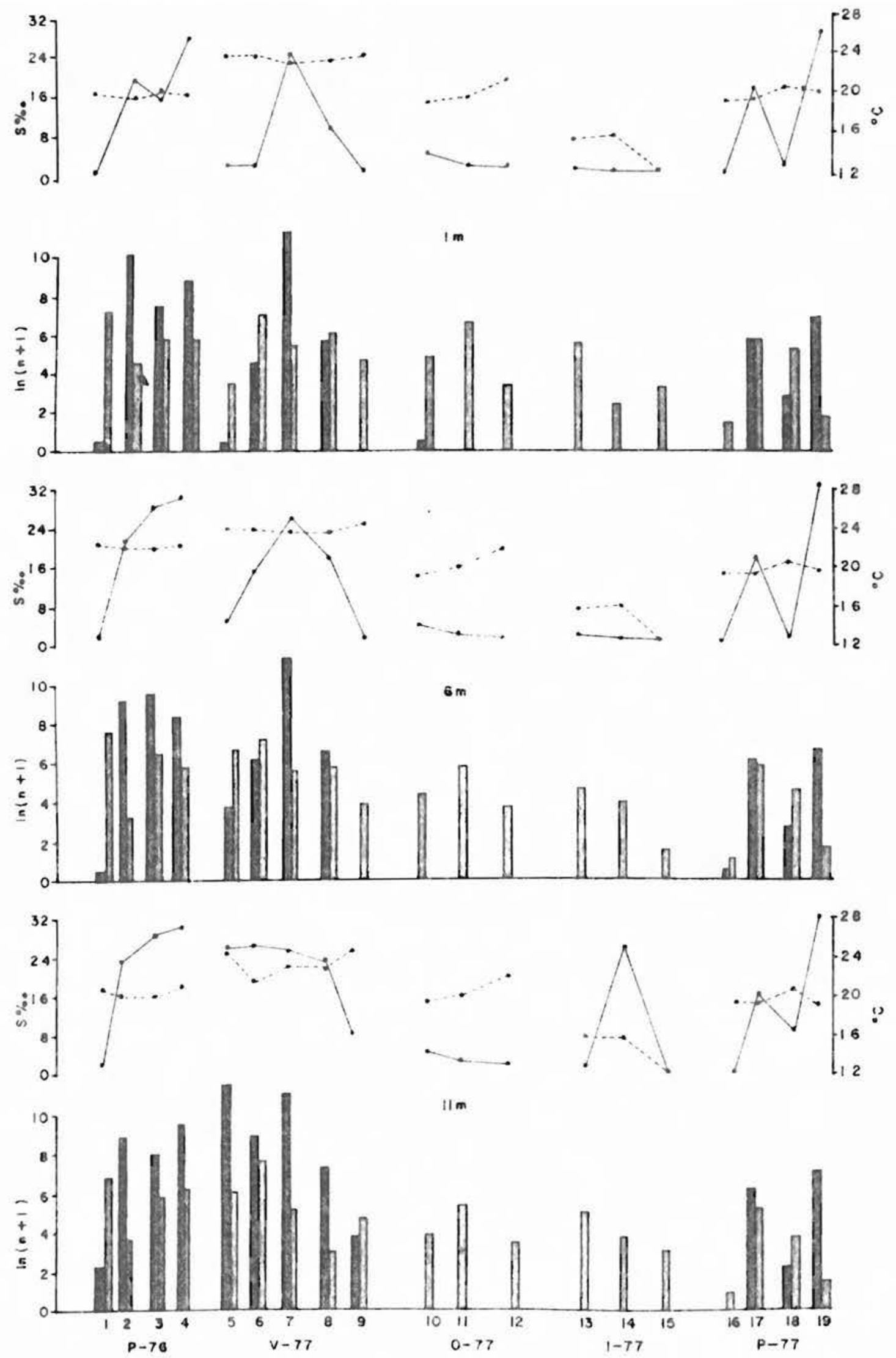
Tabla 8: Salinidades media para cada muestreo y profundidad.

\begin{tabular}{|c|c|c|c|c|c|c|c|}
\hline \multirow{2}{*}{$\begin{array}{l}\mathrm{M} \\
\mathrm{U} \\
\mathrm{E} \\
\mathrm{S} \\
\mathrm{T} \\
\mathrm{R} \\
\mathrm{A}\end{array}$} & \multicolumn{7}{|c|}{ PROFUNDIDA D (metros) } \\
\hline & 1 & 3 & 5 & 7 & 9 & 11 & 13 \\
\hline 1 & 1,5 & 1,5 & 1,5 & 1,5 & 1,5 & 1,5 & \\
\hline 2 & 20,0 & 20,0 & 21,0 & 22,0 & 23,0 & 24,0 & - \\
\hline 3 & 12,0 & 19,0 & 27,0 & 29,0 & 29,0 & 29,0 & 29,0 \\
\hline 4 & 29,0 & 30,0 & 30,0 & 30,0 & 30,0 & 30,0 & 30,0 \\
\hline 5 & 2,0 & 2,0 & 3,0 & 4,0 & 17,0 & 22,0 & 27,0 \\
\hline 6 & 2,0 & 2,0 & 2,0 & 3,0 & 8,0 & 17,0 & 27,0 \\
\hline 7 & 18,0 & 19,0 & 20,0 & 21,0 & 21,0 & 23,0 & 24,0 \\
\hline 8 & 6,0 & 7,0 & 11,0 & 13,0 & 17,0 & 21,0 & 26,0 \\
\hline 9 & 0,6 & 0,6 & 0,7 & 0,8 & 9,0 & 9,0 & 10,0 \\
\hline 10 & 3,9 & 3,9 & 3,9 & 3,9 & 4,0 & 4,0 & 6,7 \\
\hline 11 & 2,1 & 2,1 & 2,1 & 2,1 & 2,1 & 2,1 & 2,1 \\
\hline 12 & 1,8 & 1,8 & 1,8 & 1,8 & I, 8 & 1,8 & 1,8 \\
\hline 13 & 1,6 & 1,6 & 1,6 & 1,6 & 1,6 & 1,6 & 1,6 \\
\hline 14 & 1,0 & 1,0 & 1,0 & 1,0 & 1,5 & 18,4 & 24,4 \\
\hline 15 & 0,6 & 0,6 & 0,6 & 0,6 & 0,7 & 0,7 & 0,7 \\
\hline 16 & 0,4 & 0,5 & 0,5 & 0,5 & 0,5 & 0,5 & 0,5 \\
\hline 17 & 18,0 & 18,0 & 18,0 & 17,0 & 17,0 & 17,0 & 17,0 \\
\hline 18 & 0,5 & 0,5 & 0,6 & 0,5 & 0,7 & 4,0 & 10,0 \\
\hline 19 & 25,0 & 28,0 & 32,0 & 33,0 & 33,0 & 33,0 & 33,0 \\
\hline
\end{tabular}


Tabla 9: Temperaturas medias para cada muestreo y profundidad.

\begin{tabular}{|c|c|c|c|c|c|c|c|}
\hline \multirow{2}{*}{$\begin{array}{l}\mathrm{M} \\
\mathrm{U} \\
\mathrm{E} \\
\mathrm{S} \\
\mathrm{T} \\
\mathrm{R} \\
\mathrm{A}\end{array}$} & \multicolumn{7}{|c|}{ PROF U N D I D A D (metros) } \\
\hline & 1 & 3 & 5 & 7 & 9 & 11 & 13 \\
\hline 1 & 21,0 & 21,0 & 21,0 & 21,0 & 21,0 & 21,0 & - \\
\hline 2 & 21,0 & 21,0 & 21,0 & 21,0 & 20,0 & 19,0 & - \\
\hline 3 & 21,0 & 21,0 & 20,0 & 20,0 & 20,0 & 20,0 & 20,0 \\
\hline 4 & 21,0 & 21,0 & 21,0 & 21,0 & 21,0 & 21,0 & 21,0 \\
\hline 5 & 25,0 & 25,0 & 25,0 & 24,0 & 23,0 & 23,0 & 22,0 \\
\hline 6 & 25,0 & 25,0 & 25,0 & 24,0 & 24,0 & 23,0 & 21,0 \\
\hline 7 & 23,0 & 23,0 & 23,0 & 23,0 & 23,0 & 23,0 & 23,0 \\
\hline 8 & 24,0 & 24,0 & 25,0 & 24,0 & 24,0 & 23,0 & 23,0 \\
\hline 9 & 25,0 & 25,0 & 25,0 & 25,0 & 24,0 & 24,0 & 24,0 \\
\hline 10 & 17,9 & 17,9 & 17,9 & 17,9 & 17,9 & 17,9 & 17,9 \\
\hline 11 & 20,0 & 20,0 & 20,0 & 20,0 & 20,0 & 20,0 & 20,0 \\
\hline 12 & 22,0 & 22,0 & 22,0 & 22,0 & 22,0 & 22,0 & 22,0 \\
\hline 13 & 15,0 & 15,0 & 15,0 & 15,0 & 15,0 & 15,0 & 15,0 \\
\hline 14 & 16,0 & 16,0 & 16,0 & 16,0 & 16,0 & 15,5 & 15,5 \\
\hline 15 & 12,0 & 12,0 & 12,0 & 12,0 & 12,0 & 12,0 & 12,0 \\
\hline 16 & 18,0 & 18,0 & 19,0 & 18,0 & 18,0 & 18,0 & 18,0 \\
\hline 17 & 18,0 & 18,0 & 18,0 & 18,0 & 18,0 & 18,0 & 18,0 \\
\hline 18 & 21,0 & 21,0 & $2 I, 0$ & 21,0 & 21,0 & 21,0 & 20,0 \\
\hline 19 & 20,0 & 20,0 & 19,0 & 19,0 & 19,0 & 19,0 & 19,0 \\
\hline
\end{tabular}


de agua y dependiendo de la capacidad eurihalina de cada especie.

En cuanto a las larvas se evidencia un mayor número en primavera y verano y menores densidades en otoño e invier no. Comparando su abundancia con la salinidad y temperatura no se observa ninguna correlación. Como ya fue observado anterior mente en relación a la distribución horizontal, estas larvas pertenecen a especies con hábitos diferentes y al tratarlas en conjunto no se observan preferencias por determinadas condicio nes ambientales.

Calculando el porcentaje de registros de las salinidades y temperaturas en los diferentes niveles, se obtiene el siguiente resultado:

$\begin{array}{rlll}\text { S\%0 } & 1 \mathrm{~m} & 6 \mathrm{~m} & 11 \mathrm{~m} \\ 0-10 & 38 \% & 36 \% & 26 \% \\ 10-20 & 44 \% & 23 \% & 33 \% \\ 20-30 & 14 \% & 36 \% & 50 \% \\ & & & \\ \text { T20 } & 1 \mathrm{~m} & 6 \mathrm{~m} & 11 \mathrm{~m} \\ 12-15 & 29 \% & 29 \% & 42 \% \\ 15-20 & 28 \% & 36 \% & 36 \% \\ 20-25 & 36 \% & 33 \% & 31 \%\end{array}$

Las mayores frecuencias de aguas con salinidades bajas y temperaturas altas fueron registradas en niveles de superficie, mientras que en profundidad los valores se invier ten. 
Ib - VARIACIONES DEL NUNERO DE HUEVOS.

En la Fig. 55 se representó la abundancia de los huevos en cada estrato para las diferentes muestras, colocando los valores de salinidad a la derecha y los de temperatura a la izquierda.

Analizando cada muestra se concluye:

En la 1ㅇ colecta se observan bajas densidades de huevos en toda la columna de agua acompañados de salinidades mínimas de $1,5 \%$ y temperaturas de 21,0 OC.

En la 20 , se presentan salinidades mayores a $20,0 \%$ con un leve aumento en aguas más profundas, observándose también que la temperatura disminuye con la profundidad. Las mayores densidades de huevos se registraron en aguas más superficiales con 26.128 huevos, disminuyendo su número con la pro fundidad.

En el 30 se registraron salinidades de 21,0\% en la superficie, presentando un notable aumento a partir de $5 \mathrm{~m}$ (27,0\%0), estabilizándose luego en 29,0\% hasta el fondo. Ia temperatura presentó consecuentemente el proceso inverso. El mayor número de huevos se registró en $6 \mathrm{~m}$ con una densidad de 15.249 .

En el 4 으 se registró una columna de agua homogéna des de la superficie hasta el fondo con salinidades medias de 30,0\% y temperaturas de 21,00C. EI número de huevos es grande en todos los estratos, registrándose el mayor número a $1.1 \mathrm{~m}$.

En el 50 muestreo se observa una estratificación bien marcada en los parámetros ambientales yacompañando al aumento de la salinidad y disminución de la temperatura en profundidad un aumento importante en el número de huevos.

En el 6o muestreo se observa una estratificación similar tanto en los parámetros físicos como en la densidad de huevos.

En el 7o, realizado a fin de diciembre, a pesar de te ner salinidades más bajas que las registradas en el 4o, el número de huevos registrados en toda la columna de agua fue mayor. El valor máximo se observó a lm con 86.726 y el menor a $11 \mathrm{~m}$ con 62.965 .

En el 8o se presentó una estratificación semejante al observado en el 50 y 60 con un gradual aumento del número de huevos con la salinidad.

E1 9o presenta también una estratificación gradual ha 

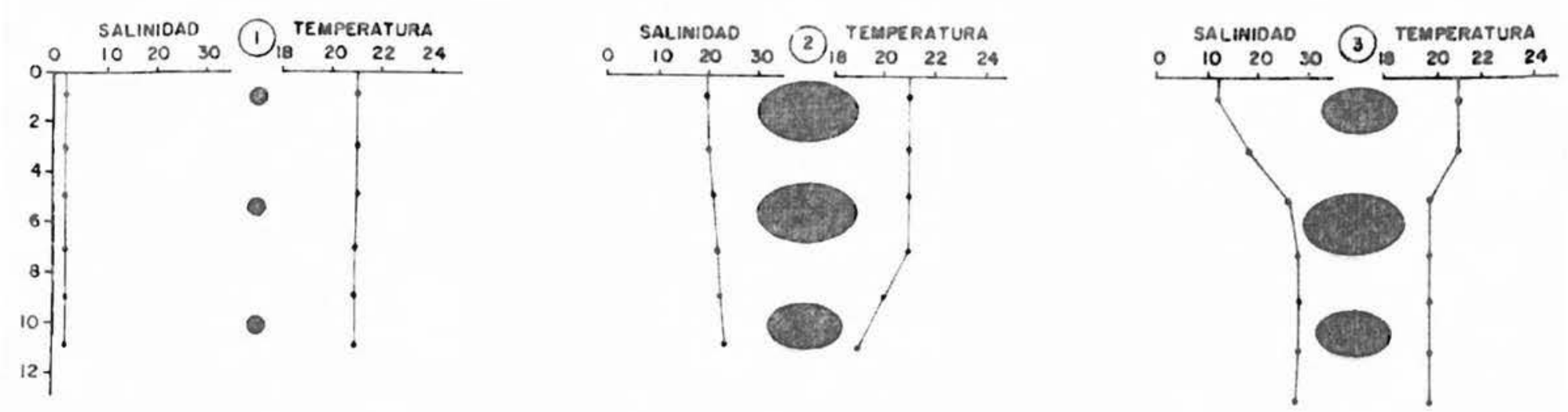

(4)

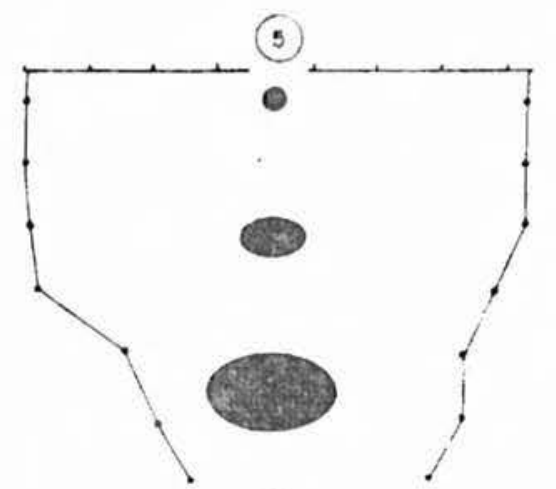

(3)

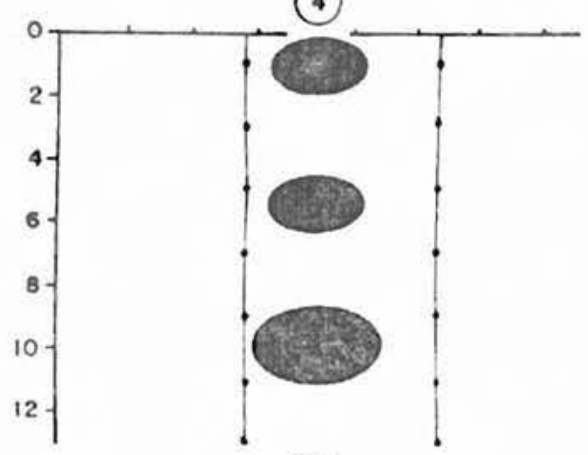

(7)

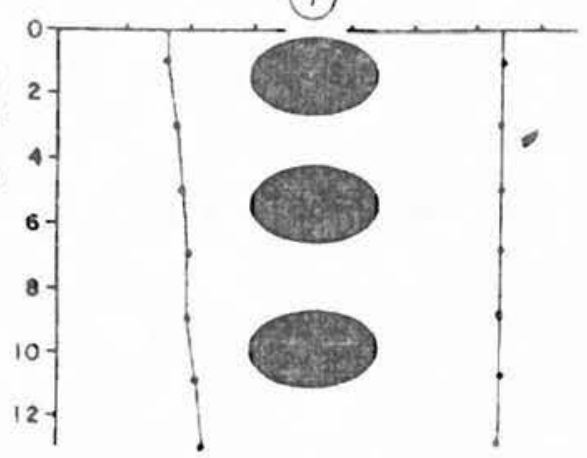

(8)
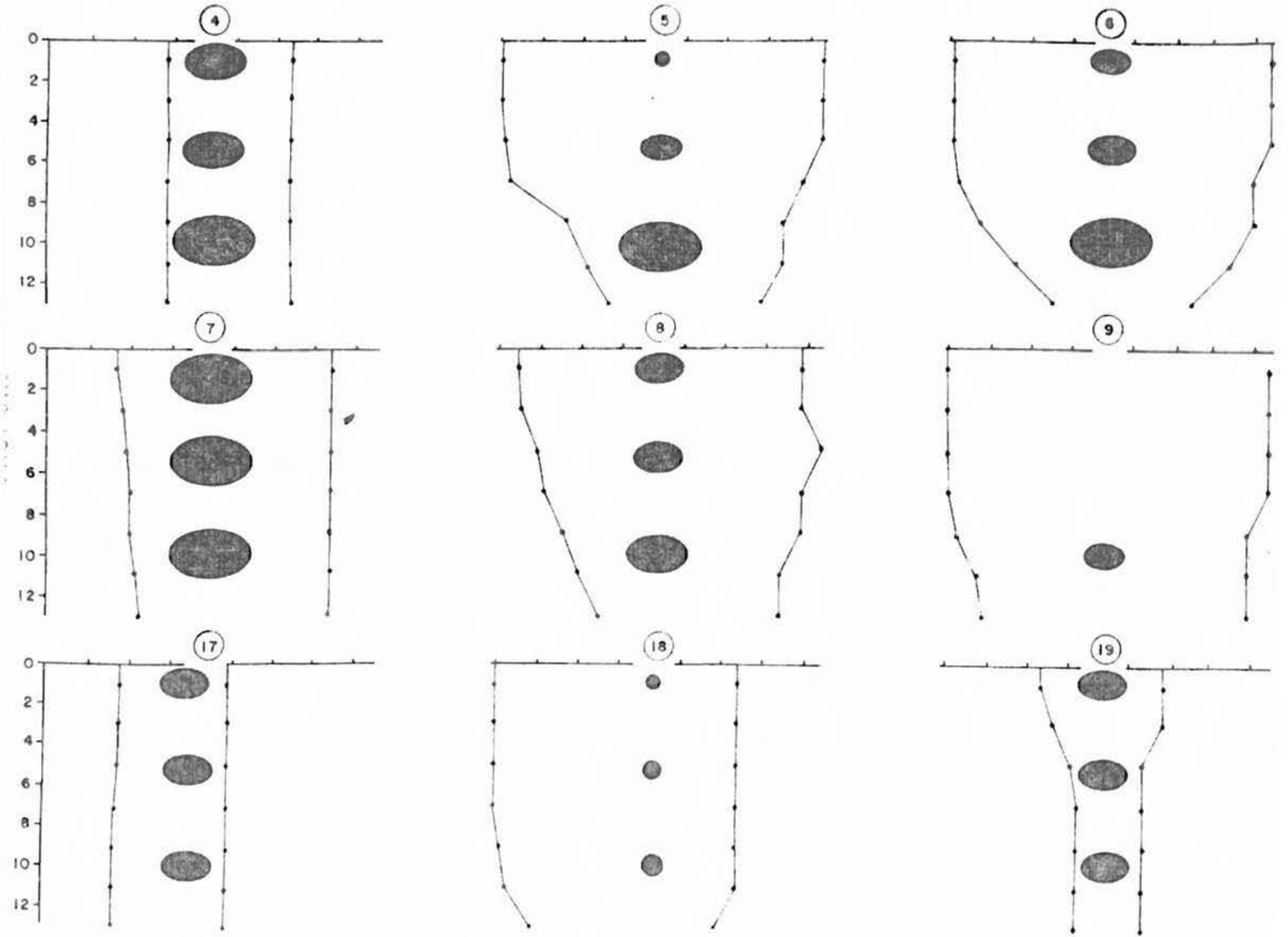

(19)

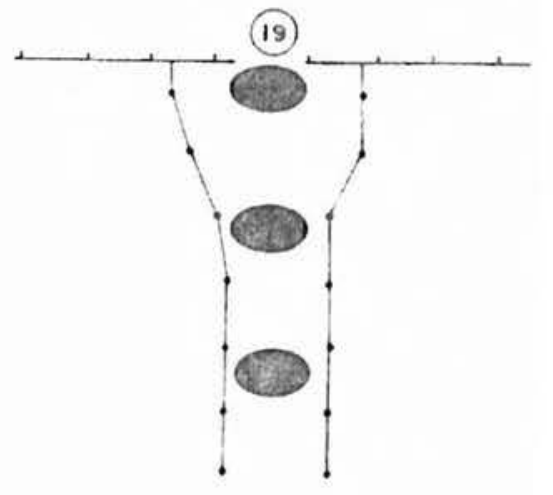

$0-50$ huevos
$51-100$ huevos
$101-1000$ huevos

$1001-10000$ huevos

$>10000$ huevos 
cia el fondo pero con salinidades bien menores. Se hallaron huevos solamente a $11 \mathrm{~m}$, donde la salinidad alcanzó valores de $9,0 \% 0$.

En el 100, que corresponde al otoño, se obtuvo solamente $I$ huevo a $I m$ de profundidad, con salinidad de $3,9 \%$. Luego desaparecen hasta el 160, realizado el 20 de setiembre de 1977, en que aparece 1 huevo a $6 \mathrm{~m}$; en dicha ocasión toda la columna de agua presentaba salinidades minimas de $0,5 \% 0$. EI 17으 se caracteriza por presentar también una co lumna de agua uniforme pero con salinidades de 18\% y $17 \%$ y temperaturas de 18ㅇ․ Ios huevos estan uniformente distri buídos en todos Ios estratos, variando entre 317 a 472.

EI 18으 presenta caracteristicas semejantes al 1으: salinidades bajas en todos los estratos y baja densidad de huevos.Finalmente el 190 tiene salinidades de 25\% , aumentando con la profundidad hasta llegar a 33,0\%o en tanto que la temperatura disminuye de $190 \mathrm{C}$ a $200 \mathrm{C}$; los huevos están distribuídos de forma uniforme, con densidades de 786 a 997.

De todo 10 expuesto se puede deducir que ciertas ca racterísticas ambientales condicionan la presencia y tipo de distribución de los huevos, pudiéndose caracterizar de la si guiente forma:

a) columna de agua homogénea, con salinidades bajas presenta una distribución uniforme de huevos con bajas densidades numéricas ( muestreo 1의 y 18ㅇ).

b) columna de agua homogénea, con salinidades de aproximadamente $20 \%$, presenta una distribución uniforme de huevos con altas densidades numéricas, dependiendo logicamente de la época ( 20,4 으, 7으, 17으 y 19으),

c) columna de agua estratificada con aumento de salinidad y disminución de la temperatura en profundidad, presenta una distribución de huevos cuyas densidades numéri cas van aumentando con la salinidad ( 50,60 , 8ㅇ y 90).

O sea que por ser los huevos de origen marino, es la salinidad principalmente la que condiciona la presencia y distribución de los mismos, independientemente de la pro fundidad.

Realizando la media del número de huevos obtenidos en diferentes salinidades sin considerar las profundidades, se obtienen los siguientes resultados: 
SALINIDAD \%O

$$
\begin{array}{r}
0-5,0 \\
5,1-10,0 \\
10,1-15,0 \\
15,1-20,0 \\
20,1-25,0 \\
25,1-30,0 \\
>30,1
\end{array}
$$

NNO DE HUEVOS

$$
\begin{array}{r}
18,2 \\
108,3 \\
487,0 \\
5.015,5 \\
6.377,1 \\
33.744,2 \\
5.121,8
\end{array}
$$

La media obtenida para valores de más de $30,0 \%$, es pequeña debido a que estos valores se registraron solamente en dos muestras obtenidas a principio de la primavera ( 19 o mues treo). A excepcion de este valor, se observa claramente el aumento del número de huevos con la salinidad, independientemente de la profundidad.

Analizando de la misma forma la abundancia de huevos con la temperatura, se tienen los siguientes resultados:

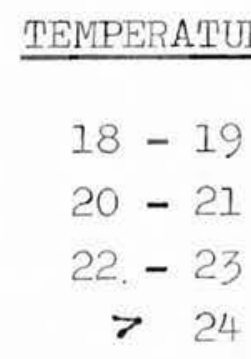

\section{№ DE HUEVOS}

$$
\begin{array}{r}
5.103,2 \\
3.223,0 \\
36.855,3 \\
4 \%, 2
\end{array}
$$

Considerando que el mayor numero de huevos está presente en aguas de origen marino, que son de temperaturas mas bajas, es de esperar que Ios huevos sean más abundantes en aguas mas frîas.Si se observan los datos obtenidos en la tabla, se ve contrariamente que el número aumenta con la temperatura. Esto es explicado por el simple hecho de que el desove mas importante ocurre al final de la primavera y verano, que es cuando la temperatura alcanza su máximo valor ( Fig. 27). Por lo tanto, la variación estacional de la temperatura nos indica un aumento de los huevos con aguas más cálidas.

Si se considera separadamente cada época, se obtienen los siguientes resultados: 


\begin{tabular}{|c|c|c|}
\hline EPOCA & TEMPERATURA 으 & $\underline{N}$ ㅇ $\mathrm{DE} H \mathrm{HU}$ \\
\hline Primavera - 76 & $\begin{array}{l}18-19 \\
20-21\end{array}$ & $\begin{array}{l}7.463 \\
7.542\end{array}$ \\
\hline Verano - 77 & $\begin{array}{l}22-23 \\
24-25\end{array}$ & $\begin{array}{r}67.204 \\
394\end{array}$ \\
\hline Primavera - 77 & $\begin{array}{l}18-19 \\
20-21\end{array}$ & $\begin{array}{l}492 \\
256\end{array}$ \\
\hline
\end{tabular}

Las amplitudes máximas de temperaturas registradas para las primaveras fueron de 180 a 21 으 y para el verano de 220 a 25ㄷ. La expresión numérica más representativa se ob serva en el verano con una media de 67.204 huevos en las temperaturas mínimas para esa época.

De esta forma se evidencia que los huevos de todas las especies penetran en el estuario con aguas de origen marino caracterizadas por su alta salinidad y temperaturas mí nimas.

Ic - VARIACIONES DEI NUNERO DE IARVAS

En las Fig. 56 a 60 se representó la distribución cuali-cuantitativa de las larvas capturadas en cada estrato en las diferentes muestras y se graficó el gradiente de salinidad de la columna de agua. En algunos casos la densidad numérica de algunas especies no fue graficada dado su bajo va lor.

En la Fig. 56, que corresponde a la primavera de 1976, se observa una gran variación tanto en la abundancia co mo en la composición de las especies. La primera muestra regis tró una columna de agua homogénea con salinidades mínimas ( $1,5 \%$ ) y temperaturas de 21으. Las especies colectadas en cada estrato son las mismas, obteniéndose los mayores registros a $6 \mathrm{~m}$ de profundidad ( Tabla 9).

En el 20 muestreo las densidades numéricas dismi nuyeron notablemente, acompañadas por un aumento de la saliní dad con respecto al muestreo anterior. También se observa una disminución de la abundancia en relación con la profundidad y un leve aumento de la salinidad. Aumentan las larvas de $\underline{M}$. fur- 
nieri en aguas más profundas y de Clupeoidei a $6 \mathrm{~m}$.

En el siguiente muestreo aumentó la abundancia de las larvas y cambió la composición de las especies, observándose un acentuado aumento de la salinidad entre la capa super ficial y las aguas más profundas. Ias 163 larvas de Clupeoidei registradas a $1 \mathrm{~m}$ disminuyen a 54 a $6 \mathrm{~m}$ y desaparecen a $11 \mathrm{~m}$. I as larvas de $\underline{M}_{\text {- furnieri }}$ y $\underline{\text { T }}$ - lepturus estan presentes en toda la columna de agua, siendo las de $\underline{M}$. furnieri más abundantes a $6 \mathrm{~m}$ y las de $\underline{\text { T. }}$ lepturus a $1 \mathrm{~lm}$.

En el 40 muestreo con salinidades entre 29\% ( $1 \mathrm{~m}$ )

y 30\%o) ( $11 \mathrm{~m}$ ) en la columna de agua, se presentan mayores abun dancias en las aguas más profundas debido principalmente al aumento de larvas de $\underline{T}$. Iepturus y Clupeoidei. Las Iarvas de M. furnieri y otros Sciaenidae se presentan más abundantes a Im y $11 \mathrm{~m}$.

El 5 o muestreo (Fig. 57) presenta un aumento de la salinidad, principalmente en aguas profundas, acompañadas de un aumento de larvas de $\underline{M}_{\text {- furnieri }}$ y $\underline{\text { T. }}$ lepturus. Las Iarvas de Clupeoidei son mas abundantes a $6 \mathrm{~m}$ con salinidades de $3 \%$.

In el siguiente muestrea el número de larvas aumen tó en toda la columna de agua a pesar de observarse un aumento de la salinidad entre $6 m(2 \% 0)$ y $11 m$ (17\%o). Las larvas de $\underline{M}$. furnieri aumentan con la profundidad y las de Clupeoidei disminuyen. Las de T. Iepturus son mínimas a $11 \mathrm{~m}$ ( 7 larvas“) y aparecen en número relativamente importante las de $\underline{P}$ - valenciennis, especialmente a 6m (158 larvas). La incidencia de Atherinidae se da en todos los niveles, siendo más abundantes a $1 \mathrm{~m}$.

En el 7으 muestreo vuelve a disminuir la abundancia con salinidades de $18 \%$ y $23 \% 0$. Ia incidencia de Clupeoidei es mayor a $6 \mathrm{~m}$ y de $\underline{M}$. furnieri a $1 \mathrm{~m}$. En aguas más superficiales es mayor la ocurrencia de Atherinidae.

Fn el 80 muestreo el aumento de la salinidad es gradual desde la superficie al fondo con una disminución del número total de larvas, siendo en todos los casos las de $\underline{M}$. furnieri las dominantes.

II 9 o muestreo presenta salinidades de $0,6 \% 0$ a $0,8 \%$ a $1 \mathrm{~m}$ y $6 \mathrm{~m}$ respectivamente y $9 \% 0$ a IIm. En Ios niveles superiores dominan las larvas de Clupeoidei y en aguas más profundas las de $\underline{M}$ - furnieri. La incidencia de larvas como

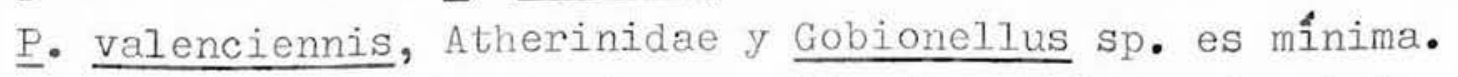

El 1.00 muestreo realizado en el mes de abril (Fig. 58) presenta una columna de agua homogénea con sali- 
nidades de 3,9\%0. La abundancia y composición de las larvas es practicamente igual en los 3 niveles, con una leve disminución a $11 \mathrm{~m}$.

EI 11 muestreo, con salinidades de 2,1\%0 en los 3 estratos, muestra una disminución de la abundancia con la profundidad; la composición de las especies es similar siendo $\underline{M}$. furnieri la dominante en todos los casos.

$\mathrm{E} 1$ 120 muestreo también presenta una columna de agua homogénea con salinidades de 1,8\%o. El número de larvas es bastante menor comparando con el anterior muestreo. La composición de las espécies no varía, siendo en este caso las larvas de Clupeoidei las más abundantes.

E1 13ㅇ muestreo, que corresponde a la época invernal ( Fig. 59) presenta salinidades minimas en los 3 estratos con predominancia absoluta de larvas de Clupeoidei.

El siguiente muestreo (14으) presenta a IIm un aumento de la salinidad de $1,0 \% 0$ a 18,4\%०. A pesar de esto, las larvas que predominan siguen siendo las de Clupeoidei, mostrando un ligero aumento en aguas profundas.

El siguiente muestreo, liltimo de esta época (150), con salinidades mínimas en toda la columna de agua, continuan siendo dominantes las larvas de Clupeoidei aunque comienzan a aparecer los primeros registros de $\underline{M}$ - furnieri.

El 160 muestreo, que corresponde a la primavera de 1977 (Fig. 60) presenta salinidades mínimas en todos los estra tos con bajos registros de larvas; las pocas presentes corresponden a $\underline{P}$. valenciennis, Atherinidae y Gobionellus sp.

En el 170 muestreo se registró un aumento de la salinidad en los tres estratos, con mayores densidades de larvas. Las larvas de $\underline{M}$ - furnieri fueron más abundantes a $6 \mathrm{~m}$, mientras que las de Clupeoidei lo fueron a $1 \mathrm{~m}$; aparecen nuevamente larvas de otros Sciaenidae, principalmente en aguas superficiales.

E1 18ㅇ muestreo, caracterizado por salinidades bajas en toda la columna, presenta dominancia de larvas de $\underline{P}$. $\underline{\text { va- }}$ lenciennis, apareciendo con menor abundancia larvas de clupeoidei, Atherinidae, M. furnieri y Gobionellus sp. en las diferentes profundidades.

El último muestreo se caracteriza por salinidades altas, aumentando con la profundidad, y minimas abundancias de larvas, siendo las de Clupeoidei las que ocurren a $1 \mathrm{~m}$, $\underline{\text { T. }}$ Iepturus a $6 \mathrm{~m}$ y 1 as de Sciaenidae a $6 \mathrm{~m}$ y $11 \mathrm{~m}$.

Como ya fue explicado anteriormente, los muestreos no son comparables cuantitativamente entre sí en especial si se 
consideran las variaciones del flujo de agua en los diferentes estratos. A pesar de esto, se analisó la distribución cuali y cuantitativa, considerando que los datos son un reflejo de la capacidad de penetración de las especies durante las diferentes épocas y condiciones ambientales del estuario. O sea que las grandes variaciones registradas, por ejemplo, en la primavera de 1976, muestran grandes cambios que ocurren en el término de 4 semanas. En el 1 I muestreo se observó una fuerte descarga del estuario lo que determinó el arrastre de larvas del interior ( salinidades bajas y presencia de $\underline{P}$ - valenciennis). En el 20 muestreo comienzan a restaurarse las condiciones de penetración de agua de origen marino, culminando en el 30 y 40 con gran abundancia de larvas de dicho origen ( $\underline{M}$. furnieri y $\underline{T}$. Iepturus). Sucesivamente se van observando determinadas características ambientales, acompañadas de especies que son indica tivas de tales condiciones.

Cuando la salinidad es igual en toda la columna de agua la distribución cuali y cuantitativa tiende a ser homogénea en todos los estratos. Si esa homogeneidad va acompan̈ada de aguas de baja salinidad, las especies más abundantes son Clupeoidei, $\underline{\text { P }}$ valenciennis y Atherinidae. Si los diferen tes estratos tienen alta salinidad, las especies más represen tativas serán M. furnieri y 1 . Iepturus.

Cuando existe estratificación, varía la diversidad y el número de individuos. Como la estratificación siempre se manifiesta a través de un aumento de la salinidad con la profundidad, las especies que más abundan en aguas superficiales son Clupeoidei, $\underline{P}$. valenciennis, Atherinidae y Gobionellus sp., y en aguas más profundas M. furnieri y $\underline{\text { T. }}$ lepturus.

La Tabla 10 representa la media del número de larvas capturadas en cadia Época del año on los diferenties estratos. A pesar de que en cada época existen grandes variaciones que se ven enmascaradas en la media estacional, se observa la tenden cia de las larvas hacia determinados estratos. Las Iarvas de Clupeoidei, $\underline{P}$. valenciennis, Atherinidae y Gobionellus sp. presentaron sus mayores registros en aguas de $6 \mathrm{~m}$ y $\mathrm{lm}$, mientras que $\underline{\text { T. }}$ Iep turus y $\underline{M}$. furnieri son más abundantes en aguas de $11 \mathrm{~m}$.

Si se considera la media total de larvas sin ciiscriminar por especie se obtiene que a Im se colectaron 293 larvas, a $6 m 353$ y a $11 \mathrm{~m}$ 265. Los mayöres registros estan dados a 6m, evidentemente por la presencia de las larvas de Clupeoidei, mientras que entre superficie y fondo las diferencias son minimas. O sea que numéricamente considerada, la estratificación no es importan 
Distribución cuali-cuantitutiva de las larvas capturadas en cada estrato por muestreo. Ia línea vertical representa la salinidad média de cada estrato. la Fig. 56 representa 13 primavera de 1976 , la Fig. 57 al verano de 1376-1377, la/ Fig. 58 al atoño de 1977 , 1 a Fig. 59 al invierno de 1077 " If Tig. 63 a la primavera de 1377 .

Simbología utilizada para las larvas:

|n.m. I. III - Clupeoidei

\% - P. valenciennis

\#D - Atherinidae

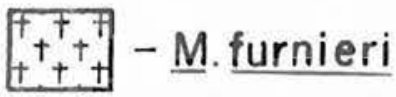
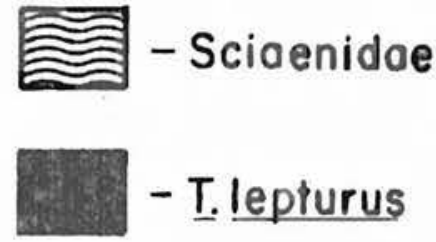

$=-\overline{-}=-$ Gobionellus sp.

$\square$ - Otros 

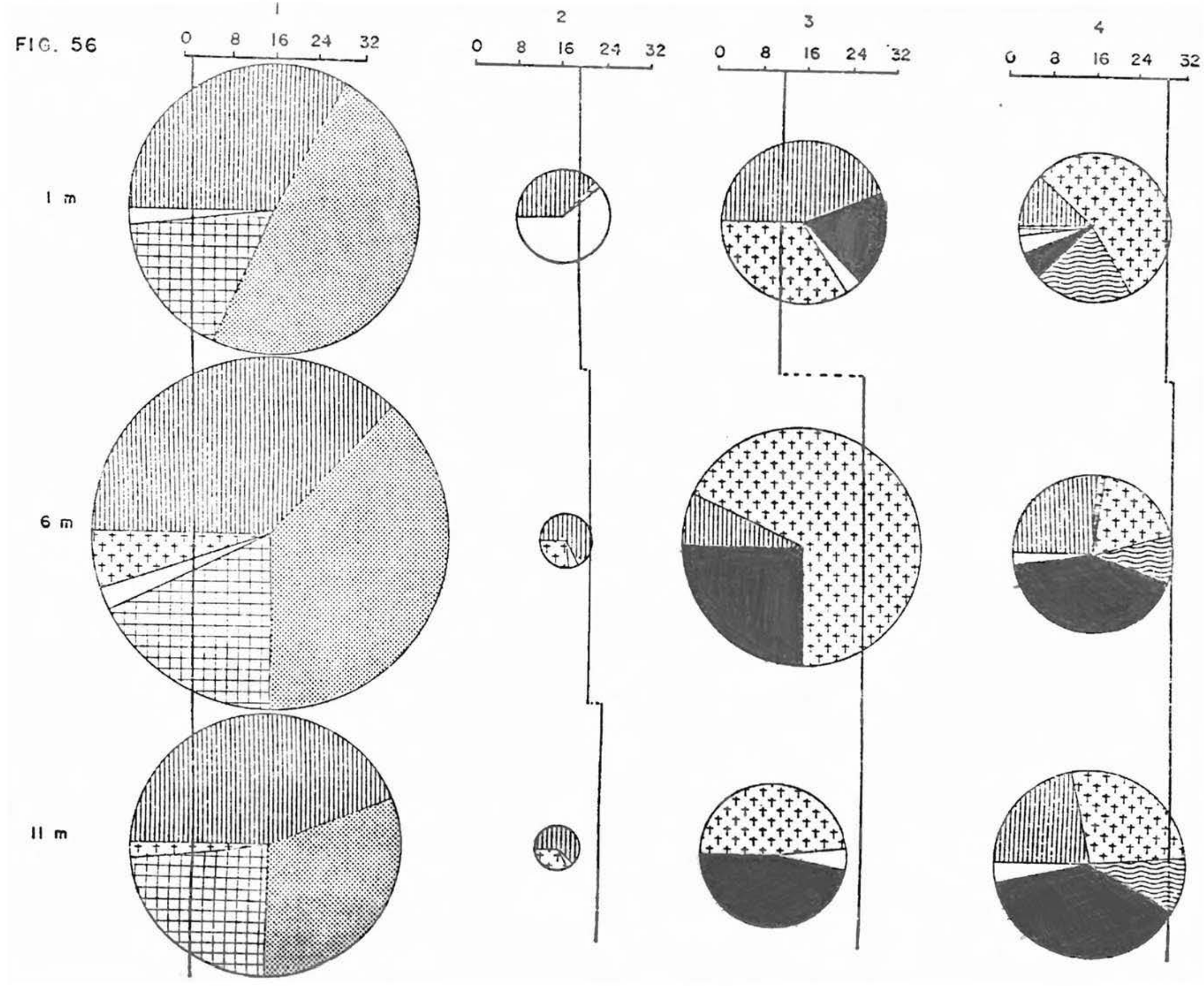
FIG. 57

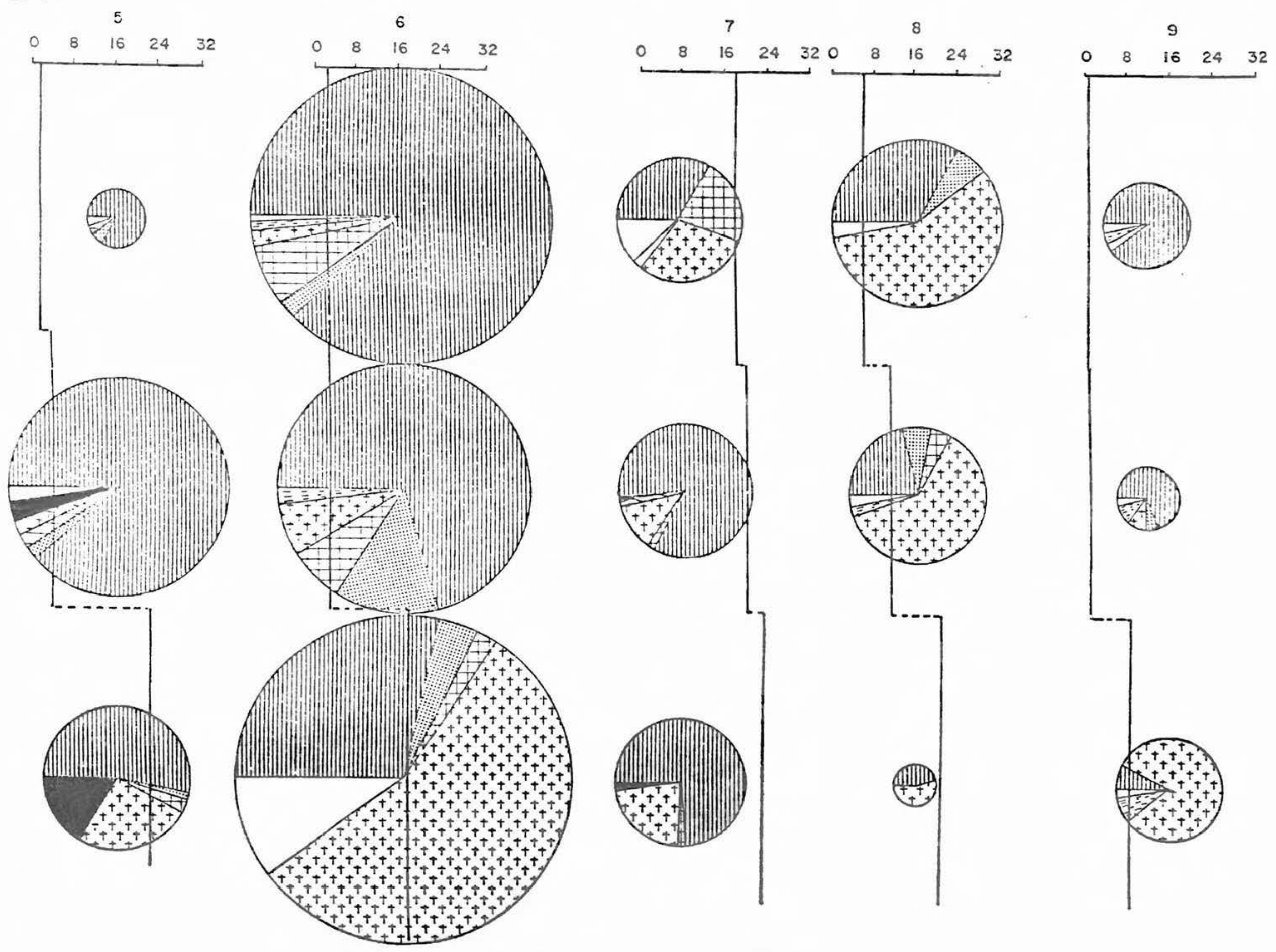



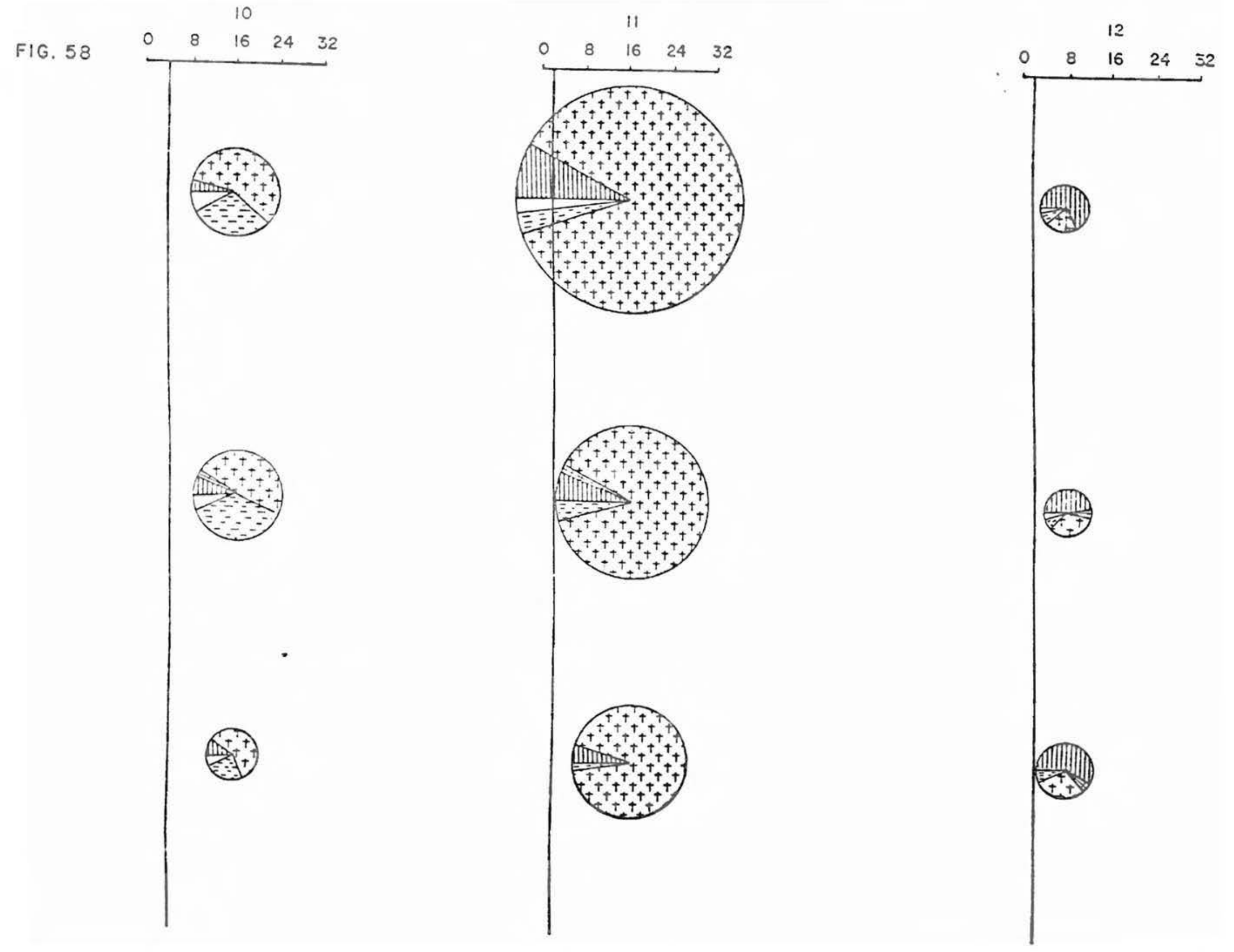

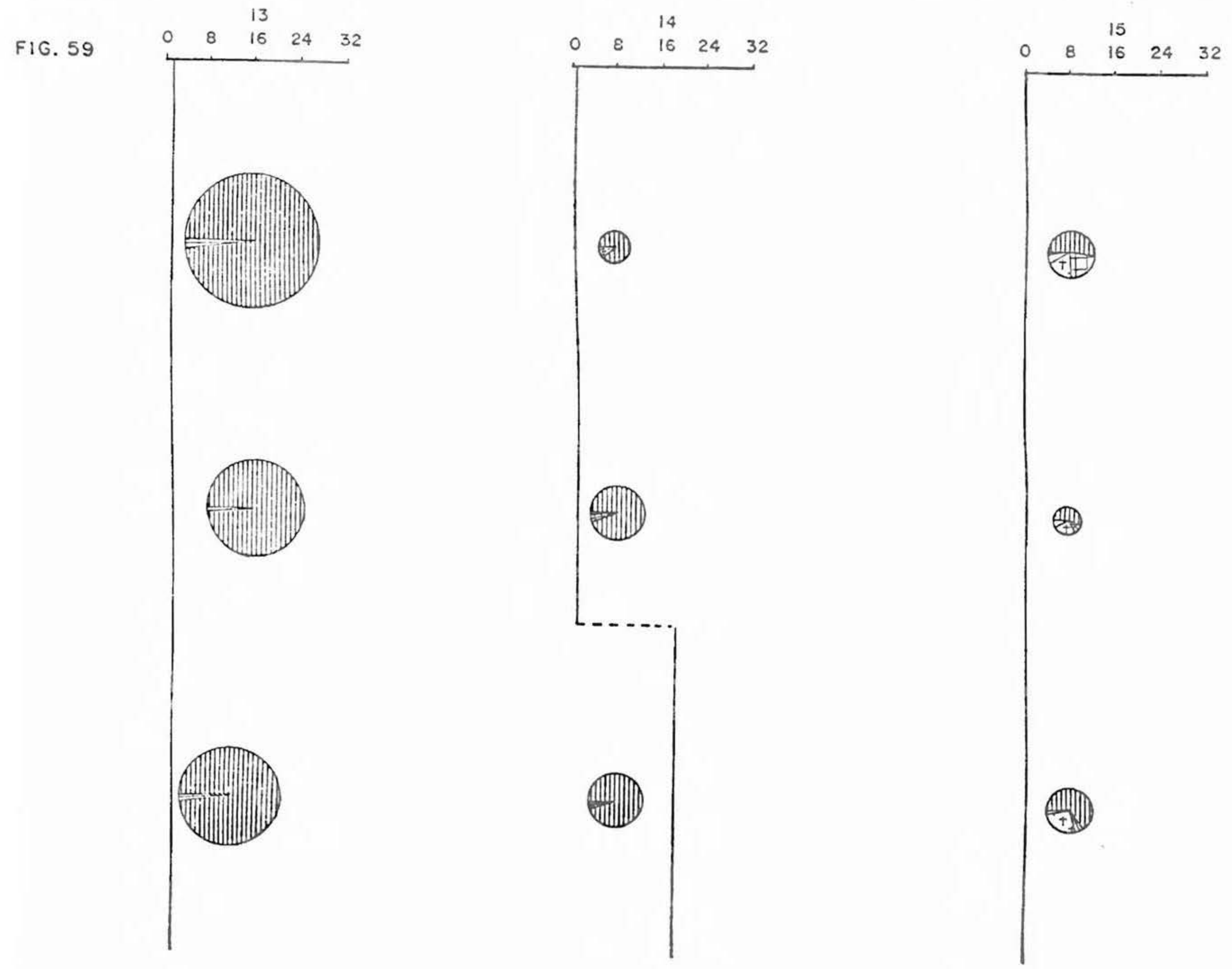

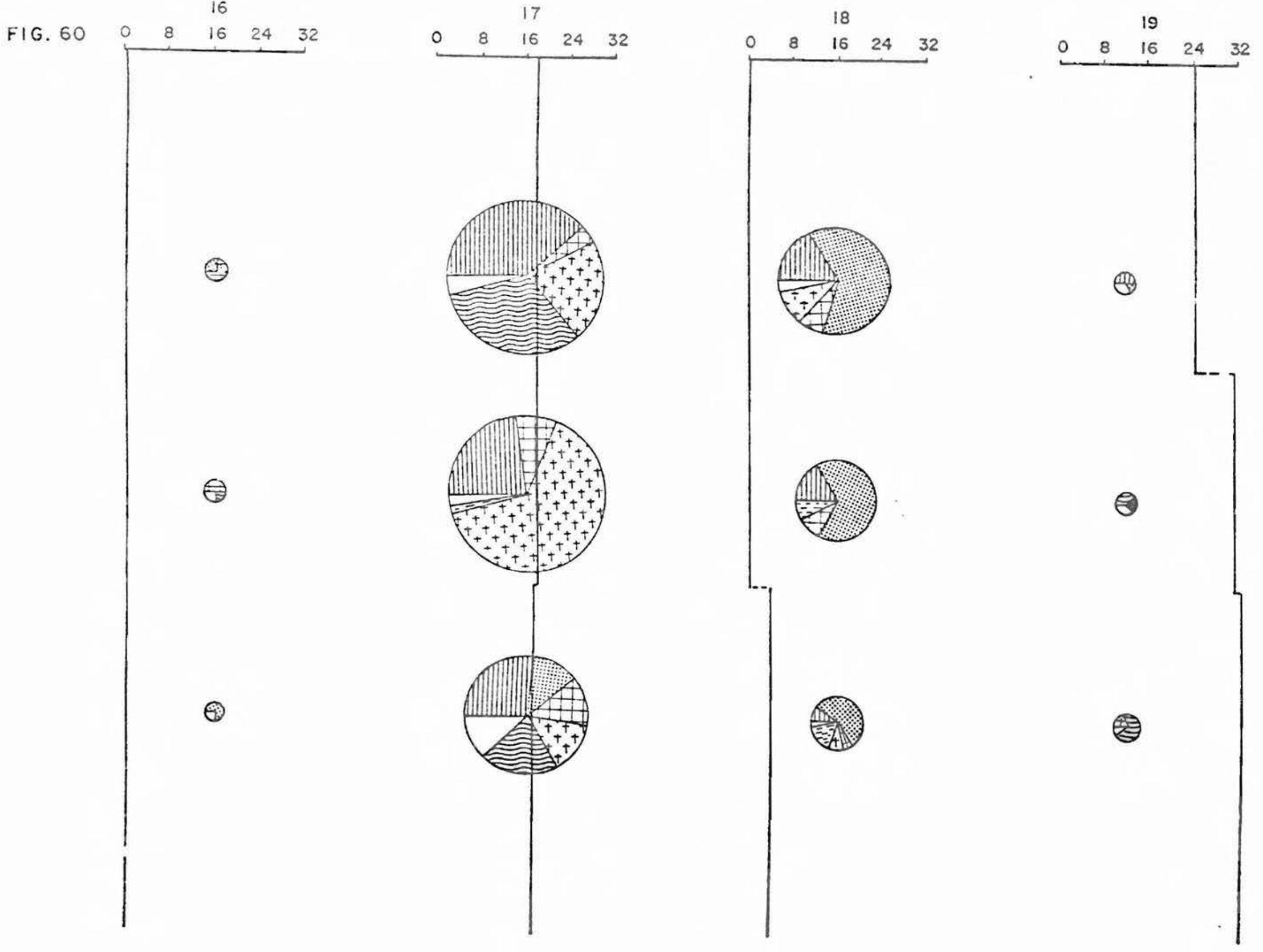
Tabla 10: Número de larvas capturadas en cada muestreo y cada profundidad( metros).

\begin{tabular}{|c|c|c|c|c|c|c|c|c|c|c|c|c|c|c|c|c|c|c|c|c|c|}
\hline \multirow{2}{*}{$\begin{array}{l}\mathrm{M} \\
\mathrm{U} \\
\mathrm{E} \\
\mathrm{S} \\
\mathrm{T} \\
\mathrm{R} \\
\mathrm{A}\end{array}$} & \multicolumn{3}{|c|}{ Clupeoidei } & \multicolumn{3}{|c|}{$\underline{P} \cdot \underline{\text { valenciennis }}$} & \multicolumn{3}{|c|}{ Atherinidae } & \multicolumn{3}{|c|}{ M. furnieri } & \multicolumn{3}{|c|}{ Sciaenidae } & \multicolumn{3}{|c|}{ T. } & \multicolumn{3}{|c|}{ Gobionellus sp. } \\
\hline & I & 6 & 11 & 1 & 6 & 11 & 1 & 6 & $1 i$ & 1 & 6 & 11 & 1 & 6 & 11 & 1 & 6 & 11 & 1 & 6 & II \\
\hline 1 & 425 & 699 & 493 & 631 & 718 & 347 & 206 & 340 & 235 & 6 & 95 & 22 & - & - & - & - & - & - & - & - & - \\
\hline 2 & 38 & 18 & 24 & - & - & - & 1 & 1 & - & - & 7 & 12 & - & - & - & - & - & - & - & - & 1 \\
\hline 3 & 163 & 54 & - & - & - & - & - & - & - & 126 & 522 & 162 & - & 2 & - & 70 & 192 & 158 & - & - & - \\
\hline 4 & 41 & 95 & 126 & - & - & - & 3 & 4 & - & 189 & 70 & 154 & 72 & 33 & 51 & 21 & 157 & 223 & - & - & - \\
\hline 5 & 34 & 750 & 219 & 2 & 17 & 4 & 2 & 17 & 12 & 1 & 17 & 106 & - & - & 1 & - & 25 & 65 & - & - & - \\
\hline 6 & 986 & 861 & 504 & 22 & 158 & 72 & 78 & 85 & 36 & 22 & 85 & 1007 & - & - & - & - & - & 7 & 11 & 24 & 33 \\
\hline 7 & 76 & 241 & 133 & - & - & - & 51 & 3 & 2 & 74 & 35 & 41 & 2 & 3 & - & - & 3 & 2 & - & - & - \\
\hline 8 & 138 & 56 & 9 & 25 & 19 & - & - & 13 & - & 242 & 167 & 11 & - & - & - & - & - & - & - & 5 & - \\
\hline 9 & 98 & 36 & 14 & - & 2 & - & - & 1 & - & 1 & 5 & 87 & - & - & - & - & - & - & 4 & 6 & 9 \\
\hline 10 & 1 & 6 & 5 & - & - & - & - & 1 & - & 76 & 39 & 29 & - & - & - & - & - & - & 39 & 30 & 12 \\
\hline 11 & 64 & 21 & 10 & - & - & - & - & 3 & - & 691 & 308 & 191 & - & - & - & - & - & - & 24 & 14 & 2 \\
\hline 12 & 20 & 17 & 21 & - & - & - & $I$ & 2 & 2 & 4 & 13 & 11 & - & - & - & - & - & - & 3 & 3 & 1 \\
\hline 13 & 251 & 113 & 156 & - & - & - & 5 & 1 & 3 & - & - & - & - & - & - & - & - & - & - & 1 & 1 \\
\hline 14 & 9 & 48 & 42 & - & - & - & - & $I$ & $I$ & - & - & 1 & - & - & - & - & - & - & 1 & 1 & 1 \\
\hline 15 & 13 & 5 & 16 & - & - & $I$ & 5 & 1 & $I$ & 5 & 3 & 6 & - & - & - & - & - & - & 1 & 1 & - \\
\hline 16 & - & - & - & $I$ & - & 2 & 2 & 1 & - & - & - & - & - & - & - & - & - & - & - & 1 & - \\
\hline 17 & 118 & 79 & 50 & - & - & 25 & 12 & 27 & 25 & 68 & 226 & 27 & 99 & 16 & 40 & - & - & - & - & 3 & - \\
\hline 18 & 22 & 15 & 4 & 111 & 60 & 22 & 12 & 8 & 2 & - & 1 & 3 & - & - & - & - & - & - & 17 & 6 & -6 \\
\hline 12 & 2 & - & - & 1 & - & - & - & - & - & - & - & - & - & 1 & 3 & - & 1 & - & - & - & - \\
\hline
\end{tabular}


te, mientras que desde el punto de vista de la diversidad sí 10 es.

Calculando la media del número de larvas y la fre cuencia de registros a diferentes salinidades y temperaturas, independientemente de la época y estrato en que fueron colectadas (Tabla 11, 12 y 13), se observan las siguientes características de cada especie:

1) Las Iarvas de Clupeoidei presentaron una constancia casi absoluta en todos los rangos de salinidad y temperatura. El mayor número de larvas se presentó en salinidades de 0 a $5 \% 0$ y temperaturas mayores a $249 \mathrm{C}$. Fueron halladas 141 larvas en temperaturas de 14 a 15 oc, que corresponden a la época invernal.

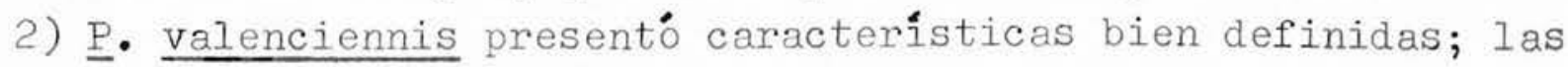
mayores frecuencias y abundancias se registraron en salinidades minimas y temperaturas elevadas.

3) Las Larvas de Atherinidae se presentaron más abundantes en salinidades de 5 a 20\% y temperaturas de 20 a 25ㄷ, a pesar de tener una elevada frecuencia en todos los rangos de salinidad y temperatura.

4) M. furnieri fue frecuente en todos los rangos de salinidad y temperatura, presentado mayores densidades en altas salinidades y temperaturas.

5) Las larvas de $\underline{\text { Tel }}$ lepturus fueron características de aguas de altas salinidades y temperaturas,

6) Las de Gobionellus sp. en número menor mostraron preferencias por salinidades bajas, mientras que aparecieron en todas las tem peraturas por el prolongado período reproductivo de esta especié. 7) Las larvas de Achirus farmani en número de 1 a 3, se presentaron en el 40 muestreo a $11 \mathrm{~m}$, en el 9 ㅇ y 10 a $1 \mathrm{~m}$, en el 11 ㅇa $6 \mathrm{~m}$ y en el 120 en los tres niveles de profundidad, mostrando preferencias por aguas de baja salinidad y alta temperatura.

8) Las larvas de los Sciaenidae correspondieron a $\underline{P} \cdot$ brasiliensis, M. ancylodon y U. canosai. En todos los casos baja densidad y preferencias por aguas profundas, de alta salinidad y temperaturas elevadas.

9) Finalmente Ias larvas de $\underline{G}$. Strumosus con mínimas abundancias aparecieron en el 4 을 muestreo a $6 \mathrm{~m}$, en el 7 으 a $1 \mathrm{~m}$, en el 80 a $6 \mathrm{~m}$ y en el 180 a $11 \mathrm{~m}$. La inconstancia y bajo número limitan cualquier apreciación sobre su comportamiento. 
Tabla 1l: Medias del numero de larvas por época.

\begin{tabular}{|c|c|c|c|c|c|c|c|c|c|c|c|c|c|c|c|c|c|c|c|c|c|}
\hline \multirow{2}{*}{ EPOCA } & \multicolumn{3}{|c|}{ Clupeoidei } & \multicolumn{3}{|c|}{ P.valenciennis } & \multicolumn{3}{|c|}{ Atherinidae } & \multicolumn{3}{|c|}{ M. furnieri } & \multicolumn{3}{|c|}{ Sciaenidae } & \multicolumn{3}{|c|}{ T. 1 epturus } & \multicolumn{3}{|c|}{ Gobionellus sp. } \\
\hline & Im & $6 \mathrm{~m}$ & $11 \mathrm{~m}$ & $\operatorname{Im}$ & $6 \mathrm{~m}$ & $11 \mathrm{~m}$ & Im & $6 \mathrm{~m}$ & $1.1 \mathrm{~m}$ & $\mathrm{Im}$ & $6 \mathrm{~m}$ & $11 \mathrm{~m}$ & $\mathrm{Im}$ & $6 \mathrm{~m}$ & $11 \mathrm{~m}$ & $I \mathrm{~m}$ & $6 \mathrm{~m}$ & $1 \mathrm{~m}$ & $\operatorname{lm}$ & $6 \mathrm{~m}$ & $11 \mathrm{~m}$ \\
\hline P & 167 & 216 & 161 & 158 & 179 & 87 & 52 & 86 & 59 & 80 & 173 & 87 & 18 & 9 & 13 & 23 & 87 & 95 & - & - & 0,3 \\
\hline V & 266 & 389 & 176 & 10 & 39 & 15 & 26 & 24 & 10 & 68 & 62 & 242 & 0,4 & 0,6 & 0,2 & - & 6 & 15 & 3 & 7 & 2 \\
\hline$I$ & 91 & 55 & 71 & - & - & - & 3 & 1 & 2 & 2 & 1 & 2 & - & - & - & - & - & - & 1 & 1 & 1 \\
\hline $\mathrm{P}$ & 36 & 23 & 13 & 28 & 15 & 12 & 6 & 9 & 7 & 17 & 57 & 8 & 25 & 0,3 & 11 & - & 0,3 & - & 4 & 2 & 2 \\
\hline TOTAL & 132 & 164 & 96 & 42 & 51 & 23 & 20 & 27 & 17 & 79 & 84 & 96 & 9 & 2 & 5 & 5 & 20 & 24 & 5 & 4 & 2 \\
\hline
\end{tabular}


Tabla 12: Media del numero de larvas para los diferentes rangos de salinidad y temperatura de las especies consideradas.

\begin{tabular}{|c|c|c|c|c|c|c|c|c|}
\hline & & Clupeoidei & $\underline{P} \cdot \underline{\text { valenciennis }}$ & Atherinidae & M. furnieri & Sciaenidae & T. Iepturus & Gobionellus sp. \\
\hline 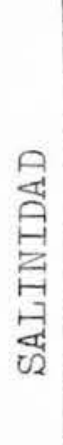 & $\begin{array}{r}0-5 \\
5-10 \\
10-15 \\
15-20 \\
20-25 \\
25-30 \\
>30\end{array}$ & $\begin{array}{r}158 \\
76 \\
110 \\
129 \\
92 \\
63 \\
-\end{array}$ & $\begin{array}{r}65 \\
13 \\
10 \\
13 \\
4 \\
- \\
-\end{array}$ & $\begin{array}{r}33 \\
128 \\
121 \\
147 \\
22 \\
2 \\
-\end{array}$ & $\begin{array}{r}51 \\
177 \\
147 \\
200 \\
27 \\
219 \\
-\end{array}$ & $\begin{array}{r}- \\
- \\
- \\
15 \\
1 \\
32 \\
3\end{array}$ & $\begin{array}{r}1 \\
- \\
35 \\
1 \\
9 \\
150 \\
1\end{array}$ & $\begin{array}{l}6 \\
1 \\
3 \\
1 \\
- \\
- \\
-\end{array}$ \\
\hline 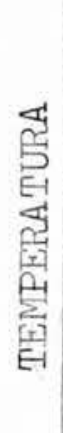 & $\begin{array}{r}12-13 \\
14-15 \\
16-17 \\
18-19 \\
20-21 \\
22-23 \\
>24\end{array}$ & $\begin{array}{r}11 \\
141 \\
17 \\
27 \\
126 \\
138 \\
330\end{array}$ & $\begin{array}{r}- \\
- \\
- \\
3 \\
105 \\
8 \\
27\end{array}$ & $\begin{array}{r}2 \\
2 \\
1 \\
7 \\
45 \\
12 \\
22\end{array}$ & $\begin{array}{r}5 \\
1 \\
17 \\
21 \\
142 \\
145 \\
70\end{array}$ & $\begin{array}{r}- \\
- \\
- \\
14 \\
6 \\
1 \\
-\end{array}$ & $\begin{array}{r}- \\
- \\
- \\
- \\
46 \\
9 \\
3\end{array}$ & $\begin{array}{r}1 \\
1 \\
11 \\
4 \\
4 \\
1 \\
7\end{array}$ \\
\hline
\end{tabular}


Tabla 13: Porcentaje de estaciones positivas para los diferentes rangos de salinidad y temperatura de las especies consideradas.

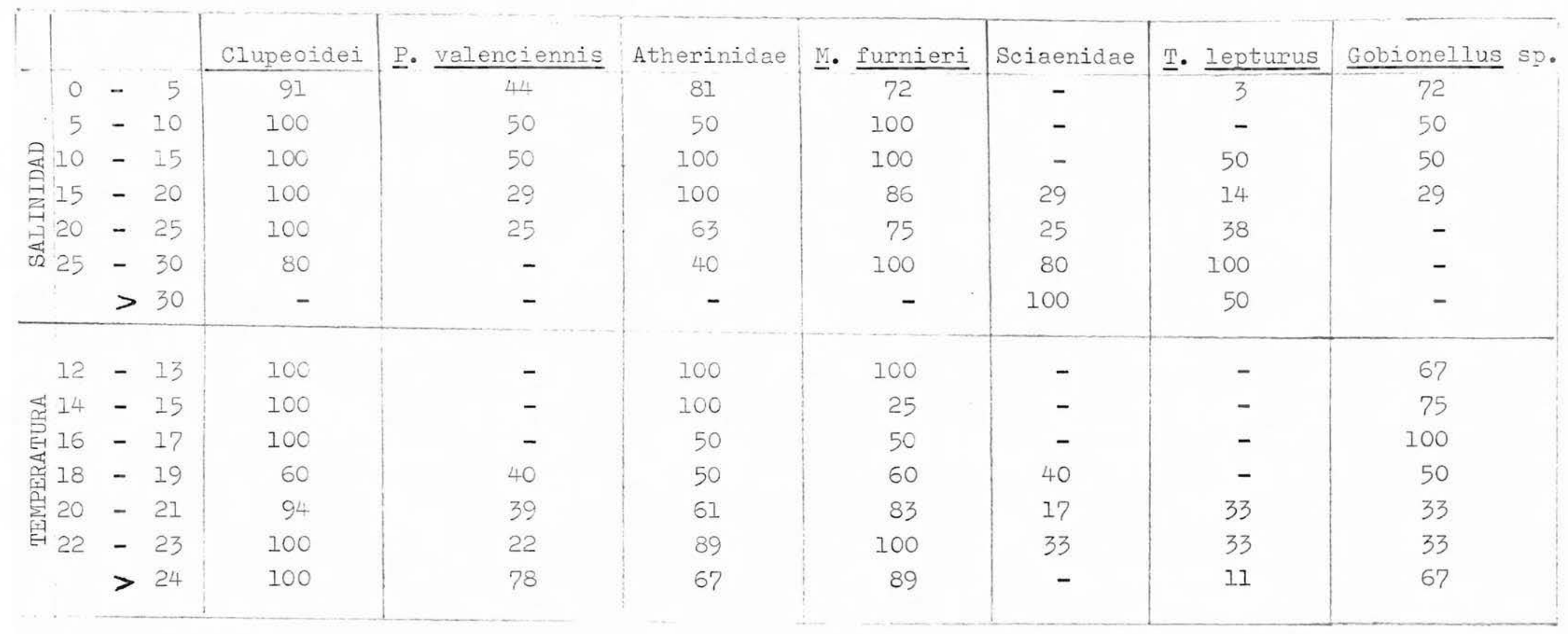




\section{Id - TRES NIVETES DE PROFUNDIDAD.}

Compurando cl número de larvas capturadas en los lances diumos y nocturnos de los diferentes niveles, se observan grandes variaciones ( Tabla 14 y 15). Estas variaciones son diferentes para cada especie. En las muestras diurnas las larvas de Clupeoidei fueron más abundantes a $6 \mathrm{~m}$, mientras que en las nocturnas lo fueron a Im. Igual comportamiento se observa en $\underline{P}$. valenciennis y en Gobionellus sp., aunque de forma menos manifiesta. Las larvas de Atherinidae, tanto de día como de noche,

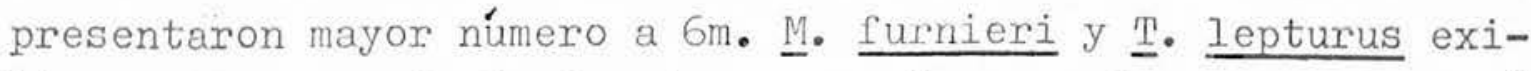
bieron una marcada tendencia a aumentar en número en aguas más profundas, independientemente de la hora del muestreo.

Considerando separadamente los muestreos realizados cuando la columna de agua fué homocénea y cuando fue estratificada, se observan comportamientos más definidos de las diferentes larvas (Fig. 61). En el primer caso ( Fig. 61 A) se observa: las larvas de Clupeoidei presentaron de día mayor abundancia a $6 \mathrm{~m}, \mathrm{y}$ de noche una distribución practicamente homogénea; P. valenciennis presentó mayores resistros en la capa superior de agua, aumentando sus valores a $6 \mathrm{~m}$ durante el día; Atherinidae presentó preferencias durante el día por aguas entre los $6 \mathrm{~m}$ y IIm, y de noche por los 6m; los mayores registros de larvas de M. furnieri y Gobionellus sp. se obtuvieron en aguas superficiales indistintamente de día o de noche, mientras que $\underline{\text { T. }}$ lepturus presentó siempre preferencias por aguas profundas.

Cuando la columna de agua fue heterogénea (Fig. 6I B) las Iarvas de Clupeoidei y $\underline{P}$ - valenciennis presentaron mayor numero a $6 \mathrm{~m}$ de día y entre $I m$ a $6 \mathrm{~m}$ de noche. Atherinidae presentó mayor densidad a $6 m$ tanto de día como de noche. $\underline{\text { M }}$ furnieri y $\underline{\text { I }}$. lepturus estuvieron siempre presentes con mayores densidades en aguas profundas. Gobionellus sp. royistró sus mayores presencias a $6 \mathrm{~m}$ de día y a $11 \mathrm{~m}$ de noche.

De este análisis se deduce que las larvas de clupeoi-

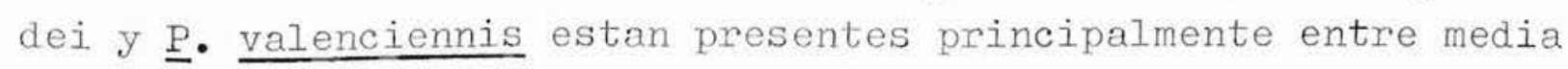
agua y superficie de noche y efectúan una migración para aguas intermedias durante el día, principalmente cuando existe estratificación. Las larvas de Atherinidae, que mostraron una marcada preferencia por aguas de $6 \mathrm{~m}$ de profundidad, tienden a migrar para aguas más profundas durante el día. Cuando la columna de 
agua es homogénea las larvas de $\underline{M}$ - furnieri se presentaron principalmente en aguas más superficiales. Posiblemente al presentar un corto período planctónico y escasa capacidad de migrar, su distribución acompaña la de los huevos. Inversamente, cuando ocurre estratificación, sus mayores registros se observan en aguas profundas al acompañar la penetración del agua de origen marino.

El hecho de que las larvas de $\underline{\text { T}}$. lepturus ( tanto de día como de noche, e independientemente de las características de la columna de agua) presentan mayor número en aguas profundas, es quizás, consecuencia de que el ambiente no le es propicio y pierden su capacidad de flotación. Ias larvas de Gobionellus sp. en aguas homogéneas presentan acentuada tendencia por niveles superficiales, independientemente de la incidencia de la luz. La naturaleza bentónica de los huevos está indicando un acentuado fototropismo positivo. En aguas con estratificación su' comportamiento es más aleatório.

En definitiva, considerando la fuerte corriente que se observa en el canal de entrada, existen larvas como las de

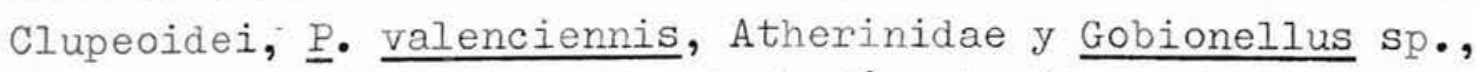
que consiguen efectuar una migración nictimeral venciendo la resistencia del medio. 
Tabla 14: Número de larvas colectadas en cada muestreo diurno.

\begin{tabular}{|c|c|c|c|c|c|c|c|c|c|c|c|c|c|c|c|c|c|c|}
\hline \multirow{2}{*}{ MUESTRA } & \multicolumn{3}{|c|}{ Clupeoidei } & \multicolumn{3}{|c|}{ P-valenciennis } & \multicolumn{3}{|c|}{ Atherinidae } & \multicolumn{3}{|c|}{ M。furnieri } & \multicolumn{3}{|c|}{ T. lepturus } & \multicolumn{3}{|c|}{ Gobionellus sp. } \\
\hline & $1 \mathrm{~m}$ & $6 \mathrm{~m}$ & $11 \mathrm{~m}$ & $\mathrm{Im}$ & $6 \mathrm{~m}$ & $11 \mathrm{~m}$ & $\operatorname{lm}$ & $6 \mathrm{~m}$ & $11 \mathrm{~m}$ & Im & $6 \mathrm{~m}$ & $11 \mathrm{~m}$ & $\operatorname{lm}$ & $6 \mathrm{~m}$ & $11 \mathrm{~m}$ & $\mathrm{Im}$ & $6 \mathrm{~m}$ & $11 \mathrm{~m}$ \\
\hline $\begin{array}{r}1 \\
2 \\
3 \\
4 \\
5 \\
6 \\
7 \\
8 \\
9 \\
10 \\
11 \\
12 \\
13 \\
14 \\
15 \\
16 \\
17 \\
18 \\
19\end{array}$ & $\begin{array}{r}352 \\
32 \\
136 \\
42 \\
9 \\
1 \\
39 \\
70 \\
4 \\
5 \\
7 \\
13 \\
180 \\
6 \\
4 \\
46 \\
10 \\
1\end{array}$ & $\begin{array}{r}562 \\
13 \\
28 \\
92 \\
401 \\
82 \\
41 \\
28 \\
26 \\
4 \\
1 \\
4 \\
77 \\
7 \\
- \\
- \\
28 \\
4 \\
-\end{array}$ & $\begin{array}{r}291 \\
15 \\
5 \\
92 \\
42 \\
16 \\
64 \\
4 \\
7 \\
3 \\
3 \\
3 \\
10 \\
125 \\
14 \\
5 \\
25 \\
25 \\
1 \\
-\end{array}$ & $\begin{array}{r}394 \\
- \\
- \\
- \\
- \\
1 \overline{2} \\
- \\
- \\
- \\
- \\
- \\
- \\
- \\
- \\
57 \\
-\end{array}$ & $\begin{array}{r}490 \\
- \\
\overline{-} \\
8 \\
50 \\
\overline{9} \\
1 \\
- \\
- \\
- \\
- \\
- \\
- \\
- \\
36 \\
-\end{array}$ & $\begin{array}{r}206 \\
= \\
\overline{-} \\
4 \\
18 \\
- \\
\overline{1} \\
= \\
- \\
- \\
- \\
- \\
- \\
- \\
15 \\
-\end{array}$ & $\begin{array}{r}132 \\
= \\
- \\
- \\
1 \\
- \\
1 \\
- \\
- \\
- \\
1 \\
- \\
- \\
4 \\
2 \\
5 \\
- \\
-\end{array}$ & $\begin{array}{r}184 \\
1 \\
- \\
- \\
9 \\
20 \\
1 \\
6 \\
1 \\
1 \\
- \\
- \\
- \\
1 \\
1 \\
1 \\
- \\
- \\
-\end{array}$ & $\begin{array}{r}167 \\
- \\
- \\
- \\
4 \\
4 \\
1 \\
- \\
- \\
- \\
- \\
- \\
1 \\
- \\
1 \\
- \\
4 \\
- \\
-\end{array}$ & $\begin{array}{r}- \\
1 \\
34 \\
168 \\
\overline{1} \\
43 \\
121 \\
1 \\
56 \\
193 \\
1 \\
- \\
\overline{4} \\
- \\
31 \\
- \\
-\end{array}$ & $\begin{array}{r}98 \\
6 \\
432 \\
50 \\
17 \\
26 \\
17 \\
84 \\
4 \\
25 \\
30 \\
6 \\
- \\
- \\
1 \\
14 \\
1 \\
-\end{array}$ & $\begin{array}{r}3 \\
4 \\
116 \\
72 \\
24 \\
711 \\
5 \\
5 \\
122 \\
13 \\
54 \\
6 \\
- \\
- \\
2 \\
- \\
9 \\
-\end{array}$ & $\begin{array}{l}- \\
- \\
4 \\
- \\
= \\
= \\
= \\
= \\
= \\
= \\
= \\
= \\
- \\
- \\
-\end{array}$ & $\begin{array}{r}- \\
96 \\
108 \\
20 \\
\overline{2} \\
\overline{-} \\
\overline{-} \\
\overline{-} \\
\overline{-} \\
\overline{-} \\
\overline{-} \\
\overline{-} \\
\overline{-}\end{array}$ & 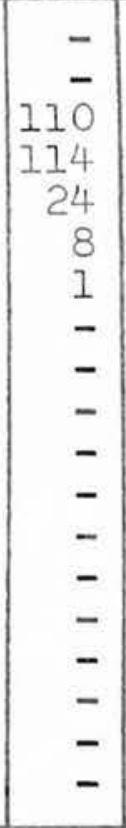 & $\begin{array}{l}- \\
\overline{-} \\
\overline{-} \\
\overline{-} \\
\overline{-} \\
\overline{-} \\
\overline{-} \\
4 \\
2 \\
1 \\
- \\
- \\
\overline{1} \\
11 \\
-\end{array}$ & $\begin{array}{l}- \\
= \\
- \\
\overline{-} \\
\overline{8} \\
- \\
5 \\
5 \\
27 \\
4 \\
2 \\
1 \\
- \\
- \\
1 \\
1 \\
4 \\
-\end{array}$ & $\begin{array}{l}- \\
- \\
- \\
- \\
- \\
- \\
\overline{6} \\
9 \\
2 \\
1 \\
- \\
- \\
- \\
- \\
5 \\
1\end{array}$ \\
\hline Total & 957 & 1398 & 723 & 463 & 594 & 244 & 147 & 226 & 182 & 663 & 811 & 1046 & 4 & 226 & 257 & 56 & 58 & 24 \\
\hline
\end{tabular}


Tabla 15: Numero de larvas colectadas en cada muestreo nocturno.

\begin{tabular}{|c|c|c|c|c|c|c|c|c|c|c|c|c|c|c|c|c|c|c|}
\hline \multirow{2}{*}{ Muestra } & \multicolumn{3}{|c|}{ Clupeoidei } & \multicolumn{3}{|c|}{ P-valenciennis } & \multicolumn{3}{|c|}{ Atherinidae } & \multicolumn{3}{|c|}{ M. furnieri } & \multicolumn{3}{|c|}{ T. } & \multicolumn{3}{|c|}{ Gobionellus sp. } \\
\hline & Im & $6 \mathrm{~m}$ & $11 \mathrm{~m}$ & $1 \mathrm{~m}$ & $6 \mathrm{~m}$ & $11 \mathrm{~m}$ & $1 \mathrm{~m}$ & $6 \mathrm{~m}$ & $11 \mathrm{~m}$ & $\operatorname{lm}$ & $6 \mathrm{~m}$ & $11 \mathrm{~m}$ & $\operatorname{lm}$ & $6 \mathrm{~m}$ & $11 \mathrm{~m}$ & $\mathrm{Im}$ & $6 \mathrm{~m}$ & $11 \mathrm{~m}$ \\
\hline $\begin{array}{r}1 \\
2 \\
3 \\
4 \\
5 \\
6 \\
7 \\
8 \\
9 \\
10 \\
11 \\
12 \\
13 \\
14 \\
15 \\
16 \\
17 \\
18 \\
19\end{array}$ & $\begin{array}{r}84 \\
6 \\
29 \\
- \\
25 \\
1256 \\
37 \\
- \\
92 \\
5 \overline{9} \\
6 \\
72 \\
2 \\
8 \\
3 \overline{2} \\
11 \\
1\end{array}$ & $\begin{array}{r}140 \\
4 \\
25 \\
24 \\
261 \\
778 \\
200 \\
- \\
9 \\
2 \\
19 \\
12 \\
36 \\
47 \\
5 \\
- \\
32 \\
9 \\
-\end{array}$ & $\begin{array}{r}181 \\
8 \\
10 \\
36 \\
177 \\
491 \\
69 \\
- \\
12 \\
2 \\
6 \\
13 \\
30 \\
28 \\
10 \\
- \\
16 \\
2 \\
-\end{array}$ & 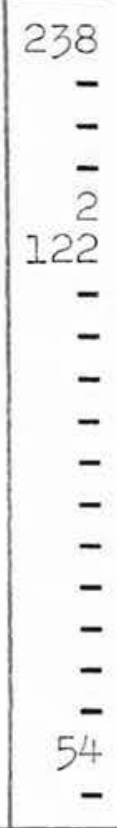 & $\begin{array}{r}242 \\
- \\
\overline{-} \\
18 \\
108 \\
\overline{-} \\
\overline{-} \\
\overline{-} \\
\overline{-} \\
\overline{-} \\
\overline{-} \\
\overline{-} \\
\overline{-}\end{array}$ & $\begin{array}{r}130 \\
- \\
- \\
- \\
\overline{-} \\
48 \\
- \\
\overline{-} \\
\overline{-} \\
\overline{-} \\
\overline{-} \\
\overline{-} \\
1 \\
7 \\
24 \\
7 \\
-\end{array}$ & $\begin{array}{r}78 \\
2 \\
- \\
4 \\
1 \\
92 \\
3 \\
-1 \\
1 \\
-1 \\
1 \\
4 \\
-1 \\
- \\
4 \\
12 \\
1\end{array}$ & $\begin{array}{r}164 \\
- \\
\overline{2} \\
7 \\
66 \\
2 \\
- \\
- \\
- \\
2 \\
2 \\
1 \\
1 \\
1 \\
- \\
8 \\
8 \\
-\end{array}$ & $\begin{array}{r}55 \\
- \\
1 \\
\overline{8} \\
32 \\
1 \\
-1 \\
1 \\
1 \\
2 \\
1 \\
1 \\
- \\
16 \\
2 \\
-\end{array}$ & $\begin{array}{r}6 \\
- \\
94 \\
20 \\
1 \\
18 \\
32 \\
- \\
\overline{9} \\
498 \\
3 \\
- \\
- \\
- \\
12 \\
- \\
-\end{array}$ & $\begin{array}{r}4 \\
1 \\
73 \\
20 \\
2 \\
56 \\
16 \\
- \\
1 \\
13 \\
278 \\
6 \\
- \\
- \\
1 \\
- \\
208 \\
- \\
-\end{array}$ & $\begin{array}{r}21 \\
8 \\
45 \\
80 \\
80 \\
296 \\
35 \\
- \\
1 \\
16 \\
136 \\
6 \\
- \\
7 \\
3 \\
24 \\
3 \\
-\end{array}$ & 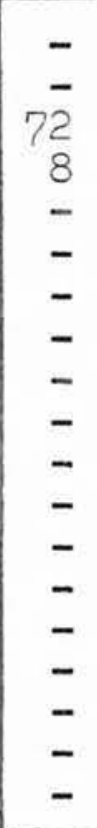 & 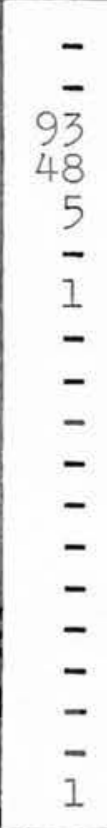 & 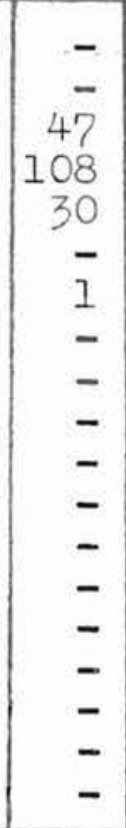 & $\begin{array}{r}\overline{-} \\
\overline{-} \\
\overline{-} \\
12 \\
- \\
\overline{4} \\
3 \\
16 \\
1 \\
\overline{1} \\
1 \\
\overline{-} \\
\overline{7} \\
-\end{array}$ & $\begin{array}{l}- \\
\overline{-} \\
\overline{-} \\
\overline{16} \\
- \\
\overline{-} \\
\overline{2} \\
7 \\
1 \\
- \\
1 \\
1 \\
\overline{1} \\
2 \\
-\end{array}$ & $\begin{array}{l}\overline{-} \\
\overline{-} \\
\overline{-} \\
3 \overline{3} \\
- \\
\overline{5} \\
2 \\
\overline{1} \\
1 \\
1 \\
\overline{-} \\
\overline{1} \\
-\end{array}$ \\
\hline Total & 1720 & 1597 & 1091 & 416 & 391 & 211 & 205 & 261 & 121 & 693 & 679 & 755 & 80 & 148 & 186 & 45 & 31 & 44 \\
\hline
\end{tabular}




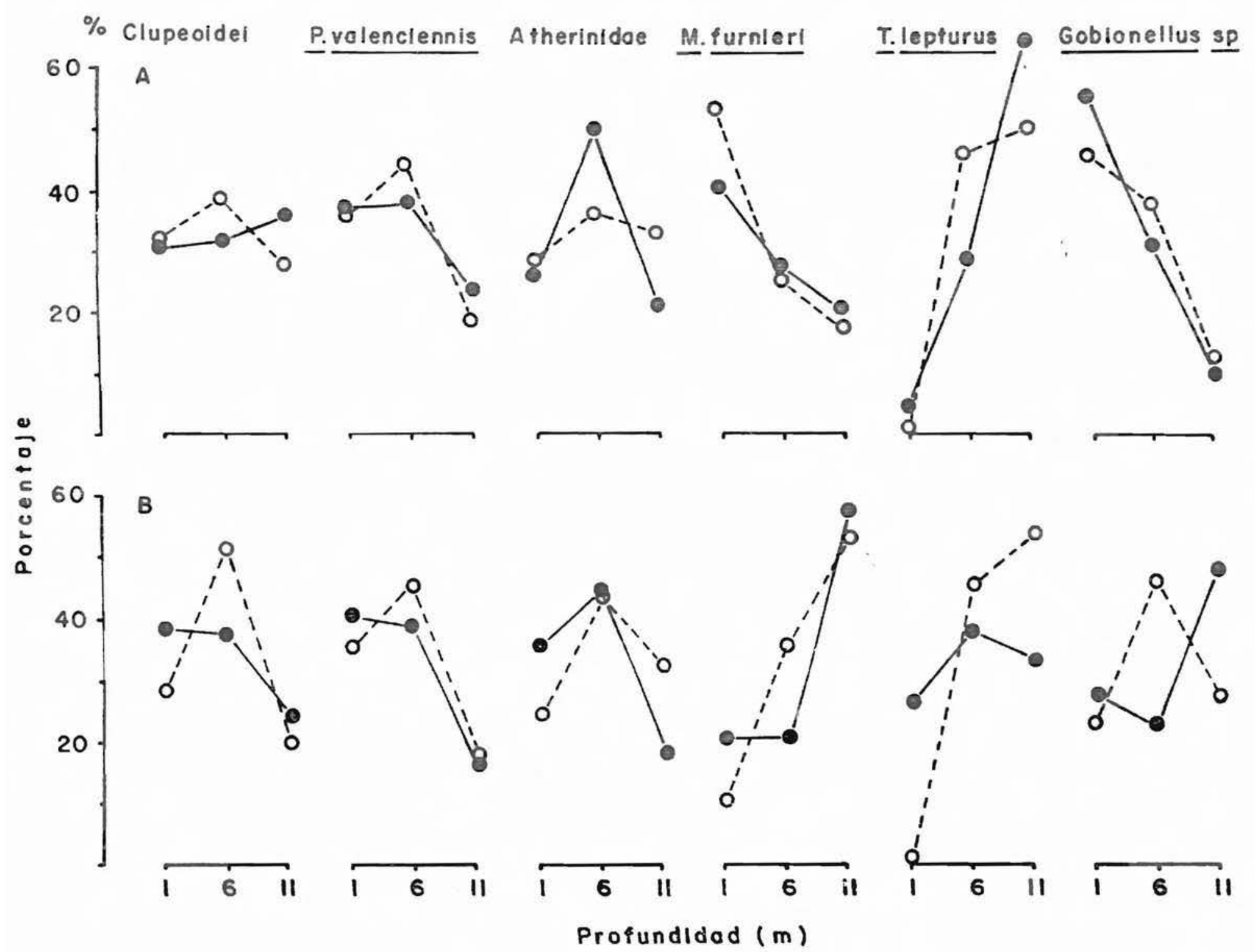

Fig. 61: Porcentaje de las larvas obtenidas en las diferentes profundidades en los muestreos diurnos (--) y nocturnos (-). A: columna de agua homogènea; B: con estratificación. 


\section{$V-\underline{\text { CONCLUSIONES }}$}

A - GENERALIDADES DEL ICTIOPLANCTON ESTUARIAL.

Lagoa dos Patos es la mayor área lagunar de América del Sur, siendo la principal cuenca receptora de las aguas fluviales del Estado de Rio Grande do Sul. El canal del estuario, con una boca de solo $700 \mathrm{~m}$, descarga en el mar las aguas que pro vienen del vasto sistema lagunar formado por Lagoa dos Patos y Lagoa Mirim. Esta forma un embudo en el área estuarial provoca corrientes muy bruscas dando mayor inestabilidad al ecosistema ( Malaval, 1916), de forma que pocas especies consiguen adaptarse y penetrar. Esta situacion determina que el estuario tenga una baja diversidad especifica. Por otra parte, los huevos y larvas planctónicas son afectadas directamente por su dependencia directa con el medio ambiente. Es asimismo importante señalar que, siendo pocas las especies que utilizan este estuario como área de cría, la competencia interespecífica es minima, lo que favorece la abundancia numérica.

La primera etapa de vida ( el desarrollo embrionario) se produce en aguas con salinidades mayores a $20 \% 0$, mientras que la etapa posterior, de alimentación y cría, ocurre en el área estuarina, con aguas oligohalinas entre 0\%a a 5\%o, donde fue encontrado el 75\% de las larvas.

\section{$B$ - DISTR IBUCION HORIZONTAT,}

La presencia de huevos planctónicos está regida exclusivamente por los flujos de penetración de agua de mar, por ser todos de origen marino. Por esta razón su ausencia en invierno no indica que las especies no desoven, ya que esta época se caracteriza por desagues prolonfados. Las mayores abundancias se registruron en primavera, verano y otoño. Las larvas planctónicas, por el contrário, son de distintos orígenes (marino, estuarino o de agua dulce) presentando por lo tanto comportamientos diferentes.

La especie dominante fue $\underline{\text { M }}$ furnieri, con una representación del 89\% de los huevos. Ias otras especies presentes fueron en orden de importancia: A. carmani, I. grossidens, $\underline{\text { B }}$ pectinata $y \underline{T}$. Iepturus. L mayor registro de huevos de $\underline{M}$ - $\underline{\text { fur- }}$ nieri fue en el verano de 1976 con una media de 935,7 huevos/ 
$100 \mathrm{~m}^{3}$

Las larvas más representativas fueron $\underline{I}$ • grossidens con un 44\%, B. pectinata con 20,1\% y $\underline{M}$. furnieri con $13,1 \%$. Los mayores registros fueron para $L$ - grossidens de 74,5 larvas/100m ${ }^{3}$ en la primavera de 1975, de $\overline{35,5 \text { larvas/100m }}{ }^{3}$ en la misma época para $\underline{B}$. pectinata y $15, \%$ larvas/100m ${ }^{3}$ en el verano de 1978 para $M_{0}$ furnieri.

Comparando la composición cuantitativa de los huevos y las larvas en las diferentes épocas, se observa que la presencia de unos no necesariamente acompaña la presencia de los otros. Mientras que la mayor incidencia de huevos es de M. fur$\underline{\text { nieri, }}$ la presencia de larvas de $\underline{\text { - }}$ grossidens y $\underline{B}$ - pectinata son las más importantes. Estos resultados son consecuencia de: a) mayor proximidad del área de desove de $\underline{M}$ - furnieri al área estuarial, posibilitando la mayor penetración de huevos; b) mayor alejamiento del desove de $\underline{B}$. pectinata y $\underline{L}$ - grossidens; c) corta fase de vida planctónida de las larvas de $\underline{\text { M. }}$ furnieri $; d)$ prolongado tiempo de vida planctónica de las larvas de $\underline{B}$ - pectinata $\mathrm{y}$ I. grossidens ; e) diferente capacidad eurihalina de los huevos de las 3 especies, siendo que $\underline{I}$ grossidens y $\underline{B} \cdot \underline{\text { pec- }}$ tinata, por ser Clupeiformes, tienen reducida capacidad de osmorregulación, etc.

En cuanto a $\underline{A}$ - garmani, que es una especie típicamente ostunrinl, ol desove estín condicionado exclusivamente n las condiciones ambientales del estuario. Sus larvas tienen un período de vida planctónico muy corto, siendo sus registros de número reducido.

Con respecto a $\underline{T}$. lepturus, el número de huevos fue pequeño y las larvas se presentaron de forma ocasional. Esta especie de hábitos marinos, penetra en el estuario en forma accidental, cuando existen condiciones de penetración de agua de origen marino y su desove ocurre en aguas próximas al canal de entrada.

Entre las larvas de especies con huevos planctónicos que se registraron en el estuario estaban $\underline{M} \cdot \underline{\text { ancylodon, }} \underline{\text { P }}$ bra-

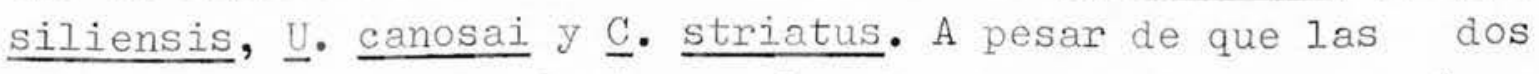
primeras son muy abundantes en Ia etapa juvenil, fueron siempre muy escasas en el estado larval. Los registros no superaron el $0,5 \%$, evidenciando que el desove ocurre en aguas más alejadas por lo que su etapa embrionaria y larval se produce en aguas tipicamente marinas; esto fue notorio nara $\underline{U}$. canosai y $\underline{\text { c. Stria- }}$ tus, cuya presencia fue ocasional. 
Las especies con huevos bentónicos como $\underline{H}$ - kronei, Blennius sp., Gobionellus sp y Gobiesox strumosus y las pertenecientes a la Familia Atherinidae no fueron abundantes, pe ro mostraron una alta constancia, principalmente las últimas. Las larvas del bagre de agua dulce $\underline{P}$. valenciennis en circuns tancias de desague del estuario son arrastradas hacia el mar en número relativamente grande. Su presencia por lo tanto, en

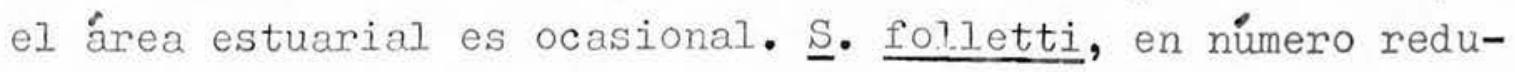
cido, es un representante de alta constancia en el área.

Se observó una gran afinidad entre larvas de $\underline{B}$. pectinata y I. grossidens aumentando ésta en aguas de menor salinidad. Estas dos especies penetran al estuario y procuran aguas más internas, donde completan su desarrollo larval; por tener el mismo hábito alimenticio ( planctófagas) y ocupar el mismo hábitat, posiblemente sean especies competidoras; mientras que, a pesar de presentar una coexistencia espacial impor tante con las larvas de $\underline{M}$. furnieri y Atherinidae, los coeficientes de afinidad con estas últimas fueron menores a 0,5 , in dicando características de comportamiento diferentes.

Los huevos de $\underline{B}$. pectinata y $\underline{I}$. grossidens estuvieron ausentes on la época invernal y en algunos otoños y primaveras por presentar salinidades muy bajas. Las mayores incidencias ocurrieron en salinidades muy elevadas, a pesar que en las épocas donde su abundancia era elevada hubo registros en salinidades menores a 5\%o. Las mayores abundancias se registraron en las temperaturas mas frias de primavera y verano y más calidas del otoño, por ser de origen marino. Sus larvas estuvieron presentes en todas las épocas del año presentando $\underline{B}$ - pectinata mayores densidades en primavera y otoño y I - grossidens en primavera y verano. Ambas fueron más abundantes en las menores salinidades a pesar de presentar alta capacidad eurihalina.

Las larvas de $\underline{\underline{P}}$ - valenciennis se presentaron siempre en aguas oligohalinas, principalmente en los momentos que ocurría un desague en el estuario, llegando a estar presentes en el canal de acceso. Su presencia se registró principalmente en primavera y verano.

Las larvas de $\mathrm{H}$ - kronei, en densidades pequeñas, estuvieron presentes en primavera, verano y otoño en salinidades mínimas y temperaturas de 22 a $240 \mathrm{C}$, a pesar de registrarse en forma ocasional en salinidades de $30 \%$.

Ias larvas de Atherinidae fueron frecuentes en todas las épocas del año con mayores registros en primavera. Estuvieron presentes en todos los rangos de salinidad, mostrando pre- 
ferencias por aguas oligohalinas.

S. folletti, en número reducido, fue constante en todas las épocas del año, mostrando alta capacidad eurihali na y euritérmica, sin preferencias por determinadas condicio nes ambientales.

Los huevos de $\underline{M}$. furnieri estuvieron presentes en todas las épocas a excepción del inviemo. Las mayores densidades se observaron en las mayores salinidades, a pesar de caracterizarse por su alta capacidad eurihalina, observándose registros en salinidades menores a 5\%o. En primavera y verano se presentaron en aguas de origen marino, consecuente mente más frias y a la inversa en otoño. Sus larvas en menor número mostraron igual tendencia y alta capacidad eurihalina.

EI número de larvas de $\underline{P} \cdot \underline{\text { brasiliensis, }} \underline{\text { M ancylo- }}$ don, U. canosai y $\underline{\mathrm{S}}$. Striatus fue muy pequeño en primavera y verano, en aguas tipicamente de origen marino.

Las larvas de Blennius $\mathrm{sp}$. estuvieron ausentes sola mente en el invierno, siendo en densidades mínimas bastante constantes. Mostraron alta capacidad eurihalina, con preferen cia por salinidades elevadas. En primavera y verano fueron más abundantes en aguas más frias y en otoño en aguas templadas.

Con poca constancia y en bajas salinidades se halla ron huevos y larvas de $\underline{\mathrm{T}}$. Iepturus en primavera, verano y oto ño. Ios mayores registros fueron en verano. Fue de todas las especies la que presentó menor capacidad eurihalina. La menor salinidad en que aparecieron los huevos y larvas fue de $20 \%$. Por ser tipicamente marina acompañó las menores temperaturas en primavera y verano y las mayores en otoño.

Las larvas de Gobionellus sp. fueron muy constantes, presentándose en todas las épocas del año. Los mayores registros ocurrieron en verano y otoño. No presentó preferencias por determinadas salinidades o temperaturas.

Los huevos de $\underline{A}$ - garmani aparecieron en primavera, verano y otoño, y sus larvas en primavera y verano solamente. Las mayores incidencias se observaron en aguas de alta salinidad, con menores temperaturas en primavera y verano y mayo res en otoño.

Finalmente las larvas de $\underline{G}$. strumosus aparecieron con alta frecuencia pero en numero reducido en todas las épo cas del año. Fstuvicron presentes en torlos los rangos de salinidad, mostrando preferencias por aguas de mayor salinidad, menor temperatura en primavera y verano y mayor en otoño. 
A pesar del error de muestreo que ofrece la falta de flujómetro en un ambiente inestable se pudieron deducir hechos significativos.

Al igual que en la distribución horizontal, los flujos y reflujos de agua condicionan la distribución vertical de Ios huevos y de determinados tipos de larvas en los diferentes niveles de profundidad.

En relación con Ios huevos se verificó que cuando la columna de agua es homogénea, con salinidades bajas, la densidad de éstos es baja en todos los niveles, en tanto que con salinidades altas aumenta la abundancia homogéneamente, dependiendo en todos los casos de la época. Con una columna de agua estratificada la mayor abundancia de los huevos se registró en las capas con mayor salinidad, presentes a mayor profundidad.

Los mayores registros de huevos se observaron en pri mavera $y$ verano en aguas de menor temperatura por ser de origen marino.

En relación a las larvas se observó que su presencia responde a determinadas condiciones ambientales. Cuando la salinidad es igual en toda la columna de agua la distribución cuali-cuantitativa es homogénea en todos los niveles. Si esa homogeneidad va acompañada de aguas de poca salinidad, las especies más abundantes son: Clupeoidei, $\underline{F}$ valenciennis, Atheri nidae y Gobionellus sp. Si los diferentes niveles de profundidad se caracterizan por alta salinidad las especies más representativas serán $\underline{M}$. furnieri y $\underline{T}$. Iepturus.

Cuando existe estratificación la diversidad y número de los individuos depende de la época. Como la estratificación se traduce siempre en un aumento de la salinidad con la profun didad, las especies más abundantes en ajuas superficiales serán Clupeoidei, $\underline{P} \cdot$ valenciennis, Atherinidae y Gobionellus sp. y y en aguas más profundas 1 - furnieri y T. lepturus.

Un esquema simplificado del comportamiento de las principales especies está dado en la Fig. 62. El gráfico mues tra la densidad de huevos y larvas que penetran en el estuario, el tiempo de vida planctónico de las especies, el comportamien to de las especies estuariales y el bajo aporte de larvas de origen dulceacuícola. 


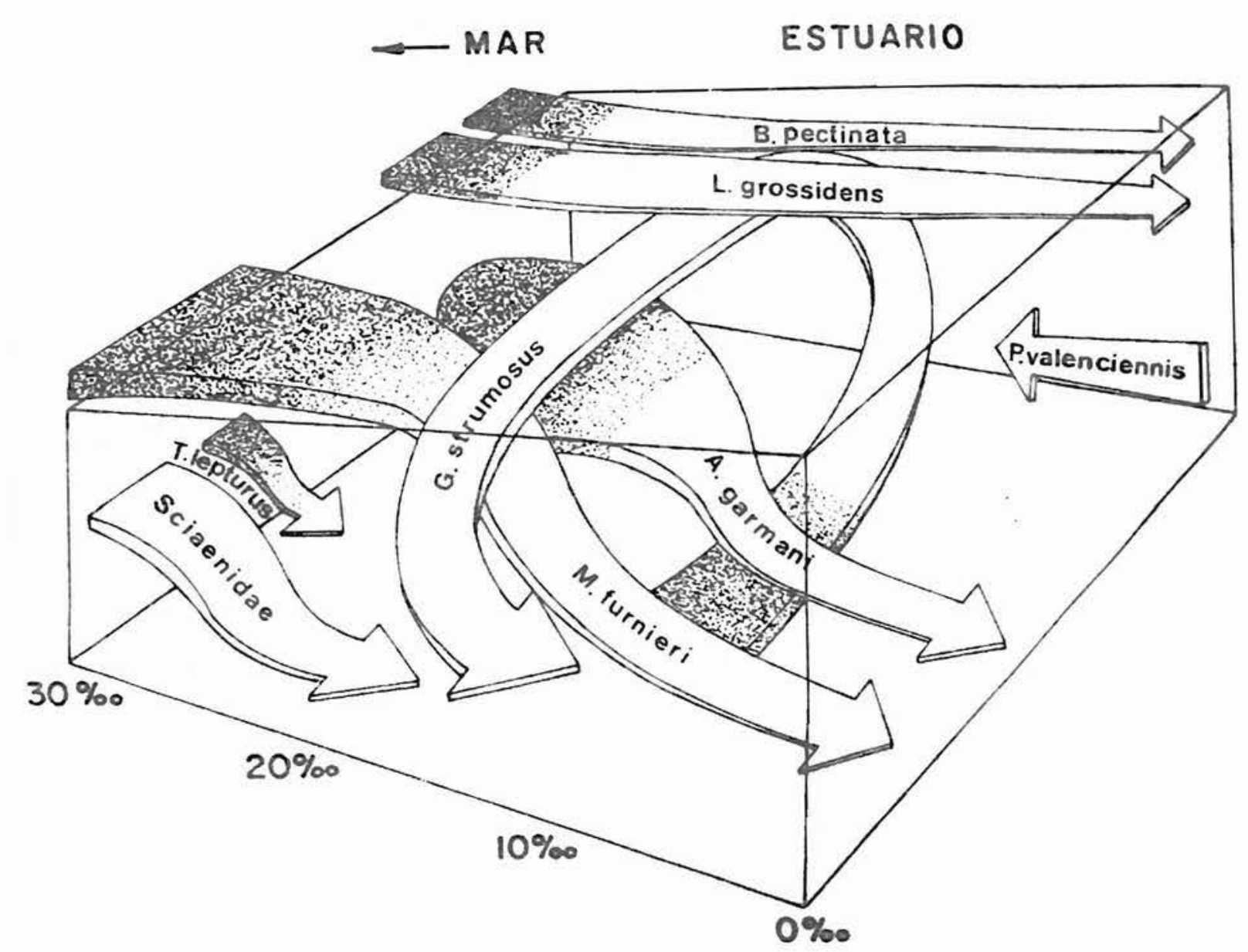

Fig. 62: Comportamiento de los huevos (parte sombreada) y de las larvas (parte blanca) en el area estuarial. 


\section{D - SUGERENCIAS}

Dado que la incidencia de huevos y larvas en el estuario esta regida por las condiciones ambientales, los resul tados dependerán no solo de la época, sino también del momento en que se realiza el muestreo. Consecuentemente, la variacion cuali-cuantitativa estacional analizada a través de pocos muestreos en este área no muestra claramente el período e intensidad del desove de cada especie ni su real capacidad de penetración.

Frente a un ambiente inestable el mayor número de observaciones otorgará más elementos para un conocimiento real sobre su capacidad como área de cría de larvas planctónicas.

Dada la estratificación de los huevos y larvas, un muestreo a diferentes profundidades y un estudio de las áreas adyacentes (tanto fuera del estuario como en aguas más internas) optimizará los resultados. La correlación de los efectivos presentes en aguas marinas próximas a la desembocadura y los presentes en aguas internas mostrarán la capacidad de penetración de las diferentes especies marinas; de igual modo, la correlación entre los efectivos de las aguas del canal y los más internos daran la pauta para la especies tipicamente estuariales.

Este análisis depende por otro lado del tiempo de vida planctónica de las larvas, su capacidad de sobrevivencia, su evitamiento de la red, etc., que son inherentes a cada especie.

Finalmente, una integración de estos estudios con las etapas de vida juvenil y adulta tanto de las especies pelágicas como demersales, ofrecerán una visión más acabada de la importancia del estuario como área de cría de aquellas especies que poseen una etapa planctónica en su ciclo de desarrollo ontogenético. 
VI - AGRADEC IMIENTOS

Deseo dejar expresado mi más sincero agradecimiento a las siguientes personas:

Al Ex-Rector de la Fundaçäo Universidade de Rio Grande, Prof. Eurípides Falcão Vieira, por incentivar la rea lización de los estudios en el área, como así también, a la actual administración que posibilitó la continuación de dichos estudios.

Al Coordinador del "Projeto Lagoa" por el esfuerzo realizado al llevar a cabo dicho proyecto y por su valiosa lectura crítica al présente trabajo.

A la Técnica del Laboratório de Ictioplancton, Sra. Lúcia M. Pacheco Pereira, por su gran colaboración en el aná lisis del material ictioplanctónico y la confección de los di bujos.

A todo el personal que partició en el "Projeto Lagoa" como también a todos los compañeros que de una u otra forna co laboraron en el presente estudio.

A Ios alumnos, Ramón Delgado y Rafael C. Mendoza por su importante colaboración.

A los dibujantes, Brasilio A. G. Laureiro y José F. Noronha por la confección de los gráficos.

Y finalmente, quiero agradecer muy especialmente al Director de la presente Tesis, Prof. Dr. Fernando C. Ramirez, por sus valiosas sugerencias, revisión y crítica al presente trabajo. 
VII - BIBLIOGRAFIA

AlIen, I. G. and M. H. Horn. 1975. Abundance, diversity and seasonality of fishes in Colorado Lagoon, Alamitos Bay, California. Estuarine and Coastal Marine sicie nce. $39371-380$.

Bearden, C. M. 1964. Distribution and abundance of Atlantic croaker, Micropogon undulatus, in south Carolina. Bears Bluff Lab. Contrib. 40. 23pp.

Blaxter, J. H. S. and G. Hempel. 1963. The influence of egg size on Herring larvae (Clupea harengus L.) . Jour. Cons. Inter. Expl. Mer. Vol. XXVIII. N2: 211-240.

Boesch, D. F. 1974. Diversity, stability and response to human disturbance in estuarine ecosystems. Proccedings of the First International Congress of Ecology, The Hague, The Netherlands.

- - 1972. Species diversity of marine macrobenthos in the Virginia Area. Chesapeake Science. Vol. 13: 206211.

Breder, C. M. Jr., and Donn E. Rosen. 1966. Modes of reproduction in Iishes. Natural llistory Press. Garden City N. J. $941 \mathrm{pp}$.

Briggs, J. C.1958.A list of Florida fishes and their distribution. Bull. Flo. St. Mus., 2 (8): 223-318.

Briggs, P. T. 1974. Occurrence of the seaweed blenny, radiated shanny and seasnail off the south of Long Island, New York, N. Y. Fish Game J. 21 (I): 84-86.

Candia, K. C. R., S. E. Cabrera y M. de L. Baiz. 1968. Contribución al conocimiento de la biologia del porteño (Parapimelodus valenciennesi, Kroyer, 1874) del Rio de la Plata. CARPAS/4/D. Téc. 42: 1-8.

Castello, J. P. 1976 a (Coord.) Projoto Lagoa. Relatório lo cruzeiro. Rio Grande. FURG. BOA. sér. rel. nol: 1-23.

1976b. (Coord.) Projeto Lagoa. Relatório 2/3 cruzeiro. Rio Grande. FURG. BOA. sér. rel. no 2: 1-47.

1976c. (Coord.) Projeto Lagoa. Relatório 40 e 5o cruzeiros. Rio Grande. FURG. BOA. sér. rel. no 3:1-48. -1976d. (Coord.) Projeto Lagoa. Io transversal de bentos e 6ㅇ e 7 cruzeiros. Rio Grande. FURG. BOA. sér. rel. no 4: 1-75. 
--------1977a. (Coord.) Projeto Lagoa. 80 e 90 cruzeiros FURG. BOA. sér. rel. no 5: 1-56.

-1977b. (Coord.) Projeto Lagoa. I0o e 11ㅇcueiros. Rio Grande. FURG. BOA. sér. rel. no 6: 1-68.

-1978a. (Coord.) Projeto Lagoa. IIo transversal de bentos e 12ㅇ e 13ㅇ cruzeiros.Rio Grande. FURG. BOA. sér. rel. no 8: 1-72.

- - - 1978b (Coord.) Projeto Lagoa. 14으 e 150 cruzeiros. Rio Grande. FURG. BOA. sér. rel. no 9: 1-49.

Castello, J. P. and I. C. Krug. 1978. Distribution, growth and spawning groups of the majuba (Lycengraulis grossidens) in the estuary of the Lagoa dos Patos -Rio Gran de do Sul-Brazil. Atlântica, Rio Grande. v.3 № úni$c 0$ : 33-46.

Castello, J. P. \& O. O. M\&ller Jr. 1978. On the relationship between rainfall and shrimp production in the estuary of the Patos Lagoon (Rio Grande do Sul, Brazil). Atläntica. Rio Grande. v.3, no único: 67-74.

Xassia, M. C., J. D. Ciechomsky y H. E. Christiansen. 1979. Estudios sobre la reproducción y fecundidad de la saraca, Brevoortia aurea (Spassiz, 1829), Hildebrand, 1848 (Pisces, Clupeidae) y la comparación de dos méto dos utilizados. Physis, Sec. A. v.38 no94: 39-46.

Cervigon, M. F. 1966. Los peces marinos de Venezuela. Fundación La Salle de Ciencias Naturales, Caracas, Monogr.11,12. $951 \mathrm{pp}$.

Ciechomsky, J. D. de. 1968. Huevos y larvas de tres especies de peces marinos, Anchoa marinii, Brevoortia aurea y Prionotus nudígula de la zona de Mar del Plata, Bol. Inst.Biol. Mar. 17: 1-28.

Clark, J. 1967. Fish and man. Conflit in the Atlantic estuaries. Am. Iittoral Soc. Spec. Publ. 5, 78pp.

Dahlberg, M. D. and E. P. Odum. 1970. Annual cycles of species occurrence, abundance and diversity in Georgia Estuarine fish populations. The American Naturalist: 83 (2): $382-392$.

Dawson, C. E. 1967. Contributions to the biology of the cutIassfish (Trichiurus lepturus) in the northern Gulf of Mexico. Trans. Am. Pish. Soc. 96(2): 117-121. 
-1967a. Notes on the species of the goby genus Evorthodus. Copeia (4): 855-857.

-1969. Studies on the gobies of Mississippi Sound and adjacent waters.11. An illustrated key to gobioid fishes. Publ. Gulf Coast Res. Lab. Mus. 60pp.

Dovel, W. I. 1963. Larval development of clingfish, Gobiesox strumosus, 4,0 to 12,0 millimeters total length. Chesapeake Sci. 4 (4): 161-166.

-..-- 1971. Fish eggs and larvae of the upper Chesapeake Bay. Univ. Md. Nat. Res. Inst. Spec. Rept. 4.iii+71pp.

Fager, E. W. 1963. Communities of organisms. Nueva York, 2:415437.

Figueiredo, J. I e N. A. Menezes. 1980. Manual de peixes marinhos do sudeste do Brasil. III. Teleostei (2). Mus. Zool. Univ. São Paulo. 90pp.

Fuster de Plaza, N. I. y E. E. Boschi. 1961. Areas de migración de la anchoa Lycengraulis olidus (Gunther) en las aguas argentinas (Pisces, Fam. Engraulidae). Contr. Cient. Univ, B. Aires. Fac. Cienc. Exact, y Nat, Ser. Zool., Buenos Aires, I(3): 127-183.

Futch, C. R. 1970. Contributions to the ecology of larval and juvenil lined sole, Achirus lineatus, in Tampa Bay, Florida. Mar. Res. Iab. Fla. Dep. Nat. Res. Leaflet Ser. vol. 4 Part.1 no 17.

Futch, C. R., W. R. W. Topp and E. D. Houde. 1972. Developmenttal osteology of the lined sole, Achirus lineatus (Pisces: Soleidae). Marine Science, vol. 16: 33-58.

Graham, J. J. and P. M. W. Venno. 1968. Sampling larval herring from tide waters with buoyed and anchored nets. J. Fish. Res. Bd. Canada. 25(6): 1169-1179.

Gunter, G. 1948. Seassonal variations in abundance of certain estuarine and marine fishes in Louisiana, with particular reference to life histories. Ecol. Monogr.8(3):314-346.

Hempel, G. and J. H. S. Blaxter. 1967. Egg weigth in Atlantic herring (Clupea harengus I.). Jour. Cons. Inter. Expl. Mer. vol. 31. no 2: $170-195$.

Herz, R. 1977. Circulacäo das águas de superficie da Lagoa dos Pa tos. Tesis de doctoramiento. Univ. São Paulo. Off. set. 
Hildebrand, S. F. and W. C. Schroeder. 1928. Fishes of Chesapeake Bay. U. S. Bur. Fish. Bull. 53 ( Pt. 1): 1-138.

Hildebrand, S. F. and I. E. Cable. 1930. Development and life history of fourteen teleostean fishes at Beaufort.

N. C. U. S. Bur. Fish. Bull. 46: 383-488

Hollister, G. 1934. Clearing and dyeing fish for bone study. 2ooIogica. N. Y. 12: 89-101.

Houde, E. D., C. R. Fucth and R. Detwyler. 1970. Development of the lined sole, Achirus lineatus, described from laboratory reared and Tampa Bay speciments. Fla. Dep. Nat. Resour. Tech. Ser. 62: $43 \mathrm{pp}$.

Longhurst, A. R. 1964. Reveu de la situation actuelle en synécologie benthique. Bull. Inst. Oceanogr., Mónaco. 63 $(1317): 1-54$.

Malaval, M. B. 1916. Memória de Malaval. Relatório interno dirigido á Inspectoría de Portos, Rios e Canais. Rio Grande (No publicado).

Margalef, R. 1977. Ecología. Ed. Omega, S. A. Barcelona. pp: 359382.

Massmann, W. H. 1963. The "critical zone" in estuaries. Bull. Sport. Fish. Inst. 141.

- 1964. A positive approach to coastal sport fishery problems. 18 th Proc. Oct. S. E. Ass. Game \& Fish. Comm.

Matsuura Y. \& K. Nakatani. 1979. Ocorrências de larvas e jovens de peixes na ilha Anchicti (SP), con al fumas unotações sobre a morfología da castanha, Umbrina coroides Cuvier, 1830. Bolm. Inst. Oceanoijr., S. Paulo, 28 (1): 165-183.

Mc Hugh, J. I. 1966. Management of estuarine fisheries. An. Fish. Soc., Spec. Publ. 5: 135-15/.

-1967. Wstuarine nekton. In G. H. Lauff (editor) Estuaries, p. 581-620. Am. Assoc. Adv . Sci. Publ. 83.

Moore, R. H. 1978. Variations in the diversity of summer stuarine fish populations in Aransas Bay, Texas, 1966-1973. Estuarinc and coastal Marine Science. $\underline{6}$ : 495-501.

Musick, J. A. 1972. Fishes of Chesapeake Bay and adjacent coastal plain. Pages. 175-212 in M. I. Wass, ed., A check list of the biota of Chesapeake Bay. Vims. Spec. Sci. Rept. 650. 290pp. 
Parin, N. V. and V. E. Bekker. 1973. Family Trichiuridae. pages 462-464. in J. C. Hureau and T. Monod., eds. Checklist of the fishes of the north-eastern Atlantic and of the Mediterranean. UNESCO, vol. I.

Parker, J. C. 1971. The biology of the spot, Leiostomus xanthurus Lacépéde, and Atlantic croaker, Micropogon undulatus (Iinnaeus), in two Golf of Mexico nursery areas. Diss. Abstr. Int. 32(3): 1380 B (Abstr.).

Pearcy, W. G. and Myers, S. S. 1974. Larval fishes of Yaquina Bay, Oregon: a nursery ground for marine fishes. Fishery Bulletin, vol. 72, n이: 201-213.

Pearson, J. C. 1929. Natural history and conservation of the redfish and other commercial sciaenods on the Texas coast. U. S. Bur. Fish. Bull. 44: 129-214.

-1941. The young of the some marine fishes taken in lower Chesapeake Bay, Virginia, with special reference to the pray sea trout Cynoscion regalis (Bloch). U. S. Fish. Wild1. Ser. Fish. Bull. 36: 77-102.

Randal1, J. E. 1968. Caribbean reef fishes. T. F. H. Publ., Neptune City, N. J. 318pp.

Remane, A. 1971. Ecology of brackish water. Die Binnengewasser 25: $1-210$.

Reid, G. K. 1954. An ecological study of the Gulf of Mexico fishes in the vicinity of Cedar Key, Florida. Bull. Mar. Sci. Gulf Carib., 4(1): 1-94.

Xreintjes, J. W. 1969. Synopsis of Biological data of the Atlantic menhaden Brevoortia tyrannus. FAO. Fisheries Synopsis no 42. U. S. Fish. Wildl. Ser. Circ. 320: 1-30.

Ringuelet, R. A., R. H. Aramburu y A. A. de Aramburu. 1967. Los pe ces argentinos de agua dulce, Pcia. Bs. Aires. Com. Invest. Cient. La Plata. 1-602.

Runyan, S. 1961. Early development of the clingfish Gobiesox strumosus. Cope. Chesapeake. Sci. 2(3-4): 113-141.

Sadosky, M. y R. Ch. Guber de. 1960. Elementos de cálculo diferencial e integral. Fasc. 1 Ed. Alsina. Bs. As. 270pp. 
Saksena, V. P. and E. B. Joseph. 1972. Dissolved oxigen requeriments of newly-hatched larvae of the striped blenny (Chasmodes bosquianus), the naked goby (Gobiosoma bosci) and the skilletfish (Gobiesox strumosus). Chesapeake Sci. 13 (1): 23-28.

Schwartz, F. J. 1962. Survivors of an ancient primitive group. The beaked fishes of Maryland. Md. Conserv. 39(2): 21-25.

Scott, T. D., C. J. M. Glover and R. V. Southcott. 1974. The marine and freswater fishes of South Australia. 2d. ed. A; B. James, Government Printer, South Australia. 392pp.

Springer, V. G. and K. D. Woodburn. 1960. An ecological study of the fishes of the Tampa Bay area. F'la. Bd. Conserv. Mar. Lab., Prof. Pap. Ser. nol: 1-104.

Symposium in the classification of the brackish-waters.1959 Venice. 8-14 april 1958 - vol. XI, Suppl., Arch. Oceanograf. Limnol. Venezia. 248pp.

Tabb, D. C. and R. B. Manning. 1961. A checklist of the flora and fauna of northern Florida Bay and Adjacent brackish waters of the Florida Mainland collected during the period July, 1957 through September, 1960. Bull. Mar. Sci. Gulf Carib. 1l(4): 552-649.

Tavolga, W. 1954. A new species of fish of the genus Blennius from Florida. Copeia. 1954.(2): 135-139.

Tsukahara, H. 1961. Biology of the cutlassfish, Trichiurus lepturus Linneaeus. Part 1. Early life history. Rec. Oceanogr. Wks. Japan. Spec. no5: 117-121.

- - ---1962. Biology of the cutlassfish, Trichiurus lepturus Linneacus. Part. ?. Age and growth. Rec. Oceanogr. Wks. Japan, Spec. no 6: 57-64.

Wallace, D. H. 1940. Sexual development of the croaker, Micropogon undulatus, and distribution of the early stages in Chesapeake Bay. Trans. Am. Hish. Soc. 70: 475-482.

Weiss, G. e I. C. Krug. 1977. Características do desenvolvimento e metamorfose de lycengraulis clidus (Engraulidae) e Brevoortia pectinata (Clupeidae) no estuário da Lagoa dos Patos, RS. Brasil. Attântica, Rio Grande. HURG. BUA. 2(I): $83-11 \%$ 
Weiss, G., Souza J. A. Feijö de e A. Santos. 1976. Contribuição ao conhecimento do ictioplancton marinho da plataforma Sul do Brasil. Atlântica, Rio Grande. H'URG. BOA. $1(1 / 2): 1-99$.

Weiss, G. e Souza, J. A. Heijó de. 1977. Estudo comparativo preliminar de post-larvas e juvenís das três espécies de Engraulidae da costa Sul do Brasil, Uruguai e Argentina. Atlântica, Rio Grande, FURG. BOA. 2(1): 1-20.

Weiss, (i. e Haimovici, M. Características da desova, fecundidade e desenvolvimento embrionário e larval de Achirus garmani no estuário da Lagoa dos Patos. (Manuscrito).

White, M. I. and M. E. Chittenden, Jr. 1976. Aspects of the life history of the Atlantic croaker Micropogon undulatus.

Tex. A. \& M. Univ. L'ent. Mar. Resour. 54pp.

Wojciechowsky, J. 19'/2. Observations on biology of cutlassfish Trichiurus lepturus L. (Irichiuridae) of Mauritania Shelf. ACTA. Ichth. Psicar. 2 (2): 67-75.

Yamada, U. 1971. The reproductive characteristics of the ribbon fish, Trichiurus lepturus Linne, in the Last China Sea. Bull. Seikai. Reg. Fish. Res. Lab. 41: 63-81.

Zijlstra, J. J. 1969. Egg weights of Nort Sea herring ( Clupea harengus I.) - Inter. Coun. Expl. Sea. C.M./H. 10:8pp.
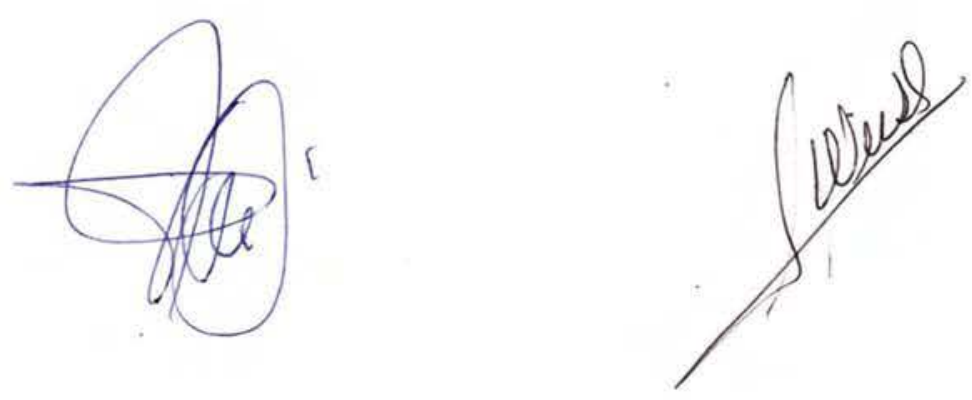